\title{
A CRITIQUE OF THE GLOBAL LITERATURE ON THE CONSERVATION REFUGEE PROBLEM
}

\author{
By \\ Harrison Esam Awuh
}

A thesis

Submitted to Victoria University of Wellington

In fulfillment of the requirements for the degree of

Master of Science

In Geography

Victoria University of Wellington 


\section{PREFACE}

Before I became interested in Conservation Refugees I had developed an interest in Traditional Ecological Knowledge (TEK). I was raised in a city cut off from my tribe in the Bamenda Highlands of the North West Province of Cameroon. Growing up in the city meant I could not speak my native dialect because English, French and Creole were the only languages spoken around me. When I visited my extended family in the countryside I was ridiculed for not being able to speak my native dialect. I went hunting and fishing with my cousins and I was fascinated by their knowledge of the environment. It then dawned on me that growing up in the city had deprived me of the Traditional Ecological Knowledge (TEK) of my natural environment.

I read a great deal about TEK and realized that marginalization was one of the major barriers to its transmission. I read an article by Mvondo (2006) on the Baka of South East Cameroon, how they are marginalized with regards to environmental justice. After reading the article I observed that the Baka only found themselves in that situation because they were displaced from the Protected Areas established in what used to be their ancestral domain.

I proceeded to read more about people displaced for conservation like the Baka around the world and uncovered a considerable amount of material. I observed that apart from Brockington and Igoe who did a global review of the literature in 2006 on who conservation refugees were and where they lived; no study had actually carried out a sufficiently critical review of the global literature on conservation refugees to expose their plight. This research reported here will therefore act as the voice of the politically weak, remote, uneducated, unorganized and poor people around the world who constitute conservation refugees. This study voices their concerns in the hope that more consideration will be given to their plight by conservation promoters. 


\section{TABLE OF CONTENTS}

ACKNOWLEDGEMENTS ....................................................vi

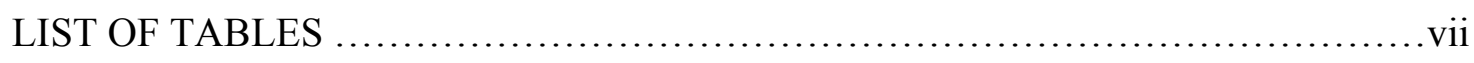

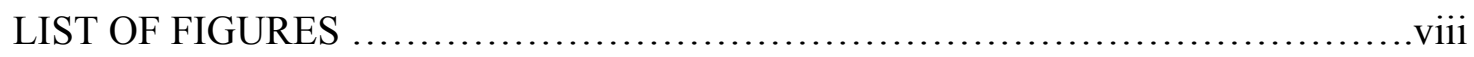

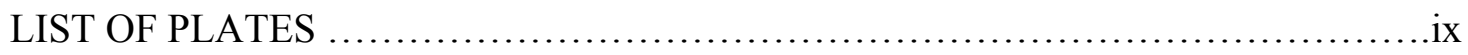

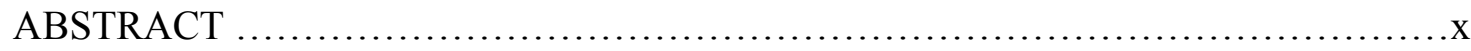

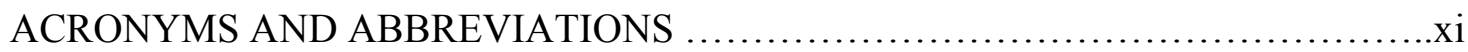

CHAPTERS

1 INTRODUCTION

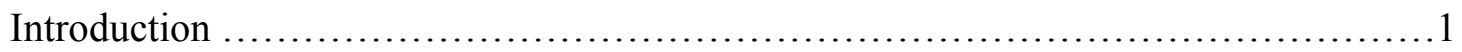

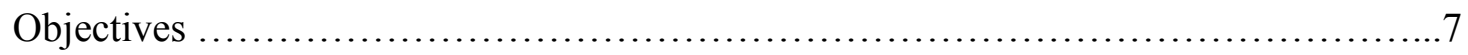

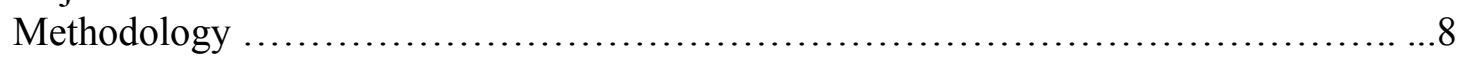

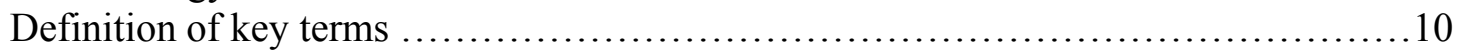

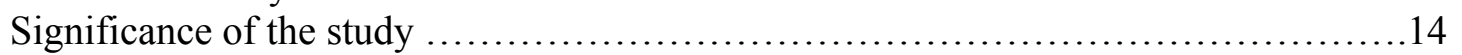

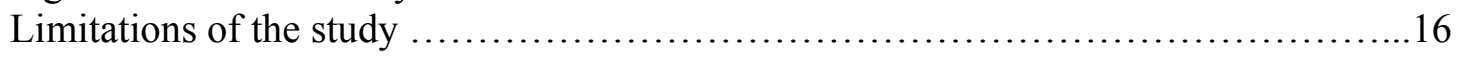

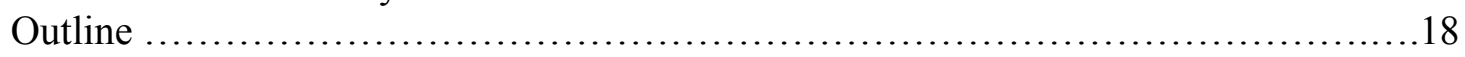

2 THE EVOLUTION OF LAWS AND DECLARATIONS AIMED AT PROTECTING THE RIGHTS OF INDIGENOUS PEOPLE

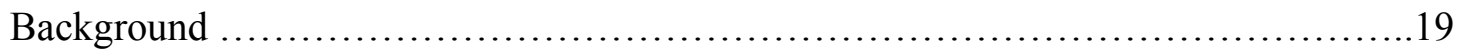

The International Labour Organization Conventions 107 and 169 ....................22

The Universal Declaration on the Rights of Indigenous Peoples ......................26

Reasons for the failure of international conventions and declarations to prevent

evictions and displacements.................................................... 28

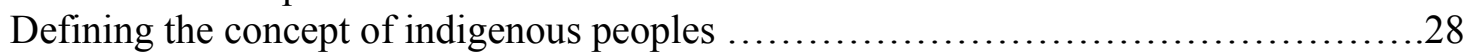

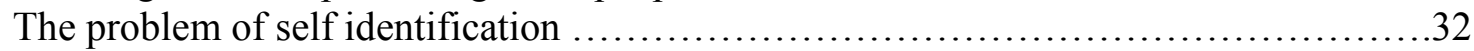

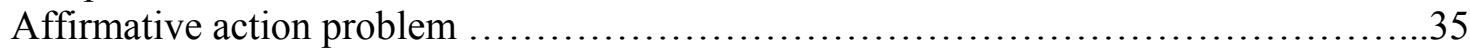

Lack of respect for international conventions and declarations by states ................37

Lack of recognition for customary land tenure ....................................40

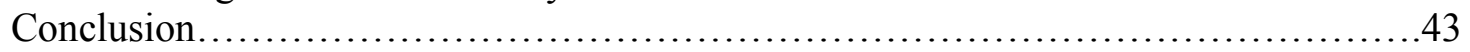




\section{CONSERVATION REFUGEES AND THEIR GLOBAL DISTRIBUTION}

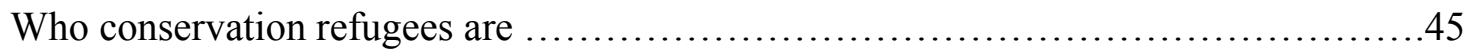

Global distribution of conservation refugees ................................... 52

Reasons for the variation in the global distribution of conservation refugees ............57

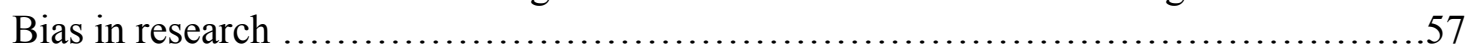

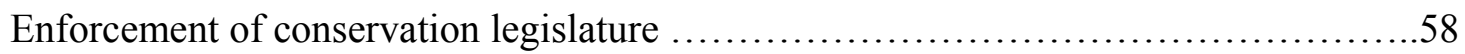

Global numbers of conservation refugees .......................................65

Conclusion ................................................................67

\section{CHANGES IN CONSERVATION AND DEVELOPMENT POLICY}

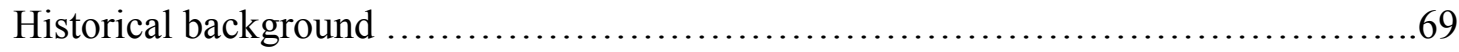

Rise of Integrated Conservation and Development Projects ..........................72

Critique of Integrated Conservation and Development Projects ........................74

Protected Areas Require Strict Protection ........................................ 75

Biodiversity Protection is a Moral Imperative .................................... 76

Conservation Linked to Development Does Not Protect Biodiversity ..................78

Harmonious, Ecologically Friendly Local Communities do not exist ...................79

Emergency Situations Require Extreme Measures ............................... 80

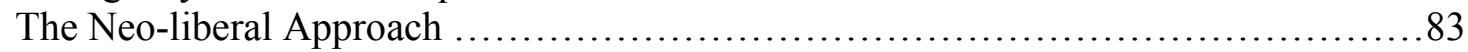

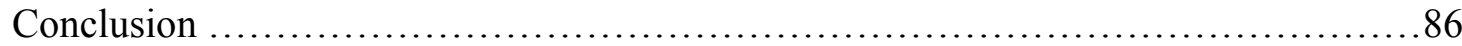

\section{RESETTLEMENT AND COMPENSATION}

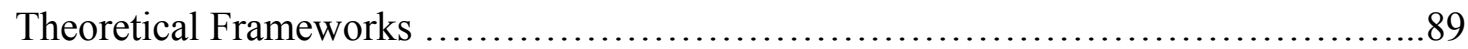

The Department for International Development Framework ..........................89

The Impoverishment Risk Reconstruct Model .....................................91

Facing the risk of landlessness ................................................. 91

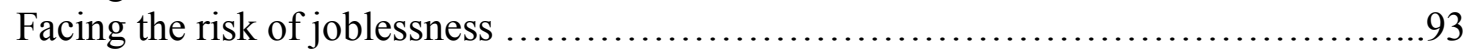

Facing the risk of homelessness .............................................. 94

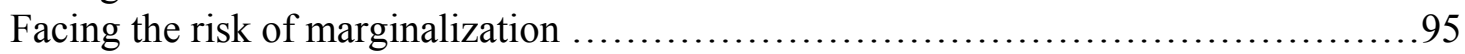

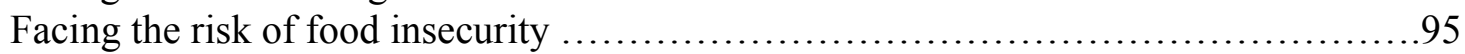

Facing the risk of increased morbidity and mortality ..............................96

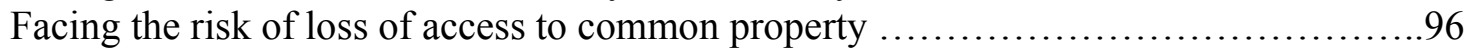

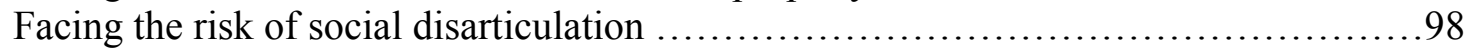

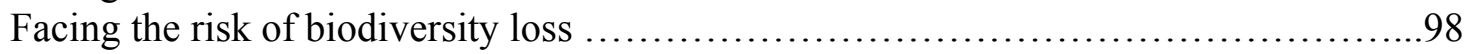

A critique of the theoretical frameworks of resettlement and compensation ............100

Compensation in the form of financial capital can only succeed in the short-run ........101

How can loss be quantified? ................................................. 104

The problem of involuntary hosts in resettlement schemes ........................ 106

Risks are perceived differently by different sections of the population ................107

There is no voluntary resettlement ............................................ 107

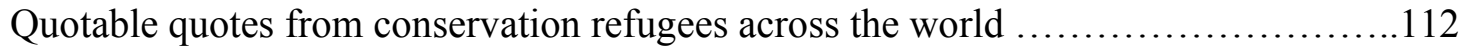

Conclusion .................................................................. 116 


\section{THE BAKA OF SOUTH-EAST CAMEROON AND THE OGIEK OF KENYA}

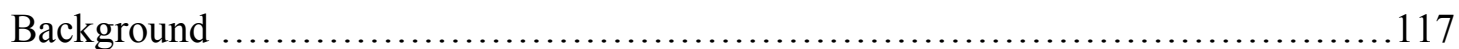

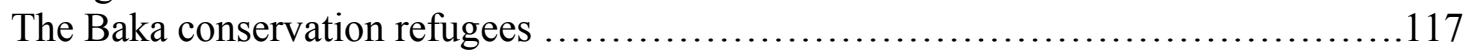

Legal and constitutional framework in place .................................... 121

The Dja Biosphere Reserve, Boumba Bek/Nki and Lobeke National Parks .............124

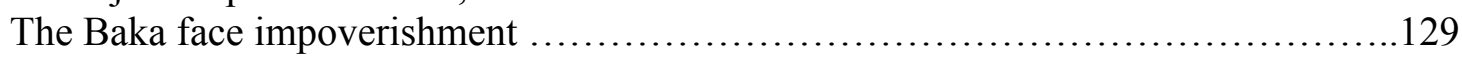

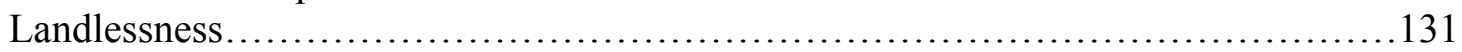

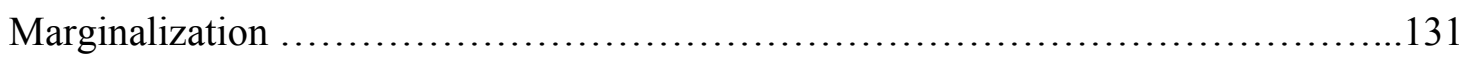

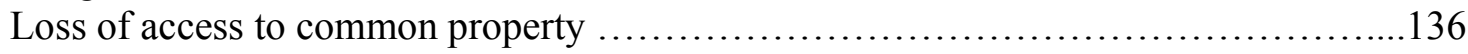

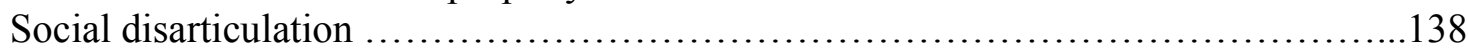

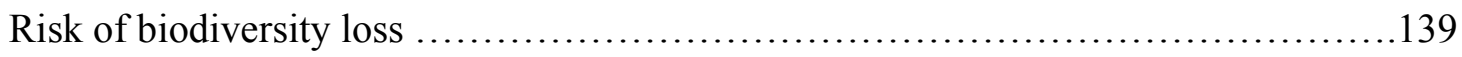

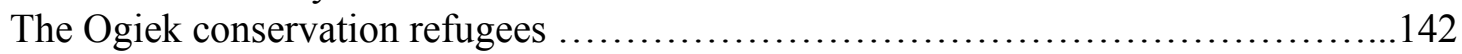

Legal framework in place .................................................. 144

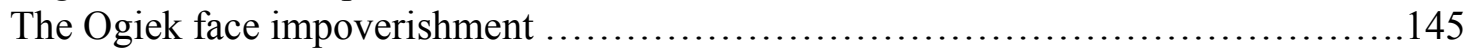

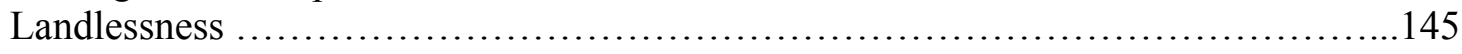

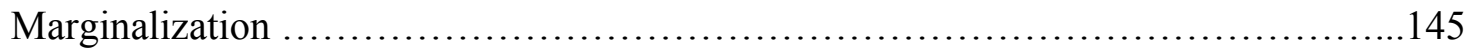

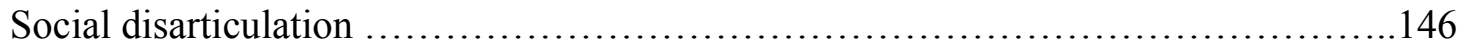

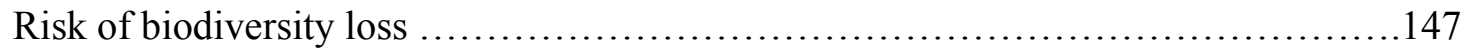

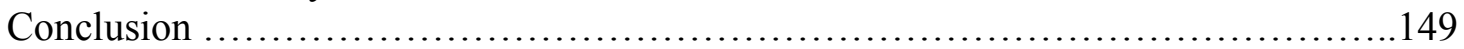

\section{CONCLUSION}

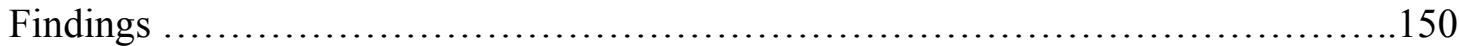

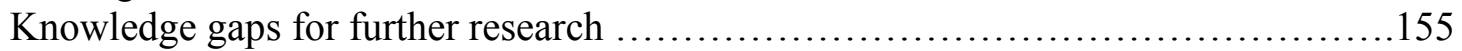

Recommendations ............................................................. 161

Case studies of effective management of protected areas by indigenous peoples ......169

Co-managed projects ........................................................... 169

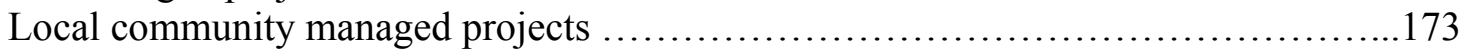

Conclusion .................................................................. 177

\section{APPENDICES}

Appendix 1: International Labour Conference, Convention 169 ........................ 180

Appendix 2: Agenda 21 of Rio Earth Summit ................................... 191

Appendix 3: Declaration on the Rights of Indigenous Peoples .......................195

Appendix 4: Ogiek Rural Integral Projects on the Mau Forest evictions ................202

Appendix 5: Open letter from the Ogiek to the President of Kenya ..................203

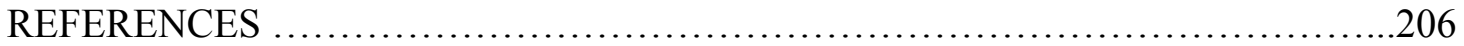




\section{ACKNOWLEDGEMENTS}

I will like to thank very specially Professor Phillip Morrison for his constant encouragement and inspiration, without which this thesis would never have been written. I am also greatly indebted to Ms. Sara Kindon and Dr. Michael Gavin for their efforts in reading and making suggestions to an earlier piece of work which laid the foundation for this study. There are no adequate words to express my gratitude to Shona de Sain who greatly helped me through a very difficult period. This thesis also owes much to the intellectual stimulus received at the School of Geography and Earth Science (SGEES), Victoria University, Wellington. I am also indebted to Dr. Schmidt-Soltau, Professor Daniel Brockington, Dr. Billy Adams, Professor Michael Cernea, Dr. James Igoe and Charles Dowie whose publications inspired me through this study. My gratitude to Suzanne Weaver at SGEES, Victoria University, Wellington and I also wish to specially thank Floor Spijkers.

Thanks,

Harrison Esam Awuh 


\section{LIST OF TABLES}

1. Concept-centric literature review approach used in this study.................... 9

2. Top 25 countries considered megadiversity countries ...........................46

3. Top 12 Countries by number of species and endemism $\ldots \ldots \ldots \ldots \ldots \ldots \ldots \ldots \ldots \ldots \ldots \ldots$

4. Indigenous people in global 200 terrestrial ecoregions considered priority areas .....48

5. The geographical distribution of reported evictions from protected areas between

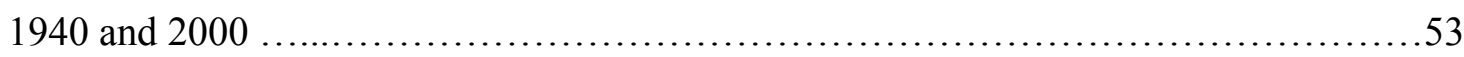

6. Distribution of conservation refugees in selected countries across the world ..........55

7. Percentages of indigenous peoples and reported cases of evictions from selected

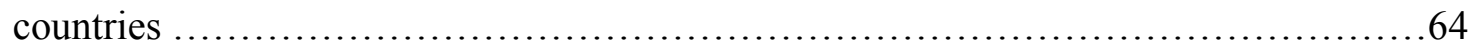

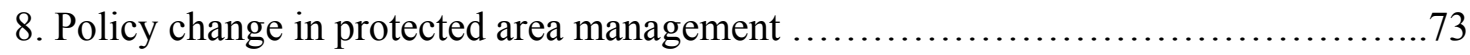




\section{LIST OF FIGURES}

1. Percent of total land area reserved as protected areas .................................

2. The surface area of protected areas and the number of displaced people in Central

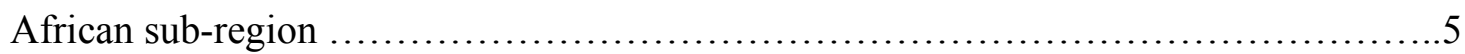

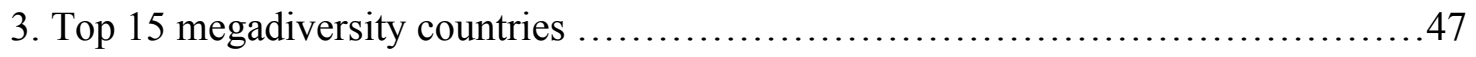

4. Overlaps of Interests which leads to the conservation refugee problem ..............50

5. Map of Cameroon showing the location of the Baka ...........................121

6. Map of Cameroon showing the protected areas from which the Baka have been

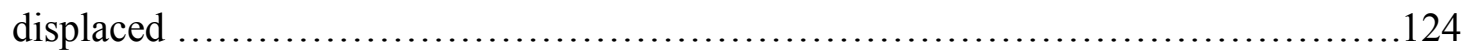

7. Map of Kenya showing the Rift Valley and Mau Forest from which the Ogiek

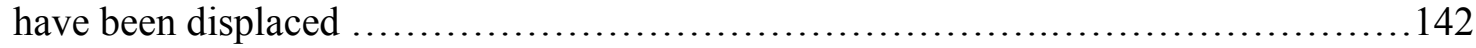




\section{LIST OF PLATES}

1. Indigenous Baka dancers in the forests of South East Cameroon ..................41

2. Yosemite National Park as it looks today ................................... 70

3. Paiute Indians (California, USA) ....................................... 94

4. A Baka hunter-gatherer takes a break with a bottle of beer ..................... 104

5. An elderly man evicted from Giswati forest in Rwanda ......................... 108

6. Would-be displaced people being "informed" about resettlement in Cross River

National Park (Nigeria) ................................................ 110

7. An abandoned village in the Lope National Park (Gabon) ...................... 112

8. Bwindi National Park (Uganda) ............................................ 113

9. Maasai conservation refugees in East Africa and a lion ........................ 115

10. Baka women and children gathering firewood and other forest products ...........118

11. The Dja Biosphere Reserve .......................................... 126

12. African grey parrots in Lobeke National Park ................................. 128

13. An illustration of restrictions to access to common property in Lobeke

National Park ...................................................... 138

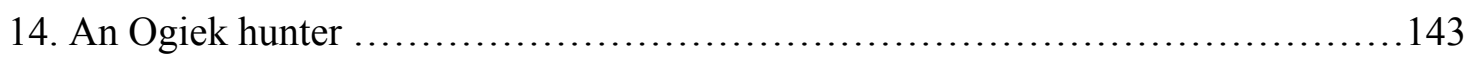

15. Logging in the Mau forest from which the Ogiek have been displaced .............147

16. An Ogiek woman in front of the wreck of her home .......................... 149 


\begin{abstract}
Displacement of people has often been driven by large scale development projects, wars, disease and ecological disasters such as famine and drought. However, there is another category of displaced people who have often been ignored. These people who are victims of a much more noble cause are referred to as conservation refugees. Conservation refugees are people displaced from protected areas.

Despite the existence of conservation refugees and their plight, only Brockington and Igoe (2006) have attempted a global literature review on the problem. While their study explains who conservation refugees are as well as when and where the displacements have occurred, my study goes further and critiques the international law and declaration designed to protect the rights of conservation refugees. I also examine conservation policies and the impacts of displacement on conservation refugees based on the Impoverishment Risk Reconstruct Model (IRR) of Cernea (1997).

My literature review explains who conservation refugees and describes their global distribution. The review of literature in English and French uncovers 170 relevant articles, of which 73 dealt with issues directly related to conservation refugees. I find that most of the approximately 3,058,000 conservation refugees are members of 28 different indigenous groups displaced across 48 protected areas.

I also introduce and discuss international law and declarations aimed at protecting conservation refugees and point out that it is not their inadequacy as laws in protecting conservation refugees but rather a local failure to enforce them. Conservation policies themselves are also a major factor in protecting inhabitants of protected areas. Often conservation organizations are more sensitive to the protection of flora and fauna rather than the well-being of the area's inhabitants. Therefore, the goal of double sustainability is not met and this affects the relationship between local people and protected areas in a negative way. One thing we have learned is that protected areas across the world operate much more successfully when they are managed with or by indigenous peoples themselves.
\end{abstract}

Key Words: Displacement, protected areas, indigenous peoples, conservation refugees. 


\title{
ACRONYMS AND ABBREVIATIONS
}

\author{
APF: African Parks Foundation \\ CBD: Convention on Biological Diversity \\ DFID: Department for International Development \\ DRIP: Declaration on the Rights of Indigenous People \\ ECOFAC: Central African Forestry Ecosystems \\ ICDP: Integrated Conservation and Development Project \\ ILO: International Labour Organization
}

IRR: Impoverishment Risks Reconstruct model

NGO: Non-Governmental Organization

UNEP: United Nations Environment Programme

WCMC: World Conservation Monitoring Centre

WCS: Wildlife Conservation Society

WDPA: World Database of Protected Areas

WPC: World Parks Congress

WRI: World Resources Institute

WWF: Worldwide Fund for Nature 


\section{Chapter One}

\section{Introduction}

In this thesis I present a critical review of the global literature on conservation refugees. This first chapter will define the key terms, background and the problem, objectives and hypotheses, methods used in the literature review, significance of the study and its limitations. I will also outline the rest of the thesis.

Community- based conservation policies which emerged in the 1990s proposed to link the twin goals of conservation and sustainable development under a single rubric (Igoe, 2006). In other words, protection of biodiversity and the alleviation of poverty hand in hand. International organizations used this paradigm for about 10 to 15 years and the Worldwide Fund for Nature (WWF) went as far as to suggest that the future of biodiversity conservation and the future of indigenous societies are linked on a global scale (Igoe, 2006). The Convention on Biological Diversity (2004) also leans on these community-based conservation policies to emphasize the importance of protecting biodiversity and the livelihood of those people who still depend on direct access to natural resources for their livelihoods.

However, there has been a resurgent "protection ideology" in international biodiversity which argues that current Integrated Conservation and Development Projects (ICDPs) or people-oriented approaches to protecting biodiversity areas are failing (Wilshusen et al., 2002). Advocates of this "protection ideology" insist that the presence of people in protected areas is anathema to their ideas (Nash, 1967; Oelschlaeger, 1991; Rabinowitz, 1999). Based on this "protection ideology" an increasing number of protected area managers believe that 
human displacement is fundamental to conservation (Terborgh et al. 2002). Consequently, within the last few years, two key concerns have come to dominate the conservationdevelopment debate: the increasingly protectionist focus of conservation policy around protected areas, in particular regarding displacements and evictions and the lack of attention to biodiversity conservation on the development agenda with the current focus on poverty reduction (Roe, 2008).

As a result of the increasingly protectionist focus of conservation policy the global number of protected areas has risen from less than 1000 in the year 1900 to about 11,000 in 1990 (Brockington and Igoe, 2006) with the global area protected for biodiversity in 1997 being twice that of 1985 (Geisler and de Sousa, 2000). The global area set aside for conservation of biodiversity has continued to rise as can be illustrated by figure 1 below from the World Resources Institute (2003) which shows the extent of land set aside as protected globally. Recent studies by the United Nations Environment Programme's World Conservation Monitoring Centre (UNEP-WCMC) have shown that there are more than 102,000 protected areas throughout the world. Taken together these protected areas cover more than 11.5 percent of the terrestrial surface of the earth, considering that is just 3.4 percent of the entire surface, since there are relatively few marine protected areas (Borrini-Feyerabend et al. 2004). Though protected areas have done much good in terms of biodiversity conservation, this increase in protected areas has meant an increase in the number of people displaced to create room for the protected areas. These displaced people will be referred to as “conservation refugees". 
Figure 1: Percent of Total Land Area reserved as Protected Areas
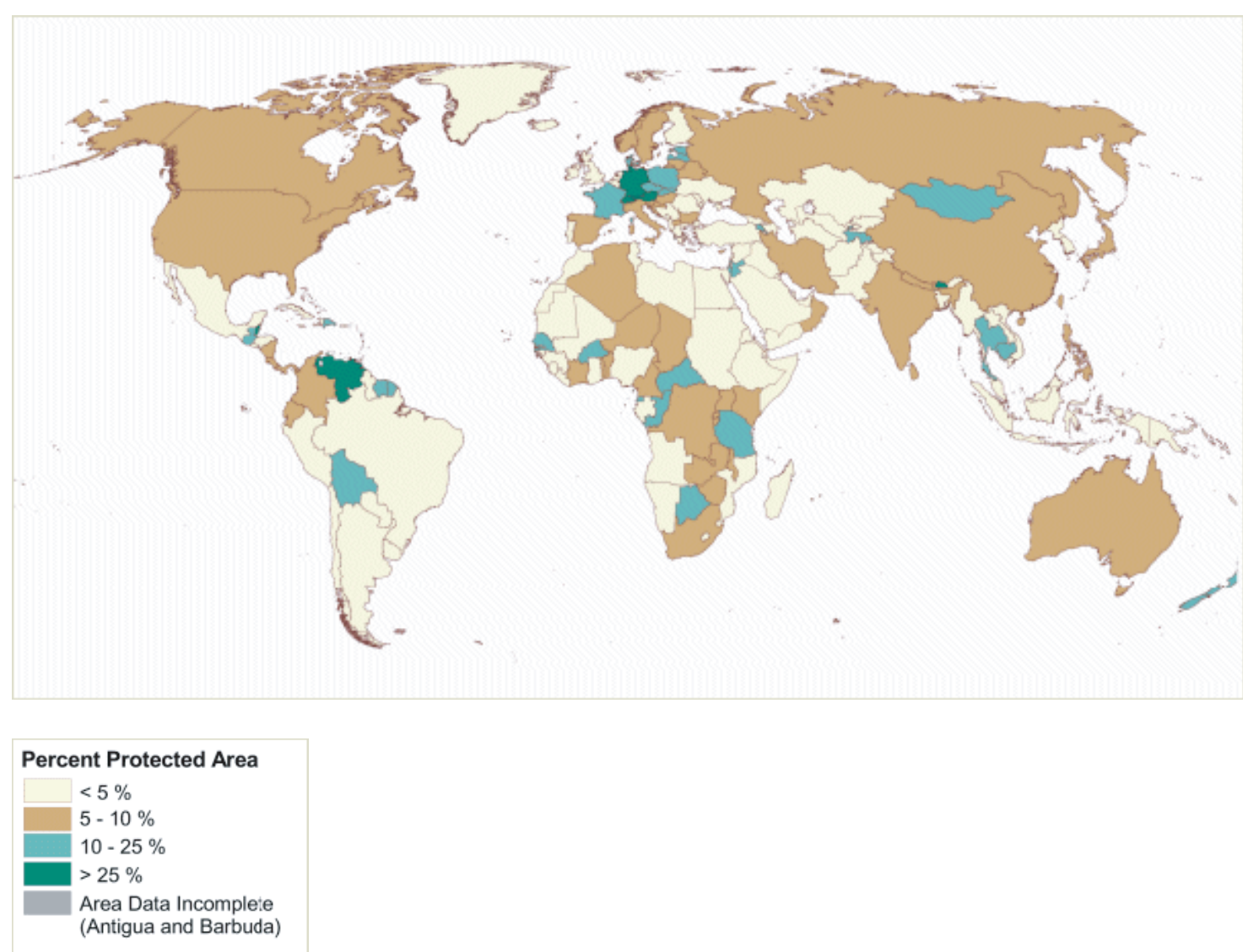

World Resources Institute (2003)

Conservation refugees are people displaced by the creation of national parks and protected areas, victims of ecological expropriation (Albert, 1994; First Peoples Worldwide, 2007). They end up moving into the subsistence landscapes, migrating to informal sectors of towns and villages with no customary land titles, and end up in wage labour ranks if they manage to find any work at all (Geisler et al., 2000). Restricting access to indigenous and other people in parks and protected areas is 'involuntary displacement' even when physical displacement and relocation are not required (Cernea, 2002, 2006; Schmidt-Soltau et al. 2007). Poole (2003) makes mention of "soft evictions" which in the context of this study will still be 
considered as involuntary displacement. Soft evictions refer to cases in which people are offered inducements to leave, have their territorial negotiations pre-empted, or are allowed to continue to occupy the protected area, but live under constant threat of removal, under strict conditions that do not allow for cultural survival (Poole, 2003). The determination of whether a displacement was voluntary or involuntary is down to the fundamental question; do the would-be displaced have the option to stay, or not? In most cases they do not have much choice but to move (Cernea et al., 2003).

Conservation refugees should not be confused with ecological or environmental refugees who are people forced to abandon their homelands as a result of adverse conditions such as unbearable heat or cold, famine, flooding, disease, desertification, drought and other consequences of climate chaos (Dowie, 2006). Unlike other refugees who go across national boundaries and gather in rehabilitation centres, conservation refugees have few logical gathering points and are difficult to enumerate. Cernea and Schmidt-Soltau (2003) estimate by 2012 there will be about 170,000 conservation refugees in the Central African sub-region alone. Figure 2 below perfectly illustrates the relationship between the increase in protected areas and the increase in the number of people displaced in the Central African sub-region between 1962 and 2012 (Cernea and Schmidt-Soltau, 2003). Geisler and de Sousa (2000) however present a bigger picture of the problem by estimating that there are between one and a half to fourteen and a half million conservation refugees in Africa alone. This might be a bit of an exaggeration of the numbers judging from the huge range between the estimates. However, these figures will keep increasing as more governments around the world are setting aside more land for national parks and reserves. 
Figure 2: The surface area of protected areas and the number of displaced people in Central African sub-region

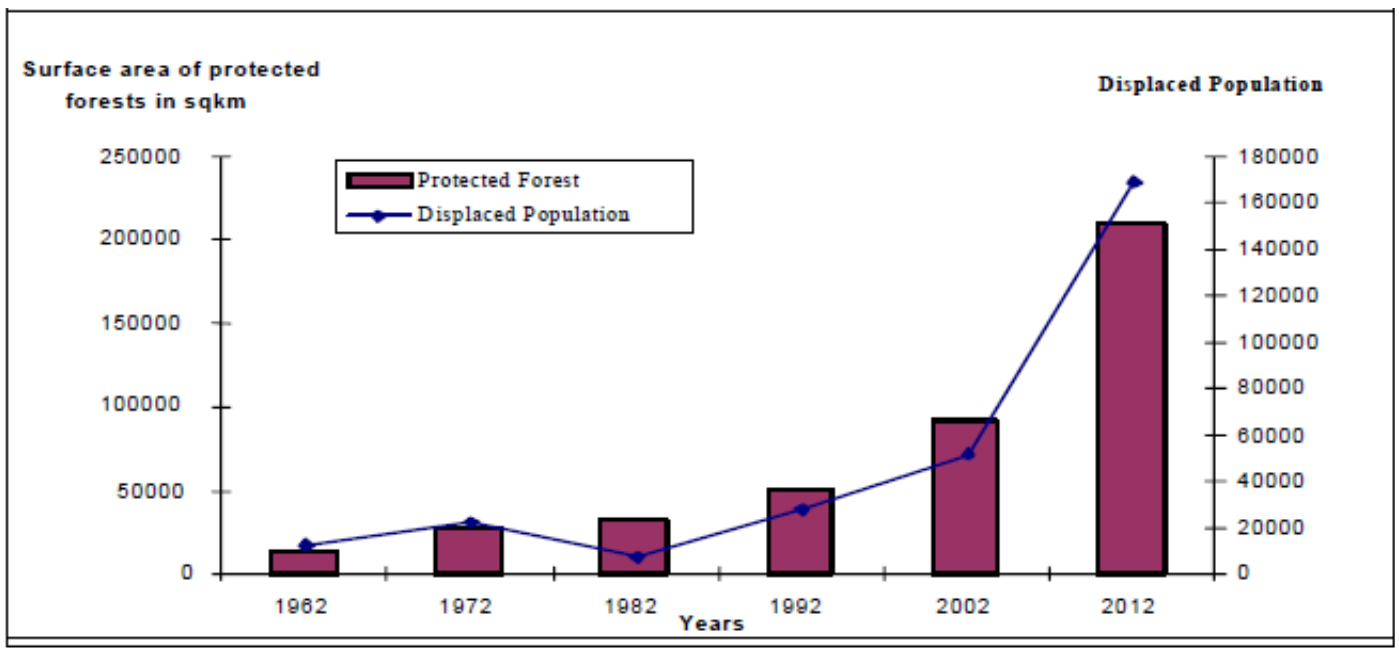

Cernea and Schmidt-Soltau (2003: Page 12)

The welcome gains from protected areas in the last generation have however been accompanied by silence over its socio-economic costs to conservation refugees (Chatty and Colchester, 2002). In the developing world for example, many areas worthy of protection are also home to predominantly poor rural people. In these circumstances we should expect that evictions without provision for better livelihoods will cause impoverishment to local people displaced for conservation (Brockington and Schmidt-Soltau, 2004). The socio-economic effects of conservation policy happen to be an area in which conservation research is shockingly behind other fields. Consequences of land loss to large scale development projects is now better recognized, and clear methodologies have been drawn up to assess their impacts than impacts of conservation induced displacements (Brockington and SchmidtSoltau, 2004; Igoe, 2006).

Despite the plight of conservation refugees around the world, only one study has made an attempt at a global review of the literature surrounding this phenomenon (Brockington and 
Igoe, 2006). This study emphasizes what is written about evictions from protected areas, where the evictions have taken place, from what sort of protected areas and when the evictions occurred. But eviction is only one aspect of displacement (Cernea, 2002, 2006; Schmidt-Soltau et al., 2007) and leaves out people who move because their source of livelihood has been cut off through restrictions on resource use in the name of conservation. Brockington and Igoe (2006) also demonstrate a strong regional bias, noting considerable amounts of work done in Africa and Asia and very little in other areas. They do not effectively address the issues around who these conservation refugees are; what distinguishes them from other refugees; what sectors of the population are most affected by displacement due to conservation; international conventions and laws designed to protect conservation refugees. The policy terrain behind the idea of evictions and displacements is largely ignored by Brockington and Igoe as well as the success or failure of resettlement and compensation schemes; why conservation projects which seem to have had such remarkable success in developed countries are causing so much misery in developing countries.

Considering these limitations, Brockington and Igoe (2006) request another review of the global literature on conservation refugees. It is in response to this call that my study will seek to carry out a critical review of what has been published to date as well as open up some knowledge gaps in studies on conservation refugees around the world for further research. My study also responds to a call from Cernea and Schmidt- Soltau (2003) for a broader, deeper and more systematic study in the social sciences for livelihood issues in parks and outside them. The concern is the negative effects displacement can have on the rural poor. In addition to concerns of human rights, conservation needs to be aware of the effect that protected area establishment, subsequent relocation, and denial of access to resources might 
have on the attitudes of local people towards the protected areas themselves (Cernea et al. 2003).

\section{Objectives}

Who are conservation refugees? What sectors of the population are most affected by displacement due to conservation? What makes them different from other refugees? Why have International Conventions and Organizations failed to protect Conservation Refugees? How do paradigm shifts in conservation and development influence evictions?

What compensation is made to conservation refugees for loss of livelihood and eviction? How successful are compensation schemes? Why have conservation schemes which seem to function well in most developed countries produced such hardship in developing countries? What are the knowledge gaps in research on the conservation refugee problem?

\section{Hypotheses}

Firstly, conservation refugees are mostly indigenous people. Secondly, there are less conservation refugees in the developed world because international conservation agencies do not have the powers to increase their conservation initiatives in the developed world as they do in the developing world. Thirdly, global figures of conservation refugees will decrease if international laws and declarations are well implemented. Fourthly, resettlement schemes can fail if they ignore the host population in the receiving areas. Also, compensation schemes are only successful in the short-run. The globalization of Western conservation practice is to blame for the Conservation refugee crisis in the developing world. Lastly, the degree of implementation of regulations in protected areas is dependent on which side of the strict conservation/conservation and development divide the promoters belong. 


\section{Methodology}

I have evaluated the extent of the coverage of global conservation refugee literature by comparing the data collected to the 2009 edition of the World Database of protected areas (http://sea.unep-wcmc.org/wdbpa). Prominent authors such as Dan Brockington, SchmidtSoltau, Mark Dowie, Michael Cernea and Jim Igoe who have done extensive research on conservation refugees have been contacted informally to seek details about their work or ask questions concerning their previous studies as well as further useful references.

I have also collected any information I can about conservation refugees from published and gray literature and from student theses in English and French. I have also used the worldwide web database for data collection especially http://scholar.google.com. I have obtained information from all subject areas, any publications, any authors and no date limits for publications. Key words in the search include; "conservation", "refugees", "conservation refugees", "displacement", "national parks and reserves". The findings of my literature survey are summarized in tables 1 below. A total of 170 articles were reviewed for this study. Of the 170 articles reviewed, 73 deal with the conservation refugee phenomenon directly and the number of articles that deal with issues or topics related to the conservation refugee phenomenon was 97.

The concept-centric approach of Table 1 determines the organizational framework of the review and synthesizes the literature better than the author-centric approach which barely presents a sum of relevant articles (Webster et al. 2002). 
Table 1: Concept-centric literature review approach used in this study

\begin{tabular}{|c|c|c|}
\hline Concept & Hypotheses & Reviewed Sources \\
\hline $\begin{array}{l}\text { Who } \\
\text { conservation } \\
\text { refugees are and } \\
\text { their global } \\
\text { distribution. }\end{array}$ & $\begin{array}{l}\text { Conservation refugees } \\
\text { are mostly indigenous } \\
\text { people. } \\
\text { There are less } \\
\text { conservation refugees } \\
\text { in developed world } \\
\text { because conservation } \\
\text { agencies do not have } \\
\text { the power to increase } \\
\text { initiatives. }\end{array}$ & $\begin{array}{l}\text { Adams and Hutton (2007), Agrawal and Redford } \\
\text { (2009), Alcorn (1993), Brockington and Igoe } \\
\text { (2006), Brockington and Scholfield (2010), } \\
\text { Carruthers (1995), Cernea (2006), Cernea and } \\
\text { Schmidt-Soltau (2003), Chapin (2004), } \\
\text { Colchester (1994), Conservation Refugees } \\
\text { (2006), Dowie (2006, 2009), First Peoples } \\
\text { Worldwide (2007), Fromherz (2008), Geisler } \\
\text { (2002), Geisler and de Sousa (2000), Ghimire } \\
\text { (1994), Ghimire and Pimbert (1997), Igoe } \\
\text { (2006), Kabra (2006), Kothari (2004), Maffi } \\
\text { (2001), Maffi and Carlson (2005), Mittermeier } \\
\text { and Goettsch-Mittermeier (1997), Nabakov and } \\
\text { Lawrence (2004), Neumann (1998), Poirier and } \\
\text { Ostergren (2002), Platzky and Walker (1985), } \\
\text { Ranger (1989), Schmidt-Soltau (2004), Toledo } \\
\text { (2010), Western (1984), WWF International } \\
\text { (1998) }\end{array}$ \\
\hline $\begin{array}{ll}\text { International } \\
\text { laws and } \\
\text { declarations }\end{array}$ & $\begin{array}{l}\text { Global figures of } \\
\text { conservation refugees } \\
\text { will decrease if laws } \\
\text { and declarations are } \\
\text { well honoured and } \\
\text { implemented }\end{array}$ & $\begin{array}{l}\text { Burger (1997), Chapin (2004, Coate and Loury } \\
\text { (1993), Colchester et al. (2001), Fromherz } \\
\text { (2008), Hitchcock (1994), ILO (1989), Jacobson } \\
\text { (1985), New Zealand Government (2010), Rio } \\
\text { Summit (1992), Rubenfeld (1997), Shikongo } \\
\text { (2007), Shutkin (1991), Stamatopoulou (1994), } \\
\text { UN (2007, 2010), UN Charter (1945), World } \\
\text { Bank (1991). }\end{array}$ \\
\hline $\begin{array}{l}\text { Conservation/ } \\
\text { development } \\
\text { policies }\end{array}$ & $\begin{array}{l}\text { Degree of } \\
\text { implementation of } \\
\text { regulations in protected } \\
\text { areas is dependent on } \\
\text { which side of the } \\
\text { conservation/developm } \\
\text { ent divide the } \\
\text { promoters belong. } \\
\text { Globalization of } \\
\text { Western conservation is } \\
\text { to blamer for } \\
\text { conservation refugee } \\
\text { crisis in the developing } \\
\text { world. }\end{array}$ & $\begin{array}{l}\text { Agrawal and Gibson (1999), Alcorn (1993), } \\
\text { Borrini-Feyerabend et al. (2004), Brandon et } \\
\text { al.(1998), Brown, K. (2002), Cernea (2006), } \\
\text { Cernea and Schmidt-Soltau (2003), Chapin } \\
\text { (2004), Clynes (2002), Christensen (2004), } \\
\text { Dowie (2009), Geisler (2002), Igoe and } \\
\text { Brockington (2007), Igoe (2006), Kabra (2006), } \\
\text { Kramer et al. (1997), Norton-Griffith and } \\
\text { Southey (1995), Oates (1999), Rabinowitz } \\
\text { (1999), Rangaran and Shahabuddin, (2006), } \\
\text { Redford et al. (1996), } \\
\text { Redford et al. (1999), Roe (2008), Ruitenbeek } \\
\text { (1992), Schmidt-Soltau and Brockington (2007), } \\
\text { Schmidt-Soltau (2004), Terborgh (1999), Wells } \\
\text { and McShane (2004), Wilshusen et al. (2002), } \\
\text { Wilkie et al. (2010), Wunder (2000). }\end{array}$ \\
\hline $\begin{array}{l}\text { Resettlement and } \\
\text { Compensation }\end{array}$ & $\begin{array}{l}\text { Resettlement schemes } \\
\text { fail when they ignore }\end{array}$ & $\begin{array}{l}\text { Byrne (2008), Carroll (1992), Cernea (2000), } \\
\text { Cernea and Schmidt-Soltau (2003), Chapin }\end{array}$ \\
\hline
\end{tabular}




\begin{tabular}{|l|l|l|}
\hline $\begin{array}{l}\text { the reluctant "host" } \\
\text { population in the } \\
\text { receiving areas. }\end{array}$ & $\begin{array}{l}\text { (2004), Cohen (1989), Coelho \& Stein (1980), } \\
\text { Cohen and Armelegos (1984), Conservation } \\
\text { Refugees (2006), Dounias and Froment (2006), } \\
\text { Dowie, (2006, 2009), Duncan \& McElwee } \\
\text { Compensation schemes } \\
\text { are only successful in } \\
\text { the short-run. }\end{array}$ \\
& $\begin{array}{l}\text { (1999), Fabricius and de Wet (2002), Fleuret and } \\
\text { Fleuret (1980), Flowers (1983), Galaty (1999), } \\
\text { Galvin et al. (1999), Geisler (2002), Gartlan } \\
(1998), \text { Gibson and Marks (1995), Grinker } \\
\text { (1994), Igoe (2006), MacLean-Stearman (2000), } \\
\text { Marquardt (1994), Nelson (2003), Nguiffo } \\
(2001), \text { Noss (2001), Schmidt-Soltau (2004), } \\
\text { Schmidt-Soltau and Brockington (2007), } \\
\text { Turnbull (1962), Wunder (2000), World Bank } \\
(2002) .\end{array}$ \\
&
\end{tabular}

\section{Definition of key terms}

It is important to begin by defining certain key terms which will be used and the context in which they will be used in this study. Key terms to be used are conservation, biodiversity, indigenous peoples, refugees and protected areas.

Conservation is defined as the protection of species and of natural or man-made resources and landscape for present and future use (Geddes and Grosset, 2001). Conservation differs from preservation in that it supports managed exploitation of resources at a sustainable level while preservation is against any form of exploitation. Conservation used to refer to the protection of flagship species such as lions, tigers, elephants or what Dowie (2009) described as "mega fauna" and particular habitats. However, emerging conservation biology has forced conservation into a new strategy which involves protection of biological diversity (Dowie, 2009). Social scientists have proceeded to define conservation as a social process, rather than a simple focus on the ecosystem. Conservation according to social scientists means organizing people's interaction with a milieu, beginning with the way they perceive it and the way they carry out their interventions (Neba et al. 2009). 
Biodiversity is the variability between and within living organisms and the ecological systems of which they are part, including genetic, species and ecosystem diversity (Convention on Biodiversity, 2001). This concept emerged in the 1980s and gained wider use and recognition in scientific circles (Laird, 2002). It is conservation of biodiversity that is the background of the problem of conservation refugees in this study, almost all of whom are indigenous peoples.

There is no legal or universally acceptable definition of what indigenous refers to. The International Labour Organization (convention 169) defines indigenous peoples as tribal people in independent countries whose social, cultural or economic conditions distinguish them from other sections of the national community and whose status is regulated wholly or partially by their own customs, traditions or special laws and regulations (International Labour Organisation, 1989).

Some Writers go as far as to distinguish between indigenous and traditional people. Chapin (2004) for example says "indigenous and traditional peoples" is a more inclusive category than simply "indigenous peoples". "Traditional peoples" includes non-indigenous groups that are long-standing residents of wilderness areas, such as the rubber tappers of Brazil and longterm Ladino and Creole residents of the Caribbean coastal region of Central America. However, in the context of this study "indigenous peoples" will be used to refer to both “indigenous and traditional peoples".

Borrini-Feyerabend et al. (2004) make a distinction between indigenous peoples and mobile people. At the $5^{\text {th }}$ World Parks Congress in Durban (2003), mobile people defined themselves as a "subset of indigenous peoples" whose livelihoods depend on extensive common property use of natural resources and whose mobility is both a management strategy for sustainable 
land use and conservation and a distinctive source of cultural identity. Mobile people have frequently been excluded from even those limited opportunities provided to sedentary indigenous peoples, for instance some "consultation" on land management options (BorriniFeyerabend et al. 2004). Mobile people here refers to nomadic people and applies to hunters and gatherers, "sea gypsies", shifting cultivators and other groups that have an attachment to particular landscapes and seascapes rather than to definite places only. In the context of this study, indigenous people will include both sedentary indigenous people and mobile indigenous people.

There is a link between conservation refugees and indigenous peoples because the idea of wilderness and traditional societies are inextricably linked together in the western psyche (Igoe, 2006). Indigenous people are the estimated three hundred million people from four thousand distinct societies, strongly attached to what were recently, and in a few instances still are, the world's last wild places (Niezen, 2003).

The term "refugee" was first used to describe people displaced by war or economic and humanitarian asylum-seekers. However in 1985 the United Nations Environment Programme recognized a broad range of environmental disasters can generate refugees (Westing, 1992). This recognition still defines the term too narrowly because it excludes the kind of environmental refugees this study is all about. The other refugees in this study will be referred to as conservation refugees so the term "refugees" in this study will refer to people displaced by the creation of national parks and protected areas.

A protected area is defined by the Convention on Biological Diversity (1992) to refer to a geographically defined area which is designated or regulated and managed to achieve specific conservation objectives. See figure 1 for a global distribution of protected areas. The 
International Union for Conservation (IUCN) defines a protected area as an area of land and/or sea especially dedicated to the protection and maintenance of biodiversity, and of natural and associated cultural resources and managed through legal or other effective means. The main difference between the two definitions is that the IUCN definition makes more reference to the cultural aspects of conservation. The Durban World Parks Congress (2003) identified and discussed four main protected area types (Borrini-Feyerabend et al. 2004). These include;

Government managed protected areas: in which a government body holds the authority, responsibility and accountability for management. In some cases the states delegate their management to a para-statal organization, $\mathrm{NGO}$ or even a private operator.

Co-managed protected areas: in which complex processes and institutional mechanisms are generally employed to share management and responsibility among a plurality of actors ranging from government authorities, Indigenous People, private entrepreneurs and land owners.

Private protected areas: refer to areas under individual, cooperative, corporate for-profit and corporate not-for-profit ownership.

Community conserved areas: in which governance is by indigenous people. Much of these come about not for the intentional conservation of biodiversity but in pursuit of a variety of interlocked objectives (spiritual, religious, survival-related), which did result in biodiversity conservation.

\section{Significance of the Study}


This research is intended to be helpful to both researchers and conservation refugees in different ways. In terms of the first, the vexing dilemma in this study is the face-off between conservation in the form of biodiversity protection and eviction or displacement which leads to loss of livelihood. The problem here is that empirical knowledge has not been available equally about both sides of this dilemma and this is one of the main reasons why livelihood and poverty alleviation which is the social side of the dilemma is loosing out to biodiversity conservation which is the biological side of the dilemma. As Cernea and Schmidt-Soltau (2003) note, biological sciences which argue for conservation have devoted a broader, deeper and more systematic research effort than the social sciences (which should stand up against evictions and displacement) for understanding what is happening when biodiversity is lost, how this occurs and what the consequences are. Social scientists on the other hand have a less systematic approach in research on livelihood issues in and around protected areas. Social scientists have not developed a strong enough argument able to escalate the social issues vested in conservation work at the same higher policy levels at which biological scientists have succeeded to articulate and place their concerns (Cernea and Schmidt-Soltau, 2003). This view is supported by Chapin (2004) who notes that, "hotspots" boundaries have been determined by biological commonalities. Ecoregions are defined in biological terms and, as such, are logical units for conserving biodiversity. Social aspects do not figure in the calculus of Worldwide Fund's ecoregions, except at the level of "threats," and they are introduced after the priority setting, based on biological criteria, has been completed (Chapin, 2004). The results and findings of this work will hopefully contribute to social research by bringing the plight of conservation refugees to the forefront hence strengthening the 
argument of social research against displacement or evictions without consideration for livelihood values and poverty alleviation.

This study will also help direct researchers to the gaps which still exist in the knowledge on conservation refugees. which further research can focus on. Hopefully, with more research on the conservation refugees problem we will arrive at a stage in which conservation policies will be sound or acceptable on both biodiversity and social/poverty grounds.

This research is also undertaken with conservation refugees in mind. Conservation refugees are often marginalized, downtrodden and powerless when confronted by huge multi-national organizations and ruthless government agencies wielding so much power. According to Igoe; [Encounters between conservationists and indigenous people are never between equals] (Dowie 2009: Page 48)

The remoteness of protected areas tends to camouflage poverty and lack of compensation from the public eye and scrutiny. The silence of some well-intentioned promoters of Protected Areas is unhelpful and needs to be replaced by a clear and principled position of opposing and preempting such forced and violent displacements (Cernea and SchmidtSoltau, 2003). These promoters of protected areas tend to be blind to the plight of people displaced from these areas because as Dowie states;

[Conservation refugees are invisible because visibility raises the price of conservation] (Dowie, 2009: Page 52)

\section{Limitations of the Study}

In the course of this study I came across a few difficulties which could have affected the quality of the information presented in this thesis. These include methodological unreliability 
of data collected by researchers, difficulties with making more accurate estimates of conservation refugee numbers and linguistic limitations in data collection.

One of the major limitations of this study is that much of the data collected by conservation researchers, social scientists and conservation refugees have been contested by their opponents who in most cases are conservation NGOs and governments. Data collected from Brockington and Igoe (2006), Brockington et al. (2006), Brockington and Schmidt-Soltau (2004), Cernea (2006), Cernea and Schmidt-Soltau (2003), Chapin (2004), Dowie (2006, 2009), Geisler and de Sousa (2000), Schmidt-Soltau (2004), Schmidt-Soltau and Brockington (2007) has shown for example that the practice of conservation NGOs with the support of states to designate Protected Areas without consultation or compensation to Indigenous Peoples have led to displacements and disruption of sources of livelihood.

However, these data have been contested by the accused conservation NGOs most notably in the work of Sunderland et al. (2009) in “Are Africa's Protected Areas Displacing Hundreds of Thousands of Rural Poor?" Sunderland et al while admitting the fact that the creation of protected areas will inevitably have some negative impacts on local people living nearby, contend that not a single person has been physically removed from any protected area in the central African sub-region. This argument does not hold much water in the context of this study because they do not deny the fact there have been displacements in the bigger picture because eviction is just one aspect of displacement. Sunderland et al. (2009) refer to data on the number of displaced people in the central African sub-region in Cernea and SchmidtSoltau (2003) as unreliable and based on rough estimates with no empirical data collection. This harsh criticism of social scientists is not surprising considering that some of the coauthors of Sunderland et al. (2009) work with some of the conservation NGOs which social 
scientists criticize (Usongo works with the WWF in Cameroon, von Loebenstein and Roth work with the German Technical Cooperation - GTZ). Debates between these groups tend to generate more heat than light and are often characterized by want of good data which can be misleading. If there was a consensus data collection for this research will be much better and easier. Instead I have had to paint an incomplete, remote picture, researched from afar with little scope for ground truthing and the details and complexity which local data could provide.

The second limitation of this study is that the data collected on conservation refugee numbers is based on reported cases of evictions only and excludes cases which were not reported. Coverage on countries in which evictions have taken place in this study is also very limited considering that either no cases have been reported from places where little research has been carried out. Estimates on conservation refugee numbers arrived at in this study should also be treated with skepticism because refugees could be construed not just as evicted people but also as people without access to resources. Unfortunately, there is no universally acceptable methodology to arrive at number of people displaced through restrictions on resource use.

Lastly, the review of literature was mainly done in the English and French languages because these are the two international languages in which I am fluent. By limiting my review to only articles written in English or French I admit it is possible I could have missed out on some valuable information published in other languages. Despite the above difficulties, every effort was made to make the quality of data collection as accurate as it could possibly be. 


\section{Outline}

This thesis is organized into seven chapters. The first chapter has motivated the study. It presented the research objectives, outlined the research methodology, the significance and limitations of the study. Chapter two is a critical examination of international law and declarations which relate to conservation refugees. Chapter three discusses who conservation refugees are and their global distribution. Policies in conservation and development and how they influence the policy terrain behind the evictions and displacement are also covered in chapter four. Chapter five is a critique of the theoretical framework behind resettlement and compensation schemes particularly the DFID (Department for International Development) framework, the IRR model (Impoverishment Risks Reconstruct) and the World Bank's resettlement policy for displaced people. Chapter six presents a case study of the Baka conservation refugees in south east Cameroon showing the policy background behind their displacement and how they face IRR risks. Chapter seven presents the findings of this research, identifies knowledge gaps for future research and advances recommendations for dealing with the conservation refugee problem. The conclusion includes a brief summary of the thesis. 


\section{Chapter Two}

\section{The evolution of law and declarations aimed at protecting the rights of indigenous peoples}

\section{Background}

A number of law and declarations are aimed at protecting indigenous people against arbitrary eviction and displacement in all its forms. In this chapter I will look at the reasons why, despite these efforts aimed at protecting the rights of indigenous people, evictions and displacements still prevail. Studies by Igoe (2006), Brockington and Igoe (2006), and Dowie (2009) have shown that a vast majority of conservation refugees are indigenous people. Conservation refugees will be used interchangeably as indigenous people because the idea of wilderness and traditional societies are inextricably linked together in the western psyche (Igoe, 2006).

The idea of protection of the rights of indigenous people first surfaced at the Berlin Colonial Conference for Africa in 1885, though the destruction of indigenous peoples and alterations of their culture had been brought up in parliamentary discussions in England in the $18^{\text {th }}$ and early $19^{\text {th }}$ centuries (Hitchcock, 1994). Interested parties at the Berlin Conference in 1885 attempted to ensure that members of indigenous groups in their colonies were protected from the actions of settlers bent on gaining access to their lands, resources and labour (Hitchcock, 1994). They affirmed the rights of native tribes to dispose freely of themselves and of their hereditary territory.

This early attempt at the recognition of the rights of indigenous people was met with fierce criticism because some colonial masters regarded native people under their control as uncivilized and therefore could not be accorded sufficient rights (Hitchcock, 1994). Based on 
this argument, settlers considered land occupied by indigenous people as "terra nullius", or land which was empty and open to occupation. As such, settlers were not obliged to pay compensation for lands over which they assumed control and they exercised the right to evict native people resident on such lands. Following the failure of the attempt by the Berlin Conference to protect indigenous people, the League of Nations made another attempt in 1919 at the Versailles Conference.

Article 23 of the League of Nations Covenant (1919) states that, guardianship of aboriginal people implies not only protection, a benevolence towards private missionary, charitable and educational effort but a positive duty of direct legislative, executive, and judicial domination of indigenous people as minor wards of the nation. Guardianship also implies equally direct legislative, executive and judicial tutorship of them for civilization, so that they may become in the shortest time civil and political adults participating on equality in their own government under democratic and republican institutions (Hitchcock, 1994).

This attempt to grant rights to indigenous peoples was a failure as well just for the same reasons as the failure of the Berlin conference resolution. Any attempt at protecting indigenous people while still perceiving them as uncivilized and in need of civilization as could be interpreted in Article 23 of the League of Nations Covenant was bound to fail because the states concerned were not willing to recognize aboriginal people as equal partners. It was still a Master/Servant relationship and therefore unworkable because rights of a master and those of a servant are never the same. Following the failure of the League of Nations, the United Nations Charter came into existence in 1945 with the Universal Declaration of Human Rights. Articles 1, 2 and 17 of the Universal Declaration of Human Rights are of relevance to this study. According to Article 1, "all human beings are born free 
and equal in dignity and rights. They are endowed with reason and conscience and should act towards one another in a spirit of brotherhood."

Under Article 2, "everyone is entitled to all the rights and freedoms set forth in the Declaration, without distinction of any kind, such as race, colour, sex, language, religion, political or other opinion, national or social origin, property, birth or other status. Furthermore, no distinction shall be made on the basis of the political, jurisdictional or international status of the country or territory to which a person belongs, whether it is independent, trust, non-self-governing or under any other limitation of sovereignty."

Article 17 has two parts with the first being that, "everyone has the right to own property alone as well as in association with others." The second part states that, "no one shall be arbitrarily deprived of his property." Though the Universal Declaration of Human Rights says a lot about civil liberty, the right to own property and therefore not to deprive people of their property, still fails to make any particular reference to indigenous people so in effect it cannot be considered strong enough to protect indigenous people against arbitrary eviction and displacement.

One major improvement with the Universal Declaration of Human Rights was that it did not refer to other people as inferior or uncivilized as was the case with the Berlin and Versailles Conference resolutions. Article 1 clearly states that all human beings are equal in rights and dignity. The most significant achievement of the Universal Declaration of Human Rights for this study is that it put in place a foundation for the development of three ground breaking declarations or charters in relation to indigenous peoples' rights. These are the International Labour Organization Convention (numbers 107 and 169 of 1957 and 1991 respectively), the 
Draft Declaration on the Rights of Indigenous People (DRIP), and Agenda 21 of the Rio Earth Summit in 1992. I will look at each in turn in subsequent sections.

\section{The International Labour Organization Convention (107 and 169)}

In 1957 the ILO adopted Convention 107 which for over 30 years would become the only international document covering the rights of indigenous people. The international community had at last recognized that much needs to be done on the rights of indigenous people around the world many of whom are low income earners in spite of their importance to the economies in their respective countries. Convention 107 contains articles on land, training employment, education, rural industry, social security and administration but for the purpose of this study emphasis will only be paid to articles 11 through 14 . This is because these articles deal with protection of the land and indigenous peoples' access to resources. These articles hold that the right of ownership, collective or individual, over lands of members of indigenous or tribal groups is recognized and that populations concerned shall not be removed without their consent. In cases where removals are necessary, people are to be provided with lands of quality at least equal to that of the lands they occupied previously. Compensation is to be provided in kind, cash or both for losses suffered (Hitchcock, 1994).

Despite these advances made in Convention 107, there were a lot of criticisms from indigenous delegates themselves who felt Convention 107 had a paternalistic nature. It was believed that the convention was geared towards the integration of indigenous people into national societies which is why many indigenous people resented it and called for a revision (Hitchcock, 1994). 
Following revisions on Convention 107, the ILO came up with Convention 169 in 1991. Once again for the purpose of this study which centers on evictions and displacements, more interest will be placed on part 2 of Convention 169 which concerns land rights (see appendix 1 for full text of Convention 169). The articles of Convention 169 directly relevant to this study are articles $13,14,15,18$ and 19 .

Under article 13, in applying the provisions of this Part of the Convention governments shall respect the special importance for the cultures and spiritual values of the peoples, their relationship with the lands or territories, or both as applicable, which they occupy or otherwise use, and in particular the collective aspects of this relationship. Also, the use of the term "lands" in Articles 15 and 16 shall include the concept of territories, which covers the total environment of the areas which the peoples concerned occupy or otherwise use. Article 14 says the rights of ownership and possession of the peoples concerned over the lands which they traditionally occupy shall be recognized. In addition, measures shall be taken in appropriate cases to safeguard the right of the peoples concerned to use lands not exclusively occupied by them, but to which they have traditionally had access for their subsistence and traditional activities. Particular attention shall be paid to the situation of nomadic people. Also under article 14, governments shall take steps as necessary to identify the lands which the peoples concerned traditionally occupy, and to guarantee effective protection of their rights of ownership and possession. Adequate procedures shall also be established within the national legal system to resolve land claims by the peoples concerned.

Under article 15, the rights of the peoples concerned to the natural resources pertaining to their lands shall be specially safeguarded. These rights include the right of these peoples to 
participate in the use, management and conservation of these resources. In cases in which the state retains the ownership of mineral or sub-surface resources or rights to other resources pertaining to lands, governments shall establish or maintain procedures through which they shall consult these peoples, with a view to ascertaining whether and to what degree their interests would be prejudiced, before undertaking or permitting any programmes for the exploration or exploitation of such resources pertaining to their lands. The peoples concerned shall wherever possible participate in the benefits of such activities, and shall receive fair compensation for any damages which they may sustain as a result of such activities.

Subject to article 16, the peoples concerned shall not be removed from the lands which they occupy. Where relocation is considered necessary as an exceptional measure, such relocation shall take place only with their free and informed consent. Where their consent cannot be obtained, such relocation shall only take place following appropriate procedures established by national laws and regulations, including public inquiries where appropriate, which provide the opportunity for effective representation of the peoples concerned. Thirdly, whenever possible, these peoples shall have the right to return to their traditional lands, as soon as the grounds for relocation cease to exist. When such return is not possible, as determined by agreement or, in the absence of such agreement, through appropriate procedures, these peoples shall be provided in all possible cases with lands of quality and legal status at least equal to that of the lands previously occupied by them, suitable to provide for their present needs and future development. Where the peoples concerned express a preference for compensation in money or in kind, they shall be so compensated under appropriate guarantees. Persons thus relocated shall be fully compensated for any resulting loss or injury. 
Under article 17, procedures established by the peoples concerned for the transmission of land rights among members of these peoples shall be respected. The peoples concerned shall be consulted whenever consideration is being given to their capacity to alienate their lands or otherwise transmit their rights outside their own community and persons not belonging to these peoples shall be prevented from taking of their members to secure the ownership, possession or use of land belonging to them.

Under article 18, adequate penalties shall be established by law for unauthorized intrusion upon, or use of, the lands of the peoples concerned, and governments shall take measures to prevent such offences.

Article 19 also states that national agrarian programmes shall secure to the peoples concerned treatment equivalent to that accorded to other sectors of the population with regard to the provision of more land for these peoples when they have not the area necessary for providing the essentials of a normal existence, or for any possible increase in their numbers and the provision of the means required to promote the development of the lands which these peoples already possess.

The main difference between Conventions 107 and 169 just covered is that while one 107 is based on the assumption that indigenous peoples are temporary societies destined to disappear with globalization, convention 169 is based on the assumption that indigenous peoples are permanent societies where recognition of, and respect for, ethnic and cultural diversity is of paramount importance. According to Convention 107 and its amendment in 169 therefore, the eviction or displacement of people without their prior consent and without appropriate compensation is illegal under international law. 
The Universal Declaration on the Rights of Indigenous Peoples came into existence because of the perceived failure of the ILO Conventions to protect the rights of indigenous peoples. The Universal Declaration on the Rights of Indigenous Peoples will be examined in greater detail in the next section.

\section{The Universal Declaration on the Rights of Indigenous Peoples}

A preliminary text of the draft of this declaration was initiated in 1985 by the first Working Group on indigenous peoples (which is a subsidiary body of the United Nations human rights think tank) as well as a Sub-Commission on Prevention of Discrimination and Protection of Minorities (Burger, 1997). After much debating and wrangling involving indigenous peoples from all over the world, and after the United Nations General Assembly had requested that the declaration before the International Decade of the World's Indigenous People (19952004), the Declaration on the Rights of Indigenous Peoples was formally adopted by the General Assembly on the $13^{\text {th }}$ of September 2007 by a vote of 143 in favour to four against (UN, 2007). The countries which have continuously abstained from the declaration after Samoa and Colombia (who originally abstained) endorsed the document are Azerbaijan, Bangladesh, Bhutan, Burundi, Georgia, Kenya, Nigeria, Russia and Ukraine. Of the original four who opposed the document, only the United States is left after Australia changed and voted in favour in 2009 (UN, 2010) and New Zealand endorsed the document in May 2010 (New Zealand Government, 2010). On November 122010 the Government of Canada formally endorsed the United Nations Declaration on the Rights of Indigenous Peoples. Canada's ambassador to the United Nations, Mr. John McNee met with the President of the United Nations General Assembly, Mr. Joseph Deiss, to advise him of Canada's official endorsement of the declaration (Tribal Link, 2010). 
The United Nations General Assembly on its $61^{\text {st }}$ Plenary adopted the following; that indigenous peoples and individuals are free and equal to all other peoples and individuals. Indigenous peoples, in exercising their right to self-determination, have the right to autonomy or self-government in matters relating to their internal and local affairs. Indigenous peoples and individuals have the right not to be subjected to forced assimilation or destruction of their culture. States shall provide effective mechanisms for prevention of, and redress for: any action which has the aim or effect of depriving them of their integrity as distinct peoples, or of their cultural values or ethnic identities; any action which has the aim or effect of dispossessing them of their lands, territories or resources; any form of forced population transfer which has the aim or effect of violating or undermining any of their rights and any form of forced assimilation or integration. Indigenous peoples shall not be forcibly removed from their lands or territories. No relocation shall take place without the free, prior and informed consent of the indigenous peoples concerned and after agreement on just and fair compensation and, where possible, with the option of return (UN, 2007).

The Declaration on the Rights of Indigenous Peoples document is related to Agenda 21 of the 1992 earth summit which took place in Rio de Janeiro, Brazil (see appendix 2 for complete text) in that some of the goals inherent in the objectives and activities of this programme area are already contained in such international legal instruments as the ILO Convention 107 and 169. All three documents stress the significance of indigenous peoples' land rights and their ownership and control of natural resources. The question which I now want to address is why have all these laws and declarations not been able to protect indigenous peoples around the world from evictions and displacement? 


\section{Reasons for the failure of international conventions and declarations to prevent evictions and displacements}

There have been a number of reasons why international declarations and conventions have not been able to eradicate the conservation refugee problem or protect indigenous people against eviction and displacement. This section will draw on several key publications in guiding the search for reasons. The main reasons identified are the lack of a universally acceptable definition of who indigenous people are, problems in defining self-identification, non-respect of international treaties by states, the problem of affirmative action, and a failure to recognize customary land titles.

\section{Defining the concept of indigenous people}

There is no universally acceptable definition of who can be considered indigenous and this might be one of the reasons international conventions and declarations are incapable of preventing the displacement of indigenous people. Hitchcock (1994) used the term "indigenous people" to refer to those groups who are descendants of the original populations residing in a country. They are usually non-European groups residing in places that were colonized by Europeans. Hitchcock also agreed with the UN special Rapporteur on the Problem of Discrimination against Indigenous Populations which notes that the term indigenous applies to those people who are isolated socially or marginal groups that have managed to preserve their traditions in spite of being incorporated into states dominated by other societies. This definition is however problematic because it seems to be based on the understanding that indigenous peoples are minorities in states dominated by other majority groups. This is not always the case because as Stamatopoulou (1994) notes, indigenous people are not racial, ethnic, religious and linguistic minorities. In certain states indigenous peoples constitute the majority of the population; and in certain States indigenous peoples 
constitute the majority in their own territories (Stamatopoulou, 1994). Perhaps the strongest justification of this argument is the case of Bolivia where 62 percent of population aged 15 and above identify themselves as indigenous and the country even elected its first indigenous president in 2005 (Fromherz, 2008).

According to the Independent Commission on the International Humanitarian Issues, four elements are included in the definition of indigenous and these include; pre-existence, nondominance, cultural difference and self-identification as indigenous. Shikongo (2007) in his study of the characteristics of indigenous people in Africa presents an excellent summary of characteristics provided by the ACHPR (African Commission on Human and Peoples' Rights).

These ACHPR characteristics are that indigenous peoples' cultures differ considerably from the dominant society and their cultures are under threat of extinction. The survival of their particular way of life depends on access and rights to their traditional land and natural resources thereon. They suffer from discrimination and exploitation as they are being regarded as less developed and less advanced by other groups. They often live in inaccessible regions, often geographically isolated and suffer from various forms of political and social marginalization. They are people who could lead a good life (based on their vision of what a good life is) and who could contribute significantly to the development of the states in which they live if given the opportunity. These groups are not problematic categories in themselves but are produced as problematic by certain political and structural factors.

The World Bank Operational Directive on Indigenous People (1991) stresses close attachment to ancestral territories, self-identification by members and by others as members of a distinct cultural group, possession of an indigenous language which is often distinct from 
a national language, presence of customary social or political institutions and subsistenceoriented production systems. Hitchcock (1994) agrees that indigenous people possess ethnic, religious or linguistic characteristics that are different from dominant groups. However he criticizes the World Bank characteristics of indigenous people by stating that some indigenous people do not fit the World Bank criteria. Hitchcock argues that substantial numbers of indigenous people have been dispossessed so that they no longer retain their ancestral territories. They have also been denied access to natural resources in many countries in which they live. He goes on to state that most African, Asian and Native American indigenous people now have market-oriented production systems. This view is supported by Wilhusen, Brechin, Fortwangler and West (2002) who argue that rapid social change, access to modern technology, increasing market orientation, growing population pressure have led indigenous people to lose the very traditional qualities that made them indigenous or their "indigenousness".

It is also important to consider the fact that the degree of indigenousness is not always the same within groups because some groups possess more of the characteristics of indigenous people than others. The Maori of New Zealand for example are highly urbanized and have more access to market-oriented production systems than the Aka foragers in the rainforests of Central Africa who are not urbanized and have less access to market-oriented production systems, so according to the above criteria, the Aka would be more indigenous than the Maori.

The above complications coupled with the fact that indigenous representatives themselves have denied the need for definition, nationally or internationally (Stamatopoulou, 1994) makes it difficult for international conventions and declarations to protect indigenous people 
from eviction or displacement as a result of conservation programmes. With no universally acceptable definition of indigenous people it is hard to determine who is indigenous and who is not. Even the present Declaration on the Rights of Indigenous Peoples document does not include any international definition of indigenous people thus allowing the right to selfdefinition to the people and their right to determine their own membership.

This self-definition is often ignored by states which should protect indigenous people within their borders from displacement. This tendency of states to ignore the Declaration on the Rights of Indigenous Peoples could be the reason why states such as the Russian Federation deny having any indigenous people on their territory (Stamatopoulou, 1994) despite an independent study showing there are 135 indigenous groups in Russia with an estimated 40 million people (Hitchcock, 1994). So it comes as no surprise that Russia has continuously abstained from adopting the Declaration on the Rights of Indigenous Peoples till present day. The UK Ambassador and Deputy Permanent Representative to the United Nations, Karen Pierce speaking on behalf of the UK at the sixty-first General Assembly did not oppose the declaration but went on to say that other ethnic groups and minority groups within the territory of the United Kingdom and her overseas territories did not fall within the scope of indigenous people (United Nations, 2007).

Failure to arrive at a universally acceptable definition of indigenous people has resulted in the lack of constitutional and legislative recognition of indigenous people in some countries. Shikongo (2005) observes that few African countries recognize the existence of indigenous people within their borders so in that regard they have no obligation to honour international declarations aimed at protecting conservation refugees who happen to be indigenous people. Shikongo cited the case of the San indigenous people of Botswana who the constitution of 
Botswana does not even recognize as one of the tribes that make up the Botswana people. The constitution makes reference to eight main tribes of Botswana, which do not include the San. In Botswana, about 1,500 San people were evicted from the Central Kalahari Game Reserve as the government which endorsed the declaration refuses to recognize them as indigenous (Shikongo, 2005).

\section{The problem of self-determination}

Self-determination for indigenous people is a key principle in the international conventions and declarations. There has been a long standing debate over the word self-determination which goes as far back as the drafting of the United Nations charter in 1945. It is no surprise though that when the term was included in the Declaration on the Rights of Indigenous Peoples document it met with such stiff opposition. Article 3 of the declaration addresses the right of indigenous people to self-determination and by virtue of that right they freely determine their political status and institutions and freely pursue their economic, social and cultural development. Fromherz (2008) notes that Canada, the United States, Australia and New Zealand based their initial opposition to the declaration on the term self-determination. These states called the declaration text "unworkable, confusing, contradictory and deeply flawed". Their fear was that self-determination could be misrepresented as conferring a unilateral right of self-determination and possible secession upon a specific subset of the population, thus threatening the political unity, territorial integrity and the stability of an existing United Nations member (Fromherz, 2008). To them it could be regarded as creating a state within a state which could lead to secession. One point in support of their opposition to the term self-determination is that during the years after the passage of the UN charter in 1945, self-determination took on a meaning that was entirely unexpected. Many countries, 
mostly socialist or developing countries began to strongly advocate a view of selfdetermination as a right to colonial independence (Fromherz, 2008).

I will argue that states should not oppose the declaration based on this misunderstanding of the term self-determination. I make three points to back up this argument based on readings from the works of Stamatopoulou (1994) and Fromherz (2008). The first argument concerns the definition of self-determination in the declaration document. Though article 3 of the declaration does not restrict the scope of the right to self-determination, article 34 provides a perfect elaboration of what the declaration understands self-determination to be. Article 34 defines self-determination as the right of indigenous people to promote, develop and maintain their institutional structures and their distinctive customs, spirituality, traditions, procedures, practices and juridical systems or customs. This in no way encourages secession of states though it could be possibly misused in that way.

Secondly, Fromherz (2008) makes a clear distinction between "external" and "internal" selfdetermination. According to him, external self-determination refers to the right to secede and form a new state or join another existing state. Internal self-determination on the other hand is the right to have the essential political rights within a state. This requires that people have a right to freedom of thought and expression, the right of peaceful assembly and freedom of association, the right to take part in public affairs, the right to vote and be elected at genuine and periodic elections (Fromherz, 2008). This right can be conceptualized as referring to three demographics within a state which include: the whole population, racial or religious minorities suffering gross discrimination, ethnic groups, indigenous people and other minorities (Fromherz, 2008). My conclusion therefore is that self-determination used in international conventions and declarations refers to only internal self-determination so it 
should not be misrepresented or misinterpreted to refer to the right to secession by minorities. With this reasoning in mind I think it will be unreasonable to ignore conventions to protect indigenous peoples from displacement on the grounds of opposing self-determination. As the third argument Stamatopoulou (1994) makes a really interesting point with regards to granting the right to self-determination to indigenous peoples within the state. She argues that at a time when ethnic conflicts threaten to dismember countries across the world, the recognition of the right of self-determination within the state might be the best way to maintain the integrity of the state. If people cannot express or be allowed to express this selfdetermination within a state by deciding on its mode of development, fully participating in political, economic, social and other institutions or exercising the right to autonomy in local affairs, then logically the only other possible way of exercising self-determination would be outside of the state (in other words secession). In this world of rapid social transformation, states and people alike could rethink the meaning of the right to self-determination and its link to democracy and all human rights and fundamental freedoms (Stamatopoulou, 1994). States could grant internal self-determination to their indigenous peoples in order to prevent them from demanding external self-determination. Forcefully evicting people will just go a long way to decreasing their feeling of belonging to the state.

Self-determination has been used as an excuse by a lot of countries to abstain from or oppose the Declaration on the Rights of Indigenous Peoples. Perhaps the declaration committees could have considered the use of a less controversial word such as "self-management" as used by ILO as a preamble to convention 169. Refusal to recognize the right of indigenous people to self-identification by states which abstained from or opposed the declaration limits the power of the international convention to protect indigenous peoples living within the 
borders of such countries from forced evictions for conservation projects. Even some states such as Egypt which endorsed the declaration still expressed reservation over the use of the term self-determination (United Nations, 2007).

\section{Affirmative Action Problem}

Due to past and ongoing processes of discrimination, colonialism, post-colonial projects of nation building, development and modernization as well as conservation, some indigenous people and minority groups around the world have become marginalized in their own countries and need recognition and protection (Shikongo, 2005). This need for recognition and protection has given birth to international conventions and declarations concerning the rights of indigenous people. There is a problem with the application of the articles of these conventions and declarations because of concerns it sparks debates about affirmative action. The application of these conventions and declarations are seen by other groups as affirmative action in favour of indigenous people. Affirmative action is therefore an important and controversial policy used to combat differences between groups (Coate and Loury, 1993). Fromherz (2008), in discussing the balance between indigenous judiciary and ordinary state judiciary has advocated an affirmative action programme which recognizes the presence of authorities representing both organs on an equal footing. The case for the defense of affirmative action through the application of international conventions has also been advanced by David Choquenhuauca, the Bolivian foreign minister at the General Assembly on the endorsement of the Declaration on the Rights of Indigenous Peoples by his government. He argues that by this declaration indigenous people were not trying to live better than anybody else. They were merely trying to live like everyone else and to exercise the same rights and in the same manner as all the people of the world (United Nations, 2007). 
Colchester et al. (2001) noted that because of the growing acceptance of the rights of indigenous people in international law, further recognition of these rights in the declaration has been objected to in some quarters. Ms. Nuorgam of Finland at the General Assembly on the endorsement of Declaration on the Rights of Indigenous Peoples said the issue of indigenous peoples' rights affects the lives of not only indigenous people, but also populations as a whole (United Nations, 2007). Meaning she does not see the need to give preferential treatment to indigenous peoples.

My argument here is that too much emphasis on the implementation of indigenous peoples' rights has been interpreted by non-indigenous groups as giving special rights to some ethnic groups over and even above the rights of all other groups within a state. Shikongo (2005) however argues that this affirmative action is not to deny other Africans (for example in his study) their legitimate claim to belong to and to identify as Africans. He argues that emphasis on indigenous rights is to focus on the particularities of the sufferings of indigenous people so that they can seek protection in international human rights law and moral standards.

In my view, talking too much about indigenous rights could lead to tribalism and ethnic conflicts. I use the works of Jacobson (1985) and Rubenfeld (1997) to support my argument here. They argue that affirmative action threatens inadvertently to entrench racial thinking and to stigmatize minorities. Defenders of affirmative action tend to respond to this assertion by denying the reality of these harms or by arguing that they are outweighed by affirmative action's benefits. The degree to which affirmative action inadvertently entrenches racism or harms minorities is of fundamental importance to affirmative action's merits as a matter of policy. The most prevalent harm-to-society argument against affirmative action is that it polarizes and stigmatizes minority groups (Jacobson, 1985; Rubenfeld, 1997). The point is 
that if indigenous peoples are given special rights, they could be resented by other segments of the population.

\section{Lack of respect for international conventions and declarations by states}

Stamatopoulou (1994) clearly identifies the problem of non-respect of treaties concluded by the United Nations and other organizations as one of the major reasons why indigenous people are exposed or left without protection in the face of problems such as eviction. Article 37 of the Declaration on the Rights of Indigenous Peoples presented earlier in this chapter clearly states that indigenous people have the right to recognition, observance and enforcement of treaties concluded with states. Stamatopoulou however does not realize that enforcement of these treaties is actually the main problem rather than a lack of political will of the states to respect these treaties. Fromherz (2008) recognizes that most international declarations and treaties are not in themselves legally binding on states and violations of the rights declared therein are not necessarily judicially enforceable against states in international courts. This observation by Fromherz can be supported by Robert Hill the Australian delegate at the Sixty-first General Assembly Plenary who said with regards to the Declaration on the Rights of Indigenous Peoples ratification that it was the clear intention of all states that the declaration be an inspirational document with political and moral force but yet no legal force. The text contained recommendations of how states could promote the welfare of indigenous people, but was not in itself legally binding. He went on to say that the declaration did not provide a proper basis for legal action complains, or other claims in any international, domestic or other proceedings (United Nations, 2007). With these points in mind it can be said that international declarations and conventions only protect indigenous people against eviction in principle and not in action since states are not under any legal 
obligation to enforce them. So my view is that most international conventions and declarations are intended to inspire rather than have legal effect.

Fromherz goes on to say that because of this non legal binding character of international declarations, treaties and conventions, their enforcement is largely, if not exclusively, dependent on voluntary acceptance and implementation by UN member states. However what both Fromherz and Stamatopoulou fail to realize is that even if there was an enforcement mechanism put in place by the United Nations or any other powerful international organs there will be two main problems to deal with. These are the problem of non-interference in internal affairs of independent states and the next problem is how to effectively enforce compliance at grassroots level.

Concerning the problem with non-interference in the affairs of independent states, I use the work of Shutkin (1991) to support my argument. Shutkin says that recent developments in jurisprudence of human rights and international environmental policy convey a potentially more forceful role for law in these matters. He goes on to say that the principle of state sovereignty unfortunately continues to thwart or limit the initiatives of groups and individuals on behalf of human rights and environmental protection while allowing states to persist in the exploitation of natural resources. As long as international law and consequently international society are seen as constituted primarily by states vis-à-vis individuals and groups, these same entities will continue to sanction the destruction of cultures and livelihoods through evictions. In 2005 for example, the state of Rwanda banned the indigenous Batwa community association that was helping the devastated and displaced Batwa recover and rebuild their lives in the wake of the 1994 genocide (Shikongo, 2007). 
The United Nations in this case failed to take any action against the state of Rwanda because of the rule of non-interference.

The next problem is how to enforce these treaties and declarations effectively at grassroots level. Even if there is a good will by the governments or NGO agencies in charge of implementing these international treaties and declarations there is always the worry that agents or staff working for these organizations might either not effectively honour the terms of the treaties and declarations or might wrongfully apply them when out there in the field. Chapin (2004) notes that Worldwide Fund - United States has continued to voice respect for indigenous peoples, yet in many of its pronouncements in the field it displays a studied lack of interest toward partnerships with indigenous or local communities of any stripe. In broad strategy statements about its ecoregional approach, Worldwide Fund (WWF) simply avoids talk of involvement with indigenous peoples at all. He quotes the director of the WWF Latin America programme, who in a 2002 reference to the Amazon Basin said;

[We don't work with indigenous people. We don't have the capacity to work with indigenous people] (Chapin, 2004: Page 21)

And also a Conservation International biologist working with the Kayapó in the Lower Xingu region of Brazil who said;

[Quite frankly, I don't care what the Indians want. We have to work to conserve the biodiversity] (Chapin, 2004: Page 21). So, this is a "greater good" argument.

\section{Lack of recognition for customary land tenure}

Most of the conventions and declarations presented earlier in this chapter make mention of the right of indigenous people to own land. Article 27 in particular of the Declaration on the Rights of Indigenous Peoples clearly states that indigenous people have the right to the land, 
territories and resources which they have traditionally owned. However these declarations and conventions do not make any specific provisions on how this right to own land is to be exercised. It is just like providing a room but not providing the keys into the room. International declarations and conventions say very little or nothing at all on the exercise of customary land tenure or customary land ownership so as a result the states have no obligation to recognize indigenous peoples' land ownership rights in the face of evictions.

Tenure is an important consideration within most developing countries with Shikongo (2005) correctly saying that the indigenous people and the land are one. Lack of recognition of traditional land ownership rights means indigenous people like the Baka on Plate 1 are simply temporal occupants on their ancestral lands, which means they can be evicted or displaced anytime. 
Plate 1: These Indigenous Baka dancers in the forests of South East Cameroon have been reduced to "temporal occupants" in a forest which is their ancestral home.

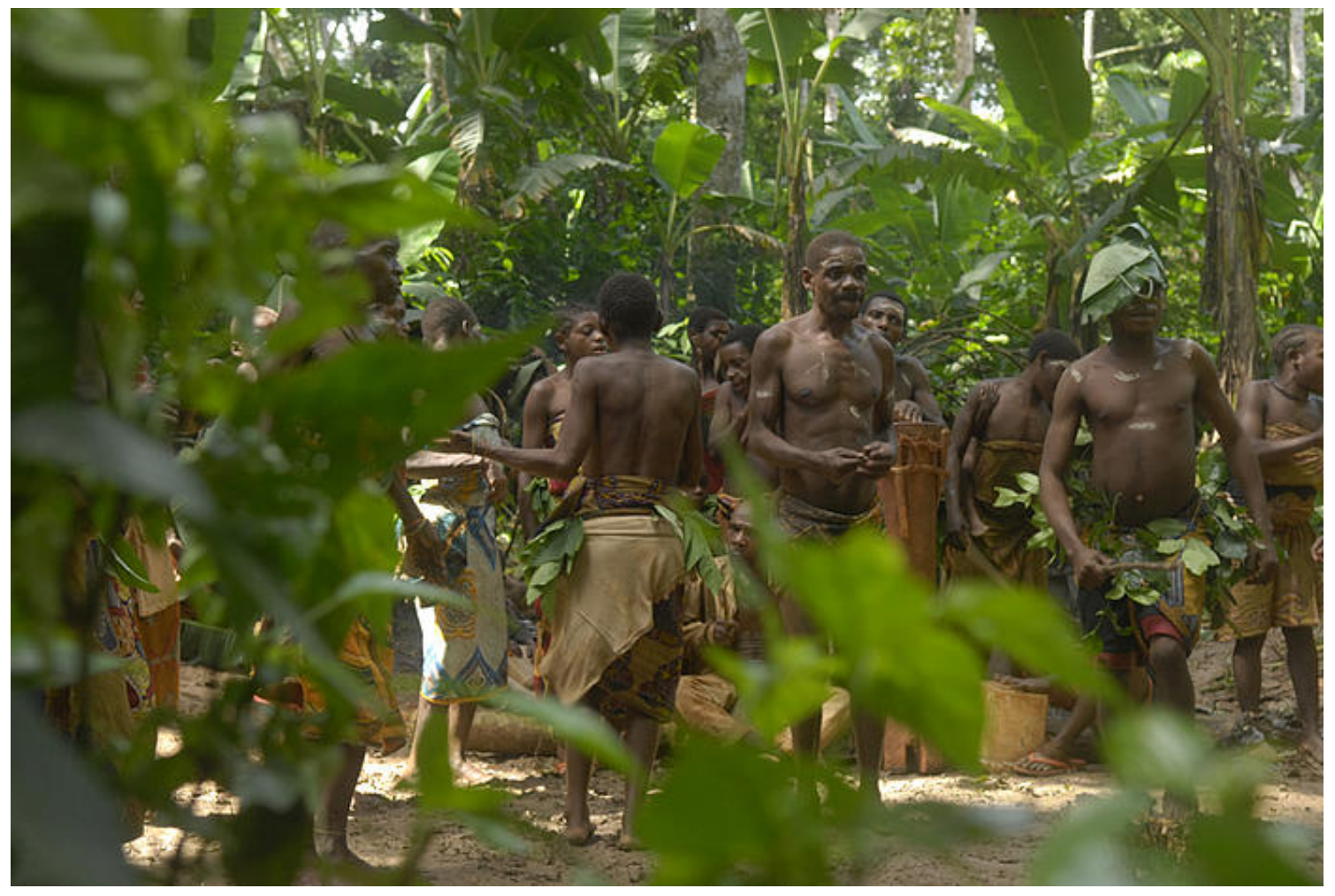

Worldwide Fund-Jengi Project, 2009

The process of colonization in most developing countries, North America and Australia introduced the principle of "terra nullis" which states that all unoccupied land belongs to the state (Fromherz, 2008). This doctrine has continued till present day with many states refusing to recognize customary land titles. Article 14 of the ILO convention 169 states that governments shall take steps as necessary to identify the lands with which the peoples concerned traditionally occupy, and to guarantee effective protection of their right of ownership. However, it does not say exactly which steps should be taken to guarantee this protection. No mention is made of the recognition of traditional land tenure systems. Any attempt to recognize customary land ownership has often been met with strong resistance as 
was the case with Australia at the General Assembly (United Nations, 2007). Australia resisted any attempts to recognize customary on the grounds that it should not be placed in equal position or above national law and that customary law is not law in the sense that modern democracies use the term; it is based on only culture and tradition (United Nations, 2007; Fromherz, 2008). Fromherz notes that article 34 of the Declaration on the Rights of Indigenous Peoples does not require states to accord indigenous customary law and courts a level of jurisdictional hierarchy even equivalent to that of national law, let alone superior to it.

In my view, this opposition to the recognition of traditional land titles is unreasonable because results from Colombia and Bolivia (which are two countries to have recognized customary land tenure) have been arguably successful. Under the framework of the 1991 constitution, Colombia stood out as one of the most advanced with regards to recognizing the collective rights of indigenous people. Colombia had 710 reservations for indigenous people by 2007 which covered about 29 percent of the national territory (United Nations, 2007). These properties could not be seized or transferred from indigenous people therein and they could not be evicted either.

Bolivia recognized herself as a multiethnic and pluricultural state through the inclusion of indigenous people in newly decentralized municipal development decisions and the recognition of the collective ownership of their traditional lands (Fromherz, 2008). The 1994 constitution of Bolivia included a limited recognition of indigenous laws and customs as alternative dispute resolution mechanisms (Fromherz, 2008). This Bolivian model has been replicated in a large part by other states in Central and South America with large indigenous populations. 


\section{Conclusion}

To conclude this chapter, Fromherz believes that though individual states such as Bolivia and to a limited degree some other Latin American states are free to develop and experiment indigenous courts, a general agreement on international declarations and conventions with specific reference to the Declaration on the Rights of Indigenous Peoples would make the declaration in particular an effective instrument and truly a triumph for indigenous people around the world.

Fromherz tries to blame the states which abstained and opposed the declaration for the inability of this instrument to effectively protect the rights of indigenous people. This cannot be true because the analysis of literature in this chapter has shown that there are certain aspects imbedded in the declaration and other conventions themselves which make their application problematic.

Even if all states sign the declarations, there will still be no guarantee they are willing to turn the articles of the declaration into law within their various borders. With this in mind it can be said that implementation is a major shortcoming with most international conventions and declarations. So long as states are under no obligation to apply these conventions and declarations, and so long as there are no channels for evicted indigenous people to legally pursue violations of their rights through eviction, then international declarations might only reduce but not completely eradicate the conservation refugee phenomenon globally. As Stamatopoulou (1994) rightly says, though the formal international recognition of global human rights vis-à-vis indigenous people strengthens their struggle and the hand of those who try to help them, including the United Nations, the road from the declaration of principles to their implementation is still certainly a long and difficult one. 
Having examined the evolution of law and declarations to protect indigenous peoples and the reasons for the failure of these initiatives, the next step in this study will be to look at who conservation refugees really are. The next chapter will explain how indigenous peoples end up as conservation refugees and the global distribution of conservation refugees.

\section{Chapter 3}




\section{Conservation Refugees and their Global Distribution}

This Chapter will seek to determine who conservation refugees are based on literature examined as well as what their global distribution is.

\section{Who conservation refugees are}

In chapter one I recognize the fact that there is a link between conservation refugees and indigenous people because the idea of wilderness and traditional societies are inextricably linked together in the western psyche (Igoe, 2006). However this is not enough reason to conclude that most conservation refugees are indigenous people. A review of the works of some other researchers will help in justifying the claim that most conservation refugees are indigenous people. Toledo's work (2010) can be used to demonstrate this link by looking at the correlation he presents between biological richness and cultural diversity on both geopolitical and biogeographic terms. He examines the strategic importance of indigenous people in the biomass appropriation stressing the remarkable overlap between indigenous territories and the world's remaining areas of high biodiversity. This view is supported by Maffi (2001) and Maffi and Carlson (2005) who also noted a global overlap between cultural diversity and biodiversity. On a global scale, cultural diversity is associated with the remaining stands of biodiversity. According to Toledo (2010) there is a positive correlation between areas of high biological richness and areas of high diversity of languages (the best single indicator of a distinct culture) according to Toledo (2010). Tables 2, 3 and Figure 3 below show that nine of the 12 main centres of cultural diversity are also in the roster for biologically megadiverse nations.

Table 2: Top 25 countries considered megadiversity countries by Mittermeier and Goettsch-Mittermeier 


\begin{tabular}{|c|c|c|}
\hline $\begin{array}{l}\text { Rank of the } \\
\text { Country } \\
\text { according to } \\
\text { degree of } \\
\text { megadiversity }\end{array}$ & Name of Country & $\begin{array}{l}\text { Number } \\
\text { of } \\
\text { endemic } \\
\text { languages }\end{array}$ \\
\hline 1 & Papua New Guinea & 847 \\
\hline 2 & Indonesia * & 655 \\
\hline 3 & Nigeria & 376 \\
\hline 4 & India $*$ & 309 \\
\hline 5 & Australia * & 261 \\
\hline 6 & Mexico * & 230 \\
\hline 7 & Cameroon & 201 \\
\hline 8 & Brazil * & 185 \\
\hline 9 & $\begin{array}{l}\text { Democratic } \\
\text { Republic of Congo } \\
\text { (Zaire) }\end{array}$ & 158 \\
\hline 10 & Philippines * & 153 \\
\hline 11 & USA & 143 \\
\hline 12 & Vanuatu & 105 \\
\hline 13 & Tanzania & 101 \\
\hline 14 & Sudan & 97 \\
\hline 15 & Malaysia & 92 \\
\hline 16 & Ethiopia & 90 \\
\hline 17 & China $*$ & 77 \\
\hline 18 & Peru * & 75 \\
\hline 19 & Chad & 74 \\
\hline 20 & Russia & 71 \\
\hline 21 & Solomon Islands & 69 \\
\hline 22 & Nepal & 68 \\
\hline 23 & Colombia * & 55 \\
\hline 24 & Cote d'Ivoire & 51 \\
\hline 25 & Canada & 47 \\
\hline
\end{tabular}

Toledo (2010: Page 13)

Figure 3: Top 15 Megadiversity Countries 


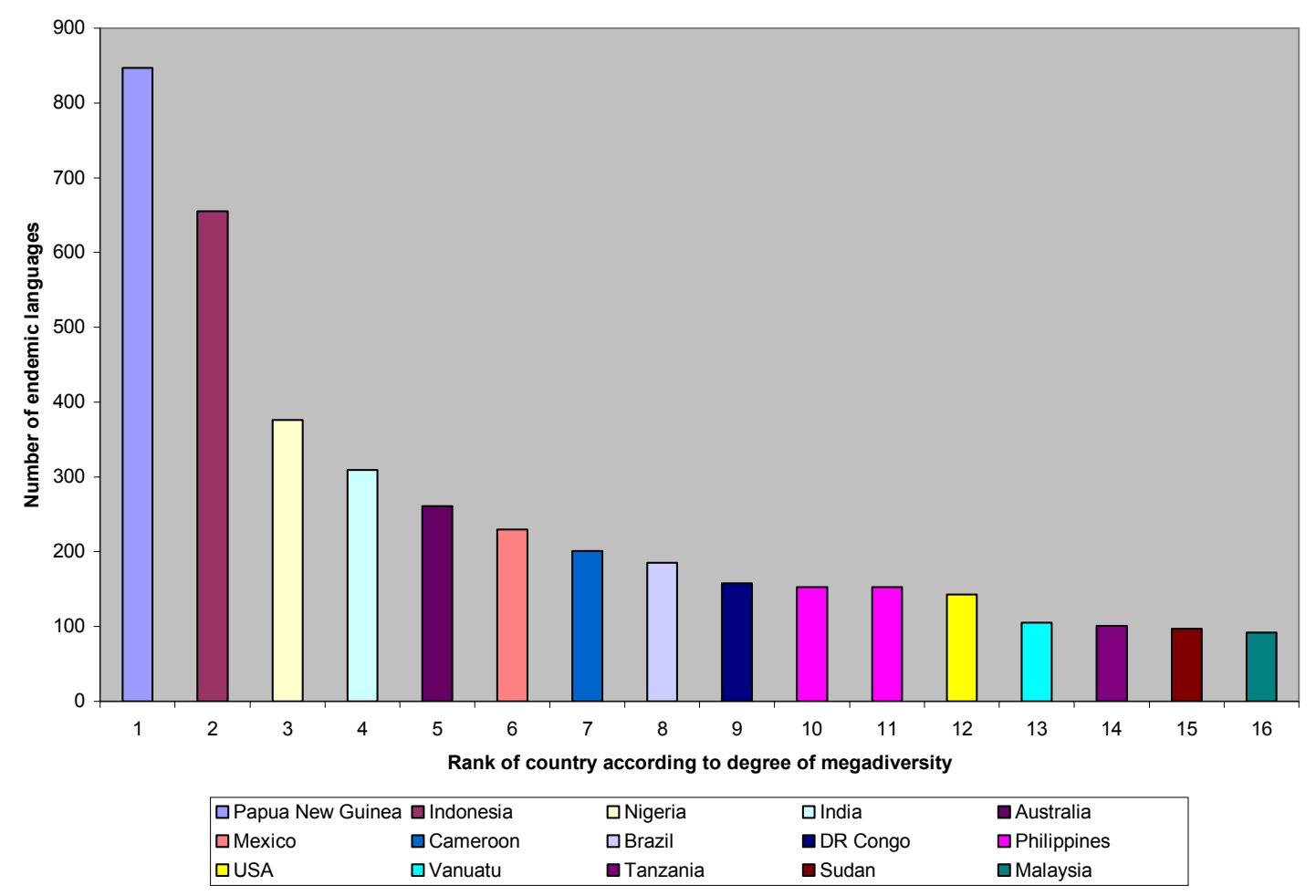

Adapted from Mittermeier and Goettsch-Mittermeier (1997)

Table 3: Top 12 Countries by number of species and endemism (Biological Diversity)

\begin{tabular}{|l|l|l|l|}
\hline Country & Richness & Endemism & Both \\
\hline Brazil $*$ & 1 & 2 & 1 \\
\hline Indonesia * & 3 & 1 & 2 \\
\hline Colombia * & 2 & 5 & 3 \\
\hline Australia $*$ & 7 & 3 & 4 \\
\hline Mexico $*$ & 5 & 7 & 5 \\
\hline Madagascar & 12 & 4 & 6 \\
\hline Peru * & 4 & 9 & 7 \\
\hline China & 6 & 11 & 8 \\
\hline $\begin{array}{l}\text { Philippines } \\
*\end{array}$ & 14 & 6 & 9 \\
\hline India * & 9 & 8 & 10 \\
\hline Ecuador & 8 & 14 & 11 \\
\hline Venezuela & 10 & 15 & 12 \\
\hline
\end{tabular}

* Top 9 countries with the overlap of cultural diversity and biodiversity

Toledo (2010: Page 14) 
The relationship between cultural diversity and biodiversity is evident again in the fact that indigenous people control legally or illegally immense areas of rich biodiversity (see Table 4). Amongst the most notable examples brought forward by Toledo (2010) are the cases of the Inuit who inhabit one fifth of the territory of Canada (222 million hectares), the indigenous people of Papua New Guinea whose lands represent 97 percent of the national territory, the Aboriginal tribes of Australia with nearly 90 million hectares of Australian territory, the Amerindians of Brazil who despite numbering only 250,000, inhabit an area of over 100 million hectares in the Amazon basin. In summary, on the global scale it is estimated that the total area under indigenous control could probably reach between 12 and 20 percent of the earth's surface (Toledo, 2010).

Table 4: Indigenous People in Global 200 terrestrial ecoregions considered priority areas by the Worldwide Fund

\begin{tabular}{|l|l|l|l|}
\hline Region & $\begin{array}{l}\text { Number of } \\
\text { ecoregions }\end{array}$ & $\begin{array}{l}\text { Number of } \\
\text { ecoregions } \\
\text { with } \\
\text { indigenous } \\
\text { peoples }\end{array}$ & $\begin{array}{l}\text { Percentage } \\
\text { of } \\
\text { indigenous } \\
\text { peoples } \\
\text { living in } \\
\text { ecoregions }\end{array}$ \\
\hline World & 136 & 108 & 79 \\
\hline Africa & 32 & 25 & 78 \\
\hline Neotropic & 31 & 25 & 81 \\
\hline Nearctic & 10 & 9 & 90 \\
\hline $\begin{array}{l}\text { Asia and } \\
\text { Pacific }\end{array}$ & 24 & 21 & 88 \\
\hline Oceania & 3 & 3 & 100 \\
\hline Paleartic & 21 & 13 & 62 \\
\hline Australasia & 15 & 12 & 80 \\
\hline
\end{tabular}

Adapted from Worldwide Fund International (1998), In Toledo (2010: Page 15)

Alcorn (1993) points out that the agendas of conservationists and indigenous people are partially or completely in conflict. According to her argument, indigenous people believe in 
preservation through use while most conservationists believe in preservation through dislocation of the local population. Although the academic debate on linkages between conservation and conflict is recent, competition amongst user groups over natural resources such as land, water and forests is ubiquitous and has a long history (Anderson et al. 1996; Ayling and Kelly, 1997). Ownership and usage of natural resources inherently carry the potential for tension and conflict as the usage agenda of one party usually excludes that of others (de Koning, 2009).

The view of a Karen (The Karen are an indigenous ethnic group in Thailand) reflects the view of most indigenous people around the world. The Karen asked why conservationists always try to "put things in boxes" or restricting access to the forest. To him conservation should be part of making a living (Alcorn, 1993). Figure 4 below illustrates this overlap of interests between conservationists who are out to create national parks free of people, indigenous people who need the "wilderness" for survival and Governments who are eager to benefit from the financial backing of the conservation institutions, assert their power over indigenous groups in remote areas and to declare ownership over territories. Most of these actors have vested interests that they try to defend. The overlap of these interests leads to conflicts resulting in displacements of indigenous peoples since they are the weakest of the three actors. 
Figure 4: Overlaps of Interests which leads to the conservation refugee problem

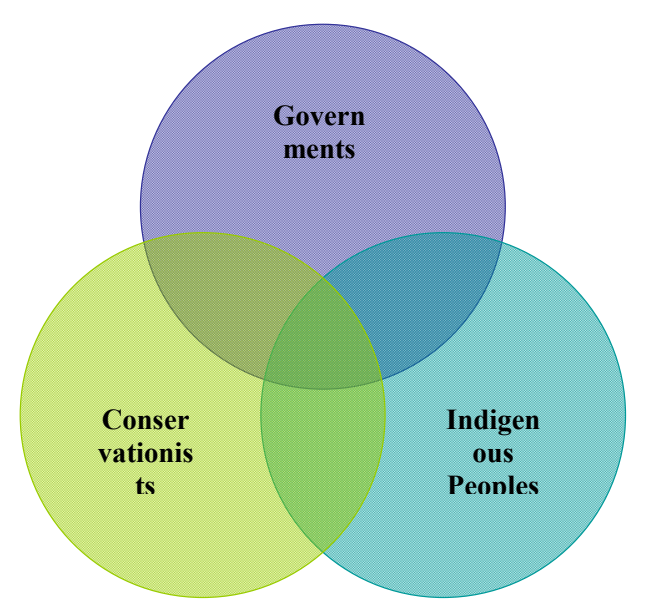

The role of governments in the conservation refugee problem cannot be overemphasized because as Schmidt-Soltau (2004) argues, it is hard to understand why most governments in the developing world allow foreigners to build a fantasy world on their territories. Financial consideration seems to be the driving force behind the inability of governments to resist displacement for conservation because conservation is a sustainable source of income for government officials (Schmidt-Soltau, 2004). In sub- Saharan Africa alone, international conservation NGOs have a budget of approximately US\$ $117,820,516$ per annum (Brockington and Scholfield, 2010). This shows how much financial power the big conservation NGOs wield. Since encounters between conservationists and indigenous peoples are never between equals (Igoe, 2006), conservationists most often than not end up having their right of way. There is a focus on large-scale conservation strategies and the importance of science, rather than social realities, in determining conservation policies. 
Sometimes the indigenous peoples are evicted, and the conservationists frequently seem to be behind the evictions.

Alcorn's argument on the different agendas of conservationists and indigenous people triggers the conservation refugee problem. This is amplified by Chapin (2004) who states that indigenous agendas almost invariably begin with the need to protect and legalize their lands for their own use. They emphasize the importance of finding ways to make a living on the land without destroying those resources. And they give high priority to documenting their people's history, traditions, and cultural identity. Conservationist agendas, by contrast, often begin with the need to establish protected areas that are off-limits to people, and to develop management plans. If they include indigenous peoples in their plans, they tend to see those people more as a possible means to an end rather than as ends in themselves. Chapin asked the question;

[How should co-management arrangements be established for lands and waters where one set of relationships to land - the aboriginal - have been built around the normative values of equity, cooperation and reciprocity that is expressed in terms of local authority and common property access arrangements while the other set of relationships to land-those regulated by the state- have been built around the normative values of competition, exclusive rights to property/resources, and centralized management authority?] (Chapin, 2004: Page 22)

Failure to arrive at an answer to the above question asked by Chapin leads to the inevitable problem of conservation refugees who are forced to move to create space for conservation projects. An understanding of how conservation refugees come about helps in the understanding of who they are. My study presents data on conservation refugees displaced from national parks and reserves across 27 countries. As Table 6 shows, most of these people displaced are indigenous people. Having looked at who conservation refugees are, the next step will be to look at their global distribution. 


\section{Global distribution of conservation refugees}

The most extensive coverage of the global trend in conservation refugees so far has been carried out by Brockington and Igoe (2006) in Evictions for Conservation: A Global Overview. They carried out a study of 184 protected areas across the globe and 162 of these 184 protected areas are included in the World Database of Protected Areas. The results of their study in Table 5 show a significant regional bias in evictions. Most cases seem to be in Africa and South East Asia. Relatively few evictions are reported from Australasia, Europe and the former Soviet Union. Table 5 also shows that most conservation refugees are in the developing world. The absence of cases of eviction from the developed countries may be interpreted as the absence of meaningful displacements in modern times, but it would be equally easy to suggest that the absence of evidence of displacement is not evidence of absence of displacements or evictions (Agrawal and Redford, 2009). 
Table 5: The geographical distribution of reported evictions from protected areas between 1940 and 2000.

\begin{tabular}{|l|l|l|}
\hline Regions & $\begin{array}{l}\text { Evictions } \\
\text { from } \\
\text { Protected } \\
\text { Areas on } \\
\text { World } \\
\text { Database } \\
\text { of } \\
\text { Protected } \\
\text { Areas }\end{array}$ & $\begin{array}{l}\text { Evictions from } \\
\text { notected Areas the } \\
\text { World Database } \\
\text { of Protected } \\
\text { Areas }\end{array}$ \\
\hline $\begin{array}{l}\text { Australia and } \\
\text { New Zealand }\end{array}$ & 0 & 3 \\
\hline Pacific & 1 & 0 \\
\hline East Asia & 3 & 3 \\
\hline $\begin{array}{l}\text { South East } \\
\text { Asia }\end{array}$ & 11 & 3 \\
\hline South Asia & 17 & 2 \\
\hline $\begin{array}{l}\text { North Africa } \\
\text { and Middle } \\
\text { East }\end{array}$ & 2 & 0 \\
\hline $\begin{array}{l}\text { West and } \\
\text { Central } \\
\text { Africa }\end{array}$ & 26 & 4 \\
\hline $\begin{array}{l}\text { Eastern and } \\
\text { Southern } \\
\text { Africa }\end{array}$ & 64 & 4 \\
\hline $\begin{array}{l}\text { North } \\
\text { America }\end{array}$ & 21 & 0 \\
\hline $\begin{array}{l}\text { Central } \\
\text { America }\end{array}$ & 10 & 0 \\
\hline Caribbean & 2 & 22 \\
\hline $\begin{array}{l}\text { South } \\
\text { America }\end{array}$ & 5 & 0 \\
\hline Total & 162 & \\
\hline Brockington & Igoe & \\
\hline
\end{tabular}

Adapted from Brockington and Igoe (2006)

There have been few evictions reported in almost all countries. According to Brockington and Igoe some of the higher proportions of evictions found in Table 6 are less a result of research effort, and more as a result of the paucity of protected areas in these countries. Only in Cameroon and to a lesser extent Botswana did they approach extensive coverage. 
Cernea and Schmidt-Soltau (2003) in Biodiversity Conservation versus Population Resettlement: Risks to Nature and Risks to People present a systematic study of indigenous people displaced from national parks in the Central African sub-region. Though they cover a very limited area, their study offers a better coverage of the problem than the global overview of Brockington and Igoe. Cernea and Schmidt-Soltau present a list of protected areas in Central Africa, the names of promoters of the projects, total area in square kilometers, impact of the project on the local population, number of people evicted, compensation schemes and the success or failure of these compensation schemes.

Though I recognize the difficulty in carrying out such a detailed study on a global scale, a systematic study of the problem like this on a global scale will be a landmark achievement. Table 6 shows an attempt to extend the systematic study carried out by Cernea and SchmidtSoltau to include more countries outside the Central African sub-region. 
Table 6: Distribution of conservation refugees in selected countries across the world

\begin{tabular}{|c|c|c|c|c|c|}
\hline Country & Promoter & Reserves & $\begin{array}{l}\text { Groups } \\
\text { Displaced }\end{array}$ & $\begin{array}{l}\text { Displaced } \\
\text { Population }\end{array}$ & $\begin{array}{l}\text { Compensation } \\
\text { Status } \\
\end{array}$ \\
\hline $\begin{array}{l}\text { Cameroon } \\
\text { (1) }\end{array}$ & $\begin{array}{l}\text { ECOFAC } \\
\text { WWF } \\
\text { WWF } \\
\text { WWF }\end{array}$ & $\begin{array}{l}\text { Dja Reserve } \\
\text { Korup NP } \\
\text { Lobeke NP } \\
\text { Boumba } \\
\text { Beck }\end{array}$ & $\begin{array}{l}\text { Baka } \\
\text { Oroko } \\
\text { Baka } \\
\text { Baka }\end{array}$ & $\begin{array}{l}7,800 \\
1,465 \\
4,000 \\
4,000\end{array}$ & $\begin{array}{l}\text { No } \\
\text { Partial } \\
\text { Partial } \\
\text { Partial }\end{array}$ \\
\hline $\begin{array}{l}\text { Central } \\
\text { African } \\
\text { Republic (1) }\end{array}$ & WWF & $\begin{array}{l}\text { Dzanga- } \\
\text { Ndoki }\end{array}$ & $\begin{array}{l}\text { Bakola } \\
\text { Pygmies }\end{array}$ & 350 & Partial \\
\hline $\begin{array}{l}\text { Equatorial } \\
\text { Guinea (1) }\end{array}$ & ECOFAC & Altos deNsok & & 10,000 & Partial \\
\hline $\begin{array}{l}\text { Republic of } \\
\text { Congo (1) }\end{array}$ & $\begin{array}{l}\text { WCS } \\
\text { ECOFAC }\end{array}$ & $\begin{array}{l}\text { Nouambele } \\
\text { Odzala }\end{array}$ & Babenzele & $\begin{array}{l}3,000 \\
9,800 \\
\end{array}$ & $\begin{array}{l}\text { Partial } \\
\text { No }\end{array}$ \\
\hline Gabon (1) & $\begin{array}{l}\text { WWF } \\
\text { WWF } \\
\text { Brainforest }\end{array}$ & $\begin{array}{l}\text { Loango } \\
\text { Moukalaba } \\
\text { Ipassa- } \\
\text { Mingouli }\end{array}$ & $\begin{array}{l}\text { Bongo } \\
\text { Baka Pygmies } \\
\text { Baka Pygmies }\end{array}$ & $\begin{array}{l}2,800 \\
8,000 \\
100\end{array}$ & $\begin{array}{l}\text { Partial } \\
\text { Partial } \\
\text { Partial }\end{array}$ \\
\hline Nigeria (1) & WWF & $\begin{array}{l}\text { Cross-River } \\
\text { Okwangwo }\end{array}$ & & 2,876 & Partial \\
\hline $\begin{array}{l}\text { Tanzania (2) } \\
(3),(6),(11)\end{array}$ & $\begin{array}{l}\text { Frankfurt } \\
\text { Zoological } \\
\text { Society }\end{array}$ & $\begin{array}{l}\text { Tarangire } \\
\text { Ngorongoro } \\
\text { Serengeti } \\
\text { Mkomazi } \\
\\
\text { Selous } \\
\text { Mibulu } \\
\end{array}$ & $\begin{array}{l}\text { Maasai } \\
\text { Maasai } \\
\text { Maasai } \\
\text { Maasai, Pare, } \\
\text { Kamba, } \\
\text { Sambaa } \\
\text { Wangindo }\end{array}$ & $\begin{array}{l}60,000 \\
1,200 \\
16,200 \\
5,000 \\
\\
40,000 \\
10,000 \\
\end{array}$ & $\begin{array}{l}\text { No } \\
\text { Unknown }\end{array}$ \\
\hline $\begin{array}{l}\text { Uganda (1), } \\
(3), \quad(10), \\
(16)\end{array}$ & $\begin{array}{l}\text { World Bank } \\
\text { World Bank } \\
\text { World Bank }\end{array}$ & $\begin{array}{l}\text { Mgahinga } \\
\text { Echuya } \\
\text { Bwindi } \\
\text { Kibale } \\
\text { Queen } \\
\text { Elizabeth NP } \\
\text { Katonga } \\
\text { Mt Elgon } \\
\end{array}$ & $\begin{array}{l}\text { Batwa } \\
\text { Batwa } \\
\text { Batwa } \\
\text { Batwa }\end{array}$ & $\begin{array}{l}30,000 \\
800 \\
1,000 \\
1,200\end{array}$ & $\begin{array}{l}\text { Unknown } \\
\text { No } \\
\text { No }\end{array}$ \\
\hline Thailand (3) & & & Karen & & Unknown \\
\hline $\begin{array}{l}\text { Botswana } \\
(3),(16)\end{array}$ & & Kalahari GR & $\begin{array}{l}\text { Gwi } \\
\text { Gana } \\
\text { Basarwa } \\
\text { San } \\
\end{array}$ & $\begin{array}{l}40,000 \\
2,000 \\
1,500\end{array}$ & $\begin{array}{l}\text { Unknown } \\
\text { No } \\
\text { No }\end{array}$ \\
\hline Peru (3) & & & Ashinika & & Unknown \\
\hline $\begin{array}{l}\text { India }(3), \\
(4),(16)\end{array}$ & $\begin{array}{l}\text { Indian } \\
\text { Government }\end{array}$ & $\begin{array}{l}\text { Assam } \\
\text { Kuno } \\
\text { Langol } \\
\text { Madya } \\
\text { Pradesh }\end{array}$ & $\begin{array}{l}\text { Adevasi } \\
\text { Sahariya } \\
\text { Adevasi } \\
\text { Adevasi }\end{array}$ & $\begin{array}{l}1,600,000 \\
5,000 \\
200 \\
755\end{array}$ & $\begin{array}{l}\text { Unknown } \\
\text { Partial } \\
\text { No } \\
\text { No }\end{array}$ \\
\hline Mexico (3) & & $\begin{array}{l}\text { Montes } \\
\text { azules }\end{array}$ & Maya & Unknown & Unknown \\
\hline
\end{tabular}




\begin{tabular}{|c|c|c|c|c|c|}
\hline Chad (3) & & & & 600,000 & Unknown \\
\hline $\begin{array}{l}\text { Kenya } \\
(8),(16)\end{array}$ & & $\begin{array}{l}\text { Mau Forest } \\
\text { Mount Elgon } \\
\text { Karuri Forest } \\
\text { Eburu Forest } \\
\text { Kipkurere } \\
\text { Embobut } \\
\text { Amboseli }\end{array}$ & $\begin{array}{l}\text { Ogiek } \\
\text { Ogiek } \\
\text { Ogiek } \\
\text { Ogiek } \\
\text { Ogiek } \\
\text { Ogiek } \\
\text { Maasai }\end{array}$ & $\begin{array}{l}51,000 \\
3,000 \\
3,000 \\
4,000 \\
2,945 \\
40,000 \\
6,000\end{array}$ & $\begin{array}{l}\text { No } \\
\text { No } \\
\text { No } \\
\text { No } \\
\text { No } \\
\text { No } \\
\text { Partial }\end{array}$ \\
\hline $\begin{array}{l}\text { Ethiopia (3), } \\
(5),(16)\end{array}$ & APF & $\begin{array}{l}\text { Omo } \\
\text { Nech Sar }\end{array}$ & $\begin{array}{l}\text { Mursi } \\
\text { Guji, Kore }\end{array}$ & $\begin{array}{l}50,000 \\
9,000\end{array}$ & $\begin{array}{l}\text { No } \\
\text { Unknown }\end{array}$ \\
\hline $\begin{array}{l}\text { United } \\
\text { States (3) }\end{array}$ & $\begin{array}{l}\text { United States } \\
\text { Government }\end{array}$ & $\begin{array}{l}\text { Yosemite } \\
\text { Yellowstone }\end{array}$ & $\begin{array}{l}\text { Miwok } \\
\text { Paiute } \\
\text { Ahwahneechee }\end{array}$ & Unknown & Unknown \\
\hline $\begin{array}{l}\text { Dominican } \\
\text { Republic (7) }\end{array}$ & $\begin{array}{l}\text { Dominican } \\
\text { Government }\end{array}$ & Los Haitises & Creole & Unknown & Partial \\
\hline $\begin{array}{l}\text { Madagascar } \\
\text { (9) }\end{array}$ & & $\begin{array}{l}\text { Mananara } \\
\text { Bioshere } \\
\text { Project }\end{array}$ & & 35,000 & Partial \\
\hline Nepal (10) & & Chitwan NP & & 100,000 & Partial \\
\hline $\begin{array}{l}\text { South Africa } \\
\text { (11) }\end{array}$ & & $\begin{array}{l}\text { Kruger NP } \\
\text { Tsitsikama }\end{array}$ & Makulele & $\begin{array}{l}250,000 \\
2,000\end{array}$ & Unknown \\
\hline Togo (12) & & $\begin{array}{l}\text { Lion's Denn } \\
\text { Keran NP }\end{array}$ & & 6,000 & Unknown \\
\hline $\begin{array}{l}\text { Zimbabwe } \\
\text { (13) }\end{array}$ & & $\begin{array}{l}\text { Nyanga NP } \\
\text { Matopos NP }\end{array}$ & & $\begin{array}{l}200 \\
2,000\end{array}$ & $\begin{array}{l}\text { Unknown } \\
\text { No }\end{array}$ \\
\hline $\begin{array}{l}\text { Democratic } \\
\text { Republic of } \\
\text { Congo (15), } \\
(16)\end{array}$ & & $\begin{array}{l}\text { Kaluzi- } \\
\text { Bienga } \\
\text { Gorilla } \\
\text { Reserve } \\
\text { Virunga Park }\end{array}$ & $\begin{array}{l}\text { Batwa } \\
\text { Bambuti }\end{array}$ & 6,000 & No \\
\hline Ghana (16) & $\begin{array}{l}\text { Ghanaian } \\
\text { Government }\end{array}$ & Digya & & 7,000 & No \\
\hline Brazil (16) & & $\begin{array}{l}\text { Jardim } \\
\text { Passauna }\end{array}$ & $\begin{array}{l}\text { non } \\
\text { indigenous } \\
\text { groups }\end{array}$ & 200 & No \\
\hline $\begin{array}{l}\text { Malaysia } \\
\text { (16) }\end{array}$ & & $\begin{array}{l}\text { Kampung } \\
\text { Puteri }\end{array}$ & & 360 & No \\
\hline $\begin{array}{l}27 \\
\text { Countries }\end{array}$ & & $\begin{array}{l}48 \text { Protected } \\
\text { Areas }\end{array}$ & $\begin{array}{l}28 \text { Indigenous } \\
\text { Groups }\end{array}$ & $\begin{array}{l}\text { 3,060,951 } \\
\text { Displaced } \\
\text { People }\end{array}$ & $\begin{array}{l}W=17, \quad X=24, \\
Y=0, Z=14\end{array}$ \\
\hline
\end{tabular}

$\mathrm{W}=$ Partial compensation, $\mathrm{X}=$ No compensation, $\mathrm{Y}=$ Full compensation, $\mathrm{Z}=$ No information available

\section{Sources}

$1=$ Cernea et al. (2003)

$2=$ Geisler (2002), Igoe (2006),

$3=$ Dowie (2009)

$4=$ Kabra (2007)

$5=$ Neumann $(1998)$

$6=$ Adams et al. (2007)

$7=$ Geisler et al. (1997)

$8=$ Western (1982) 
$9=$ Ghimire (1994)

$11=\underline{\text { www.conservationrefugees.org }}(2010)$

$13=$ Ranger (1989)

$15=$ Shikongo $(2005)$
$10=$ Colchester $(1994)$

12 = Lowry Alma (1994)

$14=$ Carruthers (1993), Ellis (1994), Platzky and

Walker (1985)

$16=$ COHRE (2006)

\section{Reasons for the variation in the global distribution of conservation refugees}

A number of reasons have been identified responsible for the higher figures of evictions and conservation refugees in the developing world than in the developed world. These include bias in research, stricter enforcement of conservation legislature and differences in conservation ideologies.

\section{Bias in research}

Researchers in evictions and displacements seem to focus a lot more on developing countries than developed countries and this may account for the huge numbers of reported evictions in developing countries. Brockington and Igoe (2006) in Evictions for Conservation: A Global Overview, admitted this bias by saying their study naturally favoured Southern and Eastern Africa with which they were most familiar. Sixty of the 250 reports they collected from around the world came from Southern and Eastern Africa alone. This makes it look like the conservation refugee problem is exclusively a third world issue. It will be misleading to think in that manner because the absence of cases of evictions from the former Soviet Union for example does not reflect an absence of evictions. Poirier and Ostergren (2002) for example insist that throughout the Soviet era both Russians and indigenous people in the former Soviet Union were evicted to create protected areas. 
Brockington and Igoe (2006) in Evictions for Conservation: A Global Overview suggest that relocation from protected areas was not an issue that pre-occupied academics and activists before 1970. Most relocations in developed countries like that of Yellowstone National Park in the USA took place before the mid $19^{\text {th }}$ century so since it was not an issue then, figures of displacement or evictions went unnoticed. The history of Protected Areas in developed countries and the dislocation and disruption they caused is still not widely appreciated (Brockington and Igoe, 2006) yet the flourishing interest in the problem of displacement from researchers and consultants today seems to focus more on the developing world with the fear of uncovering cases of evictions and displacements in protected area establishment in developed countries. Nabakov and Lawrence (2004), in Restoring a Presence had a difficult time having the US National Park Service accept the title of their ethnographic history of the Native Americans in Yellowstone National Park for fear of uncovering cases of evictions.

\section{Enforcement of conservation legislature}

Brockington and Igoe (2006), note that the greatest period of protected area growth was between 1985 and 1995 . This could be referred to as the boom years in conservation history. They go on to say that while it is clear that many of the more recent protected areas are weakly protected, it is also clear that this global proliferation of protected areas has been accompanied by a greater enforcement of existing legislation. According to Brockington and Igoe (2006), though some protected areas have been long established, evictions from them are a relatively recent development. Kothari (2004) for example suggests that some 4 million people face eviction in India as a result of the tightening of conservation legislation while Dowie (2009) points that the Indian government which has already evicted 100,000 Adivasis in Assam between April and July 2002 plans to evict two or three million more over the next 
decade. This tightening of legislation by the Indian government is largely in response to a lawsuit brought by the Worldwide Fund in 1993 which demanded the Indian government increase protected areas by eight percent to protect the Asian tiger habitat (Dowie, 2009).

The tightening of legislation alone is insufficient in explaining why there are higher figures of evictions for conservation in the developing world. Protected areas in the developed world today are prototypes of those designed in England and Wales in the years after 1949. Adams and Hutton (2007) note that protected areas in England and Wales were designated based on an understanding that nature was not particularly pristine. With this ideology, protected areas were essentially planning designations to protect beautiful lived-in landscapes which were created in fairly remote areas with low population densities such as the Peak District, Lake District, Dartmoor and Exmoor. These protected areas comprised mosaics of private landholdings, mostly under low intensity farming or grazing (Adams and Hutton, 2007). North York Moors below is a perfect example of a protected area in the developed world. 


\section{North York Moors National Park}

This is a protected area in the United Kingdom that includes land that is settled and has been farmed for millennia. The relationship between the park and the local people is so close that the Park Management Plan is included as part of the general plan of Town and Country Development, prepared with the extensive involvement of the public. In fact, the majority of the North York Moors is under private ownership (a factor common to many other protected areas in Europe) and the management plan is there fore dependent on the co-operation of the landowners. Farming and land management activities generally remain outside the control of the Park Authority. To ensure that farming and land management activities conform to the park plan, agreements are often signed between the land owners and the Park Authority. Though considered to be legally binding contracts, these agreements are entirely voluntary, although the Park Authority provides financial incentives and compensation in return for agreed works or management practices.

(Adapted from Statham in Borrini-Feyerabend et al. 2004: Page 29)

When it comes to the establishment of protected areas in developing countries, a completely different ideology was invoked with ideas of pristine nature and un-peopled "wilderness" or "unspoiled Eden". When it came to enforcement of legislation therefore, there was bound to be more interference in peoples' lives (even if not always eviction) because the dominant ideology was of an un-peopled wilderness. In the developed world, stricter conservation legislation would not result in evictions of the scale in the developing world because most protected areas in the developed world are lived-in landscapes.

The second reason for variation in evictions reported in the developed and developing countries concerns the role of conservation NGOs. Chapin (2004) and Dowie (2009) associate the big international NGOs with evictions and other forms of displacement: The Nature Conservancy, WWF, Conservation International, WCS and African Parks Foundation (APF). According to Chapin and Dowie, these NGOs have come to dominate funding for 
conservation work over the past 15 years with the billions of dollars they possess. These NGOs are in a stronger position to impose their idea of what nature should look like in the developing countries than in the developing countries. This view is supported by the Tragedy in Six Acts between People and Parks (Schmidt-Soltau, 2004) which says that international conservation NGOs do not have as much power to increase their conservation initiatives in Europe and North America as they do in the developing world. Brockington and Igoe (2006) associate these NGOs with the western ideals of wilderness and people-free landscapes. In summary, enforcement of conservation legislature will result in more evictions in the developing countries because it is the will of the international NGOs running the projects in developing countries.

The full text of the Tragedy in Six Acts (Schmidt-Soltau, 2004) is as follows;

\footnotetext{
Act 1

International NGOs do no have the powers to increase their conservation initiatives in Europe and North America

National governments are unable to collect taxes or exploit the forest due to lack of funds and legal entitlement The rural population uses and "owns" the rainforest

Act 2

International NGOs survey remote areas for their biological value and apply to the government to conserve the areas.

National governments use the justifications offered by the international NGOs to impose laws on the territories handed over to them as the state by the former colonial masters and claim ownership.

The rural population uses the rainforest, which is legally state property.

The international NGOs and the national governments conceptualize each other as legal and competent stakeholders in rainforest management.

Act 3

International NGOs introduce the idea of national parks and support zones and assist the government agencies financially and technically.

The national governments demarcate parks, and establish forest laws and instruments to enforce them.

The rural population uses the rainforest which is owned by the government and managed by the international NGOs.

Act 4

International NGOs introduce the idea of "compensating" the rural population for a reduction in hunting and gathering.

The national governments invest this money into infrastructure.

The rural population uses the rainforest - owned, managed and protected by the international NGOs - in the knowledge that they are not allowed to do so.

Act 5

International NGOs complain to national governments that they are not enforcing laws and to the rural population that they are breaking the laws.
} 
Governments ask the international NGOs to assist and finance increased law enforcement.

The rural population starts to be aware of income losses from conservation and tries to resist.

Act 6

International NGOs use the rainforest.

National governments own the rainforest.

The rural population is evicted, marginalized and impoverished.

The text is adapted from Kurtz: Report to the international society for the suppression of savage customs (in Conrad's Heart of Darkness) and the pacification of the tribes of the lower Niger (in Achebe's Things Fall Apart)

Brockington and Igoe (2006) point to critics of the view that international conservation NGOs encourage evictions who are mostly representatives of these international NGOs. These critics are often quick to point that their organizations lack the authority to evict people from protected areas. In effect they are saying that evictions are the work of national governments and elites of the states concerned. This shift in responsibility is reflected in the case between the APF and the Ethiopian government concerning the displacement or eviction of the Guji and Kore indigenous peoples. Survival International reported that, "according to the African Parks Foundation's 2004 annual report, the resettlement of the Kore and Guji people was an internal affair of the Federal and regional governments, and African Parks Foundation had no role to play in the matter.

[We didn't want to be involved in the resettlement, so I put a clause in the contract that said we wouldn't take over the park until the resettlement was completed]. (Paul Van Vlissingen, APF founder in Conservation Refugees, 2010)

This example supports the view in Figure 2 that the conservation refugee problem results from the clash of interests between indigenous peoples, conservation agencies and national governments.

It is worth noting though that not all countries in the developing world have high reports of evictions. Table 5 shows South America which is part of the developing world with as few as 
only six cases of evictions reported. According to Brockington and Igoe (2006), the relative lack of evictions in South America may reflect weakly enforced legislation. However, this interpretation is unlikely to be correct. Most countries in Latin America have indigenous groups living in over 80 percent of their protected areas (Toledo, 2010). Toledo identified many countries in Latin America with a high percentage of people identified as indigenous peoples as follows: Bolivia (70 Percent), Peru (40 Percent), Guatemala (47 Percent) and Ecuador (38 Percent).

It appears countries with a considerable amount of people identified as indigenous people in their populations seem to have less reported cases of evictions. This might be more as a result of better national legislation to accommodate the rights of indigenous peoples living in protected areas as is the case with Bolivia and Colombia mentioned in Chapter 2. Good national legislation protects indigenous peoples and leaves foreign conservationists no choice but to work out creative ways to protect wildlife while allowing indigenous peoples to thrive in their traditional settlements (Dowie, 2009).

Colombia had 710 reservations for indigenous people by 2007 which covered about 29 percent of the national territory and these properties could not be seized from them (United Nations, 2007). In the Mateven forest in Colombia for example, six indigenous tribes live in 152 villages in a four-million-acre ecologically intact Protected Area (Dowie, 2009). The 1994 constitution of Bolivia included recognition of indigenous laws and customs as alternative dispute resolution mechanisms (Fromherz, 2008). This Bolivian and Colombian model which has been replicated in other countries in Latin America is responsible for the limited number of evictions reported in South America and not weakly enforced legislation as Brockington and Igoe suggest in Eviction for Conservation (2006). Brazil for example 
replicated the Colombian and Bolivian model with the Kayapo Amerindians of the Amazon forest. The Xingu National Park in the Brazilian Amazon is Latin America's first Indianowned Park which was created to protect the lifestyle of the Kayapo and other indigenous Amazonians (Dowie, 2009). Just to add more strength to this argument, other countries from other parts of the world with significant numbers of indigenous peoples have registered fewer evictions as can be seen in Table 7. It should be noted that the selection of countries here is based on percentages of indigenous peoples in the populations according to Toledo (2010). The list of reported evictions is based on Brockington and Igoe (2006).

Table 7: Percentages of indigenous peoples and reported cases of evictions from selected countries

\begin{tabular}{|l|l|l|}
\hline Country & $\begin{array}{l}\text { Percentage } \\
\text { of } \\
\text { indigenous } \\
\text { peoples }\end{array}$ & $\begin{array}{l}\text { Reported } \\
\text { cases of } \\
\text { Protected } \\
\text { Areas } \\
\text { with } \\
\text { evictions }\end{array}$ \\
\hline $\begin{array}{l}\text { Papua New } \\
\text { Guinea }\end{array}$ & 77 & 0 \\
\hline Bolivia & 70 & 0 \\
\hline Guatemala & 47 & 1 \\
\hline Peru & 40 & $0 *$ \\
\hline Ecuador & 38 & 1 \\
\hline Burma & 33 & 0 \\
\hline Laos & 30 & 0 \\
\hline Mexico & 12 & $0 *$ \\
\hline New Zealand & 12 & 0 \\
\hline
\end{tabular}

* Brockington and Igoe have no reported cases of Protected Areas with evictions in Peru and Mexico but Dowie (2009) mentions the eviction of the Ashinika in Peru as well as the Mayans from the Montes Azules National Park in Mexico.

Adapted from Brockington and Igoe (2006), Toledo (2010) 


\section{Global numbers of conservation refugees}

I attempt to establish estimated numbers of conservation refugees displaced from selected national parks in Table 6 above. However such figures are based on reported cases of evictions alone. However, restricted access to resources in protected areas is also a form of population displacement, even if affected groups are not physically relocated (Cernea, 2006). Establishing figures based on just eviction can therefore be misleading because it ignores refugees who are victims of occupational and economic displacement.

Relying on reported cases of eviction alone to come up with numbers is a problem because in some cases of evictions can either be under-reported or present exaggerated numbers. Some widely quoted cases of eviction, for example Turnbull's account of the Ik people following expulsion from the Kidepo National Park, have subsequently been judged inaccurate (Adams and Hutton, 2007).

Geisler and de Sousa (2000) in From Refuge to Refugee highlight another problem with attempting to estimate actual conservation refugee numbers. In their case study they argue that conservation refugees may already be political refugees in some cases with precarious standing and substantial resource requirements (firewood, water and food). Renner (1996) shows in both Africa and Asia how the line blurs between traditional refugees, environmental refugees and conservation refugees considering the fact that many displaced people have multiple refugee statuses.

For these reasons there is therefore no universally acceptable methodology for estimating the number of people displaced from protected areas globally. Most published studies focus on particular cases and with the use of different methods to arrive at figures. Attempts to establish the scale of displacement quantitatively are still in an experimental stage. Geisler 
and de Sousa (2000) for example present completely different methods for estimating conservation refugee numbers. Their first method is based on multiplying average population densities and the total area of the protected areas. Their second method is built on an intensive analysis performed in Kenya, a country with 3.5 million hectares of protected areas. About a decade ago, researchers calculated the opportunity cost of biodiversity conservation in Kenya by trying to determine the net benefits of converting lands set aside for parks and reserves to agriculture and livestock production. The result generated dollar estimates of $\$ 99$ million in net returns using a conservation land base of $41,420 \mathrm{~km}^{2}$. The human population of this area was estimated to be 2.1 million inhabitants yielding a human density of 50.7 people per square kilometre. If the socio-ecological carrying capacity of Kenya is typical of that of Africa it is estimated there would be about 78 million conservation refugees in Africa for (Geisler and de Sousa, 2000). Such a method is also based on the assumption that socioecological carrying capacity is uniform across countries which is usually not the case and therefore this is a major limitation of this method.

The third method is based on summarizing case study results from researchers. This method has been used by researchers for at least four decades and its same method used in this study to arrive at the results in Table 6 . This method has its short-fall in that it is based on reported evictions only and also ignores socio-economic displacement. All the above methods ignore the point that estimates will rise if they include "partial conservation refugees" who Geisler and de Sousa (2000) define as people living outside of protected areas but depending on them for basic resource through illegal resource use. Offsetting this partial displacement is the fact that in many protected areas, evicted displaced park inhabitants re-enter protected domains illegally and thereby not fully displaced. This in turn raises the question of illegal resource 
use among conservation refugees which will be examined again in the last chapter of this study. Failure to arrive at an acceptable method of estimating the number of conservation refugees has led to surprisingly high figures as Geisler and de Sousa (2000) suggest there may be 14 million to 24 million conservation refugees in Africa alone. Cernea and SchmidtSoltau (2003) estimate 40,000 to 45,000 people have been made conservation refugees in central Africa.

\section{Conclusion}

This chapter has been able to justify the assumption that most conservation refugees are indigenous peoples. I have also been able to present a global overview of the distribution of conservation refugees. Based on figures collected from various sources I have established known estimates of conservation refugee numbers. These figures are just estimates and are only based on protected areas and countries in which there has been some research. This therefore excludes a good number of countries with more estimates than presented on Table 6. I also present methodological limitations in calculating global conservation refugee numbers. This chapter also looks at reasons for the variation in the global distribution of conservation refugees. Here I have identified bias in research, unequal enforcement of conservation legislature as the main reasons for the variation in the global distribution of conservation refugees.

Having examined the power of legislation in influencing evictions as well as the limitation of attempts to estimate conservation refugee numbers, I will follow this up by looking at the policies which are the driving force behind legislation and conservation ideas in protected areas across the world. 


\section{Chapter Four}

\section{Changes in Conservation and Development Policy}

This chapter looks at how changes in how conservation and development policies have influenced conservation ideology. For the purpose of this study policy will refer to a rule that influences the behaviour of an individual, firm or organization (Ashley and Mbile, 2005). This is important because there are conservationists who view local people's welfare and development as directly conflicting with the objectives and practice of biodiversity conservation. On the other hand there are those on the development side who have identified strict conservation as a threat to human welfare and refer to the exclusion of local people from protected areas as a denial of rights to resources and human rights violation. Then there is the third group which believes in preservation of biodiversity through use and some who see the market as the salvation to biodiversity.

\section{Historical background}

The displacement of people to create space for protected areas is neither a modern day phenomenon nor a process limited only to the developing world. As far back as 1066, William the Conqueror after winning the battle of Hastings, evicted almost 2000 local Saxons and established a nearly 100,000-acre hunting reserve (Geisler, 2002). About eight hundred years later in the 1800 s, the United States government granted protection status to Yellowstone, Yosemite (see Plate 2), and Glacier National Parks. It is interesting to note that in the language of the indigenous Ahweneechee Indians, Yosemite means "some among them are killers" referring to killings by militia around the time the Park was established (Rangarajan and Shahabuddin, 2006). Again, as in England 800 years ago, the native people were evicted, forbidden to hunt or gather on their ancestral lands or simply eliminated 
(Geisler, 2002). In pre-conservation years, limiting resource use was directed primarily at outsiders. It was not until the establishment of protected areas that the rationale for restricting local access shifted from benefiting the local few to benefiting society as a whole (Wilkie et al. 2010)

\section{Plate 2: Yosemite National Park as it looks today}

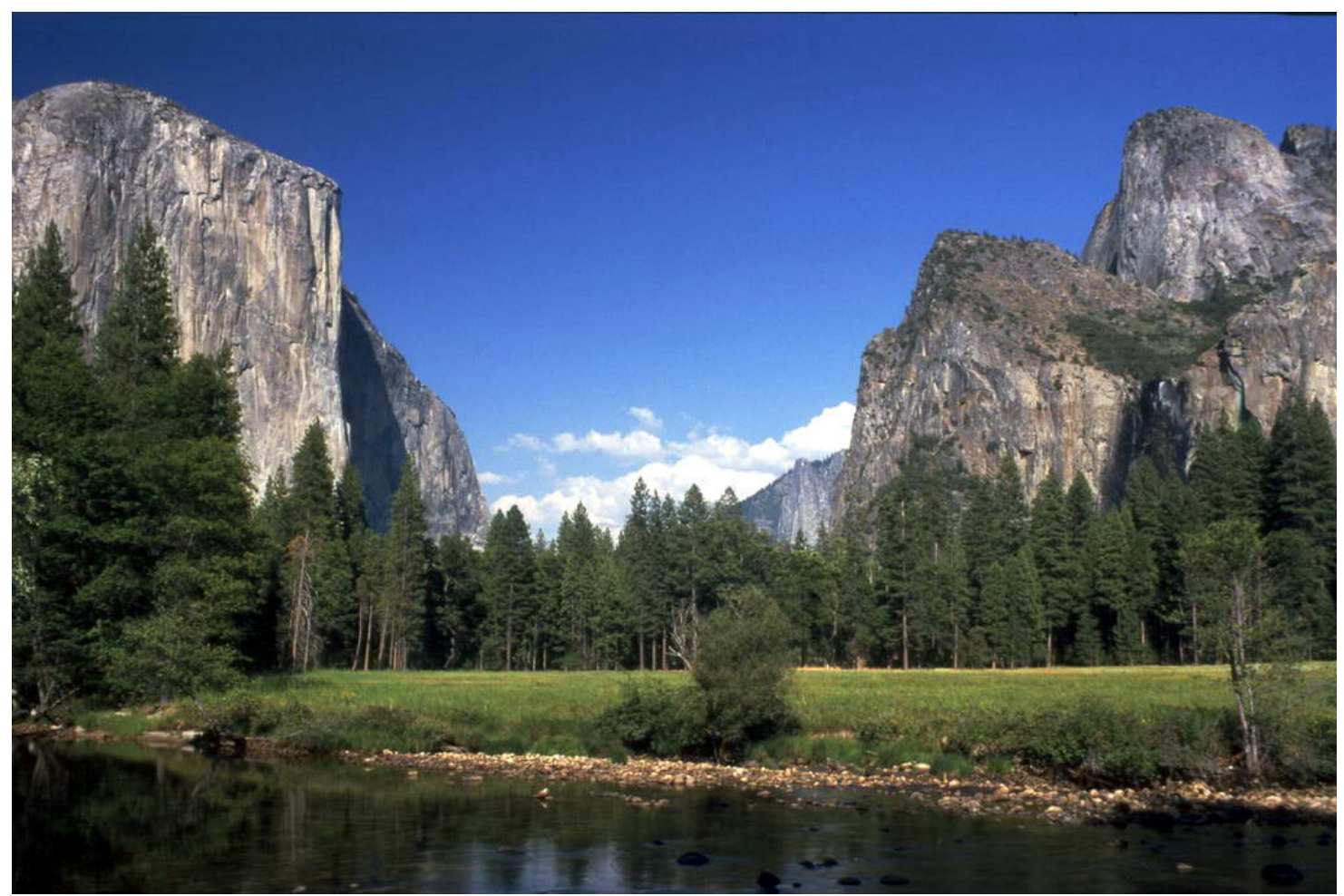

www.sfgate.com

This "eviction for conservation" policy in the United States was strengthened by John Muir, a forefather of the US conservation movement who argued that "wilderness" should be cleared of all inhabitants and set aside to satisfy the urbane human's need for recreation and spiritual renewal. This sentiment was later to become national policy with the passage of the 1964 Wilderness Act in the US. This act defined wilderness as "a place where man himself is a visitor who does not remain" (Dowie, 2009). This same approach has been applicable in the developing countries in the $19^{\text {th }}$ century by colonial powers. At that time and arguably till 
present day, this conservation paradigm introduced in developing countries is regarded with deep suspicion by segments of the population who regard environmental issues as "disease of the rich" than could impose new constraints on their central priority of economic development (Strong, 2003).

The dominant colonial approach to conservation before has been the establishment of national parks from which people were essentially resettled or excluded, often involuntarily. This green consciousness is vital to mankind but should broaden its vision to include global welfare of displaced people. Most of the world's rich biodiversity spots are found in the tropics and contain populations suffering severe economic disadvantages - about 60 percent of the world's poorest people (Geisler, 2002). In these areas an estimated 75 percent of the populations live below the poverty line of US\$ 1 per day (Sayer et al. 2007). Undertaking conservation in such areas is not sustainable if it further exacerbates the marginalization and impoverishment of the local population and disregards their development needs (Cernea et al. 2006). It should be worth noting though that poverty is a relative concept when indigenous people are concerned. If a Batwa hunter-gatherer for example does not have a television set, a car, computer, electricity or bank account, it doesn't mean he/she is poor because huntergatherers do not need all these to prove they are not poor. As Shikongo (2005) argued, wealth, health and well-being to indigenous peoples depends on things such as clean water, clean air, fertile soils, and other services provided by the natural ecosystem of which they are part and not ownership of manufactured goods.

There has been a recent slogan in global biodiversity conservation which urges people to "think global and act local" and there are valid ethical and biological arguments for conservation at local and global levels. Though this sounds like the way forward for the 
greening of our planet, but the global poor seem to disproportionately subsidize global conservation considering the fact that it is mostly the wealthy inhabitants of the earth who benefit from greening. Geisler (2002) referred to this as "biophilia" in the form of exotic vacation destinations, new targets for their tax-deductible largess, and wind fall gains for their high-end properties in or near protected zones.

\section{Rise of Integrated Conservation and Development Projects}

As a result of the problems associated with protectionism, community-based conservation policies emerged in the early 1990s and have continued to prevail in the last 15 to 20 years (Igoe, 2006). These community-based conservation policies refers to a more participatory and people-centred approach known as Integrated Conservation and Development Projects. The goal of this approach is to reduce poverty, increase income levels, nutrition, healthcare and education, as well as to conserve biodiversity (Christiansen, 2004).

Furze et al. (1996), Hughes and Flintan (2001) prescribe a number of interventions for linking conservation and development needs of the rural population in the Integrated Conservation and Development Projects approach. These include; establishing buffer zones, promoting alternative natural resource management interventions in the fields of agriculture and forestry, promoting alternative sources of income to replace existing income-generating activities perceived as counter-productive to conservation goals, reinforcing existing forest management strategies and distributing the benefits directly accruing from sustainable forest use, providing benefits such as roads, communication infrastructure and social services, distributing benefits arising from conservation - such as income from tourism and bioprospecting. 
The Integrated Conservation and Development Projects approach quickly became the standard approach adopted by a number of international conservation organizations in attempting to pursue conservation and development goals in protected areas (Chapin, 2004;

Wells et al. 2004; Igoe, 2006). This change in policy from strict protectionism to Integrated Conservation and Development Projects approach is summarized by Phillips (2003) and Borrini-Feyerabend et al. (2004) in Table 8.

Table 8: Policy change in protected area management

\begin{tabular}{|c|c|}
\hline $\begin{array}{l}\text { Conventional understanding of protected } \\
\text { areas }\end{array}$ & $\begin{array}{l}\text { Integrated Conservation } r \text { and } \\
\text { Development Projects' view of protected } \\
\text { areas }\end{array}$ \\
\hline Established as separate units & $\begin{array}{l}\text { Planned as part of national, regional and } \\
\text { international system }\end{array}$ \\
\hline Managed as "islands" & $\begin{array}{l}\text { Managed as elements of networks (protected areas } \\
\text { connected by "corridors", "stepping stones" and } \\
\text { biodiversity-friendly land uses }\end{array}$ \\
\hline $\begin{array}{l}\text { Managed reactively, within a short time scale, with } \\
\text { little regard for lessons from experience }\end{array}$ & $\begin{array}{l}\text { Managed adaptively, on a long time perspective } \\
\text { taking advantage of on-going learning }\end{array}$ \\
\hline $\begin{array}{l}\text { About protection of existing natural and landscape } \\
\text { assets and not the restoration of lost values }\end{array}$ & $\begin{array}{l}\text { About protection but also restoration and } \\
\text { rehabilitation, so that lost or eroded values can be } \\
\text { recovered }\end{array}$ \\
\hline $\begin{array}{l}\text { Set up and run for conservation and scenic } \\
\text { protection }\end{array}$ & $\begin{array}{l}\text { Set up and run for conservation but also for } \\
\text { scientific, socio-economic and cultural objectives }\end{array}$ \\
\hline Established in a technocratic way & $\begin{array}{l}\text { Established as a political act, requiring sensitivity, } \\
\text { consultations and astute judgment }\end{array}$ \\
\hline Managed by natural scientists and resource experts & $\begin{array}{l}\text { Managed by multi-skilled individuals, including } \\
\text { some with social skills }\end{array}$ \\
\hline $\begin{array}{l}\text { Established and managed as a means to control the } \\
\text { activities of local people, with regards to their needs } \\
\text { and without their involvement. }\end{array}$ & $\begin{array}{l}\text { Established and run with, for, and in some cases by } \\
\text { local people; sensitive to the concerns of local } \\
\text { communities (who are empowered as participants in } \\
\text { decision making) }\end{array}$ \\
\hline Run by central government & $\begin{array}{l}\text { Run by many partners, including different tiers of } \\
\text { government, local communities, indigenous groups, } \\
\text { the private sector, NGOs and others }\end{array}$ \\
\hline Paid for by tax payers & $\begin{array}{l}\text { Paid for from many sources and, as much as } \\
\text { possible, self-sustaining }\end{array}$ \\
\hline Benefits of conservation assumed as self-evident & Benefits of conservation evaluated and quantified \\
\hline Benefiting primarily visitors and tourists & $\begin{array}{l}\text { Benefiting primarily the local communities who } \\
\text { assume the opportunity costs of conservation }\end{array}$ \\
\hline $\begin{array}{l}\text { Viewed as an asset for which national } \\
\text { considerations prevail over local ones }\end{array}$ & $\begin{array}{l}\text { Viewed as a community heritage as well as a } \\
\text { national asset }\end{array}$ \\
\hline
\end{tabular}

However, a number of reviews have suggested that Integrated Conservation and

Development Projects do not reconcile both conservation and development agendas. 


\section{Critique of Integrated Conservation and Development Projects}

Criticism for Integrated Conservation and Development Projects came from both conservationists and social scientists and this led to a decline in their popularity and a disenchantment with community based approaches. Conservationists have argued that Integrated Conservation and Development Projects do not provide enough protection for endangered species and the environment while social scientists argue that Integrated Conservation and Development Projects function in the same mould as development projects such as dam construction, road and pipeline construction which result in highly inequitable outcomes that severely limit local people's rights (Oates, 1999; Schmidt-Soltau, 2004). Based on the backdrop of a global biodiversity crisis many conservationists view national parks and protected areas as the last save haven of large tracks of virgin ecosystems (Wilshusen et al. 2002). Be this as it may, the core fact remains that indigenous peoples have not been given enough opportunities to design and run their own projects, and with mainstream conservationists at the helm the failures mounted (Chapin, 2004). Projects in most places across the developing world dealing with agro-forestry and organic gardening fell apart because no one had figured out how to market what was grown. Local ecological conditions were often wrong for the crops introduced. Local people were not interested in setting up parks and doing management plans, which was what the conservationists proposed. Environmental education projects in indigenous areas were modeled on urban programs. In short, the conservationists had little experience working with community groups (Chapin, 2004).

Based on the above criticisms of Integrated Conservation and Development Projects, some members of the conservation community have advocated a renewed emphasis on strict 
enforcement through authoritarian enforcement practices (Wilshusen et al. 2002). Wilshusen, Brechin, Fortwangler and West (2002) in Reinventing a square wheel: Critique of a resurgent "Protection Paradigm" in international biodiversity conservation summarized the arguments against Integrated Conservation and Development Projects put forward by the conservationists under the following core elements; protected areas require strict protection, biodiversity conservation is a moral imperative, conservation linked to development does not protect biodiversity, harmonious ecologically friendly local communities do not exist and emergency situations require extreme measures (Wilshusen et al. 2002: Pages 22-35).

\section{Protected areas require strict protection}

According to Terborgh (1999), human population increase and economic growth often put a lot of pressure on the environment. In Requiem for Nature he asserts that:

[Ultimately the issue boils down to habitat, how much for humans and how much for nature? Economic forces, driven by population growth and the desire of people everywhere to advance their material well-being, are eliminating the world's remaining wild lands. Short of radical changes in governmental policy in country after country, all unprotected tropical forests appear doomed to destruction within thirty to fifty years. When that time arrives, the only remaining examples of tropical nature and, consequently, most of what remains of tropical biodiversity will reside in parks. Parks therefore stand as the last bulwark of nature in the tropics and elsewhere]. (Wilshusen et al. 2002: Page 22) 


\section{Biodiversity protection is a moral imperative}

Moral imperative refers to a thing that must be done because it is right, regardless of opposition or difficulty. The most commonly cited reasons for protecting biological diversity include pragmatic and moral arguments (Wilshusen et al. 2002). Kramer and van Schaik (1997) in Last Stand explain the utilitarian importance of preserving biodiversity in terms of economic use and nonuse values. This school of thought emphasizes real and potential use values of plant and animal species as sources of new pharmaceuticals, genetic banks for key agricultural crops, and environmental services such as good control, as well as nonuse values, which imply maintaining natural areas for recreation or other reasons (Wilshusen et al. 2002). While economic and life-supporting rationales for preserving biodiversity are compelling, many analysts recognize that, when considered in terms of net present value, tropical forests are, in Terborgh's (1999) words, "worth more dead than alive"'(Wilshusen et al. 2002). Ultimately, nature and biodiversity must be conserved because it is the right thing to do, not because they have present utilitarian value.

A number of authors have come up with research results to support this point that biodiversity conservation is just a moral imperative. Norton-Griffiths and Southey (1995) estimated the cost of maintaining Kenya's protected areas and forgoing the cost of converting these protected areas to agriculture. Their results show that protected areas were a net economic loss to Kenya equivalent to three percent of GDP. Howard (1995) compared the direct and indirect costs to maintaining protected areas in Uganda with the tangible and intangible benefits that could be accrued from them. His results showed that to maintain its protected areas, Uganda incurs an annual opportunity cost of approximately $\$ 110$ million from foregone agriculture and livestock production. Ruitenbeek (1992) estimated the social 
costs and benefits to maintain the Korup National Park in Cameroon, and found that the direct economic benefits amount to only 20 percent of the value of alternative land uses. Schmidt-Soltau (2004) realized that the cash value of game and Non Timber Forest Products from the Korup National Park (estimated at about 2.1 million Euros per annum) sold is much more than the annual budget of the Korup Project (estimated at 1.3 million Euros per annum) - which does take into account the importance of bush meat and Non Timber Forest Products harvested for the subsistence of the local population. Most of the times even ecotourism does not generate enough income to cover even the management costs of the parks and of the tourism infrastructure (Wunder, 2000).

Based on the above results, the fundamental arguments for conserving nature must be spiritual and aesthetic, motivated by feelings that well up from our deepest beings (Wilshusen et al. 2002). Terborgh's moral argument is based on two basic rights. The right of nature to exist (i.e., humans do not have the right to eradicate other species) and the right of global, regional, and local communities to enjoy the qualities of nature. These rights underlie the belief held by many conservationists that the international community can and should act on behalf of nature in different parts of the planet as "global citizens" (Wilshusen et al. 2002). 


\section{Conservation linked to development does not protect biodiversity}

The core of much of the work reviewed by Wilhusen et al (2002) in Reinventing a square wheel centers on the perceived failure of conservation with development to protect species in parks and reserves. Kramer and van Schaik (1997) expose the conflict between conservation and development at the local level in two main conclusions. One is that sustainable use depletes biodiversity (Redford and Richter 1999; Robinson 1993). The second is that integrated conservation and development projects have not effectively safeguarded protected area core zones (Wilshusen et al. 2002). Concerning sustainable use, Brandon et al. (1998) argue that there are limits on sustainable use as a primary tool for biodiversity conservation. They argue that not all things can be preserved through use and not all places should be open to use. Strategies promoting sustainable use will lead to substantial losses of biodiversity if the broader ecosystem dynamics are not taken in to consideration (Brandon et al. 1998).

The second major assertion underlying the protectionist argument is that conservation linked to development has failed focuses on integrated conservation and development projects. What is known is that alleviating poverty will not necessarily lead to improvements in biodiversity conservation.

This argument ignores socio-political realities such as conflict, organization, corruption and governance which could act as implementation short-falls to integrated conservation and development projects rather than the alleged conflict between conservation and development (Wilshusen et al. 2002). 


\section{Harmonious, ecologically friendly local communities do not exist}

The core of the critique just presented on sustainable use and development is rooted in two related observations about so-called "traditional", people. The first observation concludes that community-based natural resource management by indigenous and other traditional peoples cannot guarantee species protection (Wilshusen et al. 2002). This is due to rapid social change, which is causing these groups to lose the very "traditional" qualities that historically allowed them to live in relative harmony with nature compared to modern societies (Terborgh, 1999). Unfortunately, given growing population pressure, increased access to modern technology, increasing market orientation, and steady erosion of traditional cultures, there no longer are guarantees that biodiversity objectives will be any more likely to be achieved if resource control is placed in the hands of indigenous groups (Wilshusen et al. 2002). Secondly, the image of the idyllic native living in perfect harmony with other community members and with nature is just a myth (Brandon 1997; Redford et al. 1998; Redford and Mansour 1996; Redford and Richter 1999; Robinson 1993).

This argument is a bit of an overstatement because it appears to be based on the belief that local institutions are incapable of adapting to social change and cannot conserve resources. According to Wilshusen et al. it oversimplifies rural communities' motivations and cultural practices. Furthermore, indigenous people demonstrate a concern for maintaining the ecological processes and the species that mediate such processes. Within several indigenous communities there are people that specialize in bringing rare plants into cultivation in order to maintain them (Alcorn, 1993). In traditional societies, nature is viewed as part of human society, and proper relations with nature are necessary in order to have proper relations between people, including past and present generations. Many indigenous peoples in Africa 
and Asia have a tradition of maintaining sacred forests where animals and plants are not disturbed so this shows that the commitment of indigenous peoples to conservation is complex and old (Alcorn, 1993). The Bagando in south-east Cameroon for example do not eat apes because by tradition monkeys announced dangers arriving through the forest, and this aided the people to escape. Their culture is filled with stories of gorillas and chimpanzees helping old men and women carry heavy loads through long distances in the forest. The Bagando also believe these primates can recognize them in the forest and do not attack them (Nelson and Venant, 2008). This way they have a solid reason to conserve primate populations in their forests. In that regard it will be disrespectful to claim local institutions cannot conserve biodiversity at all even if most cannot.

\section{Emergency situations require extreme measures}

In Last Stand, van Schaik and Kramer (1997) discuss action strategies that consider two broad sets of causes for protected area degradation. Those brought about by "small players" and those precipitated by "big players." The majority of attention centers on "small" or local players (Wilshusen et al. 2002). Concerning the small players, they focus on the state's role in limiting personal freedom for the public good, economic development and incentives, and possible military intervention. Concerning the state's role in protecting the public interest, van Schaik and Kramer (1997) observed;

[Governments of civilized nations have the duty to ask their citizens to accept restraints on their freedom of action when it serves the common good. Governments have established enforcement mechanisms in implicit or explicit recognition of the underlying conflict of interest. In the case of tropical forest parks, governments can claim forest lands as national property because they serve national and international interests.] (Wilshusen et al. 2002: Page 33) 
However, it could be wrong to assume that all governments serve the common good of their citizens. Some governments could be corrupt and serve only the interests of elites and top officials at the expense of the local population.

The second alternative, might be called the "social engineering" approach since it favors increased industrial development to encourage even greater rural to urban migration than already exists, mirroring demographic trends of "developed" nations (Wilshusen et al. 2002). The counterargument here is that encouraging rural exodus in developing countries for example is not always a good idea. First of all many indigenous people may not want to give up their hunter-gatherer lifestyle for city life and even when they do they end up getting exposed to push factors in urban areas such as unemployment, new transmissible diseases, pollution and increasing parasitic loads, drug use and alcoholism, stress and depression. Secondly this fast track urbanization method proposed might trigger serious social, political and economical problems especially in developing countries which have limited services to accommodate the growing urban population.

The third alternative which is that of military intervention is not as far fetched as it sounds, since the role of the military is to protect the nation's interest, usually against outsiders but in case of emergency also against rebellious insiders (Wilshusen et al. 2002). Also, in most cases the military is often the only power with authority and is the best-organized and equipped institution in the country (Wilshusen et al. 2002). In Requiem for Nature, Terborgh (1999) suggests getting the armed forces involved in protecting biodiversity and also the possibility of creating "internationally financed elite forces within countries" (Wilshusen et al. 2002). Such forces already exist as Clynes (2002) describes the work of nongovernmental paramilitary counter-poaching activities in the Central African Republic 
sponsored by Africa Rainforest and River Conservation to fight off commercial Sudanese poaching gangs. After more than 200 rhinos were killed in South Africa for their horns in 2010, Defence Minister Lindiwe Sisulu said she agreed to help by sending in South Africa's army to fight the poachers after a request by a local animal protection body, Sanparks (BBC, 2010).

However, calling on the military to intervene is not always a good idea because as Wilhusen et al. (2002) note, there is the possibility that the military might use conservation as an excuse for territorial control or ethnic cleansing. For example in 1998 Batwa people of the Nyungwe Forest in Rwanda were driven out in order to establish a military zone (Shikongo, 2005). The extermination of about 30 percent of the indigenous Batwa population of Rwanda during the hundred-day genocide shows how armed intervention could harm indigenous peoples (Shikongo, 2005).

Criticisms of the integrated conservation and development projects approach which attempts to create a win-win situation with policies that benefit both conservation and local people have led to another change in policy. This new conservation policy is known as neo liberal conservation. 


\section{The neo-liberal approach}

Neo-liberal conservation moves beyond a world of win-win as promised by integrated conservation and development projects to a world of win-win-win-win-win-win-win solutions that benefit: corporate investors, national economies, biodiversity, local people, western consumers, development agencies and conservation organizations that receive funding from those agencies to undertake large interventions (Igoe and Brockington, 2007). The neo-liberal approach sees institutional, market and policy failures as undermining biodiversity and the solution in adding economic value to biodiversity or seeing the market economy as the salvation of biodiversity (Brown, 2002). According to Igoe and Brockington (2007), neo-liberal conservation promises; democracy and participation by dismantling restrictive state structures and practices, protection to rural communities by guaranteeing their property rights and helping them enter into conservation-oriented businesses, promotion of green business practices by demonstrating that green is also profitable, the promotion of environmental consciousness for western consumers by encouraging them to fall in love with the environment through ecotourism.

This neo-liberal approach is supported by the Environmental Kuznets Curve which tends to rely on econometric analysis in saying that environmental degradation displays an inverted U-shape over time (Sunderlin et al. 2005). The Environmental Kuznets Curve claims that degradation is low prior to economic development, increases in the course of economic development, and then decreases when income (GDP) reaches a certain level. The reason for the decrease when incomes reach a certain level being that: off-farm employment opportunities reduce the opportunity cost of labour that might otherwise exploit the natural environment, as incomes rise, so does the willingness to pay for recreation and other 
environmental services, and higher per capita incomes are associated with more effective public regulatory systems (Sunderlin et al. 2005).

Neo-liberal conservation promises a world in which one can "eat one's conservation cake and have development desert too" (Igoe and Brockington, 2007). However such ideal conditions are not always possible in the real world. Agrawal and Gibson (2009) observe there needs to be the commitment to enforce, fund and implement even legitimate and democratic decisions. The assumption behind the neo-liberal approach is that corrupt and inefficient states restrict free trade, free assembly, free speech and free press and people's lives will improve if these matters were resolved. This makes sense but how is the resolution of these problems easily feasible in a world in which corruption seems to be the order of the day in most developing countries in which conservation initiatives are most needed. This is an uphill task in a world where 78 of the top 80 most corrupt countries in the world are developing countries (Transparency International, 2009).

The second implication of the neo-liberal approach is that local people need to be brought out of nature and into the market so that they can manage nature as competent conservationists. This point of view fails to realize that this assimilation could very much be against the wishes of local people who might want to stay in nature. Also, encouraging local people to enter the global economy as investors, producers and consumers could not always be a great idea because as Igoe and Brockington (2007) put it, investments carry no guarantee of profit making. There are examples from Mayans in the Yucatan (Mexico), St John National Park (United States), and Tobago (Igoe and Brockington, 2007) where local people have followed the neo-liberal approach and ended up as losers in the bottom rungs of the investment ladder due to limited opportunities. Also, contrary to the expectations of this neo-liberal approach, 
the lure of financial benefits promised by the market economy could lead to unsustainable resource use by indigenous peoples who could see the exploitation of natural resources as a quick way to get money.

Thirdly, the neo-liberal approach proposes ecotourism as one way out but tourism is never a really reliable industry. It is highly dependent on changes in the global economy and political events nationally and internationally. Igoe and Brockington (2007) point to the case of Zanzibar whose tourist industry experienced a significant downturn in the wake of the terrorist attacks of September 11, 2001. Besides this, neo-liberal conservation does not necessarily give traditional ecological knowledge rightful recognition. With these pitfalls in mind, there needs to be radical restructuring of decision making processes and institutions at local, national and international levels in order to fulfill the aforementioned promises of neoliberal conservation and actually make it work as a sustainable conservation policy.

Finally, concerning the Environmental Kuznets Curve, though a remarkable degree of natural forest restoration has taken place in the developed world in tandem with increased levels of per capita income, in the course of the last several decades, rural incomes have been increasing in the developing world, yet natural forests have been disappearing at an alarming rate (Sunderlin et al. 2005). Also, even if forest cover does increase over time, it will not be the same forest so a lot of diversity will undoubtedly be lost in the process (Sunderlin et al. 2005). 


\section{Conclusion}

Though claims and counter-claims for and against integrated conservation and development projects have increased in recent years, there are a few hopeful signs that the mutually destructive efforts of advocates of these different perspectives are beginning to change through the realization that both arguments for conservation and for development through livelihood maintenance are correct. There is the need to find common ground to retain and expand a global constituency acknowledging the importance of biodiversity conservation within a framework which recognizes the livelihood and development needs of the local population. In the real world this kind of consensus seems to exist only in theory because carrying out co-management of protected areas within the context of integrated conservation and development projects is fraught with numerous practical difficulties in terms of achieving gains in both conservation and livelihoods.

The policy background of the protected area managers is very important in deciding if people will be allowed to stay in protected areas or face eviction. This depends on which side of the strict conservation/ integrated conservation and development divide the protected area managers belong. Kabra (2007) for example points out that, changes in the regimes governing the management and conservation of forests and commons have a critical bearing on the livelihoods of the rural poor. Kabra goes on to say that the thrust on preservation through dislocation since the second half of the $20^{\text {th }}$ century by the Indian government has far reaching consequences for the nature of agrarian livelihoods and the transition paths of such livelihoods in India. The policy background of Worldwide Fund for example appears to be pro-displacement than pro-integrated conservation and development. This is evident in Schmidt-Soltau and Brockington (2007) who present the case of Mark Infield and the 
Worldwide Fund. Infield was invited by the Worldwide Fund to carry out hunting, fishing and trapping survey of the Korup National Park under its management, to analyze the socioeconomic and biological impact of human utilization and to elaborate conservation strategies. Infield recommended an integrated conservation and development approach with the local population involved and openly warned against displacement of the local population in his report. However Worldwide Fund insisted that this passage in his report had to be taken out and replaced with one which recommended the displacement of the local population from the Park. Schmidt-Soltau and Brockington (2007) also present another case of the antiintegrated conservation and development stand of Worldwide Fund in the case of Paul Devitt in 1988 who was employed by Worldwide Fund. He tried to establish a coherent pro-poor approach for the Korup Project but his reports did not go down well with the Worldwide Fund managers of the project so his contract was not prolonged and the majority of his recommendations were ignored. It is not surprising therefore that Table 7 shows the displacement of about 1,465 people sanctioned by the Worldwide Fund in the Korup National Park in Cameroon.

The World Bank on the other hand appears to be pro-integrated conservation and development and anti-displacement. Two examples in Cernea and Schmidt-Soltau (2003) and Schmidt-Soltau and Brockington (2007) epitomize this view. The government of Cote d'Ivoire submitted a request to the World Bank for funding for a forestry-sector project. The government did an appraisal of the intended project and estimated that about 200,000 people will be displaced. The World Bank rejected this proposal, and sought and received agreement on an integrated conservation and development approach which will reduce displacement from the intended 200,000 to less than 40,000. Thus the policy background of the World 
Bank prevented what could have been a massive and violent uprooting for tens of thousands of people in Cote d'Ivoire. The World Bank urged the government of Cameroon to disassociate itself from any resettlement from national parks. The Bank recommended a change in laws to allow people to remain in Protected Areas, offer them full compensation full compensation for any reduced access to natural resources, and provide them with a comprehensive development program to enhance their social structure.

Economic and social analysis have demonstrated that the benefits of global biodiversity conservation through protected areas tend to be highest at the global and national levels and lowest at the level of local communities, while, conversely, the costs are highest for local communities and lowest at global and national levels (Cernea, 2006). Who wins and who loses when norms are established and enforced to conserve natural resources within protected areas depends on why conservation is deemed necessary and who deems that conservation is necessary (Wilkie et al. 2010). This sets up the next chapter which will look at who benefits from conservation or who loses out to conservation in terms of resettlement and compensation. 


\section{Chapter Five}

\section{Resettlement and Compensation}

The previous chapter discussed changes in conservation policies overtime and how the conservation ideology of the conservation developers can influence displacements. The next question which arises is who wins or looses when conservation policy comes into place? This chapter will attempt to answer that question by looking at the theoretical background of resettlement and compensation schemes as well as their limitations. This chapter will examine the following theoretical frameworks; Department for International Development (DFID) framework, the Impoverishment Risks Reconstruct model (IRR) and the World Bank Framework for Resettlement.

\section{Theoretical frameworks}

The greatest social impacts of protected areas arise from population displacement and the related issues of resettlement and compensation. The complexities of the enduring nature of resettlement impacts have attracted the interest of researchers over the years. For example Jimmy Igoe (2006) came up with a framework (DFID) to determine the costs and benefits of Protected Areas in relation to resettlement and Cernea and Schmidt-Soltau (2003) came up with the Impoverishment Risk and Reconstruct model (IRR) which has become the theoretical basis of the World Bank's resettlement and compensation policy.

\section{The DFID Framework}

In order to measure the costs and benefits of protected areas, Igoe (2006) came up with the DFID Sustainable Livelihoods Framework. This was in response to the lack of empirical data in discussions on whether conservation harms or benefits communities. The framework suggests that poverty is a context, not a condition. Poverty is not an inherent trait of poor 
people, but a reflection of the context in which they live - one that has historical causes. It argues that people have been historically displaced and denied access to their resources. This DFID Framework provides tools for assessing the positive and negative impacts of these historical processes and whether they are in a position to take advantage of the types of benefits offered from community conservation interventions. Specifically the framework emphasizes the ways in which historical processes and other external factors have influenced people's access to different kinds of capital. These kinds of capital include natural and financial capital as well as social, human and physical capital. Natural capital refers to the land, natural resources and ecosystem services. Natural capital is most important to rural communities and most likely to be lost to protected areas. Financial capital includes cash, credit, and other easily liquefiable assets like livestock for example. Social capital on the other hand refers to access to networks, relationships of trust, reciprocity and exchange. Connections to NGOs, government structures and private tour companies strongly influences who benefits. Human capital refers to knowledge of the existence and understanding of community conservation projects and enables people to assess whether a project is of benefit to them or not. The more people who are aware of their rights vis-à-vis a specific intervention, especially in terms of legal authority over natural resources, the more likely they are to be able to strike better deals for themselves. Finally physical capital such as roads and transportation are important because they facilitate access for example to tourist revenues. They also represent access to markets, which provide additional livelihood opportunities as well as goods and services. Communication services give people access to information which enables them take advantage of community-conservation programmes and other economic opportunities. 


\section{The Impoverishment Risk Reconstruct (IRR) model}

Population displacement from protected areas has a direct impact on livelihoods because it exposes displaced people and those in receiving communities to a wide rage of risks which Cernea and Schmidt-Soltau (2003) describe as impoverishment risks. These include; landlessness, joblessness, homelessness, marginalization, food insecurity, increased morbidity and mortality, loss of access to common property and services and social disarticulation. The IRR model was formulated partly out of a need for a consistent conceptual approach to the social impacts of displacement and partly in response to ongoing requests for a cumulative model, as well as in response to other related issues on the development agenda (Cernea and Schmidt-Soltau, 2003). The IRR model has been tested and applied in a number of studies as well as about 200 development projects of the World Bank (Cernea and Schmidt-Soltau, 2003).

The IRR identifies the following possible risks to which conservation refugees could be exposed to: from landlessness, joblessness, homelessness, marginalization, food insecurity, increased morbidity and mortality, social disarticulation and biodiversity loss (Cernea and Schmidt-Soltau, 2003: Pages 12-23).

\section{Facing the risk of landlessness}

In the Central African rainforest, land embodies not only an economic value as source of livelihood but also a social value (Cernea and Schmidt-Soltau, 2003). Cernea and SchmidtSoltau note that small hunter-gatherer bands can, in extreme cases be the customary owner and user of $\sim 1000 \mathrm{~km} 2$ of first class primary forest, valued in million US $\$$ for timber only. But this is just a hypothetic sum because they will never have a chance to cash this natural wealth, since all territories not utilized for agricultural production or officially demarcated as 
private property, have been decreed to be government land (Cernea and Schmidt-Soltau, 2003). Based on this constitutional argument (contested by many in the legal and development communities) conservation projects in the region refuse to consider traditional land titles as land ownership and they reject all claims for a proper resettlement procedure (Cernea and Schmidt-Soltau, 2003). On the other hand, the world's largest development agency, the World Bank, recommends a resettlement policy framework for all cases of displacement that;

[recognizes customary land rights and ensures that the displaced persons are informed about their options and rights pertaining to resettlement; consulted on, offered choices among, and provided with technically and economically feasible, resettlement alternatives; and provided prompt and effective compensation at full replacement cost for losses of assets attributable directly to the project] (World Bank, 2002: In Cernea and Schmidt-Soltau, 2003: Page 13). However, this argument does not explain what the 'full replacement costs' for unrecognized traditional land titles. The World Bank takes that into consideration by adding to those people who have a formal landholding title those who do not have formal legal title to land but have a customary right/entitlement to such land or assets, including those who have no recognizable legal rights can still be entitled to resettlement assistance (World Bank, 2002). The World Bank recommends that if the displacement of indigenous people cannot be avoided, preference should be given to land-based resettlement strategies (World Bank 2002). According to Cernea and Schmidt-Soltau, (2003) this means, since there was no unoccupied land in the first place, it is logical, that the conservation projects will not be able to provide an adequate piece of land without almost similarly affecting the livelihood of other people. Without land conservation refugees become much poorer than they were before displacement (Cernea and Schmidt-Soltau, 2003). 


\section{Facing the risk of joblessness}

Conservation projects should be aware that they have to offer displaced people alternative forms of income generation to protect the parks, with genuine economic incentives. For example, Cernea and Schmidt-Soltau (2003) mention the case of the Dzanga-Ndoki National Park and Dzanga-Sangha Forest Reserve (both in Cetntral African Republic) in which there was a proposition to compensate the Aka 'pygmies' for their income losses (losses in hunting and gathering for subsistence and loss of land). This was to be done through alternative income generating activities, such as farming, livestock breeding, and ecotourism. However, such a proposition is well outlined in theory but is not translated in practice (Carroll, 1992, Noss, 2001, Cernea and Schmidt-Soltau, 2003). As noted before, tourism is not able to generate significant benefits. Though there are a few positive examples of successful ecotourism projects, most of the time tourists do not generate enough income to cover even the management costs of the park and of the tourism infrastructure (Wunder 2000). Because of this, other solutions have to be found to either prevent the unacceptable incomeimpoverishment of the displaced people, or to stop displacing them for park creation. It is not up to the generosity of a conservation project to assist the former inhabitants of a park at their new location - it is a project responsibility (Cernea and Schmidt-Soltau, 2003) 


\section{Facing the risk of homelessness}

Houses of most indigenous tribes especially huts of hunter-gatherers do hardly involve much cash contribution and can be constructed without much effort anywhere else (see plate 3 ). Cernea and Schmidt-Soltau (2003) found out that people expelled from a national park erected new houses in the old style at their new plot. However, habitations suitable for a hunter-gatherer lifestyle are completely different from those for resident farmers. This can result in decreasing health and decreasing acceptance of the resettlement process. The World Bank recommends in operative 4.12 that new communities of displaced people should receive compensation services equal to those of the host population (World Bank 2002).

\section{Plate 3: Paiute Indians (California, USA) outside their hut which can be easily constructed anywhere}

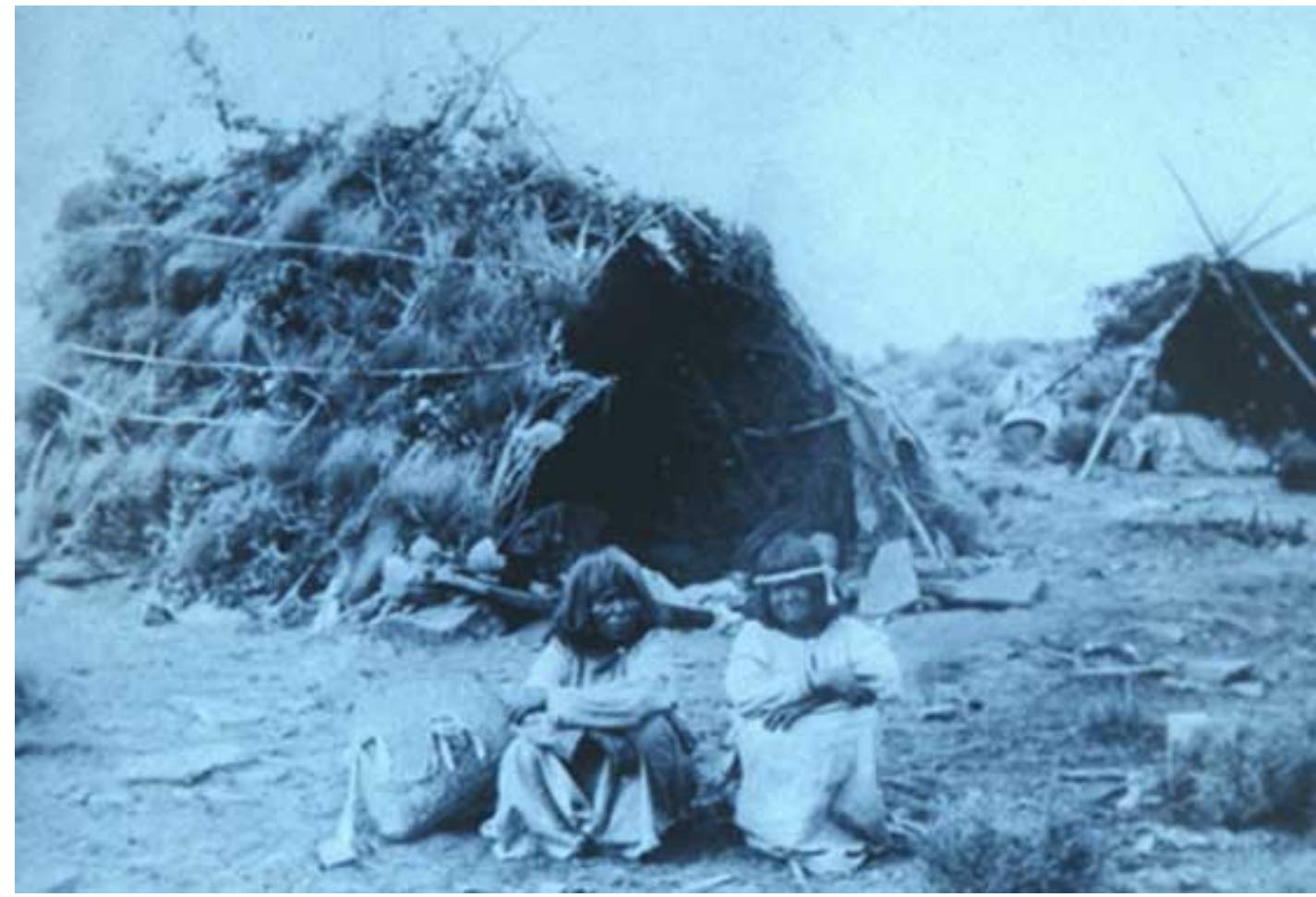

www.californianeducation.org 


\section{Facing the risk of marginalization}

Marginalization comes about directly from the instant loss of traditional rights and status of people displaced from parks as well as the geographical position of the new settlement area (Cernea and Schmisdt-Soltau, 2003). When the new neighbors speak a similar language and belong to the same ethnic group as the host community, the risk that the resettled could be marginalized or discriminated against is relatively limited (Cernea and Schmidt-Soltau, 2003). The discrimination and marginalization occurs mostly in cases where the newly resettled end up as strangers (without rights) among homogenous neighbours from a different cultural, social and economic background. Most hunter-gatherer societies displaced from nature reserves do not live as independent groups but live in that strange 'partnership' with their settled neighbours, which Turnbull (1962) refers to as slavery while others such as Nguiffo (2001) describe as an excellent intercultural partnership. This 'partnership' can exist for long time, but it is not a fair partnership for the hunter-gatherers if they do not have an option to go into the forest to exercise their socio-economic and spiritual independence (Cernea and Schmidt-Soltau, 2003).

\section{Facing the risk of food insecurity}

Dietary diversity among hunter-gatherers and incipient horticulturalists is higher than that of settled agriculturalists (Fleuret \& Fleuret 1980; Dewey 1981; Flowers 1983; Cohen 1989; MacLean-Stearman 2000). With time, the lack of formal land titles and the denial of land use rights could result in food insecurity for the resettled (Cernea and Schmidt-Soltau, 2003). The establishment of a legal title on a piece of land would go a long way to help secure the food supply and reduce the risks of unsustainable resource use. When people are resettled, those who only have the skills to survive as hunter-gatherers face an increasing risk of food 
insecurity. Besides the risk of un-sustainability of the conservation, Galvin et al. (1999) suggest that conservation policy affects the availability of resources to people living on the borders of protected areas. While children tend to be better buffered from nutritional stress than adults, the rural population living near the protected area surveyed by Galvin et al. (1999) experienced a lower nutritional state than other people from the same ethnic background. Their agricultural yield was significantly lower and the research literature insists that resettlements which are unable to achieve self-sufficiency should be considered a failure (Cernea and Schmidt-Soltau, 2003).

\section{Facing the risk of increased morbidity and mortality}

When displaced people become exposed to out-of-the forest lifestyles, they become exposed to a variety of heath risks they are not familiar with in their normal forest environments (Cernea and Schmidt-Soltau, 2003). Research also has determined that a shift from foraging to farming may be accompanied by a decline in overall health (Cohen \& Armelegos 1984). However in all cases surveyed by Cernea and Schmidt-Soltau (2003) new settlements for the resettled are closer to formal health services and facilities than the original habitations deep in the forest, which is a specific and positive risk reduction factor.

\section{Facing the risk of loss of access to common property}

There is the risk of losing access to the common property resources from the forest, since the forest in its total meaning is both the 'individual' and common property (Cernea and Schmidt-Soltau, 2003). As is the case with sedentary farmers only the user rights for 'farm plots' are held individually (by the 'house' or 'household'), while all unclaimed or unused land is owned by the community. Apart from the few cultivated products on these houseplots, all other food products - roots and fruits, medicinal plants, fish from streams, come 
from the rich sources of the forest as common properly (Cernea and Schmidt-Soltau, 2003). Byrne (2008) estimates that in India alone, there are about 300 million people who are wholly or partly dependent on the forest and forest products and that 200 million of these 300 million people live below the poverty line. Thus, separating and relocating resident communities out of the forest deprives them simultaneously of their ownership of the forest and of access to its resources as a common pool for all. This is not a potential 'risk' of impoverishment; it is real impoverishment through prohibition of access. What for other communities may be experienced as two distinct risks of impoverishment is, in this case, virtually one merged risk - a multifaceted, fundamental process of deprivation of resources and decapitalization, to which current park-establishment practice does not yet provide a remedy (Cernea and Schmidt-Soltau, 2003).

When applied to land, access to common property is the basis to maintaining the integrity of the territory and avoiding ecological fragmentation, which is in turn a key requirement for meaningful biodiversity conservation. Also, access to common property provides a strong basis for the building and functioning of community institutions, which are indispensable for sustainable biodiversity conservation. When access to common property is denied to local communities, there is the breakdown of customary resource management and of the traditional ecological knowledge that comes with the management of these resources. 


\section{Facing the risk of social disarticulation}

Social disarticulation of uprooted resettled hunter-gatherer societies is not an impoverishment risk but an impoverishment fact (Cernea and Schmidt-Soltau, 2003). Politically weak communities are further weakened by removal from their habitat. When technological change comes too fast and too soon for a society, it makes stable adaptations difficult if not impossible to achieve without severe pain, emotional stress, and conflict (Coelho \& Stein 1980)

The rapid change of lifestyle destroys existing social links within the group and its relation to others. The high prestige of the elders, resulting from their knowledge of the land, and the related social stratification becomes obsolete when people are forced to move and leadership structure in the group could change as well with younger people taking advantage of the new opportunities offered by the new environment (Cernea and Schmidt-Soltau, 2003).

\section{Facing new risks of biodiversity loss: How the displacements backfire}

The risks imposed on people, and their outcomes, entail in turn an unanticipated risk to biodiversity itself (Marquardt, 1994). Such an outcome is not predicted or taken into consideration by those who promote displacement as a solution, but it is nonetheless real, and should be of concern to promoters (Cernea and Schmidt-Soltau, 2003). Displacement forces hunter-gatherers to become cultivators-farmers, but their sedentarization can have negative impacts on other segments of the environment (Cernea and Schmidt-Soltau, 2003). Mounting evidence suggests that sedentary villages cause more soil erosion than shifting cultivation and hunter gathering (First Peoples Worldwide, 2007). In East Africa, for instance, that the expansion of national parks, game reserves and protected habitats - freed from human presence- has generally been accompanied by a declining of wildlife (Galaty 1999). 
According to research by Cernea and Schmidt-Soltau (2003), both conservationists and informants from among the rural population in central Africa explained this decline as a byproduct of the increasing involvement of the rural population into the market economy. This is supported by First Peoples Worldwide (2007) who argue that population pressure leads to increased harvesting of forest resources as relocated people tend to settle in already overpopulated areas. Displaced hunters in Gabon, for instance, have now increased incentives to intensify hunting by re-infiltrating into areas they knew or from which they were displaced (Cernea and Schmidt-Soltau, 2003).

Secondly, Fabricius and de Wet (2002) note that the main negative conservation impacts of forced removals are that they contribute to unsustainable resource use outside the protected areas, because of increased pressure on natural resources in areas already degraded due to over-population. People's expulsion from biodiversity-rich areas makes their attitudes vis-àvis conservation and conservationists increasingly negative resulting increased poaching and unprecedented incidents of natural resources being vandalized, often accompanied by land invasions (Fabricius \& de Wet, 2002). An example of this case is the Karrayu of the Awash National Park in Ethiopia where it is estimated that the Karrayu have been squeezed from an area they occupied before of 150,000 hectares to an area of just 60,000 hectares. Their traditional rotational graze use pattern has been forcefully broken, producing serious ecological degradation on the remaining part outside the National Park boundaries (BorriniFeyerabend et al. 2004). It is repeatedly noted that displacements result in environmental degradation through an increase of permanent settlements (Colchester, 1997). Soil erosion tends to be higher in permanently used agricultural plots than under shifting cultivation regimes (Duncan \& McElwee, 1999). The increased social stratification induced through 
displacement also has biological implications because it leads to more intense harvesting and extraction of forest resources. In a more or less egalitarian society, most people do not utilize the resources for anything besides their daily needs. An increasing social stratification results in the capitalization of resource and precipitates capital accumulation.

Thirdly, the customary tenure of certain resident forest groups over certain portions of the forest, acts as a built-in protective shield over flora and fauna resources against other local and outside groups that might encroach and overuse. The presence of those resident groups on the ground has been often quite an effective deterrent. Eviction of resident people eliminates the customary protector, and it is doubtful whether 'the state' can be as effective against other users, local or remote (commercial interests). The risk exist that some 'protected' areas may de facto slide into a status of 'open access' areas, a threat present always when former social arrangements break down.

Cernea and Schmidt-Soltau (2003) point to the fact that consequences of the displacement and resettlement process itself results in a set of degrading effects on forest ecosystems. They term these as a 'second generation' of degrading effects, arguing that the presence of residents in parks is causing, under certain circumstances, the 'first generation' of such effects. Trade-offs must therefore be weighted between the cost of efforts to contain the 'first generation' without resorting to displacement and the costs of the 'second generation' effects, if displacement policies are implemented. 


\section{A critique of the theoretical frameworks of resettlement and compensation}

Some sections of the DFID, IRR and the World Bank's resettlement policy framework are worth cross examining. These have been classified under counterarguments which include that compensation in the form of financial capital can only be successful in the short-run, loss cannot be quantified, involuntary hosts need to be given more consideration, risks can be perceived differently by different sections of the population and there is no such thing as voluntary resettlement.

\section{Compensation in the form of financial capital can only succeed in the short-run}

The DFID framework in particular makes mention of compensation to conservation refugees in the form of financial capital. This makes some sense because as Igoe (2006) says, financial capital can easily be converted into other kinds of capital. It can also be used to reduce food insecurity and gain political influence. In this case, anything that is given to local people is considered as a benefit. This is often the meaning of compensation according to some conservation organizations and fundraising propaganda claiming to have improved the lives of rural people, featuring pictures or videos of smiling villagers. However, providing just financial help is not always helpful because if people previously depended heavily on resources enclosed in nearby protected areas, it is unlikely that paying them money alone will offset the livelihood cost of conservation (Igoe, 2006). Protecting biodiversity is of little value to local people unless they are allowed to harvest forest products. Financial capital can easily be converted into other forms of capital but there are a lot of things money cannot buy, such as the social disarticulation of uprooted hunter-gatherer societies, the trust of the local people or their belief in conservation projects. Meaningful collaboration and active participation cannot necessarily be bought with money. 
In a nutshell it can be said that providing any form of external help is not really a sound compensation method because when this aid ceases to come in then the whole resettlement process can be in jeopardy. There are a few examples to show how the provision of external help or financial capital was viable for a limited period of time only. The Korup resettlement project in Cameroon closed due to the reduction of EU funding in January 2004 and by June 2004, most villagers of Ekundu-Kundu had returned to their old site within the reserve, which they had been forced to move out of by the project (Schmidt-Soltau and Brockington, 2007). This was a massive blow to a project which was reputed to be a model for successful resettlement.

Another serious problem for farming activities arises from conservation itself. Cernea and Schmidt-Soltau (2003) bring to light the case of the Noubale Ndoki National Park in the Republic of Congo in which the conservation project was forced to provide foodstuff from outside on a subsidized rate to the inhabitants of the nearby villages, since the increase in the elephant population, due to conservation, undermines efforts to establish farms. At first glance this system, which both provides the rural population with food and secures the lives of protected species, seems to be acceptable. In the long run however, this system is dangerous, because nobody can guarantee that the food supply is sustainable. During the 1999 civil war in Congo, the World Conservation Society (WCS) team had to leave the country. Since the villagers received neither donated food, nor had farms for subsistence, they had to re-start hunting for cash (to buy farm products) and for subsistence. They were still able to do so, since at that time the park had only existed for a couple of years. A successful resettlement scheme should be one in which there is a complete independence from any form of external help, when people are not only self-reliant in their food production 
but are able to generate all their own infrastructural needs and requirements, so that settlements are fully self-contained units. Cash compensation is not an option for huntergatherer communities because without long-lasting training programmes, resettlement could lead to a situation where the resettled spend the cash offered on alcohol and other social vices (see plate 4 below). Most authors recommend compensation in kind (such as rural development programmes) rather than cash, because they hold the view that long-term benefits are more beneficial for the rural population (Gibson and Marks, 1995). According to this argument, Gibson and Marks recommend such compensation should be directly related to the benefits generated by the park, including wages, income, and sustainable access to meat and non-timber forest products (NTFPs). They also recommend increased social services and infrastructure (schools, roads and clinics) and political empowerment through institutional development and legal strengthening of local land tenure systems.

However, the strength of such rural development programmes should not be exaggerated or overemphasized because such outreach activities are notoriously difficult to focus on those who break the law such as poachers. Besides, rhetoric is a poor counter to hunger and grievance against injustice. Persuasion in itself does little to out-weigh economic incentives to break the law and as poaching or illegal resource use often pays more according to MilnerGulland and Leader-Williams (1992). 
Plate 4: A Baka hunter-gatherer takes a break with a bottle of beer

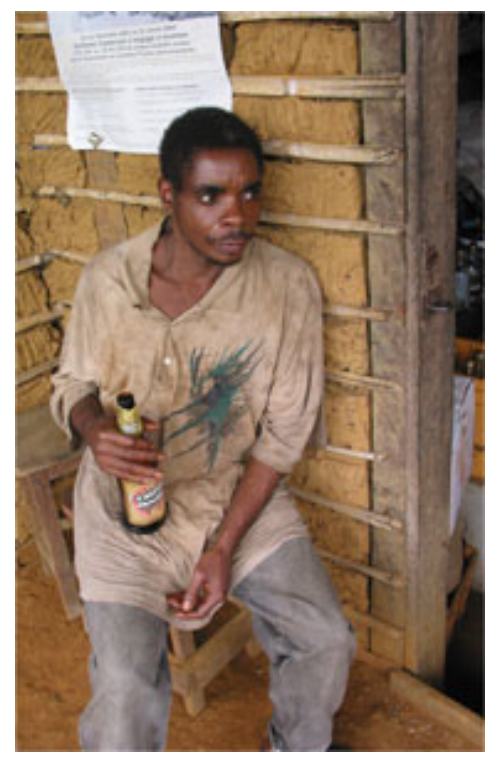

Dounias and Froment (2006)

\section{How can loss be quantified?}

In a just society the removal of citizens' property rights on the grounds that the benefits to the larger society outweigh the costs to those that lose their property is an excuse being used to deprive local people of their rights to resources in protected areas. Just as states exercise this right to take property for the common good, they should also exercise the responsibility to provide compensation for loss of property to the local people. The Impoverishment Risk Reconstruct model points out loss of common property, loss of land and loss of sources of income as major resettlement risks. The World Bank framework for resettlement also stresses on the provision of prompt and effective compensation at full replacement cost for losses of assets attributable directly to the project. There is the problem of how loss can be quantified. Though it is possible to make a partial assessment of loss of income as Cernea and SchmidtSoltau (2003) did by assessing pre-displacement incomes, economic evaluation does not 
adequately reflect the value to individuals subject to a taking. Other measures such as painand-suffering are also valid metrics worth considering in assessing the scale of loss due to a taking of property rights (Wilkie et al. 2010). Theories on resettlement and compensation ignore the fact that little quantitative analysis have been undertaken to assess the costs and benefits of conservation to local people. Most of what is known is qualitative estimates of costs and benefits of conservation projects.

There are three main reasons why it is difficult to quantify loss based on Wilkie et al. (2010). Firstly, the tangible value of natural resources to households varies considerably. Estimates of the tangible value of tropical forests to local people range from highs of over $\$ 1,000$ hectares per year to lows of $\$ 17$ hectares per year (Wilkie et al. 2010). Secondly, Studies assessing the impact of terrestrial protected areas on local people are either ex ante predictions of social impacts or post facto measures of present welfare with no baseline data on local households prior to displacement. The problem here is that post facto merely showing that people around protected areas are poor and marginalized say little about the role of protected areas on the welfare of the local communities (Wilkie et al. 2010). Thirdly, longitudinal studies have not been completed that track changes in human welfare indicators like those mentioned on the Impoverishment Risk Reconstruct model over time within households local to a protected area (Wilkie et al. 2010). Lastly, there has not been a comparison of the welfare of households that traditionally have claims on park resources with "control" households that do not - though a new study on the human welfare impacts of national parks in Gabon with soon provide some information on this (Wilkie et al. 2010). 


\section{The problem of involuntary hosts in resettlement schemes}

Cernea and Schmidt-Soltau (2003) identify one group of people who are often ignored by planners and managers of resettlement and compensation schemes. These are those I will call “involuntary hosts or second generation refugees". The rural population affected by park creation can be divided into those people who are actually displaced - the resettled (those within the resettlement scheme) and the populations who own/use the land where the displaced people relocate - the hosts (Cernea and Schmidt-Soltau, 2003). In most cases resettlement does not just happen on an empty piece of land without any people. The Impoverishment Risk Reconstruct model does not give enough consideration to involuntary hosts though Cernea (2000), Cernea and Schmidt-Soltau (2003) in their commentaries on the model make mention of the problem of people who could be accommodation resettled people against their wish. The total number of people acting as involuntary hosts is often difficult to access because project managers and planners do not give enough consideration to them in the first place. Cernea and Schmidt-Soltau (2003) in their case study of Central Africa estimate that the resettled-host ratio varies between $2: 1$ and $1: 1$. This would mean between 25,000 and 50,000 people in the area are transformed into reluctant hosts considering about 51,000 people are displaced in central Africa. Displacement does not give any options to both the reluctant hosts and the displaced or to both old and young (see Plate 5). The World Bank resettlement policy framework makes no mention at all of the reluctant host population who are key actors in the resettlement and compensation scheme.

According to Cernea (2000), Cernea and Schmidt-Soltau (2003), alienation and marginalization is less when the resettled have a similar culture with the host population which is one reason why planners of resettlement projects need to give more consideration to 
who the hosts are and to find out how accommodating or welcoming they can be to the resettled.

\section{Risks are perceived differently by different sections of the population structure}

The Impoverishment Risk Reconstruct model in particular does not consider the fact that some of the risks in the model might not be considered as risks by every section of the population so the concept of risk is a relative one. The risk of social disarticulation for example might not be considered a risk by every member of the community because some people will definitely benefit from social disarticulation. It might be a risk to the elders who in the former location had high prestige based on their knowledge of the land and the related social stratification. The younger generation might actually welcome the social disarticulation because it might trigger a shift in the balance of power freeing them from traditional values and as with the case in Cernea and Schmidt-Soltau (2003), younger men become the leading figures in the community. They pick up a few words of French and English and become able to express themselves in meetings with project staff and with representatives of the government.

\section{There is no voluntary resettlement}

The theories of resettlement and compensation examined earlier failed to consider the fact no resettlement can be termed "voluntary" in the real sense of the word. The determination of whether a resettlement is voluntary or involuntary is not related to the existence of legal titles of land ownership, but to the fundamental question: Do the displaced have an option to stay or not (Cernea and Schmidt-Soltau, 2003)? In most cases conservation refugees do not have that option to stay if they do not wish to move to resettlement sites. The question of an option to stay or not is not always a good one because as Perez (2002) reminds us, one always has 
an option to stay: even at gun point or even when the house one lives in is set on fire. The next question which should be asked is what happens if one decides to stay? What are the repercussions of deciding to stay? Most of the time would-be conservation refugees are offered "Hobson's choice". A good example is the Korup National Park Project (Cameroon) in which villagers were told that if they resettled "voluntarily" they would receive compensation but if they caused trouble by refusing to resettle, the armed forces would drive them out (Gartlan, 1982). This is clearly involuntary resettlement in all its forms. This kind of threat can be put into action as was the case in Uganda. In a project financed by European multilateral donor in Uganda, for instance, local authorities decided to speed displacement by setting on fire the houses of the target families after they refused to relocate "voluntarily" (Cernea and Schmidt-Soltau, 2003). Women and children as well as elderly people do not even get any preferential treatment when it comes to eviction as (see Plate 5).

\section{Plate 5: An elderly man evicted from Giswati forest in Rwanda}

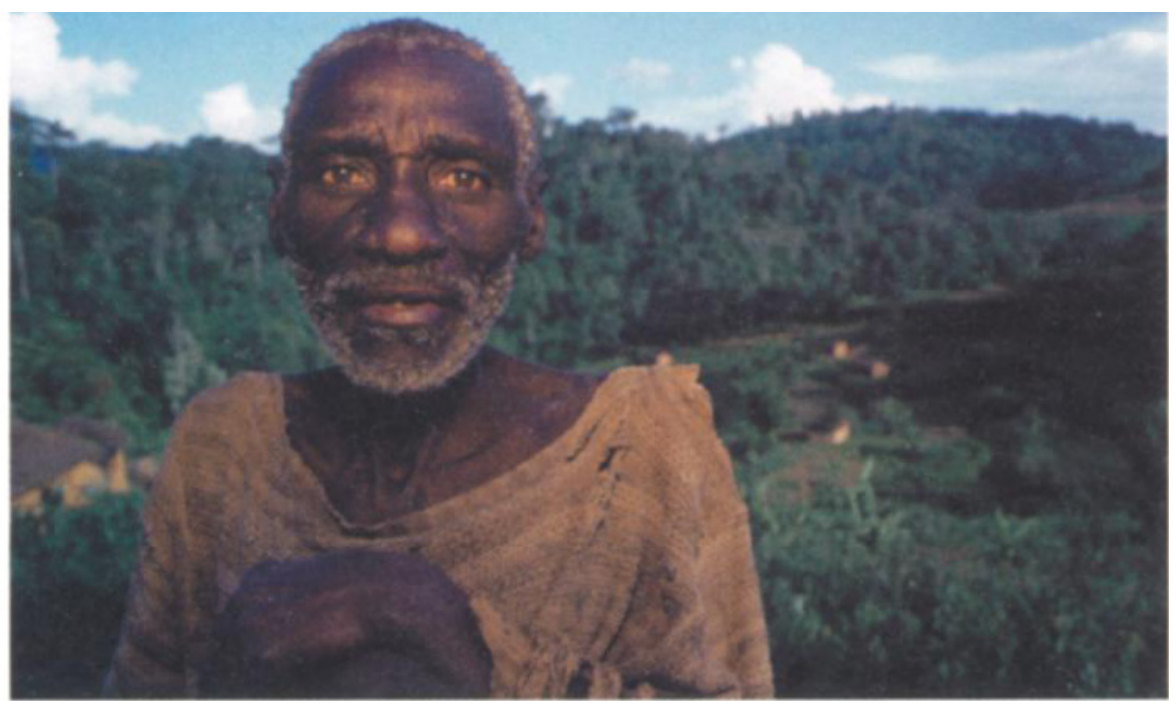

Geisler (2002)

The International Finance Cooperation (IFC) defines involuntary resettlement as that in which affected individuals or communities do not have the right to refuse land acquisition 
that result in displacement. This occurs in cases of; lawful expropriation or restrictions on land use based on eminent domain. Eminent domain is the right to move people from their homes at the behest of a higher social good such as restrictions on access to legally designated protected areas. Also, negotiated settlements in which the buyer can resort to expropriation or impose legal restrictions on land use if negotiations with the seller fail. Schmidt-Soltau and Brockington (2007) argue that resettlement has a chance to be voluntary if protected area managers are able to offer a considerable rent to the people in exchange for reduced natural resource use and management options in which the affected people are able to gain significant direct benefits such as increased hunting yield at the periphery of wildlife sanctuaries. The counterargument I present here is, would people still have access to their resources or be allowed to stay and make a living in the protected areas if they choose to reject the offer from protected area managers? More often than not the answer to this question is negative so it cannot be termed voluntary resettlement. The choices are that people can decide to remain at their present site and suffer with little or no compensation, restricted access to natural resources, little or no opportunities to use forest resources or take advantage of any development projects due to their remoteness. Alternatively, they can agree with a long list of promises of what might change if they resettle - promises which are often never fulfilled. This raises the question of free prior and pre-informed consent.

The World Bank resettlement framework as well as some international declarations examined in chapter 2 stress on free prior and pre-informed consent. In that case resettlement can only be voluntary if it is based on consent. However the situation with many cases of resettlement examined is that there is often the "informed" (see Plate 6 below) without the "consent" in the application of "pre-informed consent" and this leads to coercive actions by 
some protected area managers and governments. There is the case of the Mursi of Ethiopia who were coerced into putting their thumb prints on documents they could not even read. In July 2005, game guards from the Mago National Park visited the Mursi settlement of Maganto (known to the government as Hailu Wuha) and persuaded three men to put their thumb prints on a document defining the Mago Park boundaries. In the words of one of these men;

[We were afraid, so we just signed - they grabbed us] (Conservation Refugees, 2006).

\section{Plate 6: Would-be displaced people being "informed" about resettlement in Cross River National Park (Nigeria)}

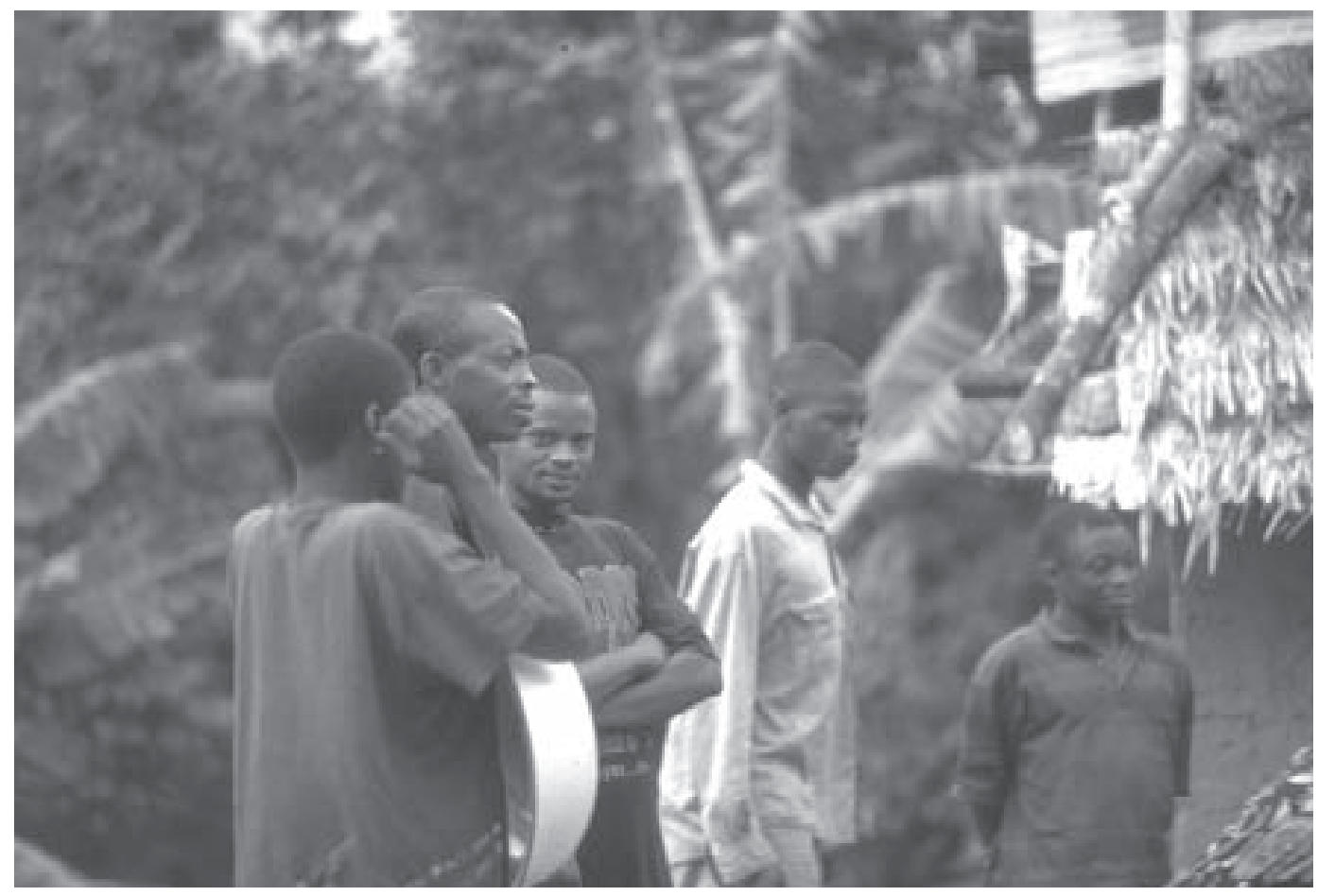

Schmidt-Soltau in Cernea (2006)

The word "pre-informed" does not seem to have a time frame when used in international legislature and theoretical frameworks for resettlement. This might expose enforcement gaps 
because different protected area managers and government agencies might give very short notices to would-be displaced people.

According to the United Nations, the responsibility lies in ensuring that criteria for "free," "prior," and "informed" be met by educating protected area managers and government agencies. I argue in this study that the word "consent" should be given more consideration in theoretical frameworks on resettlement because it is the word, "consent" which empowers the local people with the right to object to projects which do not represent their interests. Informing people about the creation of a protected areas and resettlement is different from convincing them to give their approval to the project as informed consent should mean. In the case of the Korup Project in Cameroon, the villagers in the support zone were merely informed that they were expected to stop their hunting and gathering activities and when it comes to consent only half of the villagers were willing to co-operate with the conservationists (Schmidt-Soltau, 2004). So in effect, the so-called "voluntary" resettlement was just a soft eviction. It is just a seemingly nicer way to kick people out. The following quotes from evicted people around the world go to justify the point there is no such thing as voluntary resettlement or voluntary displacement. Plate 7 shows the scene at an abandoned village after the displacement of residents. 


\section{Plate 7: An abandoned village in Lope National Park (Gabon) after eviction of residents}

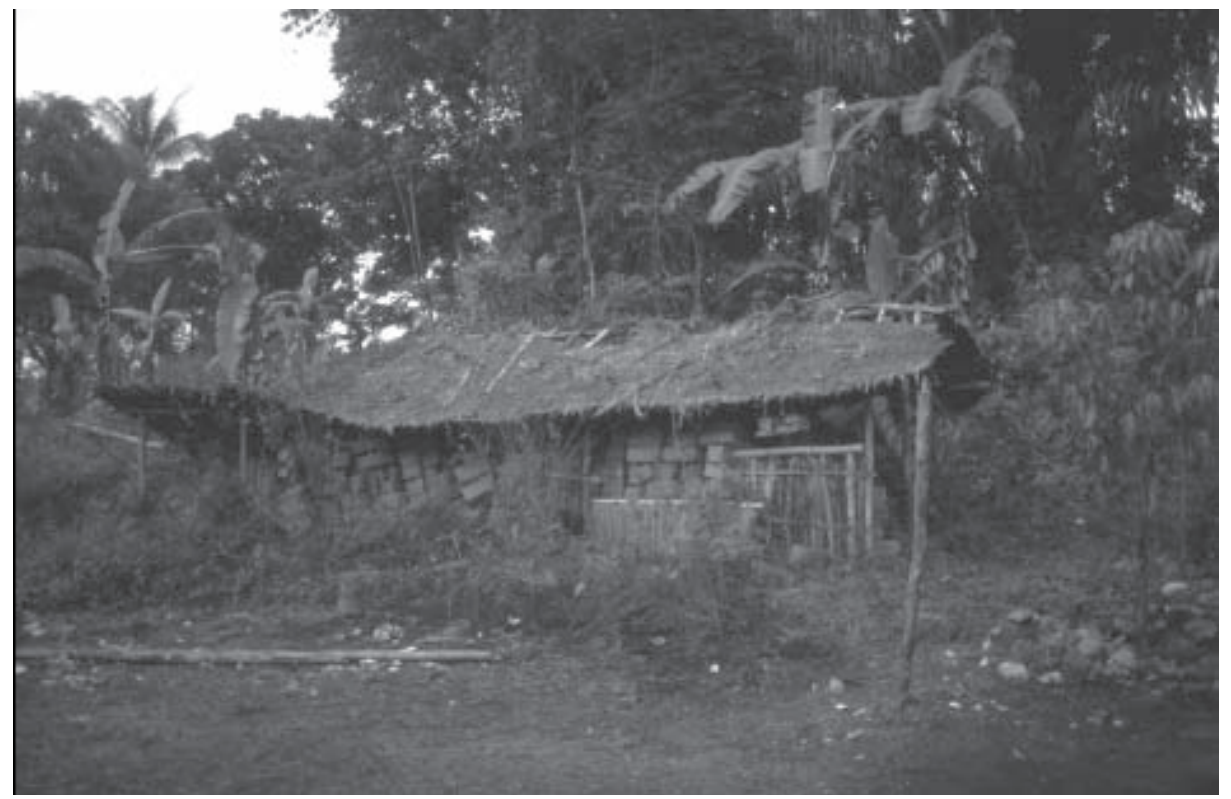

Ndameu (2001: Page 233)

\section{Quotable quotes from conservation refugees across the world}

[We did not know they were coming. I heard people around my house. I looked through the door and saw men in uniforms with guns. One of them forced open the door of our house and started shouting that we have to leave immediately because the park is not our land. I did not understand what he was talking about because all my ancestors have lived on these lands. They were so violent that I left with my children]

Kwokwo Barume - Batwa evicted from Bwindi in Uganda (Dowie, 2009: Page 63). See Plate 8 below.

[We were chased out on the first day. I did not know anything was happening until the police ran into my compound with guns. They shouted at me, told me to run, and we ran. I had 8 children with me - but we just ran off in different directions. I took my way and the children took theirs. Other people were running, panicking and even picking up the wrong children in the confusion. I lost everything. I had 31 cows and some goats and hens but they were killed. Twenty one cows were killed and the rest taken. They burned everything, even the bed and furniture and the kitchen, we are poor now].

Joy Ngoboka - Batwa, Kibale Game Corridor, Uganda (Dowie 2009: Page 63)

[Three Land Rovers entered the crater, one going to each Maasai settlement. They carried personnel of the paramilitary field force unit. Without explanation and without notice they ordered the immediate eviction of the inhabitants and their cattle. Their possessions were carried out and dumped on the roadside at Lairobi. No explanation was given and no arrangements made for resettlement of the evacuees]. 
Henry Foshrooke - Ngorongoro, Tanzania (Dowie, 2009: Page 30).

\section{Plate 8: Bwindi National Park (Uganda)}

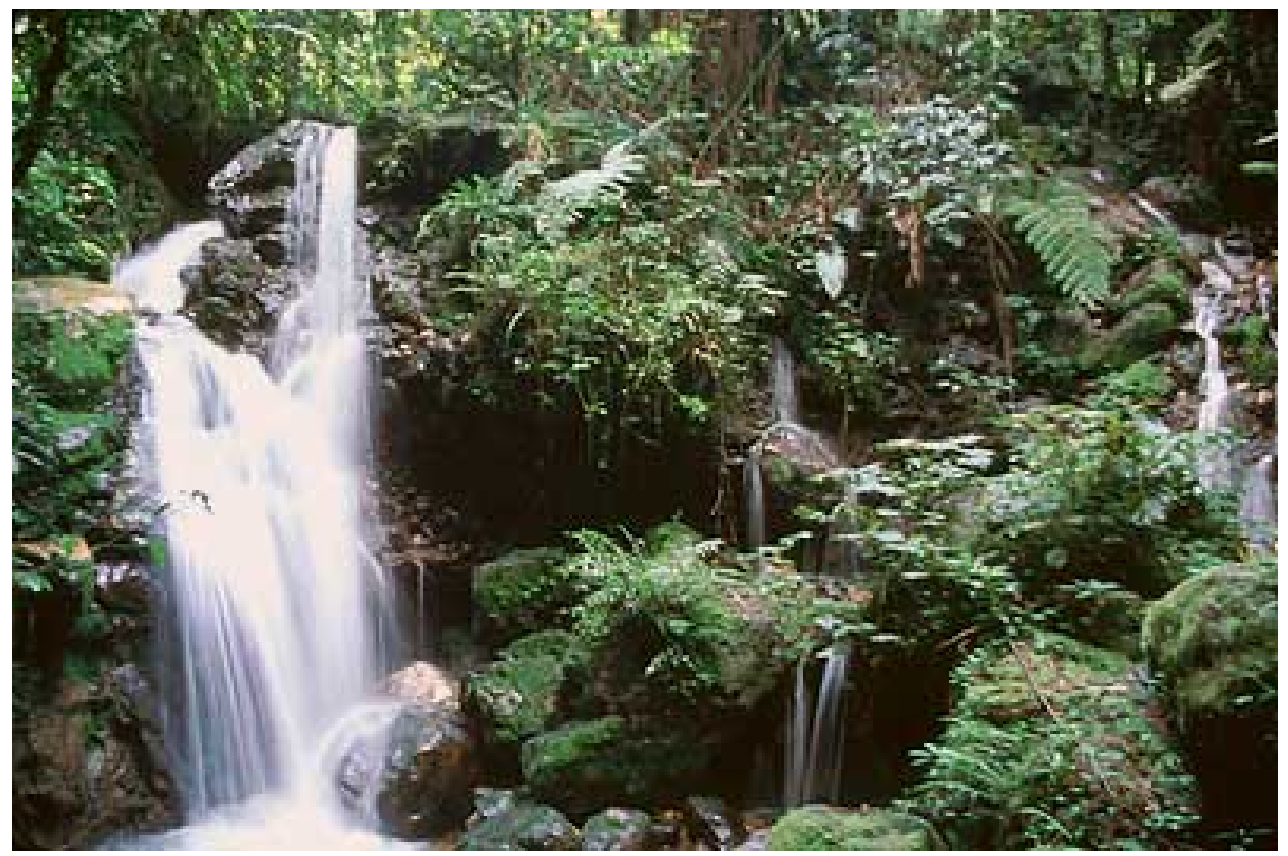

www.wildherps.com

[First we were dispossessed in the name of kings and emperors, later in the name of state development and now in the name of conservation].

Indigenous delegate at $5^{\text {th }}$ World Parks Congress in Durban, 2003 (Dowie, 2009: Page xv)

[All I know is the soldiers came from far away to chase us out with guns. They said we could never return to the forest and we were forbidden to hunt or harvest honey, water and wood]. Mtwandi- Batwa expelled from Bwindi, Uganda (Dowie, 2009: Page 69).

[We, the Indigenous Peoples, have been an integral part of the Amazon Biosphere for millennia. We have used and cared for the resources of that biosphere with a great deal of respect, because it is our home, and because we know that our survival and that of our future generations depends on it. Our accumulated knowledge about the ecology of our home, our models for living with the peculiarities of the Amazon Biosphere, our reverence and respect for the tropical forest and its other inhabitants, both plant and animal, are the keys to guaranteeing the future of the Amazon Basin, not only for our peoples, but also for all humanity].

Coordinating Body of Indigenous Organizations of the Amazon Basin (Chapin, 2004: Page 19)

[Hunting is forbidden everywhere. If you are seen with game, it will be taken off you. They did not tell us why Mabe is in the reserve. They did not tell us why we must not hunt there. Perhaps they told the Sous-Prefet ${ }^{1}$. I remember being lucky once, when they surprised us 
carrying game we had smoked. They forbade us to carry on hunting, but did not confiscate our game].

Baka displaced from the Dja Biosphere Reserve in Cameroon (Nguiffo, 2001: Page 209).

[Korup is very nice to us. They help us produce more cocoa. But there are some thieves among them. They come from time to time to take bush-meat away, which we have hunted in our forest and they even ask the owner of the meat to give them additional money. We complained to the nice people of Korup but nobody helped us].

Displaced village chief complaining about Korup Project staff in Cameroon (Schmidt-Soltau, 2004: Page 105)

[If the white people like the forest so much, they should live here. We are prepared to exchange homes].

Baro, a displaced person from the Korup National Park in Cameroon (Schmidt-Soltau, 2004: Page 102)

[How is it that supposed experts and "guardians of nature" come here after failing to conserve forests and trees in their countries of origin?]

Maasai community leader on foreign conservation agencies (Dowie, 2009: Page 29).

[When they were creating the park, no one came to consult with us, the Bagyeli. Maybe they went to talk to the Bantu, but I don't know anything about this. They do not know us].

Bagyeli Pygmy displaced from Campo Ma'an National Park in South Cameroon (Nelson, 2003: Page 3).

[What used to be my home has now become a park and I am not allowed to live there anymore].

Bambuti displaced in the Democratic Republic of Congo (Shikongo, 2005: Page 38).

[We usually hear news on the radio even when a single house is burned down by criminals. We hear all different kinds of crimes reported. In our case we lost 463 houses, but it was not reported at all].

Said one Guji tribal member evicted from the Nech Sar National Park in Ethiopia (www.conservationrefugees.org).

[Men in uniform just appeared one day out of nowhere, showing their guns, and telling us that we are now living in a National Park. That was the first we knew of it. Our own guns were confiscated . . . no more hunting, no more trapping, no more snaring, and no more slash and burn. That is how they call our agriculture. We call it crop rotation and we have been doing it in this valley for over 200 years. Soon we will be forced to sell rice to pay for greens and legumes we are no longer allowed to grow here. Hunting we can live without, as we raise chickens, pigs and the buffalo. But rotational farming is our way of life]. A displaced Karen (Dowie, 2006: Page 8) 
Such acts of barbarism further alienate the affected population and make them enemies of conservation instead of friends of conservation. Violent evictions foster antagonism and there are cases of animals and forests being deliberately destroyed to avert planned protection (Brandon et al. 1988). Dowie (2009) mentions the case of the Maasai in East Africa (see Plate 9) who after being kicked out of a protected area violently, resorted to killing the animals in the reserve just for revenge and not as poaching.

\section{Plate 9: Maasai conservation refugees in East Africa and a lion which is now master of their ancestral lands.}
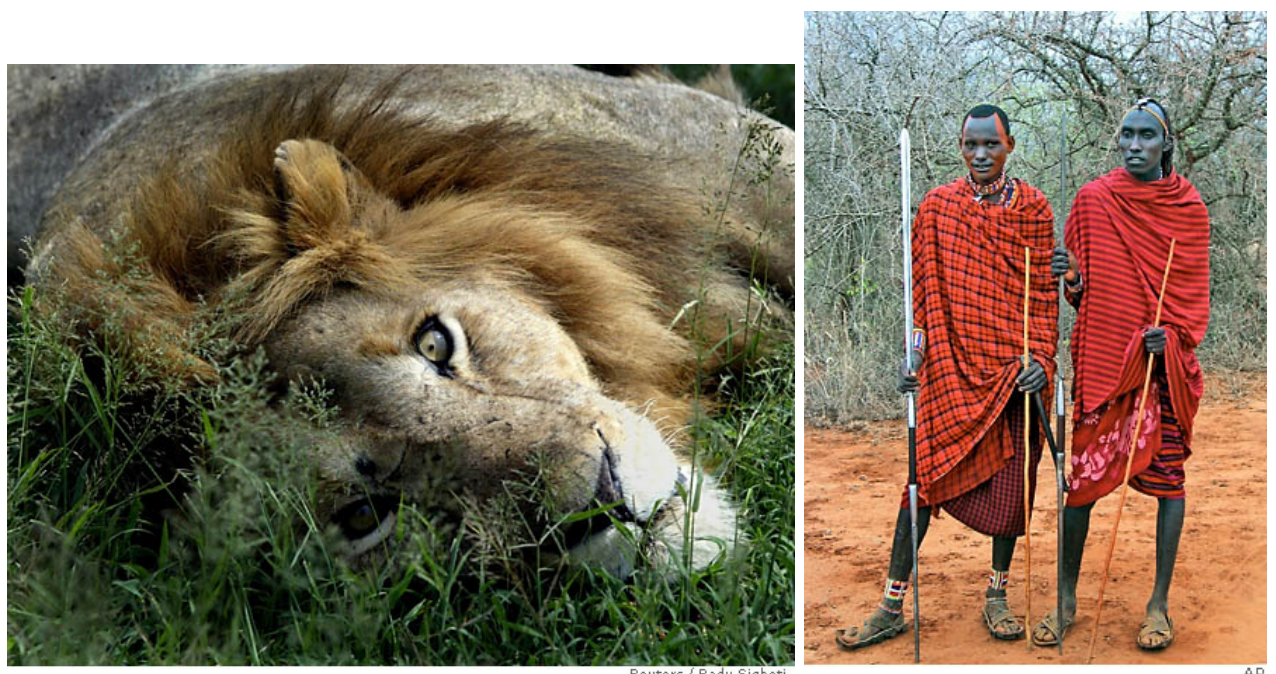

Sighetti, Reuters (2009) and Murray, Associated Press (2005)

There is also the case in India where protesting snake-charmers angry at laws prohibiting the keeping of certain snake species vital to their culture attempt to release live snakes into the assembly in Orissa (Byrne, 2008). In 1995 the United States government decided to reintroduce the threatened gray wolf population into Yellowstone National Park without the consent of local ranchers and hunters. This led to the ranchers deciding to take care of the wolves by themselves quietly - by what they call the "shoot, shovel and shut up" solution (Miller, 1996). 
[The idea is not to preserve the wild but rather to preserve peoples' relationship with the wild]. (Bill Adams in Dowie, 2009: Page ix)

It is not about what we do here but rather how we do it. A nicer way of displacing people will go a long way to improve on the relationship between people and protected areas which is vital to conservation.

\section{Conclusion}

This chapter has critiqued the theoretical frameworks behind resettlement and compensation showing limitations in each of these models which makes it difficult for conservation refugees to reap benefits from protected area establishment through resettlement and compensation. In this chapter I also present selected quotes from some conservation refugees which should further expose their plight.

There is not even an approved code of procedures as to how to conduct the logistics or relocation, or accepted standards for compensation. Compensation for loss is either simply not paid or is much below inflicted loss, illustrating the general deficiencies of compensation for displacements (Cernea and Schmidt-Soltau, 2003). Donors who finance park establishment do not provide investment resources for reconstructing the livelihoods of those displaced at the outside-the-park locations. Under-resourcing of resettlement is compounded by brutality during displacements, summary violent eviction, and wanton destruction, instead of what sometimes is termed as "humanitarian logistics" in involuntary resettlement. Field accounts of physical violence abound; unnecessary pain is inflicted and social disarticulation is often deliberately pursued as a means to inhibit people's active resistance to displacement. 


\section{Chapter Six}

\section{The Baka of South-East Cameroon and the Ogiek of Kenya}

\section{Background}

I have chosen the Baka of south-east Cameroon and the Ogiek of Kenya as case studies of conservation refugees because they fit most of the possible criteria for classifying indigenous people and conservation refugees. First of all they are known to be the first occupants of their current territories, they have a widespread knowledge of the use of natural resources in their area and their cultures and economic practices are connected with the use of these natural resources. They are marginalized by their respective states and other ethnic groups and are relegated to the bottom of the cash economy. In addition, they have been displaced from their ancestral forests with little or often no compensation.

\section{The Baka Conservation Refugees of South-East Cameroon}

Estimates by the International Union for Conservation (IUCN) on forest degradation and loss in the Central African sub-region (which covers the study area) show that on average, 60 percent of tropical forest and 60 percent of wildlife habitat have been destroyed. It is against the backdrop of these figures that the Yaounde declaration of 1999 was ratified by seven Central African heads of state, expressing the consensus that the establishment of national parks and other protected areas in the sub-region is the most effective way to protect nature. By 2002 the central African heads of state including the government of Cameroon had fulfilled their obligations of the Yaounde declaration and doubled the area of protected areas in the sub-region. The governments also came up with a plan that in 10 years time no less than 30 percent of the landmass of their states will be protected as national parks. This will be at the expense of indigenous people including the Baka who will be displaced without 
compensation to make room for these parks and reserves. The Baka are considered to be the original inhabitants of many parts of the equatorial rainforests of central Africa. The Baka traditionally live by hunting and gathering (see Plate 10).

\section{Plate 10: Baka women and children gathering firewood and other forest products in South-East Cameroon}

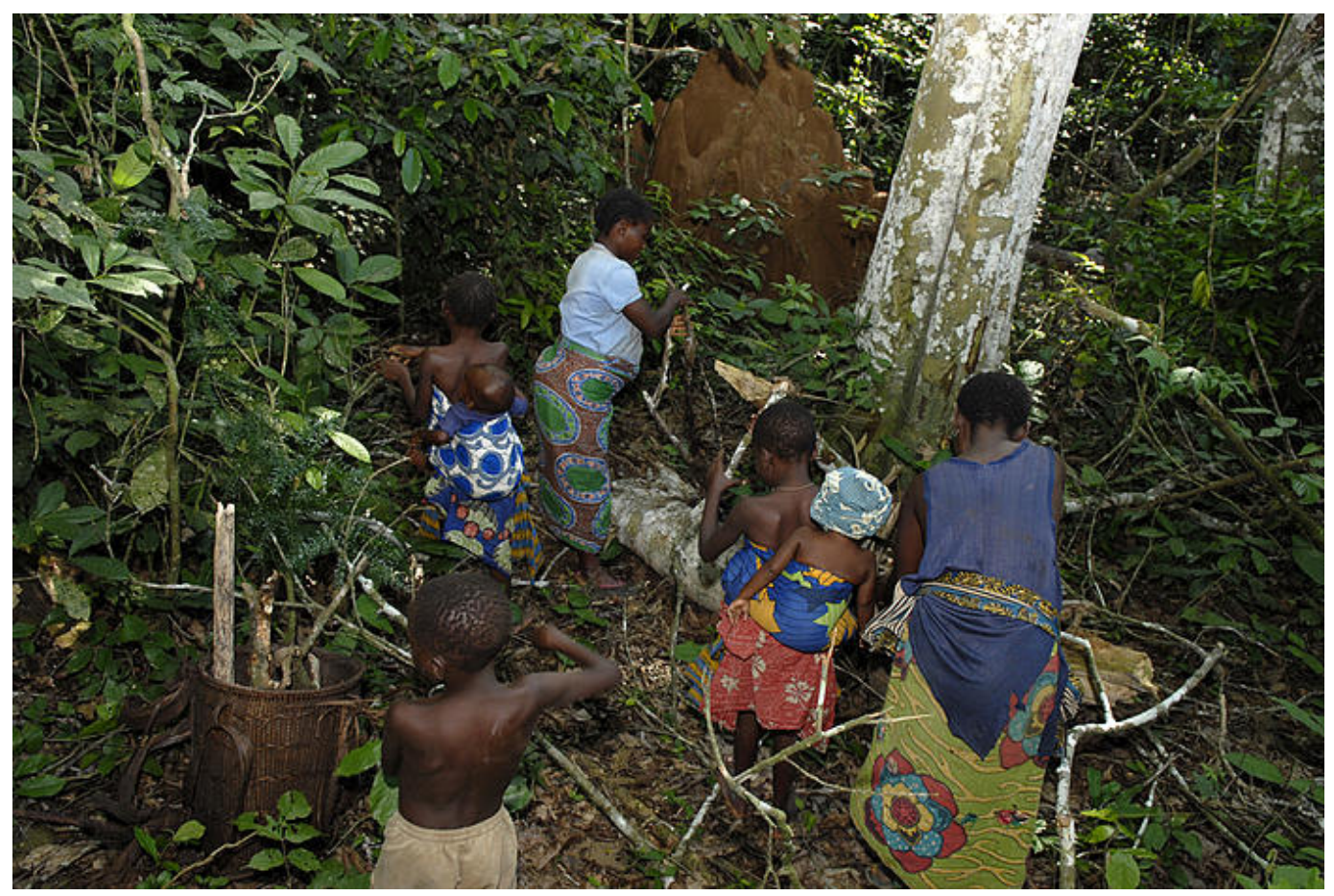

\section{$\underline{\text { www.pygmies.org/baka/ }}$}

The Baka live in small groups of approximately 50 people, are connected by friendship, blood and marriage ties and lead a semi-nomadic forest-based life. Their communities are structured around camps which constitute the socio-economic unit from which they organize their production and consumption activities (Ndameu, 2001; Shikongo, 2005). Their presence in Cameroon's forests is well recorded and certainly pre-colonial. In many places where the Baka live, it is generally accepted by other local communities that their ancestors arrived to 
find the Baka already present. There are approximately 50,000 Baka in Cameroon's forest zone (Shikongo, 2005).

For the Baka the forest has always been more than just a place of survival. Several researchers have shown that apart from the fact that the forest enables them to live, it possesses a mystical character. Abega (1998) notes to this effect, that in Baka mythology, the god Komba is 'the creator of all things'. All elements of the Baka cosmology are a creation of the god Komba, and the forest and the Baka themselves are part of this cosmology. They also believe that alongside Komba there are other human-like forest spirits who play tricks on people who do not behave according to tradition (for example those who do not like to stay in the forest). The Baka believe if rituals are not performed (due to lack of access to remote forest areas), negative consequences could befall those who fail to perform their duty (Schmidt-Soltau, 2003). The attachment that the Baka have for the forest is because:

[The forest is the foster mother: she puts her fauna and flora at the disposal of men. These possessions are transformed before being invested in food, architecture, pharmacopoeia or economic activities. This model permits permanent regeneration, being based upon respect for the rhythms of nature. The Baka respects this rhythm by fitting himself into this environment without changing it, and by associating the relationship to the environment to an entire system of representation].

(Abega in Ndameu, 2001, Page 222)

World Bank recommendations for resettlement of displaced people have been ignored in the case of the Baka with some government officials even arguing that the cost involved in resettling inhabitants of national parks according to the World Bank's socially sound guidelines is too high (Cernea and Schmidt-Soltau, 2003). So the indigenous Baka end up 
carrying the weight of conservation projects. When the forest reserves were created the Baka people were not informed so they carried on their hunting and gathering. A few years ago, due to calls for stricter enforcement of protected area law from conservation NGOs, they were told that these areas which they have always considered as their home were now part of forest reserves so their activities became restricted (Nguiffo, 2001). With these restrictions, most Baka were forced to move into neighbouring villages and settle alongside the Bantus tribes.

Settled along the roads and in close proximity to the Bantu villages, often against their will, the Baka are trying to adapt to the difficulties of co-existing with the Bantus, while their condition worsens with the restriction placed on their use of forest resources by conservation projects. The Baka have experienced changes in their production systems within the last 50 years which result more from their sudden sedentarization and accompanying constraints such as bans on hunting, fishing and collecting in the forest (Nguiffo, 2001). It is obvious that a change of lifestyle which took other societies thousands of years could not be implemented overnight or even within one generation with the Baka (Cernea et al., 2003). The Baka are also well known for their knowledge of traditional medicines, fetishes and the making of charms (Nguiffo, 2001). Figure 5 shows the location of the Baka in Cameroon. 
Figure 5: Map of Cameroon showing the location of the Baka

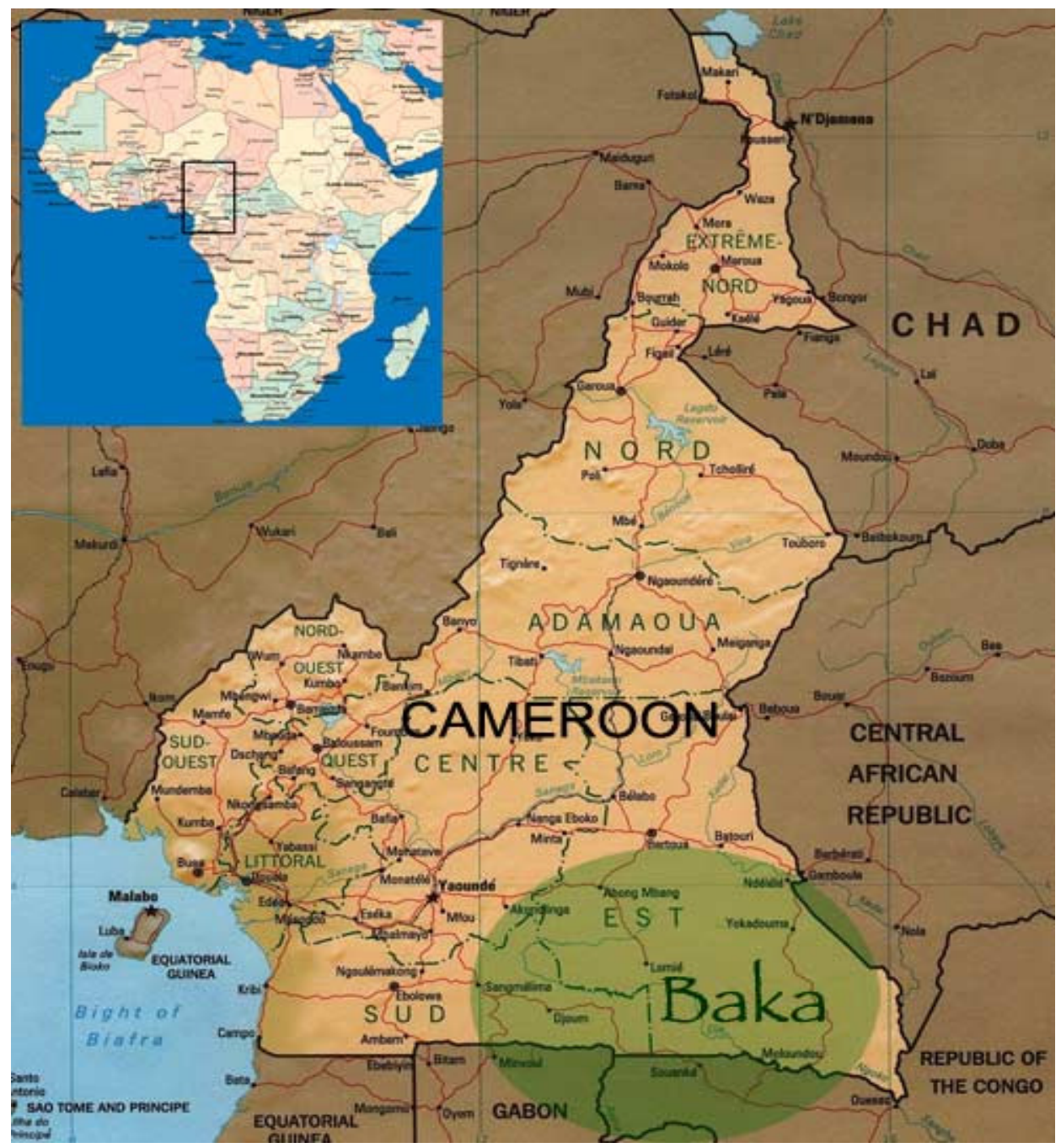

www.baka.co.uk/baka

\section{Legal and constitutional framework in place}

The Cameroon 1994 forestry law like the 1973 and 1981 laws it repealed, put all forest resources under the control of the state by classifying them as communal forests. Under section 35 of the law, all forest resources, with the exception of council forests (which themselves are divested by the state from its huge reserves) and private forests, as well as orchards, agricultural plantations, fallow land, wooded land adjoining an agricultural farm and pastoral land, are nationalized (Egbe, 2001). Sections 30 and 35 of the same law imply 
that private forest only refers to forest planted by an individual on land for which there is a title deed. An individual therefore cannot own a naturally growing tree, even if it were found on a piece of land owned by him according to law.

The new forestry law also nationalized all genetic resources in the country. No person is allowed to use genetic resources for scientific, commercial or cultural purposes without prior authorization. Even certain animal and plant species as well as forest products such as horns of wild animals found in natural forests on land belonging to an individual shall be the property of the state (Egbe, 2001). The law however recognizes the right of local people to harvest all forests products and hunt wildlife except in protected areas. An extension of the law also states that user rights of local people can be temporarily or definitely suspended or restricted for the purpose of conservation. This can only be carried out after consultation with the local population concerned and must be done in consonance with the cardinal requirement of expropriation by reason of public interest, that is, the payment of compensation (Egbe, 2001). Practically there is hardly ever any consultation with the local population and compensation is often little or nothing.

The 1994 forestry law provides that permanent or classified forests which constitute protected areas must cover up to 30 percent of the total area of the national territory representing a 10 percent increase from the 1981 forestry law it repealed (Egbe 2001). The forestry and wildlife regulations provide that the prime ministerial decree classifying a state forest must take into consideration the social environment of the local population who are entitled to maintain their user rights. However such user rights are subject to limitations if contrary to the purpose for which the protected area was created. Such customary rights are only permitted for extraction and use of secondary forest products (which in most cases will 
refer to non timber forest products) from fauna reserves and protected areas. Hunting is not permitted in any of the faunal reserves (Alpert, 1993). Community participation in forest management is still theoretical in Cameroon.

This theoretical nature of the law states that the elaboration of management plans for protected areas whose management has been sub-contracted to individual or community bodies can be drawn by the bodies themselves and approved by the forest administration. The new regulations further make provisions for community management of buffer zones surrounding protected areas. This is a laudable improvement from the letter and spirit of previous laws, which almost protected buffer zones to the same extent and in the same way as the protected areas (Egbe, 2001). As far as the practical application of this law is concerned, the "top-down" approach still prevails with authoritarian management styles which are unconnected to the atmosphere of antipathy sometimes existing between the protected area authorities and the local population. The downside of this law is that most protected areas without effective community participation tend to be regarded by the local population as "alien hegemonies", to be taken advantage of whenever possible. Secondly, some of the protected areas lack well-defined boundaries and buffer zones that mark the transition between the protected area and zones where community activities are permitted. The government has seemingly added further doubt by portraying unflinching interests in the economic value of forest resources and by accelerating the rate of exploitation around forest reserves through the issuing of logging licenses. 
The Dja Biosphere Reserve, Boumba Bek/Nki and Lobeke National Parks

The three protected areas from which the Baka have been displaced include the Dja, Boumba Bek/Nki and Lobeke (Figure 6).

Figure 6: Map of Cameroon showing the location of the three protected areas from which the Baka have been displaced.

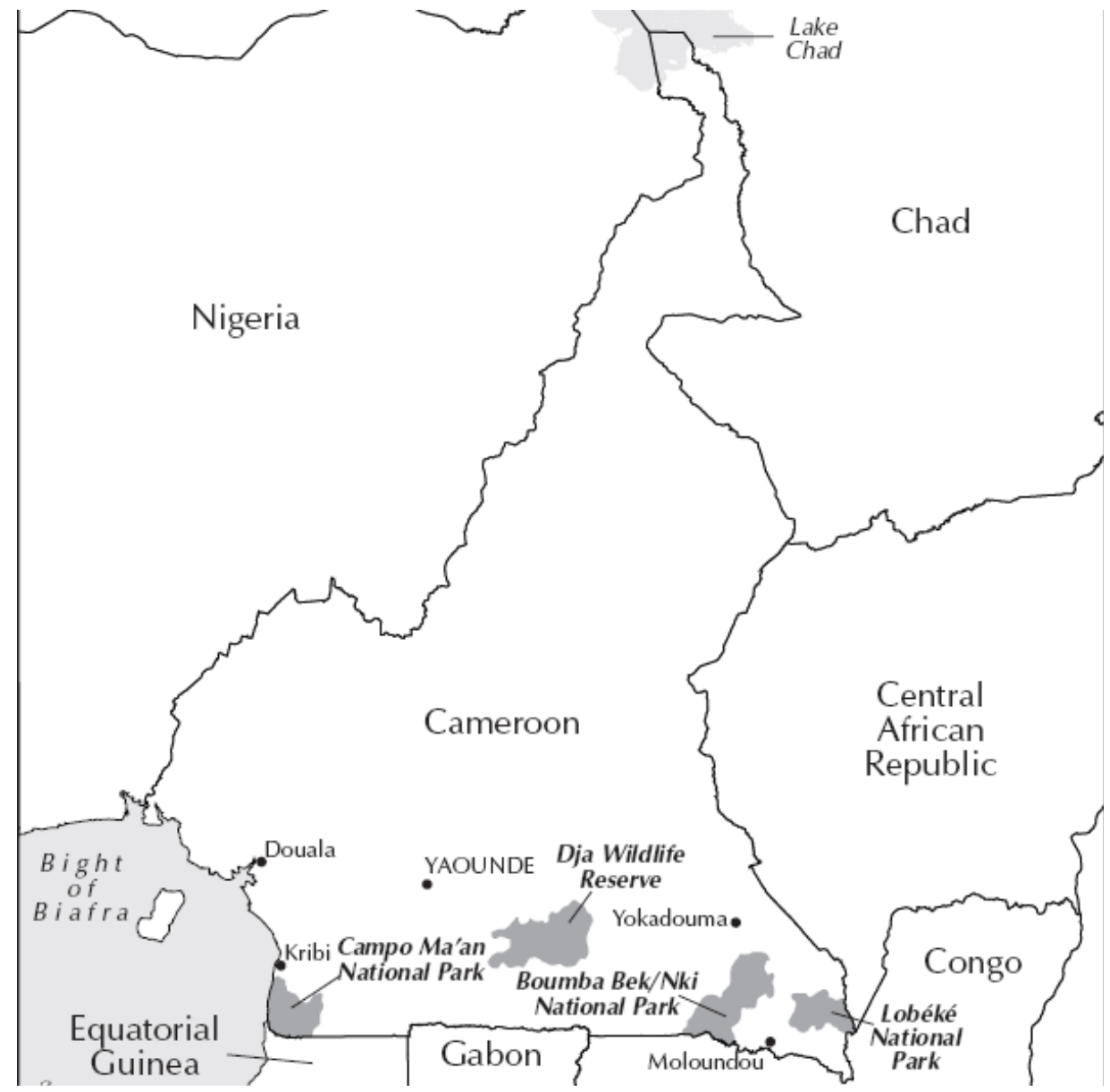

Nguiffo (2001, Page 195)

The climate in these areas is 'sub-equatorial tending to equatorial' with four seasons (Ndameu, 2001). These seasons include: a long rainy season from September to the end of November; a long dry season from the end of November to March; a short rainy season from the end of March to June; and a short dry season from July to August. 
The annual rainfall is around $1,500 \mathrm{~mm} /$ annum, with an average temperature of $24^{\circ} \mathrm{C} /$ annum. The population density is around five persons per square kilometer (Ndameu, 2001). The displaced Baka from the protected areas live along the main road, living in villages of mixed populations with the dominant groups in most of these villages being the Bantus (Bangando, Bulu, and Fang).

The Dja Biosphere Reserve is a world heritage site. It is one of the largest and best protected rainforests in Africa, almost entirely surrounded by the Dja River which forms a natural boundary. About 90 percent of its forest is still undisturbed. It is one of the International Union for Conservation's 15 critical zones for the conservation of central African biodiversity and as a result of its inaccessibility, its transitional climate, floristic diversity and borderline location it retains a rich flora and fauna with 109 species of mammals and a wide variety of primates (UNEP, 2006). It was inscribed as a world heritage site in 1987 and covers an area of about 526,000 hectares. Though this reserves fall within ancestral Baka lands, there are no documented instances of these indigenous people obtaining secure right to control their forest land and resources. Limited rights have been accorded to them by some conservation agencies in buffer zones around these national parks. The core areas of the three parks mentioned above are however out of bounds to the Baka - only ecotourism and research may be carried out within them (Poole, 2003). The creation of these conservation projects has thus put the Baka under pressure by reducing their hunting and gathering areas and increasing competition for use of resources between them and neighboring sedentary Bantu tribes (Schmidt-Soltau, 2003). 


\section{Plate 11: The Dja Biosphere Reserve}

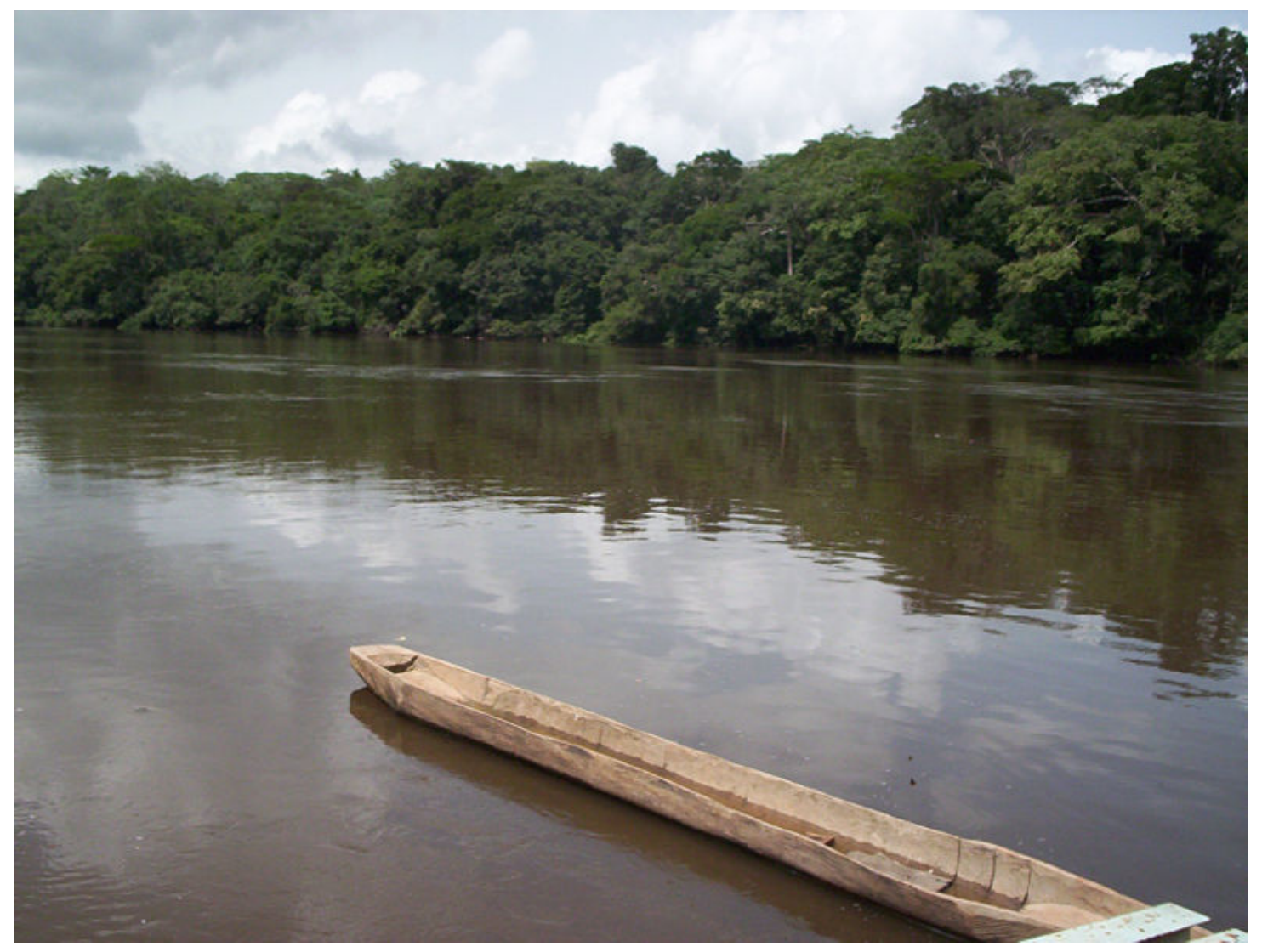

Worldwide Fund- Jenji Project

Boumba Bek/Nki National Park forms part of the sequence of protected areas in south-east Cameroon (Lobéké, and Boumba Bek/Nki). Its establishment underwent several phases. In 1995 these areas were first named "Essential Protection Zones"; followed by a categorisation indicative of land use in the southern forest zone, which ratified the initial decision. The Boumba Bek and Nki parks jointly cover an area of 648,600 hectares (Ndameu, 2001). These twin parks are the largest protected area in Cameroon (Ndameu, 2001), followed by the Dja Reserve (526,000 ha).

At present, these parks are being managed under the 'Jengi' Project of the Worldwide Fund for Nature (WWF). Other related organisations are also providing intermittent support, 
including: GTZ (German Technical Cooperation) through the 'Profornat' Project (Protection of Natural Forests), and the Ministry of Environment and Forestry (MINEF), in implementing the south-east region Operational Technical Unit(UTO).

The Boumba Bek/Nki forest is, for the Baka not only the place where they carry out the activities for their survival, but also the place where the Baka tradition survives, characterized by their attachment to the forest and their belief in the forest spirits (Ndameu, 2001). However, all this changed for the Baka once the Boumba Bek/Nki forest became a National Park. The authorities in charge of wildlife management and the various projects used the strategy of applying repressive measures against hunting activities of the Baka. These acts of repression affected the lives of the Baka in the region. One such case was the Baka community of Bethléem (from the village of Mambelé) in the Boumba Bek/Nki Forest area who were asked by the authorities, in January 1997, to leave their Limbombolo camp in the National Park (Ndameu, 2001). According to Cernea and Schmidt-Soltau (2003) an estimated 4,000 Baka have been evicted from the Boumba Bek/Nki National Park in this manner with no compensation. This figure will rise if those Baka who still live in the reserve are included. They have been deprived of a source of livelihood through restrictions on hunting and gathering.

Lobeke National Park is the smallest of the three national parks considered in this chapter. The national park was established in 1999 in south-east Cameroon and covers over 220,000 hectares of flora and fauna rich lands (Nelson, 2003). The Baka are the largest ethnic group in the area which includes a few Bantu communities. In the creation of Lobeke national park in the study area with the promotion of Worldwide Fund for Nature, there was the expulsion of an estimated 8,000 mainly Baka Pygmy groups over a total area of 4,000 square 
kilometers with little or no compensation (Cernea and Schmidt-Soltau, 2003). Close proximity to the borders of the Central African Republic and the Republic of Congo, coupled with the enormous number and variety of large mammals in the park have made the area a prime target for illegal commercial bush meat hunters and traders, and trophy hunters who pay fees to local safari companies to hunt. Live parrots (Plate 12); ivory and other illegally obtained forest resources are regularly smuggled through the area.

\section{Plate 12: African grey parrots in Lobeke National Park (Cameroon)}

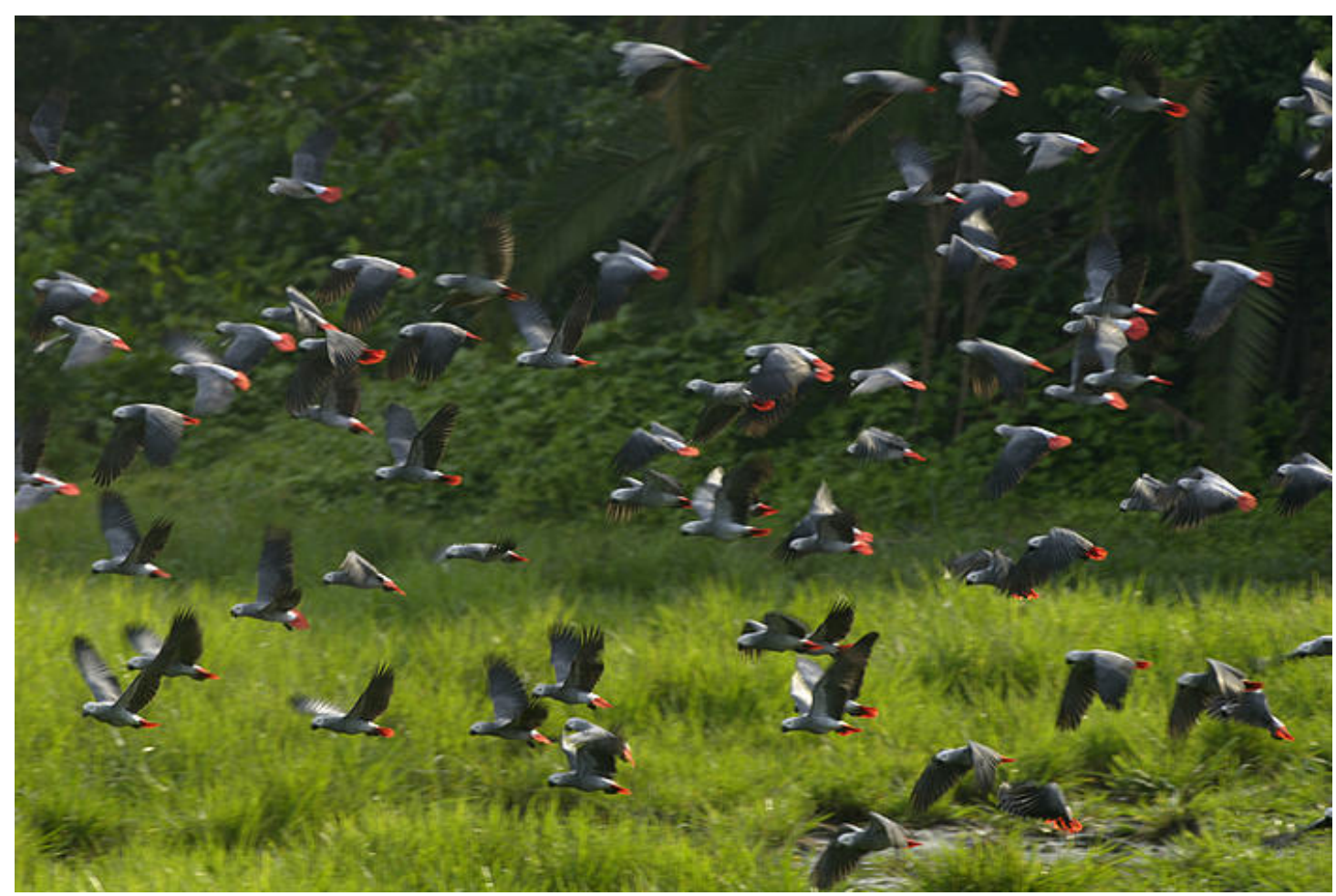

Worldwide Fund- Jenji Project 


\section{The Baka face impoverishment}

Five major impoverishment risks have been identified in the case of Baka conservation refugees in and around the three protected areas mentioned above in south-east Cameroon. These are the risks of landlessness, marginalization, loss of access to common property, social disarticulation and loss of biodiversity.

\section{Landlessness}

The creation of protected areas might affect user rights of the Baka and their right to what they consider "their ancestral lands" might be determined by the establishment of a land certificate in the name of the state. The law requires that such an issue should be widely publicized in order to warn them of the change. The normal advance notice period is 30 days for areas with land management plans and 90 days for areas without land management plans. Within this period the local population can lodge complaints to the local commission in charge (Egbe, 2001). This law is problematic because; Compensation mentioned is hardly ever paid to the displaced Baka; it is difficult to quantify the user rights accorded local communities so as to determine the compensation due to the Baka and Compensation for lost land is only possible where the owner holds a land title deed.

Considering that only about three percent of rural lands are registered, the displaced Baka are not compensated for loss of their ancestral lands. The situation is even more serious for the Baka because none of them holds recognized customary rights in the permanent forests that are home to their former villages. Since their sedentarization, they are simply "lodgers" on Bantu territory. They enjoy no rights to the land while their traditional rights to their former lands are ignored under forest law, which limits their access and usage of forest resources 
(Nguiffo, 2001). The following quote from a Baka elder displaced from Mabe in the Dja Biosphere Reserve illustrates this problem of loss of land:

[When we came back from Essea and Dja we came to live in Mabé, in the heart of the forest. This area is very good for us. We were not doing agriculture, only gathering fruits and hunting. This lifestyle lasted a long time without changes. Some time later, villagers came telling us that they did not want us to stay in the forest; they wanted us to stay in the village with them. We discussed with our grandparents, and every time people from the village came they'd bring us salt and we'd give them meat from wild animals. Life continued like this for a long time. They started by attracting us to the villages, up to their cocoa plantations. We lived in the plantations for a long period, up to 140 years. We stayed with those people, they kept us. Then afterwards they told us that we should live in the villages, and we went to live there. They showed us a plot of land where we could live and carry out agriculture. They showed us how to cultivate crops, and we learned how to do it progressively. This lasted for a long time. These elders who brought us, some of them have died. Now only their children and brothers are alive. So they've said now that we cannot live on the plot of land where we are staying. When we were in the village we thought we still had land rights in Mabé where we came from. When we went back there to hunt and gather fruit we found the authorities refused us access. They said we cannot hunt, fish, not even gather fruits. We are not allowed to do anything in our former land of Mabé. We were afraid, because we had no powers to claim, to demand from the authorities. So we came back. And if we went back to that land, we went there like thieves, hiding. If those people were to see us they'd kill us or do something very dangerous to us. We do not understand ... The law took everything from us . .. We therefore request help ... to move forward and solve our problems, so that we can also 
have the courage to defend ourselves and our rights] (Jean Bosco Eyinga in Ndameu, 2001, Page 237).

\section{Marginalization}

The interethnic relationship in the region reflects the demographic situation with the Bantu ethic group being the more dominant ethnic group in many areas where the displaced Baka have settled. This has in turn exposed the Baka to an ideology of domination by the Bantu people characterized by a master-slave relationship as Oyono (2004) presents it. The relationship between the minority Baka and the more dominant Bantu is a relationship of inferiority and superiority, scorn and condescendence, which contributes to the marginalization of the Baka by their Bantu neighbours (Mvondo and Sangkwa, 2009).

There is gross marginalization of the Baka when it comes to redistribution of forest revenue. This redistribution is mostly done through the local council but a look at the representative structure of one of these councils reveals a sad picture for the Baka. This redistribution of forest revenue is part of an ongoing decentralization process in Cameroon. However, the current model of fiscal decentralization has strengthened the powers of the more influential actors such as mayors, instead of promoting more equity in the sharing of roles and responsibilities, as well as transparent mechanisms of representation of local people in management committees (Neba, 2009). The Dimako rural council for example in East Province of Cameroon is made up of 17 villages. Among the 17 village representatives, there is no delegate from the Baka-Pygmy community. In other words, Baka villages in the local council are represented instead by Bantu tribes within the commission. All 25 Councilors in the local council are Bantus (Mvondo, 2006). Village representatives are selected based on networks of influence rather than on their legitimacy and ability to represent their 
communities which leads to the marginalization of the Baka. In a related case, the Worldwide Fund recruited and trained 26 forest guards in the Lobeke area. Among these 26 guards only two of them were Baka and the rest from the Bantu tribes (Usongo and Nkanje, 2004). This is clearly inequitable considering the fact that there are 2,500 Baka and 2,800 Bantu in the area (Usongo and Nkanje, 2004). It is therefore not surprising to hear the Baka affirm that they are never consulted on any conservation or development projects in the area. The Baka are only involved in manual forest logging activities and do not participate in any decision making over forest resources.

Financial revenue from logging activities in another Ngola community forest in the Dja area amounted to 47,748 Euro. This money was spent on; 3000 sheets of sheet metal for the roofing of 45 houses, a satellite dish, a television set for the community with cable television, national identity cards for some members and all the Baka pygmies got was food aid and some soap (Mvondo, 2006). This low level of decentralization results in low competence of civil servants at councils and other levels in dealing with marginalized Baka minorities. It comes as no surprise though to learn that most Baka do not have national identity cards or birth certificates - according to a survey organized by an NGO, less than $10 \%$ of the Baka have ID-cards so most of them without are unable to interact on a legal basis with governmental services (Schmidt- Soltau, 2003).

The displaced Baka are often victims of abusive work exploitation on the farms of their new Bantu landlords for little or no pay. Their pay is sometimes in the form of strong alcoholic drinks, which are very harmful to their health (Shikongo, 2007). The Bantu consider them as inferior people and will rarely intermarry. Many Bantu landlords and employers consider their Baka employees as their property and they do not tolerate strangers especially NGOs 
talking to them directly without their authorization (Shikongo, 2005). A Bantu chief is quoted by Shikongo as saying;

[I have 20 Pygmies that belong to me who are causing me more and more problems] (Shikongo, 2005, Page 45)

Even when it comes to day to day wages, the displaced Baka still earn less than other ethnic groups for the same job. The daily wages paid to the Baka are for example between the range of 250 Francs CFA (USD 0.50) and 500 Francs CFA (USD 1) per day, whereas a member of the Bantu ethnic groups will earn at least 1,000 Francs CFA (USD 2) per day for the same days labour (Nguiffo, 2001). The Baka are not able to generate more than 30 percent of the annual cash income of their Bantu neighbours. Schmidt-Soltau (2003) notes, while the Bantus are able to generate about 100,000 Francs CFA (USD 150) per capita per annum, the Baka can only generate about 30,000 Francs CFA (USD 50). As a result of these low incomes, coupled with the fact that the normal healthcare system is based on advanced payment of consultation fees and medication, the Baka find it difficult to afford healthcare (Schmidt-Soltau, 2003). This is made worst in cases where they do not have access to the forest anymore due to conservation so, cannot fall back on traditional medicines acquired from forest plants. Their low income also explains why most Baka cannot afford ID-cards which cost about 15,000 Francs CFA (USD 25) each, about half their annual per capita income according to Schmidt-Soltau (2003).

This marginalization of the Baka is evident in the establishment of protected areas in their areas without their free, prior and informed consent. This was the case with the Boumba Bek/Nki National Park as Ndameu (2001) pointed out. In terms of the procedure for classifying the Boumba forest as a protected area, the project had undertaken to complete a 
number of activities with the participation of the local people. They were to have had an equal involvement in the establishment of the Boumba Bek/Nki National Park for example. However, the Baka assert that they were not told about it all until after the boundaries had been put in place. As one Baka commented:

[We didn't know anything about it; but we learned that the government had set boundaries. We didn't agree with this because from the start they had not told us anything and when setting these boundaries they did not inform us, as they should have done.] (Ndameu, 2001, Page 231)

If one accepts this declaration, it is entirely possible to say that the process of consulting local peoples was not carried out in an 'optimal manner' as the law requires. The project simply limited itself to public information campaigns about the decisions which had already been taken with respect to the establishment of the protected area. MINEF (Ministry of Environment and Forestry) Notices 1238 and 1239, in establishing this forest as zoned for public use, further reinforced the restrictions on movement for the Baka in the Boumba Bek/Nki National Park (Ndameu, 2001).

The approach of community participation in the management of natural resources with an integrated conservation and development focus exists to a limited extent in the Boumba Bek/Nki and Lobeke Parks. Even when there is an attempt to bring in an integrated conservation and development approach, the "top-down" method still prevails with project workers and the authorities giving directives in accordance with decisions taken at the level of their superiors. The Baka have little say in decision making as their views are marginalized during consultations on issues concerning park management schemes although 
on paper these schemes were supposed to enable local involvement and empowerment (Nelson, 2003).

Some opportunities for dialogue between the local people and the conservation authorities were created in the Boumba Bek-Nki and Lobeke area in order to discuss joint management of the future of the park. However, the Baka were never considered as a separate community with the right to submit their grievances to the Boumba Bek Contact Group. When they did attend discussions, the resolutions put forward only contained grievances of the Bantu, who spoke for the whole community. Experience in the forest zone shows that there has never been an equal relationship between Bantu and Baka in situations where the two communities have had to join forces to express their points of view (Ndameu, 2001).

There is marginalization of the Baka when it comes to usage rights in and around the protected areas from which they have been displaced. This applies to the apparent double standards applied to conservation and the rights of usage. Shalukoma in a panel discussion reported in Ndameu (2001) that the Baka are the biggest losers in terms of use rights, as they are refused permission to hunt in the name of conservation, but sport hunters are allowed to come in and hunt. The Baka are deprived of resources in their forest but there are others who commercially exploit these forests unsustainably. The Baka cannot be happy when they see these double standards in conservation so this makes it difficult for them to understand the sense and fairness in conservation. There is a poaching problem in the protected areas under study mostly by non-Baka organized poaching gangs who avoid arrest even though everyone knows who they are, yet the Baka will be arrested for subsistence hunting (Shalukoma in Ndameu, 2001). The point is that the Baka are being punished for crimes committed by other people. This upsurge in poaching comes about as a result of an increase in the value of bush 
meat (seen as embodying the "power of wild nature") which is not available from domestic meat and fish (Ichikawa, 2006). Residents of large cities prefer bush meat to beef and pork and often have no trouble in paying the higher prices.

\section{Loss of access to common property}

The public information campaigns forbidding entry to the park by law (Plate 13) have not been well received because they limit the Baka's access to common property which is the forest and all the resources therein. In Baka culture, large fruit tress for example, Irvingia and Baillonella, belong to the community members, so in the context of conservation the Baka consider such trees in protected areas their own, which causes conflict with the law and conservation agencies. Ashley and Mbile (2005) cite a case in the village of Meko'o Mengon in which villagers had hectare stands of bita kola (Garcinia kola) before the area became a reserve but today the trees have now been cut off from their use within the boundaries of the Dja Reserve.

Forest guards charged with prohibiting entry into reserves have lost the trust and respect of the local Baka population. This is the case with the Boumba Bek/Nki reserve where the Baka feel they have become the target of forest guards, against whom there have been serious allegations of human rights abuse. Such allegations include extra-judicial beatings of people found inside the park, anyone found hunting near the park, and virtually anywhere they are encountered (Nelson and Venant, 2008). These effects of guards' behaviour in protected areas are discussed in Callister (1992) who tells a common story: the guards' insufficient psychological and material authority can create an ideal atmosphere for corruption in the form of collusion, collaboration and bribery. Though such corruption might be perceived as 
insignificant, the cumulative effect on a protected areas and its management can be devastating in the long-run.

The Baka can justify their need for mobility in the forest in terms of the products they need to gather for their survival (wild yams, game, honey and medicinal plants). This activity requires freedom of movement, and repudiates the restrictions imposed under the project. Yesterday's fears are perceived by the Baka as tomorrow's threat to the customs that constitute the basis of their existence (Ndameu, 2001). Mobility is one factor in the enjoyment of usage rights. It is fundamental to Baka society, marked as it is by a dependence on the riches of the forest and by the various rites that constitute an important element of respect within the community.

The displaced Baka have not been provided with alternative sources for their traditional demands for firewood, bush meat, fruit trees, medicinal plants and farm lands for example. The Baka have been penalized by the setting up of park boundaries in that their ability to roam around their forest and collect forest products has been limited with the displacements. Though some of them might still hunt or collect forest products illegally from the reserve, they understand the consequences of getting caught. 
Plate 13: An illustration of restrictions on access to common property in Lobeke National Park

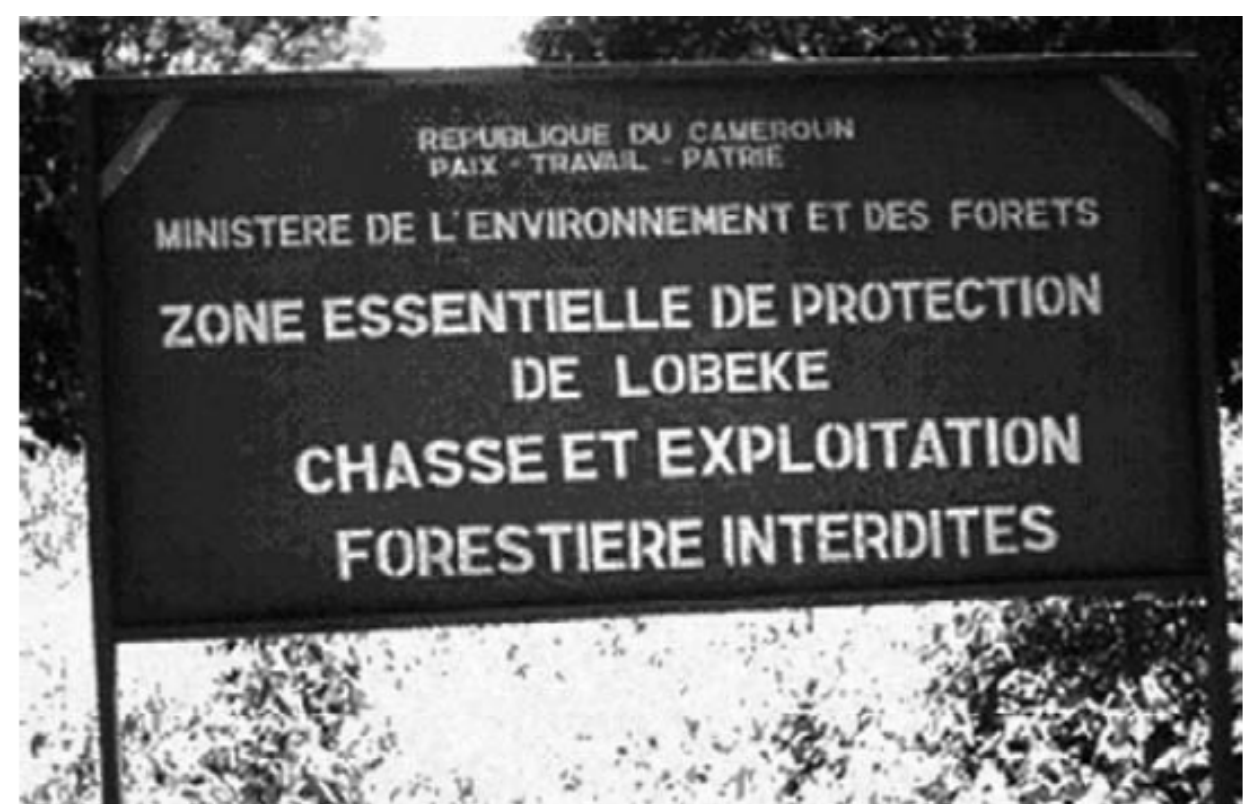

The signpost basically says "Lobeke Protected Area. Hunting and collection of forest products is forbidden". (Ndameu, 2001: Page 229)

\section{Social disarticulation}

The Baka normally hold large religious festivals known as jenji in honour of the forest god jenji. This ceremony which is held deep in the forest is the most important part of Baka ritual life, not only because of the affirmation of the cohesion of the community, but also because this is the time for initiation of boys into manhood (Bahuchet, 1991). With eviction from the forest there is the loss of this culture of initiation because the Baka are not allowed into some parts of the forest where they traditionally practiced jenji. Also, the decision making process at community level with the Baka is in the form of searching for a consensus among all elders of the various bands in the community (women are hardly ever involved in the decision making process even when they are the focus of discussion). For external affairs (interaction with foreigners and government officials) each band appoints a leader-like person known as kokoma. The kokoma is supposed to be a leader for external affairs only and 
is not supposed to have any authority within the community (Schmidt-Soltau, 2003). However with displacement, there is a socio-political organization above the level of the band which does not go along with the traditional consensus approach of social interaction. Younger people who have learned to speak French and have good relations with government officials and Bantu chiefs have assumed the kokoma position and become more influential in some resettled communities than elders. No amount of compensation can make up for this social disarticulation as a result of the displacement of the Baka.

\section{Risk of biodiversity loss}

The displacement of the Baka has created a renewed risk to biodiversity in the areas in which they have been forced to resettle around the periphery of the three parks. These fringe areas are recognized as mixed use zones with unlimited use. This refers to forests no further from the settlements than 10 kilometres or so from the village huts. These areas have become overexploited now that the Baka are sedentary and settled next to the main roads, and are of no use whatsoever because Baka remain reliant on finding food in the areas that are still fertile, where nature has not been 'violated' by the many actions of man (Ndameu, 2001). This has seen some Baka resort to poaching as a way of defiance to the authorities restricting their access to resources in the protected areas.

The decree setting out the procedures for implementing the wildlife regulations in Cameroon defines poaching as:

[The act of practicing the slaughter and capture of whichever species of wild animals for commercial gain] (Ndameu, 2001, Page 228)

The struggle for survival by Baka who have lost a source of livelihood due to displacement a corollary the promotion of a market for bush meat in the large cities. In the Boumba Bek/Nki 
region, the local peoples - the Baka and the Bantu - went along with this, attracted by the profits. They would sell off the product of their illegal activities through 'intermediaries' (who are mostly truck drivers of the logging companies) for money and sometimes for modern hunting weapons. Forest edge resettled communities have also resorted to exchanging game meat and skins for the cash needed to purchase consumer good and to pay for health care and school fees. The displaced Baka have also used their skills and knowledge to assist non-Baka hunters in their poaching, receiving income and other material benefits in return (Ndameu, 2001).

To conclude, what Cernea and Schmidt-Soltau (2003) refer to as impoverishment risks are actually impoverishment facts with the Baka. Faced with these impoverishment facts through the decisions taken about managing natural resources, the Baka's reaction has been in some cases not to respect them. The Baka seem to reject the dominant socio-political system by their passive participation in meetings or nonattendance altogether (Mvondo and Sangkwa, 2009). They seem to be saying to the authorities:

[Since you reached these decisions without us, we will go about our business without paying any attention to them, or to you]. (Ndameu, 2001, Page 233) and;

[We have no choice but to continue hunting, even if we are prohibited to do so]. (Ichikawa, 2006, Page 18)

The law states that all land should be under the exclusive control of the State and this constitutes a major problem for the Baka. The application of this logic could well mean the loss of forest myths and culture, and the loss of the idea that freedom and permanence are elements fundamental to existence, if establishing protected areas becomes synonymous with restricting this freedom. The difficulty in achieving a protected area management plan that 
will be respected by the Baka is a point of concern to conservationists working in the three parks. The government of Cameroon endorsed the Declaration on the Rights of Indigenous Peoples as well as other declarations protecting the rights of indigenous peoples but as is typical of most governments around the world, respect for these declarations leaves a lot to be desired.

Local conservation authorities in the area have so far found few adequate local incentives to prevent the trade in illegal bush meat, and governance of the logging sector in Cameroon has been chronically weak (Nelson, 2003). The director of ECOFAC (Central African Forestry Ecosystems) stated that though he is opposed to the idea of people hunting and living in the Dja Reserve he cannot always prevent this as his organization lacks the resources to effectively enforce legislation (Ashley and Mbile, 2005). So, legality aside, some people enter the forest and exploit resources and as Ashley and Mbile (2005) stated, what has been lost is not the Baka's access to resources within the protected areas but the right to access these resources so the Baka have become illegal resource users in a forest which is their ancestral home. The conservation priority of the international conservation community has continued to override local Baka livelihood concerns and their customary rights, rather than target commercial trade in bush meat and backing it up with strong enforcement measures. The protection measures now in place seem to target those with the most to lose who in this case are the Baka (Nelson, 2003). The story of the Baka conservation refugees is similar to that of the Ogiek in Kenya. 
The Ogiek Conservation refugees of Kenya

The Ogiek are an indigenous hunter-gatherer community with a population of approximately 20,000 people (Ohenjo, 2003). Today, they occupy the Mau Escarpment and Aberdare around the Rift Valley, as well as part of the Mt. Elgon Forest in western Kenya (see Figure).

Figure 7: Map of Kenya showing the Rift Valley and the Mau Forest Complex Inhabited by the Ogiek

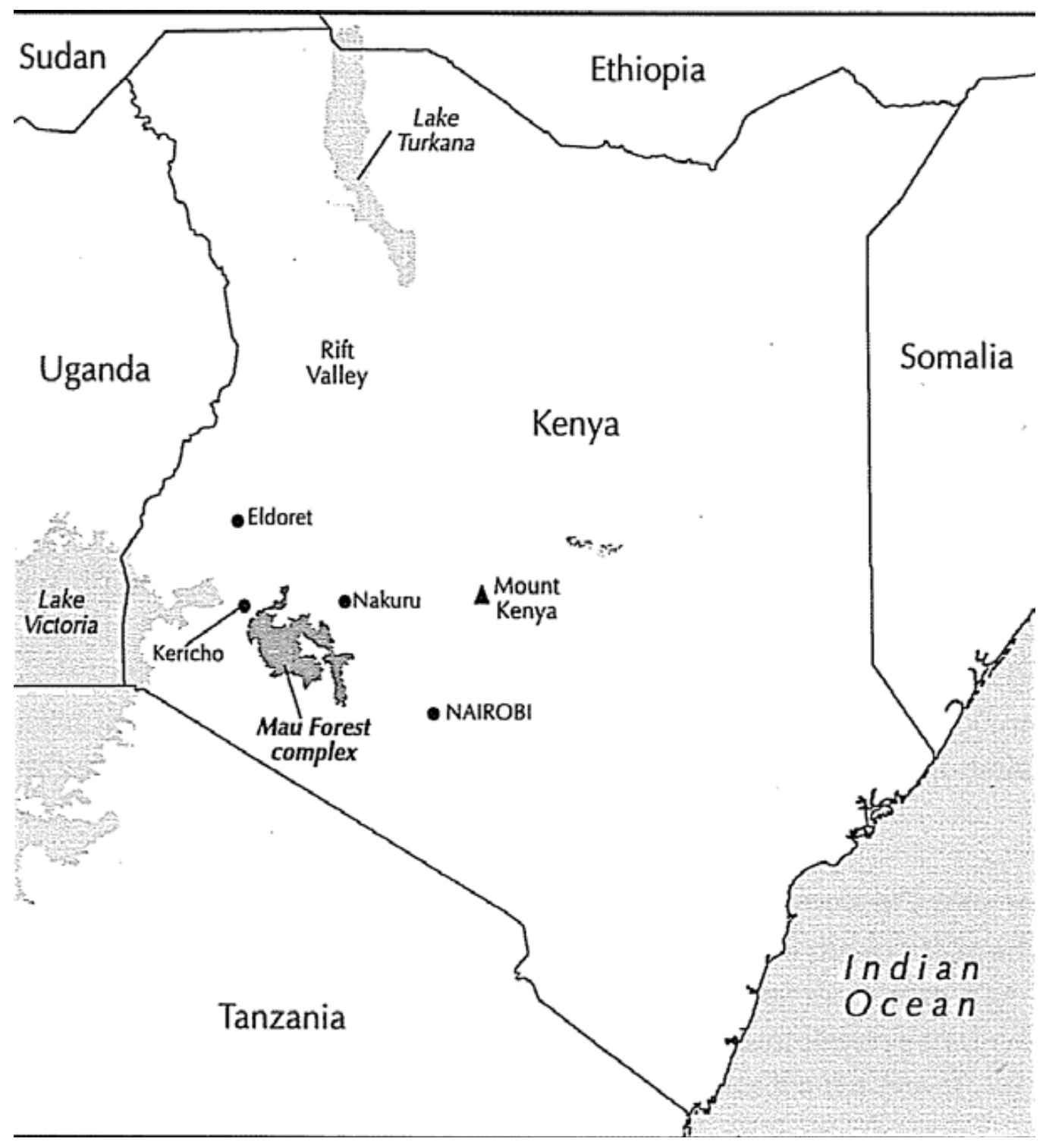

Oundo (2008, Page 9) 
From the early 1900s onwards, successive governments have tried to evict Ogiek communities from their ancestral lands without consultation, consent or compensation (Ohenjo, 2003). They have been excluded from development plans and pushed onto land that is not suitable for their way of life. The destruction of forests in Ogiek-inhabited areas, and the displacement of Ogiek people have occurred as a result of: logging, especially from the 1990s onwards; government evictions; development projects, such as the establishment of Mt. Elgon Game Reserve; and the cultivation of land for export crops by private individuals, which is permitted under existing land laws for cultivation of export crops and flower farming (Ohenjo, 2003). Having lost their traditional occupation which is hunting and gathering (see Plate 14), the Ogiek themselves have been forced into cultivation farming, though they lack the necessary skills.

\section{Plate 14: An Ogiek hunter}

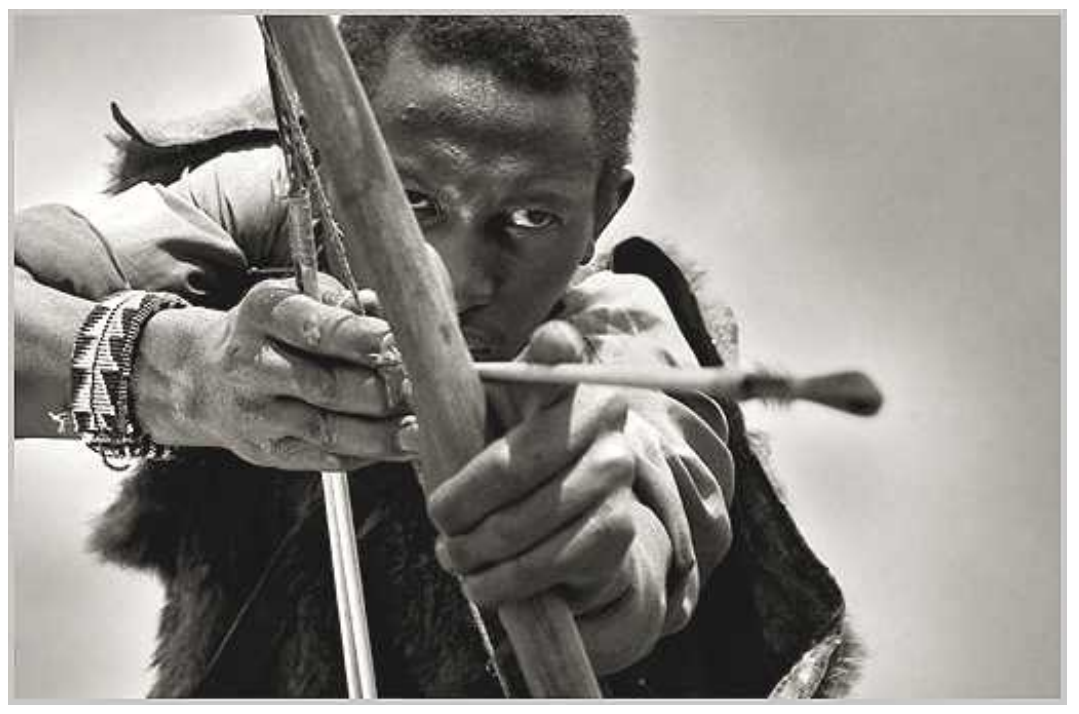

www.ogiekpeople.org 


\section{Legal framework in place}

There are more than twenty laws in Kenya pertaining directly to land, and at least an equal number that deal indirectly with land. Land legislation can be categorized into three areas: trust land; government land; and private land (UNHRP, 2009). Trust land comprises 65 percent of all land in Kenya and it is difficult to determine how much trust land actually remains. Trust land was established ostensibly to protect the land rights, or at a minimum the usufruct rights, of indigenous peoples. However, it has not had this effect. Through a variety of laws and mechanisms, trust land has been taken from indigenous peoples. Government land includes land reserved for the use of Government and the land within forest reserves outside trust land areas. Government land is vested in the President who has the power to make grants and dispositions of any estates, interest or rights in or over this land. Private land is communally owned land which could be subdivided into individual plots, allowing the land to be privately owned with freehold titles. To purchase this land, prospective buyers would make deals with groups of community representatives who would sell the land (UNHRP, 2009).

Informal settlements or slums that are established on Government land can be subject to demolition or eviction if they lack sufficient political patronage and cannot secure a 'temporary occupation license' (UNHRP, 2009). In other words, security of tenure in informal settlements has less to do with law than with politics. As a result of the legal system which restricts the access to resources, the Ogiek face impoverishment risks. 


\section{Ogiek facing impoverishment}

Impoverishment risks faced by the displaced Ogieks include; landlessness, marginalization, social disarticulation and risk of biodiversity loss.

\section{Landlessness}

What constitutes Government land has been disputed by the Ogiek who have challenged the excision of parts of the Mau Forest by the Government and its allocation to select persons who are currently in the government's favour. The shift in Kenya from communal to private land ownership has had negative effects on the Ogiek. For example, in several High Court cases it has been determined that once land has been privatized and registered under the Registered Land Act, the customary rights of access of others on that land are extinguished (UNHRP, 2009). In turn, in cases where a group representative converts indigenous lands to private registered lands, all of the group members would lose communal rights to the land and thus would be forced to find alternate means of sustaining a livelihood (UNHRP, 2009).

\section{Marginalization}

The literacy rate for Ogieks is the lowest in Kenya, at approximately 20 percent (UNHRP, 2009). Overall, Ogiek communities receive inferior education to other communities and school curricula do not recognize or teach traditional forms of economic production. Dropout rates for the Ogiek are especially high at secondary level. Primary schools are few and far between with no secondary school specifically serving the interests of Ogiek children. As a result, many of them who finish primary school have to go to boarding schools far away (Ohenjo, 2003).

On health matters, displaced Ogiek communities are also disadvantaged. They are particularly vulnerable to HIV because of a lack of accurate information, and traditional 
practices such as polygamy, female genital mutilation or circumcision, and ritual cleansing which refers to a widow having sex with a man of low social standing, upon the death of her husband (UNHRP, 2009). In addition, the health standards of the Ogiek have deteriorated drastically over the years because they have been barred from accessing medicinal plants in the forest. Most have no money to obtain adequate health services, for example in Mau there is only one doctor for every 6000 people (Ohenjo 2003).

Most tribes in Kenya have at least one tribal member who is either a member of Parliament or Government official - or is in close contact with one or the other, except the displaced Ogiek - who have no voice beyond the nongovernmental (NGO) level to raise their issues; as one would expect, this has left the Ogiek quite marginalized in Kenyan society (Corrie, 2009).

\section{Social disarticulation}

Forced eviction invariably leads to the dislocation of Ogiek families as men and widows migrate to the cities in search of employment and a place to live. While Ogiek people living in the cities gather regularly with other Ogieks in an effort to preserve some of their traditions and social structures, they have been unable to prevent the devaluation of tribal structures, such as the authority of the elders (UNHRP, 2009). This social disarticulation however is good to some segments of the Ogiek population especially the women who are powerless under tribal structures. Upon displacement, while Ogiek women lose the security of traditional rural life, they clearly gain a sense of personal freedom, empowerment, and independence from life in the city. 
Risk of biodiversity loss

Kenya largely relies on the waters that flow from the Mt Elgon and Mau forest areas which are Ogiek ancestral lands. Mt Elgon and Mau forest contribute about 50 percent of Kenyan freshwater supply (Ohenjo, 2003). By seemingly allowing unhindered logging and excision of forests in the Ogiek areas while displacing the indigenous Ogiek population, the Kenyan government violates the principles of sustainable development and exposes the catchments area to unsustainable natural resource exploitation (see Plate 15).

\section{Plate 15: Logging in the Mau Forest from which the Ogiek have been displaced}

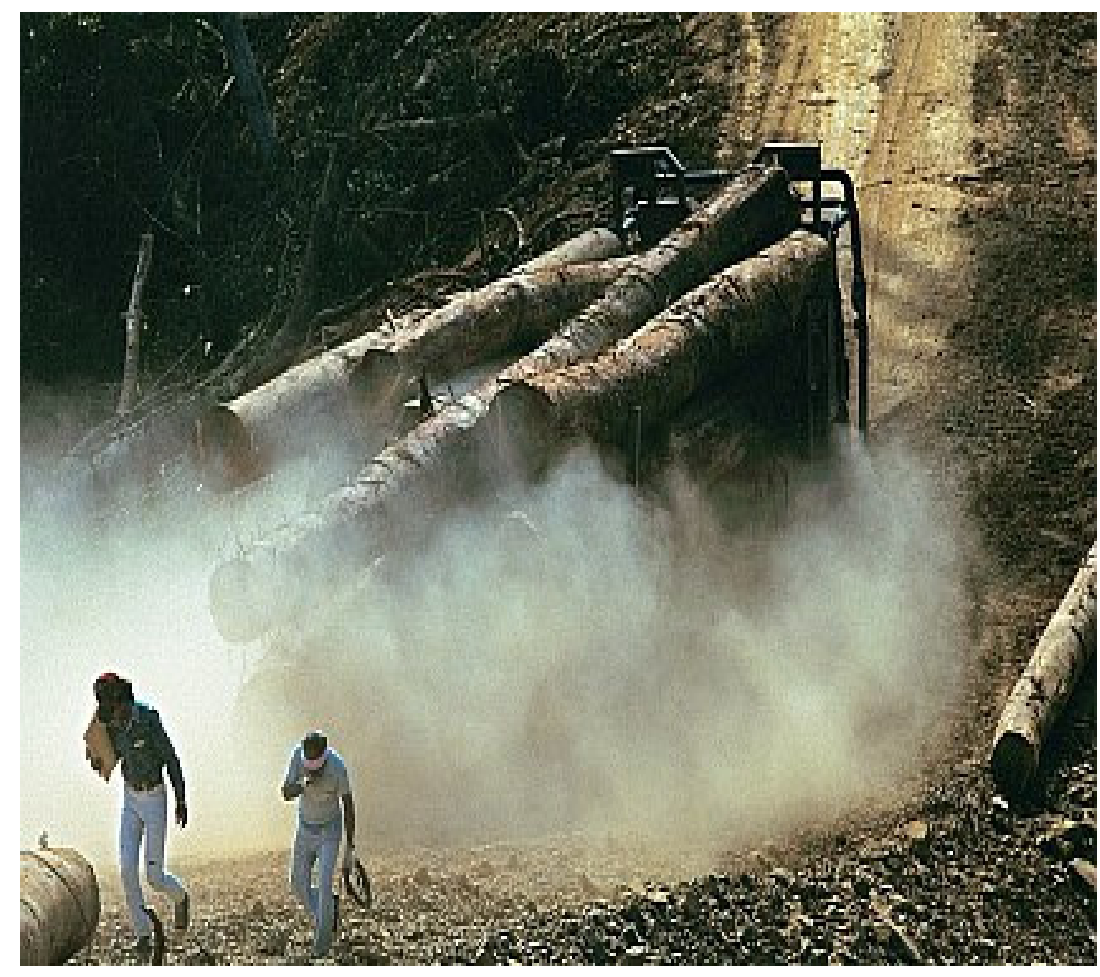

www.ec.europa.eu

Ogiek traditional economic systems have very low impact on biodiversity (Ohenjo, 2003).

For example, beekeeping is an important activity to the Ogiek communities and the bees help in pollination and regeneration of the forests (Ohenjo, 2003). Displacing the Ogiek beekeepers certainly has had negative effects on pollination and the forest ecosystem. 
To conclude, there is no indication that the plight of the Ogiek will be resolved in the near future. In 2003 the Kenyan Minister for Land and Settlement met with representatives of the Ogiek and committed to resolving their plight (Ohenjo, 2003). The Minister suggested that the Ogiek form land resettlement committees amongst themselves to assist the Government in resettling them on lands from which they had been evicted. Soon thereafter, the Assistant Minister for Environment and Natural Resources, in a ministerial directive, ordered that the Ogiek, be allowed back to their ancestral lands in the forest (Ohenjo, 2003). However, as late as June 2005 the Ogiek still face a constant threat of eviction (see appendix 4 and 5) and by 2009 it was confirmed that the Ogiek could be evicted from the Mau Forest by the end of the year. They were to be served with eviction notices by the $26^{\text {th }}$ of November 2009 (www.survivalinternational.org). This was followed by Prime Minister Raila Odinga's announcement that the Ogiek must be evicted from the Mau forest immediately to prevent irreversible damage to the ecosystem in early 2010 (Morgan, BBC- Kenya, 2010). On the $9^{\text {th }}$ of April 2010 a video was uploaded on www.youtube.com showing Ogiek houses torched in Mau forest evictions as well as interviews with Ogiek victims courtesy of www.survivalinternational.org. This shows that the word of the Kenyan government cannot be trusted as far as eviction of the Ogiek is concerned. Promises by the Kenyan government to halt the eviction of the Ogieks in the past have not been honoured (See Plate 16). Therefore, the Ogiek will continue to be conservation refugees in Kenya. 


\section{Plate 16: An Ogiek woman in front of the wreck of what used to be her house destroyed by guards sent to evict her community in Kenya.}

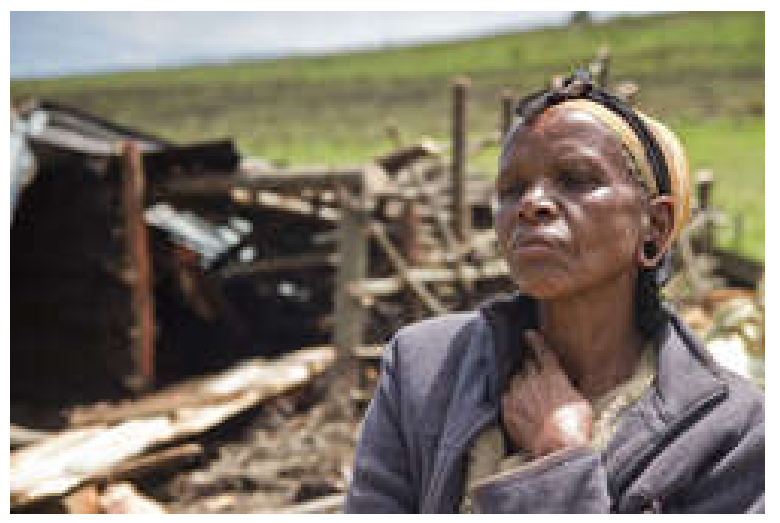

Survival International (2009)

\section{Conclusion}

The threats faced by the Baka and Ogiek people are similar to those of most hunter-gatherers around the world. Non-recognition and small population numbers make them politically vulnerable and open to marginalization. The Baka and the Ogiek face the same impoverishment risks as particularly loss of lands, marginalization, social disarticulation and loss of biodiversity. Forests are also being targeted by both logging companies and settlers looking for more farmland but the indigenous Baka and Ogiek carry the blame for unsustainable use of the forest by other groups. The only difference between the Baka and the Ogiek refugees seems to concern biodiversity loss. With the Baka the threat to biodiversity is more evident in the resettlement zones than in the reserves from which they have been displaced. However, with the Ogieks the threat to biodiversity is more evident in the reserves from which they have been displaced through uncontrolled exploitation by other groups and a decrease in pollination. 


\section{Chapter Seven}

\section{Conclusion}

This chapter will present the major findings of this study, identify knowledge gaps for future research, and make recommendations on what needs to be done to address the difficulties faced by conservation refugees.

\section{Findings}

Firstly, the concepts of indigenous people and conservation refugees have often been used interchangeably in literature without enough evidence to support the link. Chapter three showed that although not all conservation refugees are indigenous peoples, it can be said that most of them are indigenous peoples and share all or most of the characteristics of indigenous people (Chapter 2). Most conservation refugees are indeed indigenous people.

Secondly, the policy background of the conservation project promoters is more important in influencing evictions than the policy background of national governments. Chapter 4 shows how national governments are being taken advantage of by conservation organizations that are able to impose their will on developing countries because they wield so much financial power. These international conservation organizations are not able to wield the same power in developed countries because governments and the population in developed countries are richer, more powerful and more capable of defending their rights. The developing countries however where most international conservation NGOs impose their will constitute about 60 percent of the world's poorest people (Geisler, 2002). In these areas an estimated 75 percent of the populations live below the poverty line of US\$ 1 per day (Sayer et al. 2007). In chapter four I present the case of Worldwide Fund and World Bank, behaviour that illustrated just how the degree of enforcement of regulation in protected area creation and 
displacement depended on which side of the conservation/ICDP divide the promoters of protected areas belong.

One of the major limitations of international conventions and declarations is their inability to influence national governments and their legislatures. National governments consider these declarations and conventions mere guidelines with no obligation to implement them. This view is supported by Dowie (2009) who admits that the UN General Assembly and Declaration on the Rights of Indigenous Peoples contain many articles relevant to rightsbased conservation, but implementation has lagged behind declarations and policies. The assumption here is that the number of evictions will decrease if governments paid more attention to the contents of international declarations and conventions aimed at protecting indigenous people. In chapter three I presented arguments with the example of Latin American countries having fewer evictions because of better national legislature to accommodate the rights of indigenous peoples. Other countries may also experience a reduction in evictions if they follow the Latin American example. This goes to validate hypothesis three of this which states that global figures of conservation refugees will decrease if international laws and declarations are well implemented.

Hypothesis four states that resettlement schemes which ignore the host population are bound to fail. However, there has not been enough evidence to support this statement despite the claim by Cernea and Schmidt-Soltau (2003) that, when the new neighbours speak a similar language, belong to the same ethnic group or are even the same, the risk that the resettled 'spiral on a downward mobility path' is less. Resettlement schemes in current literature such as Korup and Noubale Ndoki fail to say anything much about the host population. To the best of my knowledge one of the only two case studies on resettlement which present significant 
information on resettled/host relationship is the Karuma Reserve resettlement scheme in Uganda. In this case, the host population voluntarily offered land on which to resettle the people transferred out of the Karuma Reserve. According to Kabananukye (1998), this was because the communities living inside the reserve were not significantly different (in terms of culture) from their host neighbours. Another case study from the Baka in Miatta village displaced by the Dja Biosphere Reserve Project (Cameroon) has shown that homogeneity in culture is not necessary for reduced friction between hosts and resettled. In Nguiffo (2001), the Baka in Miatta displaced from Mabe in the Dja Reserve were offered land to settle by the host Bantu community in Miatta not because of homogeneity in culture. In this case the Baka are culturally very different from the Bantu but this display of Bantu hospitality was mainly because of the economic benefits to the Bantus which come with having the Baka living next door. The Bantu community benefited from the Baka's free labour, their supply of medicinal plants and reduced price for game (WRI, 2003). The Miatta case shows that vested economic interests can also ease peaceful coexistence between hosts and resettled populations not only homogeneity of cultures. In this regard, hypothesis four will be accepted only partially on the grounds of lack of sufficient evidence.

In a related case, this study shows that voluntary resettlement only exists in theory. This is because defining voluntary or involuntary resettlement based on whether the resettled had or have the option to stay is wrong because as Perez (2002) reminds us, one always has an option to stay: even at gun point or even when the house one lives in is set on fire. The next question which should be asked is what happens if one decides to stay? What are the repercussions of deciding to stay? That is how I come to the conclusion that all resettlement is involuntary. 
Compensation schemes which ignore livelihood issues and do not effectively consider the sustainable outcomes to the local population are not sustainable. This is most evident with cases in which financial capital has been used as the major method of compensation. The shortcoming in this argument is that most conservation refugees are incapable of transforming financial capital into the social and physical capital necessary for their livelihood so, like the proverb goes; "It is better to teach a man to fish than to provide him with fish everyday". That is the reason why resettlement schemes such as Korup in Cameroon and Noubale Ndoki in the Republic of Congo failed in the long run when funding for these schemes stopped (see chapter 5). This goes to validate hypothesis five which states that Compensation schemes are only successful in the short-run

It is difficult to understand how conservation measures applied by John Muir and the state of California in the $18^{\text {th }}$ century can still be applicable in the $21^{\text {st }}$ century in Africa, Asia and Latin America. John Muir's argument for the eviction of American Indians from the Yosemite area was based on his belief that, "they were ugly and hideous, ate strange things and did not meet his standard of dignity" (Dowie, 2009). Based on his argument it can be said Muir was not only mean and degrading to the Indians but his ideas could also be considered to be some form of ethnic cleansing if not racism. This view is further strengthened by Dowie (2009) who said the US army sent in to enforce legislation designating Yosemite as a National Park and evict people living within the boundaries was asked not to arrest white shepherds in the area. The Indians were accused of slaughtering buffalos so considered to be a threat to the ecosystem of the area.

Hundreds of years later, similar arguments are being used to evict indigenous people from the forest of Africa and elsewhere to create room for National Parks. If we take the example 
of Bwindi National Park for example, 1700 Batwa pygmies were evicted based on just rumors that they were killing and eating endangered mountain gorillas (Dowie, 2009). Nobody listened when the Batwa argued that the gorillas were being killed by Hutu and Tutsi ethnic groups as well as rebels from neighbouring Democratic Republic of Congo who frequently cross the border into Uganda (Shikongo, 2005). Indigenous people like the pygmies of Equatorial Africa are still being regarded as sub-humans by their own countrymen just as American Indians were regarded as sub-humans in the early evictions in Yosemite, California. This goes to validate hypothesis six of this study which states that the globalization of Western conservation practice is to blame for the Conservation refugee crisis in the developing world. There is the case of a Congolese government official referring to the expulsion of the Babenzele Pygmy group from Nouabele Noki National Park in the Republic of Congo as not an "issue", racially labeling the Babenzele and declaring:

[With our speaking beef (the local racial nickname for the 'pygmies') we can do whatever we want] (Cernea and Schmidt-Soltau, 2003) 


\section{Knowledge gaps for further research}

As Fabricius and de Wet (2002) point out, people's expulsion from biodiversity-rich areas renders their attitudes vis-à-vis conservation and conservationists increasingly negative, with measurable increase in poaching and unprecedented incidents of natural resources being vandalized, often accompanied by land invasions. However, there has been no quantitative study to assess illegal resource use by conservation refugees around national parks from which they have been displaced. It is difficult to know how much setting aside of protected areas has contributed to biodiversity conservation. Various studies of protected areas provided basically exaggerate their effectiveness and this generalization hides a wealth of details and variations which prevent precise statements about the marginal gains from strict conservation, gains from partial protection and how such gains can be balanced against the losses to those displaced from protected areas (Hayes, 2006). The decision to displace people for conservation tends to be based more on rhetoric than on facts since site-specific studies have not been carried out a priori to quantify the threat to protected areas from the local population before considering displacement as the most viable option. Studies have seldom focused on the extent to which the assumption that people are bad for protected areas is systematically correct. Therefore such generalizations asserting an inescapable conflict between biodiversity conservation and human presence in protected areas are no more accurate than those that suggest that a more harmonious sustainable relationship can and will prevail (Agrawal and Redford, 2009).

Secondly, indigenous peoples living in protected areas are not the only or principal actors in the threat to biodiversity as most protected area managers who are anti integrated conservation and development approach make it look. The linkages between forest use and 
biodiversity decline are more complex than conservationists want to believe. For instance even casual visits to the Sariska Tiger Reserve in India by Rangarajan and Shahabuddin (2006) reveal that much of the pressure on the reserve is generated by the adjacent urban centre and not the indigenous Gujjar community. Exaggerated claims of poaching, bushfires, snaring, slash and burn agriculture are frequently put on indigenous people living within designated reserves as justification for their eviction. No study has so far been carried out to compare the quantum of biomass extracted by external actors such as non-indigenous poaching gangs, miners, safari hunters, illegal logging activities and that of indigenous people living within and around reserves in order to justify the claim that indigenous peoples are bad for protected areas. As Rangarajan and Shahabuddin point out, this contribution of external actors is seldom recognized in the management plans of reserves. This continuing access of forest lands to more powerful external players only helps in further alienating the local indigenous people and diminishes their faith in protected areas. This is particularly a cause for concern in peripheral locations where many protected areas are located, and where the success of conservation is dependent on indigenous people's acceptance or rejection.

Thirdly, most studies that support or criticize integrated conservation and development projects or strict conservation are based on a few case studies with results generalized to support arguments. While such case studies are vital in the understanding of the complexity of each situation and the problems involved, they provide a limited basis for broader generalizations regarding integrated conservation and development successes or failures. There is the need for researchers to study a larger number of cases with the use of more systematic comparative information gathered on different conservation and livelihood outcomes from different parts of the world. 
Resource use plays a vital role in knowledge acquisition (Berkes, 1999, Shikongo, 2005). With less time spent in the forest as a result of restrictions on the use of forest resources, conservation refugees will be expected to experience a change in levels of Traditional Ecological Knowledge (TEK) based on the forest ecosystem. Berkes (1993) defined TEK as a cumulative body of knowledge and beliefs handed down through generations by cultural transmission, about the relationship of living beings (including humans) with one another and with their environment.

TEK comprises a practical component of natural resource use and is important in people's perceptions of their role within the ecosystem and how they interact with natural processes (Berkes, 1993, 1999; Ford et al., 2000; Ampornpan et al., 2003). Shikongo (2005) argues that the land and indigenous people are one and without the land and its resources, knowledge of and respect for the land and ecosystem will cease to exist. TEK is operational knowledge; about practice, like the knowledge of London taxi drivers; without London such knowledge is irrelevant (Poole, 2003). So it is same with the knowledge of the forest without access to the forest. Without access to the forest, suck knowledge is no longer useful. Indigenous peoples have a wide range of specialist knowledge and skills necessary to carry out their basic livelihoods, including an incomparable knowledge of plants and animals, skills in medicine, music, dance and crafts (Poole, 2003). Indigenous people have been recognized as conservators of the environment by the international community (United Nations Brundtland Report, 1987).

Given this intricate link, eviction of a population will affect their operational knowledge of TEK because Traditional Ecological Knowledge is learned through observation and use of resources. Maintaining the richness of Traditional Ecological Knowledge depends largely on 
allowing indigenous people access to resources (Ohenjo, 2003). According to First Peoples Worldwide (2007), forced relocation not only alienates indigenous people from conservation goals but also prevents such people from practicing TEK, thus contributing to loss of TEK. However, despite an increase in literature on displacements, no study has been carried out to show how TEK is affected by displacement for conservation.

Planners and managers of conservation projects and resettlement tend to perceive risks differently to those people who are actually facing the risks of expulsion and relocation. Also, different people can be differently affected by the same impacts Cernea and SchmidtSoltau, (2003). Igoe (2006) also points out that evictions and displacements are likely to have uneven effects on different groups within communities or within households, especially as men are usually better positioned than women to take advantage of more distant types of economic opportunities, and as women are often directly dependent on access to natural resources for cooking fuel, building materials and traditional medicine. For example studies in Kenya indicate that only 5 percent of registered landholders are women, and yet women constitute over 80 percent of the agricultural labour force, and 64 percent of subsistence farmers are women. Women are more vulnerable to poverty than men. For instance, 69 percent of the active female population work as subsistence farmers compared to 43 percent of men. Given that subsistence farmers are among the very poor, this relative dependence of women upon subsistence farming explains the extreme vulnerability of women. These problems are most severe in arid and semi-arid areas where women spend a great portion of their time searching for water and fuel. Given that indigenous women are disregarded even by indigenous men, special consideration is needed to address the issue of women's inequality in the tribal context. Men enjoy a privileged status within tribes and women are 
excluded from traditional councils, which are ruled by elders and constitute the realm of power and authority within many tribes. However, no study has been carried out before to assess gender differentials in the effect of impoverishment risks (IRR) on evicted or displaced people.

Furthermore, concerning the risk of marginalization, Neba et al. (2009) argue that the exclusion of minority groups is justified by their way of life, which implies the need for intervention to change it. In that case, the capacity to constrain people may appear to be an indicator of success in management. In other words, they mean if a conservation project keeps people away from the protected areas and changes their lifestyle to ease assimilation into mainstream community, then the goal of resettlement has been achieved no matter the social impact. Though this assimilation could ease marginalization, it is not clear what the indigenous people concerned think about being assimilated or whether they will prefer to be left alone to maintain their hunter-gatherer lifestyle in spite of the marginalization which comes with this. A study needs to be carried out to assess the preference of indigenous peoples who are victims of displacement in relation to maintaining their indigenous lifestyle, being assimilated into the larger community or having a bit of both worlds.

Methods used to make estimates of the number of conservation refugees globally still show major lacunae. In chapter three I examine a number of methods which have been used or put forward by different researchers in an attempt to arrive at global figures for conservation refugees. I also identified the weaknesses of each of these methods. These methods examined in chapter three are diffuse and often unsystematic and most of them only refer to eviction despite the fact that eviction is only one aspect of displacement. There is the need to come up with a study which examines the overall nature and extent of displacements and resettlements 
on the basis of an appropriate representative sample of protected areas worldwide based on a systematic, consistent and comprehensive methodology.

Even if the problem of a systematic methodology is addressed, there is another issue which requires more attention by researchers interested in the conservation refugee problem. This refers to privately owned protected areas which are increasingly dominant in some countries such as South Africa and Tanzania. Research into displacements from protected areas seems to focus more on state protected areas than on private protected areas. Brockington and Igoe (2006) note, large parts of Scotland are effectively private protected areas and in South Africa private ranches occupy twice the area of state protected areas which are a full 11 percent of the country. There are challenges of eviction and displacement from private protected areas just as from state protected areas which warrant more study by researchers in the field of displacement for conservation.

Lastly, Cernea and Schmidt-Soltau (2003) claim that when the new neighbors speak a similar language and belong to the same ethnic group, the risk that the resettled 'spiral on a downward mobility path' is relatively limited (Cernea and Schmidt-Soltau, 2003). The alienation and marginalization occurs especially in cases, where the newly resettled end as strangers (and therefore without rights) among homogenous neighbours from a different cultural, social and economic background. However, there has been no study to verify this claim or to prove that refugees who settle next to an ethnic group with similar culture experience less impoverishment risks than their counterparts who settled next to ethnic groups with different cultures. 


\section{Recommendations}

I make seven recommendations here which include: preservation of cultural diversity vis-àvis biodiversity, better enforcement of conservation legislature, more on-the-ground research, collaboration between social science and biological science, the use of remote sensing, good governance and more involvement of indigenous peoples in conservation.

Preservation of cultural diversity vis-à-vis biodiversity: According to Toledo (2010), research accumulated over the years by researchers in the fields of anthropology, conservation biology, ethnobiology and ethnoecology have confirmed that the world's biodiversity will only be effectively conserved by preserving diversity of culture and vice versa. This represents a new bio-cultural axiom which will hopefully eradicate the problem of displacing people from protected areas. According to Toledo, this axiom is nourished by four main sets of evidence which are: geographical overlap between biological richness and linguistic diversity and between indigenous territories and biologically high-value regions, recognized importance of indigenous peoples as main managers or co-managers and dwellers of well-preserved habitats, and encouragement of a conservation-oriented behaviour among indigenous peoples.

Enforcement of legislature: There is the problem of enforcement of legislature in and around national parks. However enforcement by policing or force of law and order could be difficult over large areas. If for example there is a small area of 150 hectares, enforcement should be relatively easy. But in protected areas of half a million hectares it is hard to monitor what is happening. Large teams are needed for supervision and, as most project managers and governments cannot fund this, the best people to do it are the indigenous peoples or local community. This should not be over-emphasized though because with the advancement of 
the market economy an increasing number of indigenous peoples use modern hunting weapons so, some indigenous peoples are no longer the ecological "noble sauvage" they used to be (Terborgh, 1999). In the meantime, there is the need to maximize dialogue and involve indigenous peoples in management of protected areas as well as enforce legislation in these protected areas. This might be difficult, but indigenous people should be trained to monitor protected areas. Displacement from national parks or protected areas will alienate indigenous peoples from conservation objectives and thus require an ever increasing and, in the long run, unsustainable level of policing (Turton, 2002). Government officials involved in forced displacements often argue that the costs involved in resettling inhabitants from protected areas according to internationally sound guidelines are too high (Cernea and Schmidt-Soltau, 2003). This argument is used to justify the externalization of the cost of park creation upon the often poor occupants of protected areas who become even poorer when displaced. The question to these government officials is, why not save yourself the trouble of having to worry about the costs of resettlement by getting these local people involved in the conservation projects? That way there will be no need for external policing because with enough sensitization the communities will police themselves and this is a more economically feasible option. The following quote from a Baka in the Lobeke National Park in south east Cameroon (Nelson and Venant, 2008) can be used to strengthen this argument;

[When WWF arrived did they find this forest destroyed? No, they came because the forest was rich ... and we showed them all these places they now want to protect - we guided them through the forest to those places ... we need this forest to survive, and we should be left to continue our traditional use ... if this is done, then when people come to destroy this place (like poachers), we will be the first to report them to authorities ... but they do not listen to us now] (Nelson and Venant, 2008, Page 13)

Another case is from Jum et al. (2009) in Ottotomo Forest Reserve, Cameroon, where the conservation agency urged indigenous peoples to take action on encroachment from illegal 
forest exploiters and to report instances immediately to the appropriate authorities. In response to this, several cases were reported, either verbally or in writing. In July 2003, for example, a village representative reported an illegal harvest of a Non-Timber Forest Product in the forest. Other cases of illegal resource use were reported after that by the indigenous peoples of the area. This has given the indigenous peoples around the reserve more confidence in the conservation agency in charge of managing the reserve and vice versa, and the two stakeholders now work hand in hand.

More on-the-ground research: There is a clear inability of conservation organizations to provide convincing figures on the magnitude of displacements (Agrawal et al. 2009). A lot of researchers contact organizations or government agencies when seeking information about the actual number of people displaced from new national parks and reserves. This is not always a good choice because the information from such sources is often deceptive as these conservation actors try to minimize the effects of their actions on the local population by giving false estimates or figures of the actual number of people displaced. Evidence to support this argument can be drawn from Brockington and Igoe (2006) in their global review of conservation related evictions. Data from their study presents 13 newly-created national parks in Gabon. While the Wildlife Conservation Society states there were no people settled within the boundaries of these reserves, an independent researcher was quoted as suggesting there were more than 7000 people living within these new protected areas before they were created. In a related case Cernea and Schmidt-Soltau (2006) report that there were close to 17000 conservation refugees in Central Africa alone based on their independent studies. However, conservationists working in this area emphatically refute these figures (Maisels et al. 2007, Sunderland et al. 2009). This just goes to show how figures from conservation 
bodies can be very unreliable. I therefore recommend that in order to get a more reliable estimate of the number of evictions, researchers need to go to the field more and talk to local people face to face in order to get a real feel for what is going on. The likely reason behind marginal numbers of conservation refugees often reported by conservation agencies is because visibility of conservation refugees increases the cost of conservation. This implies the higher the figures the greater their responsibility with regards to compensation to the displaced.

Collaboration between social science and biological science: The difference between ideologies of biological scientists and social scientists as noted before in chapter one is widened by the fact that neither of the two groups is willing to draw knowledge from the other in approaching the problem of eviction and displacement in protected areas. For instance biological evidence is rarely backed up by a consideration of the socio-ecomomic conditions of displaced people. On the other hand, the wealth of sociological material on displacement places more emphasis on loss of livelihood and deprivation while ignoring rich insights provided by biological sciences on ecosystems and species composition (Rangarajan and Shahabuddin, 2006). Social scientists who are the proponents of development should recognize that conservation is a prerequisite for development, being the means by which people can make the best use of the living resources on which they depend (Strong, 1977). Scientists and forest managers need to be sensitized to the socio-economic and cultural needs of resident peoples just as much as social scientists require an understanding of the ecological requirements of endangered species. Conservation scientists must acknowledge that conservation is much about people as it is about plants and animals and it is the presence of people in parks that makes conservation necessary and not the presence of animals and plants 
(Strong, 1977). According to Rangarajan and Shahabuddin, this sensitization has to be coupled with coordinated engagement of social scientists, biologists and forest managers on such critical questions as whether, how and where to relocate. Relocation should therefore be a last and not a preferred first option for managers of protected areas. While such a holistic exercise which combines ecological and social reasoning cannot, in itself, resolve issues of social and environmental justice, it can hopefully help create the space for an informed and serious debate.

The use of remote sensing: Schwartzman and Zimmerman (2005) recommend the use of remote sensing in order to achieve a better spatial analysis and a broader comparative basis in assessing how effective protected areas are in conserving forest cover and functioning as deforestation buffers against external and internal threats to conservation. This approach is limited because satellite data cannot detect crops under tree cover, and so will underestimate agroforestry. Nor can remote sensing distinguish between fallowed land growing trees and unused land (Schmidt-Soltau and Brockington, 2007). The recommendation of Schwartzman and Zimmerman can however be useful if it is applied in association with ecological, ethnographic and economic analyses of the most debated aspects, such as impacts on game populations of human activities, displacements of local inhabitants and opportunity costs of these displacements. This can be used as an effective method when comparing realities within and outside protected areas in order to arrive at the decision between parks with people and parks free of people.

Good governance: The idea of good governance was brought forward at the $5^{\text {th }}$ World Parks Congress in Durban, South Africa (2003). If applied in management of protected areas it could go a long way in reducing conflicts between park management and indigenous peoples. 
Good governance relates to power, relationships, responsibility and accountability. In a protected area context it relates to a broad range of issues ranging from policy to practice, behaviour to meaning, and investments to impacts (Borrini-Feyerabend et al. 2004). The Durban Congress developed a set of good governance principles for protected areas which include; legitimacy and voice (ensuring the capacity of men and women to influence decisions, on the basis of freedom of association and speech), subsidiarity (attributing management authority and responsibility to the institutions closest to the resources at stake), fairness (sharing equitably the costs and benefits of conservation and providing recourse to impartial judgment in case of conflict), doing no harm (making sure that the costs of conservation are not dumped on some weak social actors without any form of compensation), direction (establishing long-term conservation objectives grounded in an appreciation of ecological, historical, social and cultural complexities), performance (meeting the needs and concerns of all stakeholders while making a wise use of resources), and accountability (having clearly demarcated lines of responsibility and ensuring a transparent flow of information about processes and institutions (Borrini-Feyerabend et al. 2004)

Borrini-Feyerabend et al. note that though the above principles are important, overarching them all is the respect for human rights. Thus, a rights-based approach is considered as the most equitable path to conservation and this has now been established as part of the IUCN's view of conservation (Borrini-Feyerabend et al. 2004).

[Mere exhortations to poor people to value and respect the ecosystems contained within Parks will not succeed. It is critically important that alternative means of livelihood be found for the poor, so they are not forced to act in a manner that undermines the global effort to 
protect these ecosystems, driven by hunger and underdevelopment] (Former South African President Thabo Mbeki In Dowie, 2009: Page xviii)

[I see no future for Parks, unless they address the needs of communities as equal partners in their development] (Former South African President Nelson Mandela at the Durban Congress in Dowie, 2009: Page xix)

More involvement of indigenous peoples in conservation: According to Chapin (2004) if we are to make any headway, cooperation among groups and sectors is crucial. There are still some among us who strongly believe that conservation cannot be effective unless the residents of the area to be conserved are thoroughly involved. This is not solely a matter of social justice, which must in any case be a strong component of all conservation work. It is also a matter of pragmatism. Indigenous peoples live in most of the ecosystems that conservationists are so anxious to preserve. Often they are responsible for the relatively intact state of those ecosystems (Chapin, 2004; Dowie, 2006), and they are without doubt preferable to the most common alternatives - logging, oil drilling, cattle ranching, and largescale industrial agriculture that are destroying ever larger tracts of forest throughout the tropical latitudes. Forming partnerships and collaborative alliances between indigenous and traditional peoples and conservationists is no easy task, but it would seem to be one of the most effective ways to save the increasingly threadbare ecosystems that still exist.

Conservation organizations need to take the lead in setting the agenda on how to address conservation-induced displacements in a manner which is ethically appropriate and sustainable to both people and biodiversity. In order to yield longer lasting benefits from compensation schemes, I recommend that provisions should be put in place to facilitate conservation refugees' ability to translate access to new kinds of capital into positive 
livelihood outcomes. This could possibly be the best way out for conservation refugees because the current trend of displacement seems to be irreversible. As Dowie (2006) stated, national parks and protected areas surrounded by angry and hungry people who describe themselves as "enemies of conservation" are generally doomed to fail. Therefore it is important to work with, rather than against indigenous people as long as such indigenous people are committed to the basic goals of conservation. Case studies from around the world have shown how effective integrating indigenous peoples in conservation can be. 


\section{Case studies of effective management of protected areas by indigenous people}

Despite the history of eviction and displacements and criticisms of integrated conservation and development projects, there seems to be a bright future for conservation initiatives which consider livelihood outcomes to the local community. Encouragingly, numerous examples of indigenous peoples effectively involved in conservation illustrate in practice how conservation benefits and the respect of indigenous and community rights can co-exist in a synergistic manner. There has been a growing recognition of the unique knowledge, skills, resources and institutions that indigenous peoples and local and mobile communities can bring to protected area management. Management practices that engage communities or which are run exclusively by local communities are seen to enhance the long-term effectiveness of conservation (Borrini-Feyerabend et al. 2004). These case studies will be sub-divided into conservation projects run by indigenous peoples and other stakeholders (comanagement projects) and conservation projects run entirely by local people (local community managed projects).

\section{Co-managed Projects}

Case studies of conservation projects jointly managed by indigenous peoples in association with other stakeholders to be presented in this section include; Gurig (Australia), Retezal (Romania), Kayan Mentarang (Indonesia), Kaa-ya Iya del Gran Chaco (Bolivia) and Ottotomo Forest Reserve (Cameroon). Co-management offers a solution to the conflicts that characterize forest management because recognition of conflicting interests is basic to the process of negotiating the rights, regulations and duties of local populations and state agencies (Hilhorst and Aarnink, 1999). Sustainability and conflict resolution could be better 
achieved if stakeholders agree upon collaborative management objectives and indicators to monitor the process.

\section{Retezal National Park (Romania)}

The Retezat National Park Management Authority (PMA) was established in November 1999. Early in 2000, the park area was enlarged and a stakeholder analysis was under taken. In 2001, a Consultative Council was established, with 25 representatives from the main interests concerned: local communities, forest districts, NGOs, mountain rescue teams, school inspectorates, local scientific bodies and county level institutes. All important management decisions are supposed to be made only after consulting the Council and, if necessary, the public at large. During the first meetings of the Council, short training sessions were held on participatory approaches and "how to work together". The local people are the bearers of the cultural and traditional values of the area, which contribute much to the landscape and biodiversity of the national park, so their understanding and collaboration are essential. But the participatory approach is new to them, and quite different from that adopted under the former communist administration. To develop local peoples' confidence in a more participatory role, a "learning by doing" route has been taken by the PMA.

(Adapted from Stanciu in Borrini-Feyerabend et al. 2004: Page 42)

\section{Gurig National Park (Australia)}

In 1981, Gurig National Park became the first jointly managed National Park in Australia; since then, further co-management arrangements have been developed for other parks in various states and territories. Co-management represents a trade-off between the rights and interests of traditional owners and the rights and interests of government conservation agencies and the wider Australian community. In the most sophisticated arrangements, land ownership is transferred to Aboriginal people in exchange for the peoples' agreement that the area will remain under protected status as a national park for the foreseeable future and that responsibility for park management will be shared. Often, a key element in these arrangements is the use of leases or other legal mechanisms, under which the land for protection is simultaneously returned to Aboriginal ownership and leased back to a government conservation agency under a co-management board, with all parties committing to arbitration in case of disputes

(Adapted from Borrini-Feyerabend et al. 2004: Page 38) 


\section{Kayan Mentarang National Park (Indonesia)}

The Kayan Mentarang National Park (KMNP) situated in the interior of East Kalimantan (Indonesian Borneo) lies at the border with Sarawak to the west and Sabah to the north. About 16,000 Dayak people live inside or near the park. These are still communities largely regulated by customary law, or adat, in the conduct of their daily affairs and the management of natural resources in their customary territory (wilayahadat) and which declare traditional forest areas with protection status or strict management regime. These are referred to as tana ulen, i.e. land to which access is restricted. In 1980, the area was established as a Nature Reserve, under a strict protection status that allowed no human activity. Later on, a study that included community mapping exercises showed that the Dayak communities had rightful claims to the land and its resources. This study recommended a change of status from Nature Reserve to National Park, where traditional activities are allowed. A Worldwide Fund project helped them in a number of tasks, including biological and economic inventories, participatory planning workshops (to identify precisely the tana ulen forests, and include this knowledge in zoning recommendations), redrawing the boundaries of the park, compiling and recording their customary rules and strengthening their own organizations. The Alliance of the Indigenous People of Kayan Mentarang National Park (FoMMA) was formally established on October 2000 by the leaders of the ten customary lands of the park. FoMMA created a forum for indigenous communities to debate issues and convey their views on the management of natural resources in the customary lands of the KMNP. FoMMA now legally represents the concerned indigenous people in the Policy Board (Dewan Penentu Kebijakan), a new institution set up to preside over the park's management. The Policy Board includes representatives of the central government (the agency for Forest Protection and Nature Conservation), the provincial and district governments and FoMMA. The operating principles of the board emphasize coordination, competence, shared responsibilities, and equal partnership among all stakeholders.

(Adapted from Ferrari in Borrini-Feyerabend et al. 2004: Page 45) 


\section{Kaa-ya Iya del Gran Chaco National Park (Bolivia)}

The Kaa-ya Iya National Park (83.4 million hectares) is the largest in Bolivia and contains the world's largest area of dry tropical forest under protection. Another unique characteristic of this park is that it was created in response to demands for territorial recognition by the Guaraní Izoceño people. This is the first protected area in the Americas to be declared at the behest of the indigenous people, and it is the only park in the Americas where an indigenous peoples' organization has primary administrative responsibility (CABI - Capitanía del Alto y Bajo Izozog). The Park's Management Committee comprises staff of the Ministry of Sustainable Development and Planning and representatives of CABI, WCS (a foreign environmental NGO), local municipalities, a community group of Chiquitanos, the Ayoreo Community of Santa Teresita and the group of women of the Izozog indigenous communities. The indigenous representatives are the majority in the committee, which is in charge of several management policies and decisions. In 1993, the new Agrarian Reform Law recognised Bolivia as a multi-ethnic and multicultural country, allowing for community land ownership and legalising the creation of indigenous territories (Territorio Comunitario de Origen - TCO). With the passing of this law, CABI and the indigenous communities could become fully involved in management of the park and address a number of conservation problems. In addition, CABI had been able to secure significant compensatory payments ( $\$ 3.7$ million) from industry for the impact of a gas pipeline that runs through their indigenous territory and the park. This and other incomes were invested by CABI in the running of the park, greatly strengthening their standing as co-management partners. The compensation funds have also supported the indigenous organizations themselves, promoted rural development and accelerated the titling of indigenous lands. The park's creation helped to halt the rapid expanse of the agro-industrial sector and ensured that vast expanses of traditional lands were not clear-cut for farming.

(Adapted from Winer in Borrini-Feyerabend et al. 2004: Page 36) 


\section{Ottotomo Forest Reserve (Cameroon)}

The Ottotomo Forest Reserve was created in 1930 and made off-limits to human activities. Soon after, however, population increase and expanding cacao farming prompted encroachment, hunting and illegal forest exploitation. Conflicts between the local population and the state reserve management authority, the Office Nationale de Development des Forets (ONADEF), were frequent. Local people claimed customary user rights in the reserve on the basis of their presence before the reserve was established and their rights were being denied by ONADEF on the basis of forestry conservation (de Koning, 2009).

The Centre for International Forestry Research (CIFOR) intervened by putting in place an Adaptive Collaborative Management plan (ACM) which did not exclusively target the local communities, but also, conservation needs were taken into account. The CIFOR team was able to forge a joint understanding of the contemporary problems - the legal dualism of land ownership and the lack of communication between state officials and the local community (de Koning, 2009).

The result of this intervention by CIFOR was an agreement between the local Ewondo community and ONADEF to create a buffer zone within the reserve and provide additional farmland and income generating agro-forestry activities. This increased the stakeholders' confidence in and commitment to join resource management. In the beginning stages of the ACM intervention, poaching declined and the local monitoring of illegal hunting practices improved. Social negotiation thus resulted in a win-win situation for the two major stakeholders.

(Adapted from de Koning, 2009: Page 201)

\section{Local community managed projects}

Case studies of conservation projects managed entirely by indigenous peoples to be presented in this section include; Alto Fragua-Indiwasi (Colombia), Coron (Philippines), Farole (Ethiopia), Cuvu Tikina (Fiji) and Chartang-Kushkizar (Iran). Unlike the previous examples of co-managed projects, there is basically no intervention from any external bodies or organizations in the management of the local community projects presented in this section. This shows that local people are more than capable of managing protected areas without being told what to do or what needs to be done. 


\section{Alto Fragua-Indiwasi National Park (Colombia)}

The Alto Fragua-Indiwasi National Park was created in February 2002, after negotiations involving the Colombian government, the Association of Indigenous Ingano Councils and the Amazon Conservation Team, an environmental NGO focusing on projects to assist the Ingano Indians and other indigenous groups in the Amazon basin. Under the terms of the decree that created the park, the Ingano are the principal actors in its design and management. The area, whose name means "House of the Sun" in the Ingano language, is a sacred place for the indigenous communities. This is one of the reasons why traditional authorities have insisted that the area's management should be entrusted to them. The creation of Indiwasi National Park has been a long-time dream of the Ingano communities of the Amazon Piedmont, for whom it makes a natural part of their Life Plan (Plan de $V i d a$ ), that is, a broader, long-term vision for the entirety of their territory and the region. For the first time an indigenous community was fully recognized by the state as the principal actor in the design and management of an official Protected Area. It is all the more remarkable that this community-promoted refuge has been developed in a context of armed violence, drug trafficking, and many other social problems that affect surrounding areas.

(Adapted from Oviedo in Borrini-Feyerabend et al. 2004: Page 53)

\section{Coron Island National Park (Philippines)}

The Tagbanwa people of the Philippines inhabit a beautiful limestone island for which they have established stringent use regulations. The forest resources are to be used for domestic purposes only. All the fresh water lakes but one are sacred. Entry to those lakes is strictly forbidden for all except religious and cultural purposes. The only lake accessible for tourism is Lake Kayangan, which has regulations concerning the number of people allowed in, garbage disposal, resource use, etc. Until recently, the Tagbanwa's territorial rights were not legally recognized, leading to encroachment by migrant fishers, tourism operators, politicians seeking land deals and government agencies. This caused several problems, the main one of which was the impoverishment of the marine resources, essential to local livelihoods. In the mid-1980s, however, the islanders organized themselves into the Tagbanwa Foundation of Coron Island (TFCI) and started lobbying to regain management control over their natural resources. In 1998, they managed to get a Certificate of Ancestral Domain Claim for 22,284 hectares of land and marine waters. Finally, in 2001, after having produced a high quality map and an Ancestral Land Management Plan, they managed to obtain a Certificate of Ancestral Domain Title (CADT), which grants collective right to land. The Tagbanwa wish to remain "right holders" - the owners and protectors of their territories - and refuse to be classified as one "stake holder" among others. (Ferrari and de Vera in Borrini-Feyerabend et al. 2004: Page $55)$. 


\section{Farole Mountain (Ethiopia)}

Forole is a sacred mountain just north of the border between Kenya and Ethiopia where the Galbo peoples (a sub-group of the Gabbra) hold the jila galana ceremonies. Most of the Galbo live in Kenya, but they move in pilgrimage to the Forole on the occasion of the ceremony. The trees of Forole Mountain are totally protected by the Gabbra and access to the upper part is only allowed to a few people who preside over the ceremony of the sacrifice to the Sacred Python. The lower part of the mountain provides permanent water and is used as reserve grazing area by both the Gabbra and the Borana pastoralists. Sometimes there are tensions over pastoral resources between the two groups, but the Borana fully respect the sacredness of Forole Mountain and the inherent restrictions, indirectly assuring its conservation. This Community Conserved Area is thus not unequivocally associated with a single ethnic group.

(Adapted from Bassi in Borrini-Feyerabend et al. 2004: Page 63)

\section{Cuvu Tikina (Fiji)}

The South Pacific Islanders relate with their coastal resources through a vast body of Traditional Ecological Knowledge and management systems. In the second half of the 20th century the state of these coastal resources greatly deteriorated in parallel with the erosion of traditional management of these areas. Fortunately, in recent years there has been a revitalization of indigenous coastal management practices around the Pacific, for example in Vanuatu, Fiji and Western Samoa. In Cuvu Tikina, the communities and a local NGO worked together to map and evaluate the natural resources, to generate and exchange information and to plan together. Besides local management plans, the communities agreed to establish closed fishing areas, to set up an environment committee and to hire fish wardens (trained and supported by the Fisheries Department) to take care of day to day management. The closed fishing areas are based on the traditional system of "taboo" in which areas or species can be restricted for differing lengths of time. These systems were reviewed and re-appreciated as part of the planning process. Results so far are very encouraging and include the recovery of some species' populations and the strengthening of relations between the community and various regional and governmental institutions and tourist operators.

(Adapted from Govan in Borrini-Feyerabend et al. 2004: Page 69) 


\section{Chartang-Kushkizar wetland (Iran)}

The Kuhi - one of about 20 sub-tribes of the Shish Bayli Tribe of the Qashqai nomadic pastoralists of southern Iran - have been engaged for a few years in participatory action research about their own "sustainable livelihoods" and the conservation of biodiversity in their landscape. Their action-research is focused on a resource management unit comprising their summering and wintering grounds and their associated migration routes in between. The Kuhi held several workshops and one of the major problems they identified was the breakdown of the traditional strength of the sub-tribes. They analyzed their situation in some depth and decided to recreate their autonomous organization in a manner that would also be able to respond to modern challenges, including notions of participatory democracy. Extended negotiations among them led to the "Council for Sustainable Livelihoods of the Kuhi Migratory Pastoralists" and its associated Community Investment Fund, which is now pursuing initiatives in each of the five categories of problems/needs identified by the sub-tribe. The new idea that excited them the most, however, is about restoring natural resources to their common property care and control. A unique opportunity in this sense is the Chartang-Kushkizar wetland, extending some $9 \mathrm{~km}$ in length, shared between the Kuhi and the Kolahli Sub-tribes. This has been a community- conserved wetland from time immemorial. The Kuhi know that they obtain many "ecosystem benefits" from this wetland, including water reserves, reeds for handicrafts, fish, medicinal plants, micro-climate control and wild life. This initiative is showing how nomadic livelihoods can be reconciled with conservation and how the cultural identity and organization of the relevant indigenous and local communities are necessary prerequisites for their full involvement in conservation.

(Adapted from Borrini-Feyerabend et al. 2004: Page 57)

The above examples show how a "bottom-top" approach has proved to be really effective in cases across the world. This "bottom-top" gives local people a sense of responsibility and increases community participation as opposed to the "top-bottom" approach which makes local people feel excluded from the conservation efforts. Conservation projects which exclude local people may conserve natural resources to an extent but not conserve human resources (peoples' access to livelihood). In order to achieve double sustainability in conservation it is wise to involve local people in protected area management. 


\section{Conclusion}

The aim of my study has been to critically examine the global literature on the conservation refugee problem with the goal of examining why conservation projects seems to be afflicting pain to local communities. This study is not meant to be anti-conservation. Rather, it is meant to lend more support to the argument that conservation efforts which disregard livelihood issues of the local population are bound to fail. Conservation organizations have done a lot of good in protecting some of the world's richest biodiversity spots. So, this study is not trying to portray conservationist in a negative light. Evicting people for conservation has been the most dominant conservation paradigm in most developing countries whereas the challenge for conservation of protected areas should be to integrate social development aspects, both as an end for biodiversity conservation and as a strategy for achieving better ecosystem management. Strict protection of protected areas through eviction tends to hide a wealth of details and variations which prevent precise statements about marginal gains from eviction for conservation, gains from partial protection, and how such gains are balanced against the losses of those displaced from protected areas (Agrawal and Redford, 2009).

According to Dowie (2006), more and more conservationists seem to be wondering how, after setting aside protected area land masses about the size of Africa, global biodiversity seems to decline. There is certainly something wrong with mainstream biodiversity conservation strategy. The Convention on Biological Diversity has documented that in Africa where so many parks and reserves have been created and where the evictions of indigenous peoples are highest, it is surprising to note that 90 percent of biodiversity still lies outside protected areas. If we want to preserve biodiversity globally in a more efficient and effective manner in places that are often still occupied by indigenous peoples living in ways that are 
ecologically sustainable, history and the results from this study show us that displacing them will be negative for conservation efforts. Where the political will to achieve double sustainability is not available, the rural population will lose and biodiversity conservation is unlikely to win local support (Brockington and Schmidt-Soltau, 2004).

In fact evidence from the Kanha National Park in India has shown that some degree of human use has actually favoured increase in animal diversity at the landscape level by creating a heterogeneous ecological mosaic so that some biodiversity elements are favoured over others in different patches (Rangarajan and Shahabuddin, 2006). In this case, the existence of villagers in forests in the past resulted in the formation of open grasslands which were beneficial to endangered native herbivores including deer and antelopes. After village relocations from the Kanha Park such formations have to be managed with fire and cutting in order to maximize biodiversity values in the park. The moral of this story is that some degree of human presence and activity in conservation can lead to both ecological and socioeconomic sustainability.

The future of the conservation-development debate and the resulting problems of evictions and displacements seem to be even more uncertain with the emergence of the climate change problem. It is within the climate change agenda that the next formulations of the conservation-development debate are likely to develop (Roe, 2008). The IPCC (Intergovernmental Panel on Climate Change) recently concluded that the resilience of many ecosystems is likely to be exceeded this century as a result of global warming and related climate impacts such as wildfires and floods. It is likely to be the poorest communities who are hit the hardest, as a result of their geographic location, vulnerability to environmental hazards and their direct reliance on ecosystem services (IPCC, 2007). The recent focus of 
climate change on reduced emission from deforestation makes the search for solutions in the conservation-development face-off particularly important because the proposals for an appropriate mechanism for implementing a suitable reduced emission strategy have significant implications for conservation and subsequently for its impacts on the poor and vulnerable people who often lose out to conservation (Griffiths, 2007; Roe et al., 2007). It appears after more than 50 years of the conservation-development debate, climate change might be the glue that binds the conservation and development communities together and invigorates a time-pressured search for sustainable solutions that could eradicate or reduce the problem of conservation refugees. 


\title{
Appendix 1: International Labour Conference, Convention 169
}

\author{
INTERNATIONAL LABOUR CONFERENCE \\ Convention 169
}

CONVENTION CONCERNING INDIGENOUS AND TRIBAL PEOPLES IN

INDEPENDENT COUNTRIES 27 June 1989, Adopted by the General Conference

The General Conference of the International Labour Organisation, Having been convened at Geneva by the Governing Body of the International Labour

Office, and having met in its 76th Session on 7 June 1989, and

Noting the international standards contained in the Indigenous and Tribal

Populations Convention and Recommendation, 1957, and

Recalling the terms of the Universal Declaration of Human Rights, the

International Covenant on Economic, Social and Cultural Rights, the

International Covenant on Civil and Political Rights, and the many international

instruments on the prevention of discrimination, and

Considering that the developments which have taken place in international law

since 1957, as well as developments in the situation of indigenous and tribal

peoples in all regions of the world, have made it appropriate to adopt new

international standards on the subject with a view to removing the

assimilationist orientation of the earlier standards, and

Recognising the aspirations of these peoples to exercise control over their own institutions, ways of life and economic development and to maintain and develop their identities, languages and religions, within the framework of the States in which they live, and

Noting that in many parts of the world these peoples are unable to enjoy their fundamental human rights to the same degree as the rest of the population of the States within which they live, and that their laws, values, customs and perspectives have often been eroded, and Calling attention to the distinctive contributions of indigenous and tribal peoples to the cultural diversity and social and ecological harmony of humankind and to international co-operation and understanding, and

Noting that the following provisions have been framed with the co-operation of the United Nations, the Food and Agriculture Organisation of the United Nations, the United Nations Educational, Scientific and Cultural Organisation and the World Health Organisation, as well as of the Inter-American Indian Institute, at appropriate levels and in their respective fields, and that it is proposed to continue this co-operation in promoting and securing the application of these provisions, and

Having decided upon the adoption of certain proposals with regard to the partial revision of the Indigenous and Tribal Populations Convention, 1957 (No. 107), which is the fourth item on the agenda of the session, and Having determined that these proposals shall take the form of an international Convention revising the Indigenous and Tribal Populations Convention, 1957; adopts this twenty-seventh day of June of the year one thousand nine hundred and 
eighty-nine the following Convention, which may be cited as the Indigenous and Tribal Peoples Convention, 1989:

\section{PART I. GENERAL POLICY}

\section{Article 1}

1. This Convention applies to:

(a) tribal peoples in independent countries whose social, cultural and economic conditions distinguish them from other sections of the national community, and whose status is regulated wholly or partially by their own customs or traditions or by special laws or regulations;

(b) peoples in independent countries who are regarded as indigenous on geographical region to which the country belongs, at the time of conquest or colonisation or the establishment of present state boundaries and who, irrespective of their legal status, retain some or all of their own social, economic, cultural and political institutions.

2. Self-identification as indigenous or tribal shall be regarded as a fundamental criterion for determining the groups to which the provisions of this Convention apply.

3. The use of the term "peoples" in this Convention shall not be construed as having any implications as regards the rights which may attach to the term under international law.

Article 2

1. Governments shall have the responsibility for developing, with the participation of the peoples concerned, co-ordinated and systematic action to protect the rights of these peoples and to guarantee respect for their integrity.

2. Such action shall include measures for:

(a) ensuring that members of these peoples benefit on an equal footing from the rights and opportunities which national laws and regulations grant to other members of the population;

(b) promoting the full realisation of the social, economic and cultural rights of these peoples with respect for their social and cultural identity, their customs and traditions and their institutions;

(c) assisting the members of the peoples concerned to eliminate socio-economic gaps that may exist between indigenous and other members of the national community, in a manner compatible with their aspirations and ways of life.

\section{Article 3}

1. Indigenous and tribal peoples shall enjoy the full measure of human rights and fundamental freedoms without hindrance or discrimination. The provisions of the Convention shall be applied without discrimination to male and female members of these peoples.

2. No form of force or coercion shall be used in violation of the human rights and fundamental freedoms of the peoples concerned, including the rights contained in this Convention.

Article 4 
1. Special measures shall be adopted as appropriate for safeguarding the persons, institutions, property, labour, cultures and environment of the peoples concerned.

2. Such special measures shall not be contrary to the freely-expressed wishes of the peoples concerned.

3. Enjoyment of the general rights of citizenship, without discrimination, shall not be prejudiced in any way by such special measures.

Article 5

In applying the provisions of this Convention:

(a) the social, cultural, religious and spiritual values and practices of these peoples shall be recognised and protected, and due account shall be taken of the

(b) the integrity of the values, practices and institutions of these peoples shall be respected;

(c) policies aimed at mitigating the difficulties experienced by these peoples in facing new conditions of life and work shall be adopted, with the participation and co-operation of the peoples affected.

Article 6

1. In applying the provisions of this Convention, governments shall:

(a) consult the peoples concerned, through appropriate procedures and in particular through their representative institutions, whenever consideration is being given to legislative or administrative measures which may affect them directly;

(b) establish means by which these peoples can freely participate, to at least the same extent as other sectors of the population, at all levels of decision-making in elective institutions and administrative and other bodies responsible for policies and programmes which concern them;

(c) establish means for the full development of these peoples' own institutions and initiatives, and in appropriate cases provide the resources necessary for this purpose.

2. The consultations carried out in application of this Convention shall be undertaken, in good faith and in a form appropriate to the circumstances, with the objective of achieving agreement or consent to the proposed measures. Article 7

1. The peoples concerned shall have the right to decide their own priorities for the process of development as it affects their lives, beliefs, institutions and spiritual well-being and the lands they occupy or otherwise use, and to exercise control, to the extent possible, over their own economic, social and cultural development. In addition, they shall participate in the formulation, implementation and evaluation of plans and programmes for national and regional development which may affect them directly.

2. The improvement of the conditions of life and work and levels of health and education of the peoples concerned, with their participation and co-operation, shall be a matter of priority in plans for the overall economic development of areas they inhabit. Special projects for development of the areas in question shall also be so designed as to promote such improvement. 3. Governments shall ensure that, whenever appropriate, studies are carried 
out, in co-operation with the peoples concerned, to assess the social, spiritual, cultural and environmental impact on them of planned development activities. The results of these studies shall be considered as fundamental criteria for the implementation of these activities.

4. Governments shall take measures, in co-operation with the peoples concerned, to protect and preserve the environment of the territories they inhabit.

Article 8

1. In applying national laws and regulations to the peoples concerned, due regard shall be had to their customs or customary laws.

2. These peoples shall have the right to retain their own customs and institutions, where these are not incompatible with fundamental rights defined Procedures shall be established, whenever necessary, to resolve conflicts which may arise in the application of this principle.

3 . The application of paragraphs 1 and 2 of this Article shall not prevent members of these peoples from exercising the rights granted to all citizens and from assuming the corresponding duties.

Article 9

1. To the extent compatible with the national legal system and internationally recognised human rights, the methods customarily practised by the peoples concerned for dealing with offences committed by their members shall be respected.

2. The customs of these peoples in regard to penal matters shall be taken into consideration by the authorities and courts dealing with such cases. Article 10

1. In imposing penalties laid down by general law on members of these peoples account shall be taken of their economic, social and cultural characteristics.

2. Preference shall be given to methods of punishment other than confinement in prison.

Article 11

The exaction from members of the peoples concerned of compulsory personal services in any form, whether paid or unpaid, shall be prohibited and punishable by law, except in cases prescribed by law for all citizens.

Article 12

The peoples concerned shall be safeguarded against the abuse of their rights and shall be able to take legal proceedings, either individually or through their representative bodies, for the effective protection of these rights. Measures shall be taken to ensure that members of these peoples can understand and be understood in legal proceedings, where necessary through the provision of interpretation or by other effective means.

\section{PART II. LAND}

Article 13

1. In applying the provisions of this Part of the Convention governments 
shall respect the special importance for the cultures and spiritual values of the peoples concerned of their relationship with the lands or territories, or both as applicable, which they occupy or otherwise use, and in particular the collective aspects of this relationship.

2. The use of the term "lands" in Articles 15 and 16 shall include the concept of territories, which covers the total environment of the areas which the peoples concerned occupy or otherwise use.

Article 14

1. The rights of ownership and possession of the peoples concerned over the lands which they traditionally occupy shall be recognised. In addition, measures shall be taken in appropriate cases to safeguard the right of the peoples concerned to use lands not exclusively occupied by them, but to which they have traditionally had access for their subsistence and traditional activities. Particular attention shall be paid to the situation of nomadic 2. Governments shall take steps as necessary to identify the lands which the peoples concerned traditionally occupy, and to guarantee effective protection of their rights of ownership and possession.

3. Adequate procedures shall be established within the national legal system to resolve land claims by the peoples concerned.

Article 15

1. The rights of the peoples concerned to the natural resources pertaining to their lands shall be specially safeguarded. These rights include the right of these peoples to participate in the use, management and conservation of these resources.

2. In cases in which the State retains the ownership of mineral or sub-surface resources or rights to other resources pertaining to lands, governments shall establish or maintain procedures through which they shall consult these peoples, with a view to ascertaining whether and to what degree their interests would be prejudiced, before undertaking or permitting any programmes for the exploration or exploitation of such resources pertaining to their lands. The peoples concerned shall wherever possible participate in the benefits of such activities, and shall receive fair compensation for any damages which they may sustain as a result of such activities.

Article 16

1. Subject to the following paragraphs of this Article, the peoples concerned shall not be removed from the lands which they occupy.

2 . Where the relocation of these peoples is considered necessary as an exceptional measure, such relocation shall take place only with their free and informed consent. Where their consent cannot be obtained, such relocation shall [*1388] take place only following appropriate procedures established by national laws and regulations, including public inquiries where appropriate, which provide the opportunity for effective representation of the peoples concerned.

3. Whenever possible, these peoples shall have the right to return to their traditional lands, as soon as the grounds for relocation cease to exist.

4. When such return is not possible, as determined by agreement or, in the 
absence of such agreement, through appropriate procedures, these peoples shall be provided in all possible cases with lands of quality and legal status at least equal to that of the lands previously occupied by them, suitable to provide for their present needs and future development. Where the peoples concerned express a preference for compensation in money or in kind, they shall be so compensated under appropriate guarantees.

5. Persons thus relocated shall be fully compensated for any resulting loss or injury.

Article 17

1. Procedures established by the peoples concerned for the transmission of land rights among members of these peoples shall be respected.

2. The peoples concerned shall be consulted whenever consideration is being given to their capacity to alienate their lands or otherwise transmit their rights outside their own community.

3. Persons not belonging to these peoples shall be prevented from taking of their members to secure the ownership, possession or use of land belonging to them.

Article 18

Adequate penalties shall be established by law for unauthorised intrusion upon, or use of, the lands of the peoples concerned, and governments shall take measures to prevent such offences.

Article 19

National agrarian programmes shall secure to the peoples concerned treatment equivalent to that accorded to other sectors of the population with regard to: (a) the provision of more land for these peoples when they have not the area necessary for providing the essentials of a normal existence, or for any possible increase in their numbers;

(b) the provision of the means required to promote the development of the lands which these peoples already possess.

\section{PART III. RECRUITMENT AND CONDITIONS OF EMPLOYMENT}

\section{Article 20}

1. Governments shall, within the framework of national laws and regulations, and in co-operation with the peoples concerned, adopt special measures to ensure the effective protection with regard to recruitment and conditions of employment of workers belonging to these peoples, to the extent that they are not effectively protected by laws applicable to workers in general.

2. Governments shall do everything possible to prevent any discrimination between workers belonging to the peoples concerned and other workers, in particular as regards:

(a) admission to employment, including skilled employment, as well as measures for promotion and advancement;

(b) equal remuneration for work of equal value;

(c) medical and social assistance, occupational safety and health, all social security benefits and any other occupationally related benefits, and housing; 
(d) the right of association and freedom for all lawful trade union activities, and the right to conclude collective agreements with employers or employers' organisations.

3. The measures taken shall include measures to ensure:

(a) that workers belonging to the peoples concerned, including seasonal, casual and migrant workers in agricultural and other employment, as well as those employed by labour contractors, enjoy the protection afforded by national law and practice to other such workers in the same sectors, and that they are fully informed of their rights under labour legislation and of the means of redress available to them;

(b) that workers belonging to these peoples are not subjected to working conditions hazardous to their health, in particular through exposure to pesticides or other toxic substances;

(c) that workers belonging to these peoples are not subjected to coercive

(d) that workers belonging to these peoples enjoy equal opportunities and equal treatment in employment for men and women, and protection from sexual harassment.

4. Particular attention shall be paid to the establishment of adequate labour inspection services in areas where workers belonging to the peoples concerned undertake wage employment, in order to ensure compliance with the provisions of this Part of this Convention.

\section{PART IV. VOCATIONAL TRAINING, HANDICRAFTS AND RURAL INDUSTRIES}

\section{Article 21}

Members of the peoples concerned shall enjoy opportunities at least equal to those of other citizens in respect of vocational training measures.

Article 22

1. Measures shall be taken to promote the voluntary participation of members of the peoples concerned in vocational training programmes of general application.

2. Whenever existing programmes of vocational training of general application do not meet the special needs of the peoples concerned, governments shall, with the participation of these peoples, ensure the provision of special training programmes and facilities.

3. Any special training programmes shall be based on the economic environment, social and cultural conditions and practical needs of the peoples concerned. Any studies made in this connection shall be carried out in co-operation with these peoples, who shall be consulted on the organisation and operation of such programmes. Where feasible, these peoples shall progressively assume responsibility for the organisation and operation of such special training programmes, if they so decide.

Article 23

1. Handicrafts, rural and community-based industries, and subsistence economy and traditional activities of the peoples concerned, such as hunting, fishing, trapping and gathering, shall be recognised as important factors in the 
maintenance of their cultures and in their economic self-reliance and development. Governments shall, with the participation of these people and whenever appropriate, ensure that these activities are strengthened and promoted.

2. Upon the request of the peoples concerned, appropriate technical and financial assistance shall be provided wherever possible, taking into account the traditional technologies and cultural characteristics of these peoples, as well as the importance of sustainable and equitable development.

\section{PART V. SOCIAL SECURITY AND HEALTH}

\section{Article 24}

Social security schemes shall be extended progressively to cover the peoples concerned, and applied without discrimination against them.

Article 25

1. Governments shall ensure that adequate health services are made available to the peoples concerned, or shall provide them with resources to allow them to design and deliver such services under their own responsibility and control. 2 . Health services shall, to the extent possible, be community-based. These services shall be planned and administered in co-operation with the peoples concerned and take into account their economic, geographic, social and cultural conditions as well as their traditional preventive care, healing practices and medicines.

3. The health care system shall give preference to the training and employment of local community health workers, and focus on primary health care while maintaining strong links with other levels of health care services.

4. The provision of such health services shall be coordinated with other social, economic and cultural measures in the country.

\section{PART VI. EDUCATION AND MEANS OF COMMUNICATION}

\section{Article 26}

Measures shall be taken to ensure that members of the peoples concerned have the opportunity to acquire education at all levels on at least an equal footing with the rest of the national community.

\section{Article 27}

1. Education programmes and services for the peoples concerned shall be developed and implemented in co-operation with them to address their special needs, and shall incorporate their histories, their knowledge and technologies, their value systems and their further social, economic and cultural aspirations. 2. The competent authority shall ensure the training of members of these peoples and their involvement in the formulation and implementation of education programmes, with a view to the progressive transfer of responsibility for the conduct of these programmes to these peoples as appropriate.

3 . In addition, governments shall recognise the right of these peoples to establish their own educational institutions and facilities, provided that such 
institutions meet minimum standards established by the competent authority in consultation with these peoples. Appropriate resources shall be provided for this purpose.

Article 28

1. Children belonging to the peoples concerned shall, wherever practicable, be taught to read and write in their own indigenous language or in the language most commonly used by the group to which they belong. When this is not practicable, the competent authorities shall undertake consultations with these peoples with a view to the adoption of measures to achieve this objective. 2. Adequate measures shall be taken to ensure that these peoples have the opportunity to attain fluency in the national language or in one of the official languages of the country.

3. Measures shall be taken to preserve and promote the development and practice of the indigenous languages of the peoples concerned.

Article 29

The imparting of general knowledge and skills that will help children belonging to the peoples concerned to participate fully and on an equal footing in their own community and in the national community shall be an aim of education for these peoples.

Article 30

1. Governments shall adopt measures appropriate to the traditions and cultures of the peoples concerned, to make known to them their rights and duties, especially in regard to labour, economic opportunities, education and health matters, social welfare and their rights deriving from this Convention. 2. If necessary, this shall be done by means of written translations and through the use of mass communications in the languages of these peoples. Article 31

Educational measures shall be taken among all sections of the national community, and particularly among those that are in most direct contact with the peoples concerned, with the object of eliminating prejudices that they may harbour in respect of these peoples. To this end, efforts shall be made to ensure that history textbooks and other educational materials provide a fair, accurate and informative portrayal of the societies and cultures of these peoples.

\section{PART VII. CONTACTS AND CO-OPERATION ACROSS BORDERS}

\section{Article 32}

Governments shall take appropriate measures, including by means of international agreements, to facilitate contacts and co-operation between indigenous and tribal peoples across borders, including activities in the economic, social, cultural, spiritual and environmental fields. 


\section{PART VIII. ADMINISTRATION}

Article 33

1. The governmental authority responsible for the matters covered in this Convention shall ensure that agencies or other appropriate mechanisms exist to administer the programmes affecting the peoples concerned, and shall ensure that they have the means necessary for the proper fulfilment of the functions assigned to them.

2. These programmes shall include:

(a) the planning, co-ordination, execution and evaluation, in co-operation with the peoples concerned, of the measures provided for in this Convention;

(b) the proposing of legislative and other measures to the competent authorities and supervision of the application of the measures taken, in co-operation with the peoples concerned.

\section{PART IX. GENERAL PROVISIONS}

\section{Article 34}

The nature and scope of the measures to be taken to give effect to this Convention shall be determined in a flexible manner, having regard to the conditions characteristic of each country.

\section{Article 35}

The application of the provisions of this Convention shall not adversely affect rights and benefits of the peoples concerned pursuant to other Conventions and Recommendations, international instruments, treaties, or national laws, awards, custom or agreements.

\section{PART X. FINAL PROVISIONS}

\section{Article 36}

This Convention revises the Indigenous and Tribal Populations Convention, 1957.

Article 37

The formal ratifications of this Convention shall be communicated to the Director-General of the International Labour Office for registration.

Article 38

1. This Convention shall be binding only upon those Members of the International Labour Organisation whose ratifications have been registered with the Director-General.

2. It shall come into force twelve months after the date on which the ratifications of two Members have been registered with the Director-General. 3. Thereafter, this Convention shall come into force for any Member twelve months after the date on which its ratification has been registered.

Article 39

1. A Member which has ratified this Convention may denounce it after the expiration of ten years from the date on which the Convention first comes into 
force, by an act communicated to the Director-General of the International Labour Office for registration. Such denunciation shall not take effect until one year after the date on which it is registered.

2. Each Member which has ratified this Convention and which does not, within the year following the expiration of the period of ten years mentioned in the preceding paragraph, exercise the right of denunciation provided for in this Article, will be bound for another period of ten years and, thereafter, may denounce this Convention at the expiration of each period of ten years under the

terms provided for in this Article.

Article 40

1. The Director-General of the International Labour Office shall notify all Members of the International Labour Organisation of the registration of all ratifications and denunciations communicated to him by the Members of the Organisation.

2. When notifying the Members of the Organisation of the registration of the second ratification communicated to him, the Director-General shall draw the attention of the Members of the Organisation to the date upon which the Convention will come into force.

Article 41

The Director-General of the International Labour Office shall communicate to the SecretaryGeneral of the United Nations for registration in accordance with Article 102 of the Charter of the United Nations full particulars of all ratifications and acts of denunciation registered by him in accordance with the provisions of the preceding Articles.

Article 42

At such times as it may consider necessary the Governing Body of the

International Labour Office shall present to the General Conference a report on the agenda of the Conference the question of its revision in whole or in part.

Article 43

1. Should the Conference adopt a new Convention revising this Convention in whole or in part, then, unless the new Convention otherwise provides -

(a) the ratification by a Member of the new revising Convention shall ipso jure involve the immediate denunciation of this Convention, notwithstanding the provisions of Article 39 above, if and when the new revising Convention shall have come into force;

(b) as from the date when the new revising Convention comes into force this Convention shall cease to be open to ratification by the Members.

2. This Convention shall in any case remain in force in its actual form and content for those Members which have ratified it but have not ratified the revising Convention.

Article 44

The English and French versions of the text of this Convention are equally authoritative. 


\section{Appendix 2: Agenda 21 of the Rio Earth Summit}

\section{Programme Area}

\section{Basis for action}

1. Indigenous people and their communities have an historical relationship with their lands and are generally descendants of the original inhabitants of such lands. In the context of this chapter the term "lands" is understood to include the environment of the areas which the people concerned traditionally occupy. Indigenous people and their communities represent a significant percentage of the global population. They have developed over many generations a holistic traditional scientific knowledge of their lands, natural resources and environment. Indigenous people and their communities shall enjoy the full measure of human rights and fundamental freedoms without hindrance or discrimination. Their ability to participate fully in sustainable development practices on their lands has tended to be limited as a result of factors of an economic, social and historical nature. In view of the interrelationship between the natural environment and its sustainable development and the cultural, social, economic and physical well-being of indigenous people, national and international efforts to implement environmentally sound and sustainable development should recognize, accommodate, promote and strengthen the role of indigenous people and their communities.

2. Some of the goals inherent in the objectives and activities of this programme area are already contained in such international legal instruments as the ILO Indigenous and Tribal Peoples Convention (No. 169) and are being incorporated into the draft universal declaration on indigenous rights, being prepared by the United Nations working group on indigenous populations. The International Year for the World's Indigenous People (1993), proclaimed by the General Assembly in its resolution 45/164 of 18 December 1990, presents a timely opportunity to mobilize further international technical and financial cooperation.

\section{Objectives}

3. In full partnership with indigenous people and their communities, Governments and, where appropriate, intergovernmental organizations should aim at fulfilling the following objectives:

a. Establishment of a process to empower indigenous people and their communities through measures that include:

i. Adoption or strengthening of appropriate policies and/or legal instruments at the national level;

ii. Recognition that the lands of indigenous people and their communities should be protected from activities that are environmentally unsound or that the indigenous people concerned 
consider to be socially and culturally inappropriate;

iii. Recognition of their values, traditional knowledge and resource management practices with a view to promoting environmentally sound and sustainable development;

iv. Recognition that traditional and direct dependence on renewable resources and ecosystems, including sustainable harvesting, continues to be essential to the cultural, economic and physical well-being of indigenous people and their communities;

v. Development and strengthening of national dispute-resolution arrangements in relation to settlement of land and resource-management concerns;

vi. Support for alternative environmentally sound means of production to ensure a range of choices on how to improve their quality of life so that they effectively participate in sustainable development;

vii. Enhancement of capacity-building for indigenous communities, based on the adaptation and exchange of traditional experience, knowledge and resource-management practices, to ensure their sustainable development;

b. Establishment, where appropriate, of arrangements to strengthen the active participation of indigenous people and their communities in the national formulation of policies, laws and programmes relating to resource management and other development processes that may affect them, and their initiation of proposals for such policies and programmes;

c. Involvement of indigenous people and their communities at the national and local levels in resource management and conservation strategies and other relevant programmes established to support and review sustainable development strategies, such as those suggested in other programme areas of Agenda 21.

\section{Activities}

4. Some indigenous people and their communities may require, in accordance with national legislation, greater control over their lands, self-management of their resources, participation in development decisions affecting them, including, where appropriate, participation in the establishment or management of protected areas. The following are some of the specific measures which Governments could take:

a. Consider the ratification and application of existing international conventions relevant to indigenous people and their communities (where not yet done) and provide support for the adoption by the General Assembly of a declaration on indigenous rights;

b. Adopt or strengthen appropriate policies and/or legal instruments that will protect indigenous intellectual and cultural property and the right to preserve customary and administrative systems 
and practices.

5. United Nations organizations and other international development and finance organizations and Governments should, drawing on the active participation of indigenous people and their communities, as appropriate, take the following measures, inter alia, to incorporate their values, views and knowledge, including the unique contribution of indigenous women, in resource management and other policies and programmes that may affect them:

a. Appoint a special focal point within each international organization, and organize annual interorganizational coordination meetings in consultation with Governments and indigenous organizations, as appropriate, and develop a procedure within and between operational agencies for assisting Governments in ensuring the coherent and coordinated incorporation of the views of indigenous people in the design and implementation of policies and programmes. Under this procedure, indigenous people and their communities should be informed and consulted and allowed to participate in national decision-making, in particular regarding regional and international cooperative efforts. In addition, these policies and programmes should take fully into account strategies based on local indigenous initiatives;

b. Provide technical and financial assistance for capacity-building programmes to support the sustainable self-development of indigenous people and their communities;

c. Strengthen research and education programmes aimed at:

i. Achieving a better understanding of indigenous people's knowledge and management experience related to the environment, and applying this to contemporary development challenges;

ii. Increasing the efficiency of indigenous people's resource management systems, for example, by promoting the adaptation and dissemination of suitable technological innovations;

d. Contribute to the endeavours of indigenous people and their communities in resource management and conservation strategies (such as those that may be developed under appropriate projects funded through the Global Environment Facility and the Tropical Forestry Action Plan) and other programme areas of Agenda 21, including programmes to collect, analyse and use data and other information in support of sustainable development projects.

6. Governments, in full partnership with indigenous people and their communities should, where appropriate:

a. Develop or strengthen national arrangements to consult with indigenous people and their communities with a view to reflecting their needs and incorporating their values and traditional and other knowledge and practices in national policies and programmes in the field of natural resource management and conservation and other development programmes affecting them; 
b. Cooperate at the regional level, where appropriate, to address common indigenous issues with a view to recognizing and strengthening their participation in sustainable development.

\section{Means of implementation}

\section{(a) Financing and cost evaluation}

7. The Conference secretariat has estimated the average total annual cost (1993-2000) of implementing the activities of this programme to be about $\$ 3$ million on grant or concessional terms. These are indicative and order-of-magnitude estimates only and have not been reviewed by Governments. Actual costs and financial terms, including any that are non-concessional, will depend upon, inter alia, the specific strategies and programmes Governments decide upon for implementation.

\section{(b) Legal and administrative frameworks}

8. Governments should incorporate, in collaboration with the indigenous people affected, the rights and responsibilities of indigenous people and their communities in the legislation of each country, suitable to the country's specific situation. Developing countries may require technical assistance to implement these activities.

\section{(c) Human resource development}

9. International development agencies and Governments should commit financial and other resources to education and training for indigenous people and their communities to develop their capacities to achieve their sustainable self-development, and to contribute to and participate in sustainable and equitable development at the national level. Particular attention should be given to strengthening the role of indigenous women. 


\section{Appendix 3: The Declaration on the Rights of Indigenous People (DRIP)}

Concerned that indigenous peoples have suffered from historic injustices as a result of, inter alia, their colonization and dispossession of their lands, territories and resources, thus preventing them from exercising, in particular, their right to development in accordance with their own needs and interests,

Recognizing the urgent need to respect and promote the inherent rights of indigenous peoples which derive from their political, economic and social structures and from their cultures, spiritual traditions, histories and philosophies, especially their rights to their lands, territories and resources,

Convinced that control by indigenous peoples over developments affecting them and their lands, territories and resources will enable them to maintain and strengthen their institutions, cultures and traditions, and to promote their development in accordance with their aspirations and needs,

Adopts the following articles of the DRIP;

\section{Article 1}

Indigenous peoples have the right to the full enjoyment, as a collective or as individuals, of all human rights and fundamental freedoms as recognized in the Charter of the United Nations, the Universal Declaration of Human Rights and international human rights law.

\section{Article 2}

Indigenous peoples and individuals are free and equal to all other peoples and individuals and have the right to be free from any kind of discrimination, in the exercise of their rights, in particular that based on their indigenous origin or identity.

\section{Article 3}

Indigenous peoples have the right to self-determination. By virtue of that right they freely determine their political status and freely pursue their economic, social and cultural development.

\section{Article 4}

Indigenous peoples, in exercising their right to self-determination, have the right to autonomy or selfgovernment in matters relating to their internal and local affairs, as well as ways and means for financing their autonomous functions.

\section{Article 5}

Indigenous peoples have the right to maintain and strengthen their distinct political, legal, economic, social and cultural institutions, while retaining their right to participate fully, if they so choose, in the political, economic, social and cultural life of the State.

\section{Article 6}

Every indigenous individual has the right to a nationality.

\section{Article 7}

1. Indigenous individuals have the rights to life, physical and mental integrity, liberty and security of person.

2. Indigenous peoples have the collective right to live in freedom, peace and security as distinct 
peoples and shall not be subjected to any act of genocide or any other act of violence, including forcibly removing children of the group to another group.

\section{Article 8}

1. Indigenous peoples and individuals have the right not to be subjected to forced assimilation or destruction of their culture.

2. States shall provide effective mechanisms for prevention of, and redress for:

(a) Any action which has the aim or effect of depriving them of their integrity as distinct peoples, or of their cultural values or ethnic identities;

(b) Any action which has the aim or effect of dispossessing them of their lands, territories or resources;

(c) Any form of forced population transfer which has the aim or effect of violating or undermining any of their rights;

(d) Any form of forced assimilation or integration;

(e) Any form of propaganda designed to promote or incite racial or ethnic discrimination directed against them.

\section{Article 9}

Indigenous peoples and individuals have the right to belong to an indigenous community or nation, in accordance with the traditions and customs of the community or nation concerned. No discrimination of any kind may arise from the exercise of such a right.

\section{Article 10}

Indigenous peoples shall not be forcibly removed from their lands or territories. No relocation shall take place without the free, prior and informed consent of the indigenous peoples concerned and after agreement on just and fair compensation and, where possible, with the option of return.

\section{Article 11}

1. Indigenous peoples have the right to practise and revitalize their cultural traditions and customs. This includes the right to maintain, protect and develop the past, present and future manifestations of their cultures, such as archaeological and historical sites, artefacts, designs, ceremonies, technologies and visual and performing arts and literature.

2. States shall provide redress through effective mechanisms, which may include restitution, developed in conjunction with indigenous peoples, with respect to their cultural, intellectual, religious and spiritual property taken without their free, prior and informed consent or in violation of their laws, traditions and customs.

\section{Article 12}

1. Indigenous peoples have the right to manifest, practise, develop and teach their spiritual and religious traditions, customs and ceremonies; the right to maintain, protect, and have access in privacy to their religious and cultural sites; the right to the use and control of their ceremonial objects; and the right to the repatriation of their human remains.

2. States shall seek to enable the access and/or repatriation of ceremonial objects and human remains in their possession through fair, transparent and effective mechanisms developed in conjunction with indigenous peoples concerned.

\section{Article 13}

1. Indigenous peoples have the right to revitalize, use, develop and transmit to future generations their histories, languages, oral traditions, philosophies, writing systems and literatures, and to designate and retain their own names for communities, places and persons.

2. States shall take effective measures to ensure that this right is protected and also to ensure that 
indigenous peoples can understand and be understood in political, legal and administrative proceedings, where necessary through the provision of interpretation or by other appropriate means.

\begin{abstract}
Article 14
1. Indigenous peoples have the right to establish and control their educational systems and institutions providing education in their own languages, in a manner appropriate to their cultural methods of teaching and learning.

2. Indigenous individuals, particularly children, have the right to all levels and forms of education of the State without discrimination.

3. States shall, in conjunction with indigenous peoples, take effective measures, in order for indigenous individuals, particularly children, including those living outside their communities, to have access, when possible, to an education in their own culture and provided in their own language.
\end{abstract}

\title{
Article 15
}

1. Indigenous peoples have the right to the dignity and diversity of their cultures, traditions, histories and aspirations which shall be appropriately reflected in education and public information.

2. States shall take effective measures, in consultation and cooperation with the indigenous peoples concerned, to combat prejudice and eliminate discrimination and to promote tolerance, understanding and good relations among indigenous peoples and all other segments of society.

\section{Article 16}

1. Indigenous peoples have the right to establish their own media in their own languages and to have access to all forms of non-indigenous media without discrimination.

2. States shall take effective measures to ensure that State-owned media duly reflect indigenous cultural diversity. States, without prejudice to ensuring full freedom of expression, should encourage privately owned media to adequately reflect indigenous cultural diversity.

\section{Article 17}

1. Indigenous individuals and peoples have the right to enjoy fully all rights established under applicable international and domestic labour law.

2. States shall in consultation and cooperation with indigenous peoples take specific measures to protect indigenous children from economic exploitation and from performing any work that is likely to be hazardous or to interfere with the child's education, or to be harmful to the child's health or physical, mental, spiritual, moral or social development, taking into account their special vulnerability and the importance of education for their empowerment.

3. Indigenous individuals have the right not to be subjected to any discriminatory conditions of labour and, inter alia, employment or salary.

\section{Article 18}

Indigenous peoples have the right to participate in decision-making in matters which would affect their rights, through representatives chosen by themselves in accordance with their own procedures, as well as to maintain and develop their own indigenous decision-making institutions.

\section{Article 19}

States shall consult and cooperate in good faith with the indigenous peoples concerned through their own representative institutions in order to obtain their free, prior and informed consent before adopting and implementing legislative or administrative measures that may affect them.

\section{Article 20}

1. Indigenous peoples have the right to maintain and develop their political, economic and social systems or institutions, to be secure in the enjoyment of their own means of subsistence and 
development, and to engage freely in all their traditional and other economic activities.

2. Indigenous peoples deprived of their means of subsistence and development are entitled to just and fair redress.

\section{Article 21}

1. Indigenous peoples have the right, without discrimination, to the improvement of their economic and social conditions, including, inter alia, in the areas of education, employment, vocational training and retraining, housing, sanitation, health and social security.

2. States shall take effective measures and, where appropriate, special measures to ensure continuing improvement of their economic and social conditions. Particular attention shall be paid to the rights and special needs of indigenous elders, women, youth, children and persons with disabilities.

\section{Article 22}

1. Particular attention shall be paid to the rights and special needs of indigenous elders, women, youth, children and persons with disabilities in the implementation of this Declaration.

2. States shall take measures, in conjunction with indigenous peoples, to ensure that indigenous women and children enjoy the full protection and guarantees against all forms of violence and discrimination.

\section{Article 23}

Indigenous peoples have the right to determine and develop priorities and strategies for exercising their right to development. In particular, indigenous peoples have the right to be actively involved in developing and determining health, housing and other economic and social programmes affecting them and, as far as possible, to administer such programmes through their own institutions.

\section{Article 24}

1. Indigenous peoples have the right to their traditional medicines and to maintain their health practices, including the conservation of their vital medicinal plants, animals and minerals. Indigenous individuals also have the right to access, without any discrimination, to all social and health services. 2. Indigenous individuals have an equal right to the enjoyment of the highest attainable standard of physical and mental health. States shall take the necessary steps with a view to achieving progressively the full realization of this right.

\section{Article 25}

Indigenous peoples have the right to maintain and strengthen their distinctive spiritual relationship with their traditionally owned or otherwise occupied and used lands, territories, waters and coastal seas and other resources and to uphold their responsibilities to future generations in this regard.

\section{Article 26}

1. Indigenous peoples have the right to the lands, territories and resources which they have traditionally owned, occupied or otherwise used or acquired.

2. Indigenous peoples have the right to own, use, develop and control the lands, territories and resources that they possess by reason of traditional ownership or other traditional occupation or use, as well as those which they have otherwise acquired.

3. States shall give legal recognition and protection to these lands, territories and resources. Such recognition shall be conducted with due respect to the customs, traditions and land tenure systems of the indigenous peoples concerned.

\section{Article 27}

States shall establish and implement, in conjunction with indigenous peoples concerned, a fair, independent, impartial, open and transparent process, giving due recognition to indigenous peoples' 
laws, traditions, customs and land tenure systems, to recognize and adjudicate the rights of indigenous peoples pertaining to their lands, territories and resources, including those which were traditionally owned or otherwise occupied or used. Indigenous peoples shall have the right to participate in this process.

\section{Article 28}

1. Indigenous peoples have the right to redress, by means that can include restitution or, when this is not possible, just, fair and equitable compensation, for the lands, territories and resources which they have traditionally owned or otherwise occupied or used, and which have been confiscated, taken, occupied, used or damaged without their free, prior and informed consent.

2. Unless otherwise freely agreed upon by the peoples concerned, compensation shall take the form of lands, territories and resources equal in quality, size and legal status or of monetary compensation or other appropriate redress.

\section{Article 29}

1. Indigenous peoples have the right to the conservation and protection of the environment and the productive capacity of their lands or territories and resources. States shall establish and implement assistance programmes for indigenous peoples for such conservation and protection, without discrimination.

2. States shall take effective measures to ensure that no storage or disposal of hazardous materials shall take place in the lands or territories of indigenous peoples without their free, prior and informed consent.

3. States shall also take effective measures to ensure, as needed, that programmes for monitoring, maintaining and restoring the health of indigenous peoples, as developed and implemented by the peoples affected by such materials, are duly implemented.

\section{Article 30}

1. Military activities shall not take place in the lands or territories of indigenous peoples, unless justified by a relevant public interest or otherwise freely agreed with or requested by the indigenous peoples concerned.

2. States shall undertake effective consultations with the indigenous peoples concerned, through appropriate procedures and in particular through their representative institutions, prior to using their lands or territories for military activities.

\section{Article 31}

1. Indigenous peoples have the right to maintain, control, protect and develop their cultural heritage, traditional knowledge and traditional cultural expressions, as well as the manifestations of their sciences, technologies and cultures, including human and genetic resources, seeds, medicines, knowledge of the properties of fauna and flora, oral traditions, literatures, designs, sports and traditional games and visual and performing arts. They also have the right to maintain, control, protect and develop their intellectual property over such cultural heritage, traditional knowledge, and traditional cultural expressions.

2. In conjunction with indigenous peoples, States shall take effective measures to recognize and protect the exercise of these rights.

\section{Article 32}

1. Indigenous peoples have the right to determine and develop priorities and strategies for the development or use of their lands or territories and other resources.

2. States shall consult and cooperate in good faith with the indigenous peoples concerned through their own representative institutions in order to obtain their free and informed consent prior to the approval of any project affecting their lands or territories and other resources, particularly in 
connection with the development, utilization or exploitation of mineral, water or other resources. 3. States shall provide effective mechanisms for just and fair redress for any such activities, and appropriate measures shall be taken to mitigate adverse environmental, economic, social, cultural or spiritual impact.

\section{Article 33}

1. Indigenous peoples have the right to determine their own identity or membership in accordance with their customs and traditions. This does not impair the right of indigenous individuals to obtain citizenship of the States in which they live.

2. Indigenous peoples have the right to determine the structures and to select the membership of their institutions in accordance with their own procedures.

\section{Article 34}

Indigenous peoples have the right to promote, develop and maintain their institutional structures and their distinctive customs, spirituality, traditions, procedures, practices and, in the cases where they exist, juridical systems or customs, in accordance with international human rights standards.

\section{Article 35}

Indigenous peoples have the right to determine the responsibilities of individuals to their communities.

\section{Article 36}

1. Indigenous peoples, in particular those divided by international borders, have the right to maintain and develop contacts, relations and cooperation, including activities for spiritual, cultural, political, economic and social purposes, with their own members as well as other peoples across borders.

2. States, in consultation and cooperation with indigenous peoples, shall take effective measures to facilitate the exercise and ensure the implementation of this right.

\section{Article 37}

1. Indigenous peoples have the right to the recognition, observance and enforcement of treaties, agreements and other constructive arrangements concluded with States or their successors and to have States honour and respect such treaties, agreements and other constructive arrangements. 2. Nothing in this Declaration may be interpreted as diminishing or eliminating the rights of indigenous peoples contained in treaties, agreements and other constructive arrangements.

\section{Article 38}

States in consultation and cooperation with indigenous peoples, shall take the appropriate measures, including legislative measures, to achieve the ends of this Declaration.

\section{Article 39}

Indigenous peoples have the right to have access to financial and technical assistance from States and through international cooperation, for the enjoyment of the rights contained in this Declaration.

\section{Article 40}

Indigenous peoples have the right to access to and prompt decision through just and fair procedures for the resolution of conflicts and disputes with States or other parties, as well as to effective remedies for all infringements of their individual and collective rights. Such a decision shall give due consideration to the customs, traditions, rules and legal systems of the indigenous peoples concerned and international human rights. 


\title{
Article 41
}

The organs and specialized agencies of the United Nations system and other intergovernmental organizations shall contribute to the full realization of the provisions of this Declaration through the mobilization, inter alia, of financial cooperation and technical assistance. Ways and means of ensuring participation of indigenous peoples on issues affecting them shall be established.

\section{Article 42}

The United Nations, its bodies, including the Permanent Forum on Indigenous Issues, and specialized agencies, including at the country level, and States shall promote respect for and full application of the provisions of this Declaration and follow up the effectiveness of this Declaration.

\section{Article 43}

The rights recognized herein constitute the minimum standards for the survival, dignity and wellbeing of the indigenous peoples of the world.

\section{Article 44}

All the rights and freedoms recognized herein are equally guaranteed to male and female indigenous individuals.

\section{Article 45}

Nothing in this Declaration may be construed as diminishing or extinguishing the rights indigenous peoples have now or may acquire in the future.

\begin{abstract}
Article 46
1. Nothing in this Declaration may be interpreted as implying for any State, people, group or person any right to engage in any activity or to perform any act contrary to the Charter of the United Nations or construed as authorizing or encouraging any action which would dismember or impair, totally or in part, the territorial integrity or political unity of sovereign and independent States.

2. In the exercise of the rights enunciated in the present Declaration, human rights and fundamental freedoms of all shall be respected. The exercise of the rights set forth in this Declaration shall be subject only to such limitations as are determined by law and in accordance with international human rights obligations. Any such limitations shall be non-discriminatory and strictly necessary solely for the purpose of securing due recognition and respect for the rights and freedoms of others and for meeting the just and most compelling requirements of a democratic society.

3. The provisions set forth in this Declaration shall be interpreted in accordance with the principles of justice, democracy, and respect for human rights, equality, non-discrimination, good governance and good faith.
\end{abstract}




\section{Appendix 4: Ogiek Rural Integral Projects on the Mau Forest evictions OGIEK RURAL INTEGRAL PROJECTS (ORIP)}

\author{
DISTRICT INFORMATION BUILDING \\ P.O. BOX 741, NAROK KENYA \\ TEL: 254-50-23417/23206
}

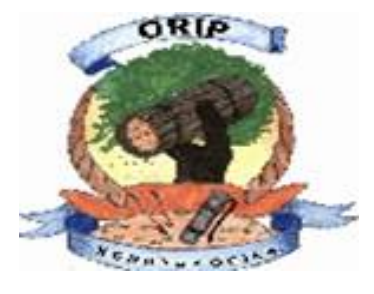

I-MAIL: info@orip.or.ke

Website: www.orip.or.ke

Date: June 10, 2005

\section{MAU FOREST EVICTIONS}

The Kenyan government continues to evict people from the Mau Narok forest west of Narok and over 3,000 Ogiek so far are homeless. The total number of Ogiek evicted in Narok district numbers over 3,500 people. If the exercise is not halted and dialogue sought over 10,000 Ogiek people will be affected.

Despite the fact that the Ogiek are the original inhabitants and the territorial owners of the Mau forest, they continue to suffer in the hands of Kenyan authorities.

The government has not come up with clear eviction policies and on housing rights hence contravening the constitution of Kenya.

We are appealing to our government to reconsider its decision and spare the Ogiek further harassment and eviction. We further appeal to our friends to pressure the government to respect indigenous peoples rights as enshrined in International Covenants and Instruments some of which Kenya is signatory.

Yours sincerely,

CHARLES SAINA SENA, EXECUTIVE DIRECTOR;ORIP 


\section{Appendix 5: Open letter from the Ogiek people to the president of Kenya}

\section{BONA FIDE HUMAN RIGHTS MONITOR}

P.O BOX 12069

NAKURU

Date: 07/06/2005

H.E. PRESIDENT

MWAI KIBAKI

STATE HOUSE

NAIROBI, KENYA
TEL:051212736

TEL:020574998

\section{RE: KINDLY SAVE THE OGIEK OF KENYA FROM EVICTION:}

Dear President,

This is to bring the above subject into your concern.

The Ogiek are the remaining forest dwellers who reside in Mau complex per history before 1900. These comprises of Narok South, Nakuru and Mt. Elgon. The Ogiek are the caretakers of fauna and flora since time memorial. They suffered through the previous regime hence voted you as "Kibaki Tosha" 2002. The Ogiek are supporting your decision in condemning and fighting corruption within all sectors of the Republic. Congratulations for your entire effort as the president as you even promised the Ogiek in Tinet for the title deeds last year.

Despite them having no members of parliament of their own, nor nominated neither spokesman, they rely on the provincial administration to reach your office for their grievances.

\section{Cry for justice}

Recently the Narok District commissioner Mr. Farah Hassan deployed administrative police, forest guards and Narok county council security to torch and or burn their homes and houses. The affected areas are Enaikishomi former group ranch number 115 with approx. 300 title deeds and Nkaroni former group ranch number 118 with approx. 1,000 title deeds. The DC didn't consult the elders from the area hence officers rushing anyhow torching their houses.

The two ranches are the Ogiek reserves allocated to them through land adjudication. The 
government surveyors and the minister of land issued the community with title deeds after the whole process was implemented.

By torching their houses, slaughtering animals, burning of schools etc. the DC is staining the reputation and or the image of your government in the observation of human rights law.

Some Maasai groups like 'Friends of Mau forest conservation Association' are seriously fundraising money and inciting pressure to the perpetrators to evict only Ogiek. This association and World Wide Fund for Nature (WWF) or is it Frog pretends to protect Mau but in real sense they are the targeted beneficial.

Only Ogiek groups have been the targets of displacement as the association have raised more than Kshs 500,000 to facilitate the same. Hence the big question is: Why as the government neglected this community and back the Maasai? Why all this sort of injustices on human rights violation? Is it due that the Maasai have got the Minister and the MPs while this small community have got no post in your government at all?

\section{Demand}

(1) The Ogiek community has got nowhere else to go except to remain in their ancestral land with their title deeds.

(2) We can not rule out the possibility of clashes, if the whole matter is overlooked and is not addressed. So kindly take serious measures in advance.

(3) Hon. William Ole Ntimama is the main culprit who incites the Provincial Administration to evict the Ogiek in Enoo Supukia, Sasimwani, Nkaroni and Enaikishomi

(4) The Minister should come clean and declare that the Kikuyu, the Kipsigis and the rest of the tribes should keep off setting foot in Narok, with the intention to live or buy land in Narok districts.

(6) Kindly provide the Ogiek with such positions as DC's, D.O's. in your government.

(7) The Mau forest should remain the Ogiek home henceforth

(8) Kindly stop the ongoing eviction by Narok county council and act on the Ndung'u recommendations besides giving Kenyans a new constitution,

Lastly but not least, Sir, the Ogiek are kindly requesting for your protection from the hands of the butchers of Kenya.

Hoping for your urgent response soon.

Yours Faithfully, 
PETER KIPLANGAT.

BONA FIDE HUMAN RIGHTS MONITOR

NAKURU.

For the undersign.

1. John Koipitat Sena.

2. Daniel Sulunye

3. Simon Sena

4. Moses Rana

5. Johnstone Kipterer

6. Joseph Mapelu 


\section{References}

Abega, S. (1998). Les Pygmees Baka: Le droit a la difference. Yaounde, Cameroon.

Adams, W., Hutton, J. (2007). People, Parks and Poverty: Political ecology and biodiversity conservation. Conservation and Society, 5 (2), 147-183

Agrawal, A., Gibson, C. (1999). Enchantment and disenchantment: The role of community in natural resource conservation. World Development, 27, 629649

Agrawal, A., Redford, K. (2009). Conservation and Displacement: An overview. Conservation and Society, 7(1), 1-10.

Alcorn, J. (1993). Indigenous people and conservation. Conservation Biology, 7 (2), 424-426.

Alpert, P. (1993). Conserving biodiversity in Cameroon. Ambio, 12 (1), 44-49.

Ampornpan, L., Dhillion, S (2003). The environment of Na Haeo, Thailand: Biodiversity, non-timber products, landuse and conservation. Bangkok: Craftsman Press.

Anderson, J., Gauthier, M., Thomas, G., Wondolleck, J. (1996). Setting the stage. Forests, Trees and People Programme. FAO, Rome

Ashley, R., Mbile, P. (2005). The policy terrain in protected area landscapes: How laws and institutions affect conservation, livelihoods and agroforestry in the landscapes surrounding Campo Ma'an National Park and The Dja Biosphere Reserve, Cameroon. Agroforestry in landscape mosaics Working Paper Series, World Agroforestry Centre, tropical Resources Institute of Yale University, and the University of Georgia.

Ayling, R., Kelly, K. (1997). Dealing with conflict: Natural resources and dispute resolution. Commonwealth Forestry Review, 76 (3), 182-185.

Bahuchet, S. (1991) Spatial mobility and access to resources among the African Pygmies. In: Casimir, M., Rao, A. Mobility and territoriality; social and spatial boundaries among foragers, fishers and pastoralists. Berg Publishers, Oxford and New York, 205-257

Bassi, M. (2003). Enhancing equity in the relationship between protected areas and local communities in the context of global change: horn of Africa and Kenya. TILCEPA report. www.iucn.org/themes/ceesp/Wkg_grp/TILCEPA/commu nity.htm 
BBC. (2010), South African Military to join rhino poaching fight. www.bbc.co.uk, Accessed November 7, 2010.

Berkes, F. (Ed.). (1993). Traditional ecological knowledge in perspective. Ottawa: International program on traditional ecological knowledge and international development research centre.

Berkes, F. (1999). Sacred Ecology:TEK and Resource Management. Philadelphia: Taylor and Francis.

Borrini-Feyerabend, G., Kothari, A., Oviedo, G., Phillips, A. (2004). Indigenous and local communities and Protected Areas: Towards equity and enhanced conservation. IUCN/WCPA, Series 11.

Brandon, K. (1997). Policy and practical considerations in land-use strategies for biodiversity conservation. In Last stand: Protected areas and the defense of tropical biodiversity, eds. R. A. Kramer, C. P. van Schaik, and J. Johnson, 90-114. New York: Oxford University Press.

Brandon, K., K. H. Redford, and S. E. Sanderson, eds. (1998). Parks in peril: People, politics, and protected areas. Washington, DC: Island Press.

Brockington, D., Igoe, J. (2006). Eviction for Conservation: A global overview. conservation and Society, 4 (3), 424-470.

Brockington, D., Igoe, J., Schmidt-Soltau, K (2006). Conservation, Human Rights and Poverty Reduction. Conservation Biology, 20 (1), 250-252.

Brockington, D., Scholfield, K. (2010). The work of conservation organisations in sub-Saharan Africa. Journal of Modern African Studies, 48 (1), 1-33.

Brockington, D., Schmidt-Soltau, K. (2004). The social and environmental impacts of wilderness and development. Oryx, 38 (2), 140-142.

Brown, K. (2002). Innovations for conservation and development. The Geographical Journal. 168 (1), 6-17.

Burger, J. (1997). United Nations Draft Declaration on the Rights of Indigenous People. St. Thomas Law Review. 209-229.

Byrne, D. (2008). Authoritarian conservation and its alternatives. Transforming Cultures eJournal, 3 (1), 404-410

Callister, D. (1999). Corrupt and illegal activities in the forestry sector: Current understandings and implications for World Bank forestry policy. World Bank, Washington DC. 
Carroll, R.W. (1992). The Development, Protection and Management of the Dzangha- Sangha Dense Forest Special Reserve and Dzangha-Ndoki National Park in Southwestern Central African Republic. Bangui: WWFPress.

Carruthers, J. (1995). The Kruger National Park: A social and political history. Natal University Press, Durban

CBD (2004). Convention on Biological Diversity. Available from www.biodiv.org (accessed May 2010)

Cernea, M. M. (1997). The Risks and Reconstruction model for Resettling Displaced Populations. World Development, 25(10), 1569-1589.

Cernea, M. M. (2000). Risk, safeguards and reconstruction: a model for Population displacement and resettlement. In: Cernea, M. M. \& McDowell, C. Risk and reconstruction: experiences of resettlers and refugees. Washington: World Bank.

Cernea, M. M. (2002). For a New Economics of Resettlement: A Sociological Critique of the Compensation Principle. Unpublished manuscript, Ithaca.

Cernea, M. M. (2006). Population displacement inside protected areas: a redefinition of concepts in conservation policies. Policy matters, 14, 8-23.

Cernea, M. M., Schmidt-Soltau, K. (2003). National Parks and Poverty Risks: Is Population Resettlement the Solution? Paper presentation at The International Conference on Rural Livelihoods, Forests, and Biodiversity, Bonn, Germany

Cernea, M. M., Schmidt-Soltau, K. (2006). Poverty Risks and National Parks: Policy issues in conservation and resettlement. World Development

Chapin, M. (2004). A challenge to conservationists. World Watch Magazine, Nov/Dec: $17-31$

Chatty, D., Colchester, M. (2002). Conservation and mobile indigenous peoples: Displacements, forced settlement and sustainable development. Berghahn, Oxford, UK.

Christensen, J. (2004). Win-Win illusions. Conservation in Practice, 5 (1), 12-19

Clynes, T. (2002). They shoot poachers, don't they? Observer Magazine, 24, November 2004, 34-47. 
Coate, S., Loury, G. (1993) Will affirmative action policies eliminate negative stereotypes? The American Economic Review, 83 (5), 1220-1240.

Coelho, G. V. \& Stein, J.J. (1980). Change, vulnerability, and coping: stress of uprooting and overcrowding. In: Coelho, G. V. \& Amed, P.I. (Eds.). Uprooting and development. New York: Plenium Press.

Cohen, M. N. \& Armelegos, G. (1984). Paleopathology and the origins of agriculture. Orlando: Academic Press.

Cohen, M. N. (1989). Health and the rise of civilisation. New Haven \& London: Yale University Press.

Colchester, M. (1994). Salvaging Nature: Indigenous people, protected areas and biodiversity conservation. UNRISD discussion paper. Geneva: United Nations Research Institute for Social Development.

Colchester, M. (1997). Salvaging Nature: Indigenous people and protected areas. In: Ghimire \& Pimbert 1997.

Conservation Refugees (2006). Ethiopia: Mursi land threatened by government. www.conservationrefugees.org (accessed 18 July 2010).

Corrie, D. (2009). The Ogiek: the ghost tribe of Kenya. Pan-tribal Confederacy of Indigenous Tribal Nations. Paper presented at the eighth Session of the United Nations Permanent Forum on Indigenous Issues (UNPFII), in New York City; May 18-29th May 2009.

De Koning, R. (2009). ACM as a tool for conflict management: In Search of Common Ground: Adaptive Collaborative management in Cameroon. CIFOR, Indonesia.

Dewey, K. G. (1981). Nutritional consequences of the transformation from subsistence to commercial agriculture in Tabasco. Mexico. Human Ecology 9:157-181.

Dounias, E., Froment, A. (2006). When forest-based hunter-gatherers become sedentary: Consequences for diet and health. Unasylva, 57, 26-32.

Dowie, M. (2006). Conservation Refugees: When protecting nature means kicking people out. Orion, November/December.

Dowie, M. (2009) Conservation Refugees. The Hundred-Year Conflict between Conservation and Native Peoples. MIT Press, Massachusetts 
Duncan, C.R. \& McElwee, P.D. (1999). Conservation at what cost? The logic of sedentarization, resettlement and displacement in Southeast Asia. Paper presented at the Conference Displacement, Forced Settlement and Conservation. St. Anne's College, Oxford.

Egbe, S. (2001). The concept of community forestry under Cameroonian law. Journal of African Law, 45 (1), 25-50

Fabricius, C. \& de Wet, C. (2002). The influence of forced removals and land restitutions on conservation in South Africa. In: Chatty \& Colchester 2002. P.149-163.

Ferrari, M.F. (2002). Synthesis of Lessons Learned in the Establishment and Management of Protected Areas by Indigenous and Local Communities in South-East Asia. Report for TILCEPA.

Ferrari, M.F. and de Vera, D. (2003). A "participatory" or a "rights based" approach? Which is best for protected areas and indigenous peoples in the Philippines? Policy Matters 12: 166-170.

First Peoples Worldwide, (2007). Conservation Evictions: First Peoples Worldwide Background Paper, Fredericksburg.

Fleuret P. \& Fleuret A. (1980). Nutrition, consumption, and agricultural change. Human Organisation 39: 250-260.

Flowers, M.(1983). Seasonal factors in subsistence, nutrition, and child growth in central Brazilian Indian community. In: Hames, R. \& Vickers, W. (Eds.) Adaptive Responses of native Amazonians. New York: Academic Press.

Fromherz, C. (2008). Indigenous Peoples' Courts: Egalitarian juridical pluralism, self-determination, and the United Nations Declaration on the Rights of Indigenous Peoples. University of Pennsylvania Law Review. 156, 13411381.

Galaty, J.G. (1999). Unsettling realities: pastoral land rights and conservation in east Africa. Paper presented at the conference Displacement, Forced Settlement and Conservation. St. Anne's College, Oxford.

Galvin, K.A. \& Ellis, J. \& Boone, R.B. \& Magennis, A. \& Smith, M. \& Lynn, S.J. (1999). Compatibility of pastoralism and conservation? A test case using integrated assessment in the Ngorongoro conservation area (Tanzania). Paper presented at the conference Displacement, Forced Settlement and Conservation. St. Anne's College, Oxford.

Geddes, Grosset (2001). Dictionary of Geography. New Lanark: David Dale House 
Geisler, C. (2002). Endangered Humans. Foreign Policy, 130, 80-81

Geisler, C., De Sousa, R (2000). From refuge to refugee: the African case In U. o. W. Land Tenue Centre (Ed.). Madison.

Geisler, C., Warne, R., Barton, A. (1997). The wandering commons: A conservation conundrum in the Dominican Republic. Agriculture and Human Values, 14, 325-335.

Gartlan, S. (1998). Every man for himself and God against all: History, social science and conservation of nature. In: resource use in the trinational Sangha river region of Equatorial Africa: Histories, knowledge, forms and institutions. Yale School of Forestry and Environmental Studies, Yale, USA.

Ghimire, K. (1994). Parks and People: Livelihood issues in National Parks Management in Thailand and Madagascar. Development and Change, 25, 195-229.

Gibson, C. C., and S. A. Marks. (1995). Transforming rural hunters into conservationists: An assessment of community-based wildlife management programs in Africa. World Development, 23, 941-957.

Griffiths, T. (2007). Seeing RED? Avoided deforestation and the rights of indigenous peoples and local communities. FPP, Moreton-in- Marsh, UK.

Grinker, R.R. (1994). Houses in the Rainforest - Ethnicity and Inequality among Farmers and Foragers in Central Africa. Berkeley: University of California Press.

Hilhorst, T., Aarnink, N. (1999). Co-managing the commons: Setting the stage in Mali and Zambia. Bulletins of the Royal Tropical Institute, 346, Amsterdam.

Ichikawa, M. (2006). Problems in the conservation of rainforests in Cameroon. African Study Monographs, 33, 3-20

Igoe, J. (2006) Measuring the costs and benefits of conservation to local communities. Journal of Ecological Anthropology, 10, 72-76

Igoe, J., Brockington, D. (2007). Neoliberal Conservation: A Brief Introduction. Conservation and Society, 5 (4), 432-449.

Igoe, J., Croucher, B. (2007) Conservation, Commerce and Communities: The story of community-based wildlife management areas in Tanzania's Northern Tourist Circuit. Conservation and Society, 5 (4), 534-561. 
IPCC (2007). Climate change 2007: Climate change impacts, adaptation and vulnerability. Summary for policymakers. Working group 2 contribution to the IPCC, fourth assessment report. IPCC, Geneva, Switzerland.

Jacobson, C. (1985) Resistance to affirmative action: Self-Interest or racism. The Journal of Conflict Resolution. 29 (2), 306-329.

Jum, C., Abega, M., Bengono, F. (2009). Action research as a strategy for collaborative management in Ottotomo. In: In Search of Common Ground: Adaptive Collaborative management in Cameroon. CIFOR, Indonesia.

Kababanukye, K. (1998). Community Involvement in Protected Areas in Uganda. World Bank/WBI, 1-3.

Kabra, A. (2006). Impact of involuntary displacement on a tribal community: A case study of the Sahariya Adivasi displaced from Kuno Wildlife Sanctuary, Madhya Pradesh. In: Aasha Kapoor Mehta and Andrew Shepherd (eds), Chronic Poverty and Development Policy in India. Sage, New Delhi

Kothari, A. (2004). Displacement fears. Frontline 21: www.frontlineonnet.com viewed 15 July 2010

Kramer, R. A., van Schaik, C., Johnson, J. eds. (1997). The last stand: Protected areas and the defense of tropical biodiversity. New York: Oxford University Press.

Laird, S (2002). Biodiversity and Traditional Knowledge. Equitable Partnerships in Practice. London: Earthscan Publications Ltd.

Langholz, J. (2003). "Privatizing Conservation," in Contested Nature. Promoting International Biodiversity Conservation with Social Justice in the twenty-first century. New York: University of New York Press.

Lowry, A. (1994). Parks, Politics and Pluralism: The demise of National Parks in Togo. Society and Natural Resources, 7, 321-329.

MacLean-Stearman, A. (2000). A pound of flesh: social change and Modernization as factors in hunting sustainability among neotropical indigenous societies. In: Robinson \& Bennett 2000.

Maffi, L. (2001). On Biocultural Diversity: Linking language, knowledge and environment. Washington DC: Smithsonian Institution Press.

Maffi, L., Carlson, T (2005). Ethnobotany and Conservation of Biocultural Diversity. New York: New York Botanical Gardens Press. 
Marquardt, M. (1994). Settlement and Resettlement : Experience from Uganda's National Parks and Reserves. In: Cook, C. (ed.) Involuntary Resettlement in Africa. World Bank Technical Paper 227: Washington, DC.

Miller, T. (1996). Living in the environment: Principles, connections and solutions. Wadsworth, Belmont, California.

Milner-Gulland, E., Leader-Williams, N. (1992). A model of incentives for the illegal exploitation of black rhinos and elephants: Poaching ways in Luangwa valley, Zambia. Journal of Applied Ecology, 29, 388-401

Mittermeier, R., Goettsch-Mittermeier, C. (1997). Megadiversity: The biologically richest countries of the world. Conservation International/ CEMEX/Sierra Madre. Mexico City

Mvondo, S. (2006). Decentralized forest resources and access of minorities to environmental justice: An analysis of the case of the Baka in southern Cameroon. International Journal of Environmental Studies, 63 (5), 681-689.

Mvondo, S., Sangkwa, F. (2009). Council Forests: The case of Dimako. In: In Search of Common Ground: Adaptive Collaborative management in Cameroon. CIFOR, Indonesia.

Nabakov, P., Lawrence, L. (2004). Restoring a Presence: A documentary overview of native Americans and Yellowstone National Park. Norman, OK: University of Oklahoma Press.

Nash, R. (1967). Wilderness and the American Mind. New Haven: Yale University Press.

Ndameu, B. (2001). Cameroon - Boumba Bek, In Indigenous people and protected areas in Africa. Edited by Nelson, J., Hossack, L. Moreton-in-Marsh: Forest Peoples Programme.

Neba, G. (2009). Planning and monitoring forests in multistakeholder settings. In: In Search of Common Ground: Adaptive Collaborative management in Cameroon. CIFOR, Indonesia.

Neba, G., Nguiebouri, J., Tiani, A., Diaw, M. (2009). Changing management direction in Campo-Ma'an. In: In Search of Common Ground: Adaptive Collaborative management in Cameroon. CIFOR, Indonesia.

Nelson, J. (2003). Baka losing out to Lobeke and Boumba National Parks. WRM bulletin, number 69 . 
Nelson, J., Venant, M. (2008). Indigenous peoples' participation in mapping of traditional forest resources for sustainable livelihoods and great ape conservation. United Nations Environment Programme/ Forest Peoples Programme.

Neumann, R. (1998). Imposing wilderness: Struggles over livelihood and nature preservation in Africa. Berkeley: University of California Press.

New Zealand Government, (2010). UN Declaration of Rights of Indigenous People. www.beehive.govt.nz

Nguiffo, S. (2001). Cameroon - Dja, In Indigenous people and protected areas in Africa. Edited by Nelson, J., Hossack, L. Moreton-in-Marsh: Forest Peoples Programme

Niezem, R (2003). The Origins of Indigenism: Human rights and the politics of identity. Berkeley: University of California Press

Noss, A. (2001). Conservation, Development and the 'Forest People' - The Aka of the Central African Republic. In: Weber et al. 2001.

Norton-Griffiths, M., Southey, C. (1995). The opportunity cost of biodiversity conservation in Kenya. Ecological Economics, 12, 125-139.

Oates, J. (1999). Myth and reality in the rain forest: How conservation strategies are failing in West Africa. Berkeley: University of California Press.

Oelschlaeger, M. (1991). The Idea of Wilderness. New Haven: Yale University.

Ohenjo, N., (2003), "Kenya 's castaways: The Ogiek and national development processes", Minority Rights Groups International and CEMIRIDE, London,

Oundo, S. (2008). Claiming indigenous lands from bottom up: Dispossession of the Ogiek in the Mau Forest, Kenya. Institute of Social Studies, The Hague, Netherlands.

Oviedo, G. (2002). "Lessons learned in the establishment and management of protected areas by indigenous and local communities, South America: enhancing equity in the relationship between protected areas and indigenous and local communities in the context of global change". www.iucn.org/themes/ceesp/Publications/TILCEPA/CCA-GOviedo.pdf

Oyono, P. (2004). Institutional Deficit: Representation and decentralized forest management in Cameroon. Working Paper, Environmental Governance in Africa. World Resources Institute, Washington DC. 
Platzky, L., Walker, C. (1985). The surplus people: Forced removals in South Africa. Ravan Press, Johannesburg.

Poirier, R., Ostergren, D. (2002). Evicting people from nature: Indigenous land rights and National Parks in Australia, Russia and the United States. Natural Resources Journal, 42, 331-351.

Poole, P. (2003). Cultural Mapping and Indigenous People: UNESCO.

Porter, A. (1999). Refugees from Lost Habitat and Reorganization of Genetic Population Structure. Conservation Biology, 13 (4), 850-859.

Porter, M., Haslam, N (2009). Predisplacement and Postdisplacement Factors Associated with the Mental Health of Refugees and Internally Displaced People. JAMA, 294(5), 602-612.

Rabinowitz, A. (1999). Nature's last bastions: Sustainable use of our tropical forest may be little more than wishful thinking. Natural History, 108, 70-72.

Rangaran, M., Shahabuddin, G. (2006). Displacement and relocation from Protected Areas: Towards a biological and historical synthesis. Conservation and Society, 4 (3), 359-378.

Ranger, T. (1989). Whose heritage? The case of the Matopo National Park. Journal of Southern African Studies, 15, 217-249.

Ranger, T. (1999). Voices from the rocks: Nature, culture and history in the matopos hills of Zimbabwe. James Currey, Oxford.

Redford, K. H., and J. Mansour, eds. (1996). Traditional peoples and biodiversity conservation in large tropical landscapes. Rosslyn, VA: The Nature Conservancy.

Redford, K. H., and B. Richter. (1999). Conservation of biodiversity in a world of use. Conservation Biology, 13, 1243-1256.

Redford, K. H., K. Brandon, and S. E. Sanderson. (1998). Holding ground. In Parks in peril: people, politics, and protected areas, eds. K. Brandon, K. H. Redford, and S. E. Sanderson, 455-464. Washington, DC: Island Press.

Robinson, J. C. (1993). The limits to caring: Sustainable living and the loss of biodiversity. Conservation Biology, 7, 20-28.

Roe, D. (2008). The origins and evolution of the conservation-poverty debate: a review of key literature, events and policy processes. Oryx, 42 (4), 491503. 
Roe, D., Reid, H., Vaughan, K., Brickell, E., Elliot, J. (2007). Climate, carbon, conservation and communities. An IIED/WWF briefing. International Institute for Environment and Development, London, UK.

Ruitenbeek, H. (1992). The rainforest supply price: A tool for evaluating rainforest conservation expenditures. Ecological Economics, 6, 57-78.

Schmidt- Soltau, K. (2003). Indigenous People Development Plan for the Participatory Community Development Programme. Ministry of Economic Affairs, Republic of Cameroon

Schmidt-Soltau, K. (2004). The Costs of Rainforest Conservation: Local Responses Towards Integrated Conservation and Development Projects. Journal of Contemporary African Studies, 22(1).

Schmidt-Soltau, K. , Brockington, D. (2007). Protected Areas and Resettlement: What scope for Voluntary Relocation. World Development, 35(12), 21822202.

Schwartzman, S., Zimmerman, B. (2005). Conservation alliances with indigenous people. Conservation Biology, 19, 721-727.

Shikongo, S. (2005). Report on threats to the practice and transmission of traditional knowledge, Regional report: Africa: UNEP/CBD.

Shutkin, W. (1991). Human Rights Law and the Environment. Journal of International Law, 479-511.

Stamatopoulou, E. (1994). Indigenous Peoples and the United Nations: Human Rights as a developing dynamic. Human Rights Quarterly, 16 (1), 58-81.

Stanciu, E. (2001). "First steps towards collaborative management of Retezat National Park, Romania". CM News 6: 7.

Statham, K. (1994). "The farm scheme of North York Moors National Park, United Kingdom". In Western and Wright (1994).

Strong, M. (1977). The international community and the environment. Environmental conservation, 4, 165-172.

Strong, M. (2003). Stockholm: the founding of IIED. In: Evidence for hope. The search for sustainable development. 19-27. Earthscan, London, UK.

Sunderland, K., Maisels, F., Oates J., Asaha, S., Balinga, M., Defo, L., Usongo, L., von Loebenstein, K., Roth, P. (2009). Are Africa's Protected Areas dis placing thousands of rural poor? Conservation Society, 7 (1), 30-45 
Sunderlin, W., Angelsen, A., Belcher, B., Burgers, P., Nasi, R., Santoso, L., Wunder, S. (2005). Livelihoods, forests and conservation in developing countries: An overview. World Development. 33(9), 1383-1402.

Terborgh, J. 1999. Requiem for nature. Washington, DC: Island Press, Shearwater Books.

Terborgh, J., Peres, C (2002). The problem of people in parks: Making parks work. Washington: Island.

Toledo, V. (2010). Indigenous people and biodiversity. In Levin, S. (eds) Encyclopaedia of biodiversity. Academic Press

Tribal Link. (2010). Canada Endorses United Nations Declaration on the Rights of Indigenous Peoples. www.triballink.org (accessed 22 November 2010).

Turnbull, C.M. (1962). The forest people. New York: Simon \& Schuster.

United Nations (2007). General Assembly Adopts Declaration on Rights of Indigenous People. Department of Public Information, News and Media Division, New York.

United Nations Housing Rights Programme (2009) Indigenous peoples' right to adequate housing: A global overview. Report Number 7, UN-Habitat/ $\mathrm{OHCHR}$

Usongo, L., Nkanje, B. (2004). Participatory approaches towards forest conservation: The case of Lobeke National Park, south east Cameroon. International Journal of Sustainable Development and World Ecology. 11(2), 119-127.

Webster, J., Watson, R (2002). Analyzing the past to prepare for the future: Writing a literature review. MIS Quarterly, 26 (2), 13-23.

Wells, M., McShane, T. (2004). Integrating protected area management with local needs and aspirations. Ambio, 33 (8), 513-519.

Western, D. (1984). Amboseli National Park: human values and the conservation of a savannah ecosystem. In National Parks, Conservation and Development: The role of protected areas in sustaining societies. Proceedings of the World Congress on National Parks, Bali, Indonesia, 11-22 October, 1982. Eds. McNeely, J., Miller, K. Washington DC: Smithsonian Institution Press.

Westing, A. (1992). Environmental refugees: a growing category of displaced persons. Environmental Conservation, 19, 201-207. 
Wilkie, D., Redford, K., McShane, T. (2010). Taking of rights for natural resource conservation: A discussion about compensation. Journal of Sustainable Forestry, 29, 135-151

Wilshusen, P., Brechin, S., Fortwangler, C., West, P. (2002). Reinventing a square wheel: Critique of a resurgent "Protection Paradigm" in international biodiversity conservation. Society and Natural Resources, 15, 17-40.

Winer, N. (2001). Co-management in Southern Bolivia: a form of territorial recognition for the Guarani Izoceno People. CM News 5: 21-22.

Winer, N. (2003). Co-management of protected areas, the oil and gas industry and indigenous empowerment - the experience of Bolivia's Kaa-lya del Gran Chaco". Policy Matters 12: 181-191.

World Bank (2002). Operational Policy 4.12: Involuntary Resettlement. Washington: World Bank.

World Commission on Environment and Development. (1987). Our Common Future. Oxford University Press, Oxford

World Rainforest Movement. (2003). Cameroon: Baka livelihoods damaged by EU-funded conservation Protected Areas. WRM Bulletin, number 70.

Wunder, S. (2000). Ecotourism and economic incentives - an empirical approach. Ecological Economics 32(3):465-79.

WWF International. (1998). People and Conservation Unit, Unpublished Report 